

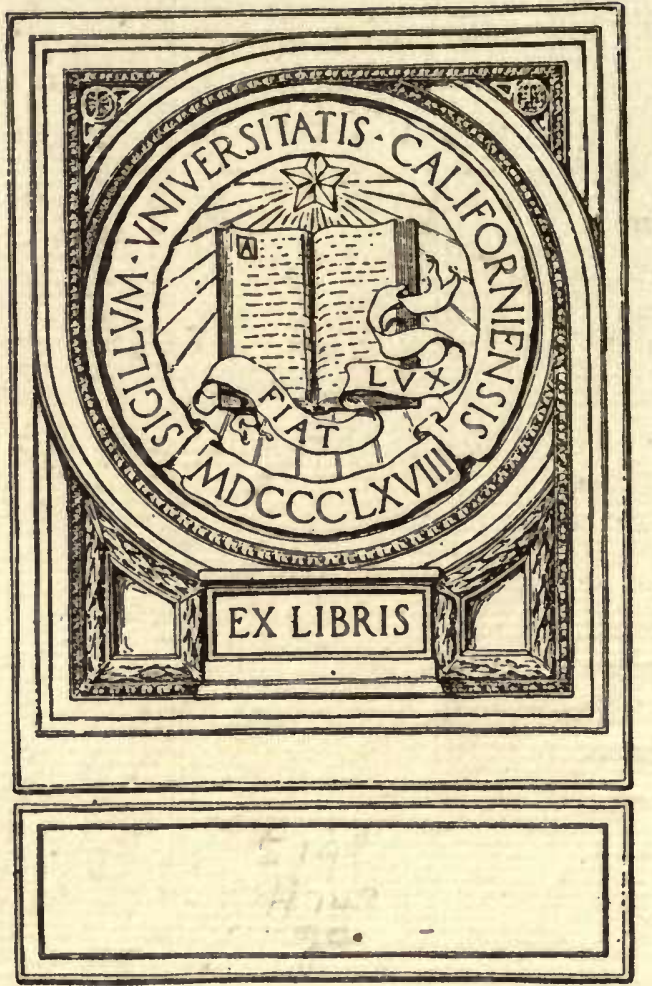








\title{
THE GARDENS OF
}

ENGLAND

\author{
IN THE \\ NORTHERN \\ COUNTIES
}

EDITED BY CHARLES HOLME

MCMXI

“THE STUDIO” LTD.

LONDON, PARIS, NEW YORK 
$\because \because \quad \because \vdots \vdots$

$\therefore$ ०० 


\section{PREFATORY NOTE}

The Editor desires to express his cordial thanks to the owners, whose names appear under the illustrations, for allowing their gardens to be represented in this volume. Special facilities have been accorded Mr. W. J. Day, the photographer, which have enabled him to obtain, exclusively for this volume, the unique series of garden subjects here illustrated. The Editor also wishes to acknowledge his indebtedness to Mr. Thomas H. Mawson, Hon. A.R.I.B.A., the distinguished garden-architect, for the valuable assistance he has rendered, and also the help given to Mr. Day by the head-gardeners.

To Mr. E. A. Chadwick, Mr. G. S. Elgood, R.I., Mr. E. Arthur Rowe, Mr. Arthur Severn, R.I., and Messrs. Dowdeswells, the Editor tenders his thanks for the loan of the drawings reproduced in colours.

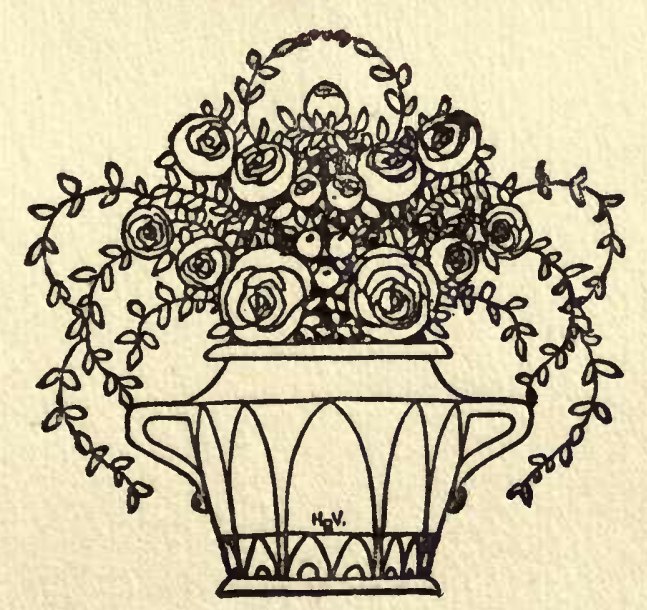




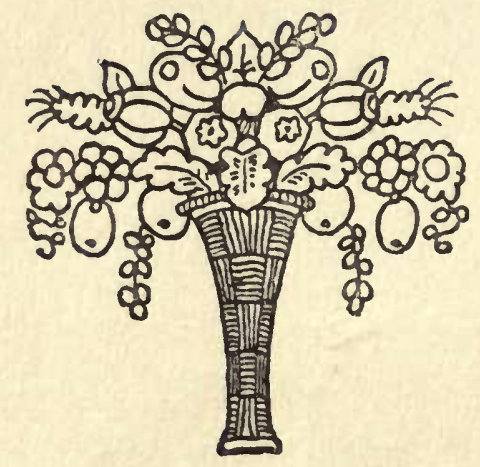




\section{ARTICLES}

Types of Gardens

Notes on the Illustrations . . . . . . ” xviii

\section{ILLUSTRATIONS IN COLOUR}

Plate

I. Levens Hall, Westmoreland

x. The Lake at Bramham Park, Yorkshire
ARTIST

E. Arthur Rowe

George S. Elgood, R.I.

xvir. Path to the Lake at Brantwood, Arthur Severn, Lancashire

R.I.

Lxxiv. The Rose Garden at Levens Hall, George S. Elgood, Westmoreland

R.I.

Lxxix. Sundial at Levens Hall, Westmoreland E. Arthur Rowe cxiv. Entrance Gateway at Shrublands, West- Ernest A. Chadmoreland wick

cxvir. The Tennis Court at Shrublands, West- Ernest A. Chadmoreland wick

cxxiv. Speke Hall, Lancashire

George S. Elgood, R.I. 


\section{LIST OF PHOTOGRAPHS}

Plate

SUBJECT

II. The Palace Garden at Bishop Auck- The Bishop of Durham land, Durham

III. The End of the Lake at Blagdon, Viscount Ridley Northumberland

IV. The Dene Pool at Blagdon, Northumberland

v. The Rose Garden at Blagdon, Northumberland

vi. Interior of a Pergola at Blagdon, Northumberland

viI. The Lily Pond at Blagdon, Northumberland

viII. Trimmed and Natural Beeches at Bramham Park, Yorkshire

IX. The Museum Garden at Bramham Park, Yorkshire

xi. The Chapel Garden at Bramham Park, Yorkshire

xII. Beech Avenues at Bramham Park, Yorkshire

XIII. The Lake at Bramham Park, Yorkshire.

xIv. Gothic Garden Temple at Bramham Park, Yorkshire

xv. The Dene at Brancepeth Castle, Viscount Boyne

xvi. A Stream at Brancepeth Castle, Durham

xviII. Path to the Lake at Brockhole, Westmoreland

xIx. The Dutch Garden at Brockhole, Westmoreland

xx. The Dutch Garden at Bromborough Hall, Cheshire

xxi. The Japanese Garden at Bromborough Hall, Cheshire

xxil. Entrance to Brougham Hail, Cumberland

xxiı. Brougham Hall, Cumberland

xxiv. Terrace Walk at the Bungalow, Rivington, Lancashire

xxv. The Garth at the Bungalow, Rivington, Lancashire

xxvi. The Orangery at Byram Hall, York- Sir John W. Ramsden, Bart. shire

xxviı. The Rose Garden at Byram Hall, Yorkshire

xxviri. Stone Seat at Carnatic Hall, Lanca- Miss Kate Holland shire

xxix. Lily Pool at Carnatic Hall, Lancashire
G. R. Lane-Fox, Esq.

$\begin{array}{lll}" & " & " \\ " & " & \\ " & n & " \\ " & n & n\end{array}$

Sir Wm. B. Forwood

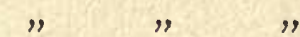

Lord Brougham and Vaux

W. H. Lever, Esq.

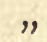

"

" $\quad$ 


\section{LIST OF PHOTOGRAPHS}

\section{Plate}

SUBJECT

OWNER

xxx. The Devil's Bridge at Castle Eden, Rowland Burdon, Esq.

Durham

xxxi. The Beech Walk at Castle Eden, Durham

xxxir. Castle Howard, Yorkshire

xxxiII. The Cedar Grove at Castle Howard, Yorkshire

xxxiv. A Garden Gateway at Castle Howard, Yorkshire

xxxv. The Triton Fountain at Castle Howard, Yorkshire

xxxvi. The Rock Garden at Chevet Park, Sir Thos. Pilkington, Bart. Yorkshire

xxxviI. Garden House at Cleveley, Lancashire

xxxviII. Rustic Bridge at Cragside, North-

The late T. Sutton Timmis, Esq.

The Earl of Carlisle

xxxix. A "Douglas" Pine at Cragside, Northumberland

xL. The Lily Pond at Croxteth Hall, The Earl of Sefton Lancashire

xLI. Croxteth Hall, Lancashire XLII. Winding Path at Croxteth Hall, Lan-
cashire

XLIII. Lily Pond at Eller How, Westmore- Mrs. E. Boyle land

XLIV. Terraced Border at Farfield Hall, George Douglas, Esq. Yorkshire

xLv. Circular Flower Garden at Ford Lord Joicey Castle, Northumberland

XLvi. Thatched Pagoda at Ford Castle, " " Northumberland

XLvir. Topiary at Fulford Hall, Yorkshire Captain W. H. Key

xLviII. The Fuchsia Garden at Gledhow Hall, Lord Airedale Yorkshire

xuIx. Gateway at Grimston Park, York- John Fielden, Esq. shire

L. The Emperors' Walk at Grimston Park, Yorkshire

LI. The Lion Statues at Grimston Park, Yorkshire

LII. The Venus Garden at Harewood The Earl of Harewood House, Yorkshire

LiII. The Formal Garden at Harewood House, Yorkshire

LIv. Topiary Avenue at Heslington Hall, Lord Deramore Yorkshire

Lv. Heslington Hall, Yorkshire

LVI. Yews at Heslington Hall, Yorkshire

LVII. Ivy-clad Tea House at Heslington Hall, Yorkshire

LVIII. Yews at Hovingham Hall, Yorkshire

$", "$

Sir Wm. Worsley, Bart. 


\section{LIST OF PHOTOGRAPHS}

OWNER

LIX. The Terrace at Hutton John, Cumberland

Lx. Arbour at Hutton John, Cumberland

LXI. Woodland Walks at Jesmond Dene, Sir Andre" Noble, Bart. Northumberland

LxiI. Garden Subway at Jesmond Dene, Northumberland

LxIII. Grass Walk at Kirklees Park, York- Sir Geo. J. Armytage, Bart. shire

LXIV. Brooklet at Kirklees Park, Yorkshire

LXV. Sundial at Knowsley, Lancashire

LXVI. Water-lilies at Knowsley, Lancashire

The Earl of Derby"

LXVII. Stone Flower-basket at Knowsley, Lancashire

LxviII. View of the Lake at Knowsley, Lancashire

LxIx. Formal Garden at Lambton Castle, The Earl of Durham Durham

Lxx. Lambton Castle, Durham

LXXI. Steps to Portico at Lambton Castle, Durham

LxxII. Levens Hall, Westmoreland

LXxiII. The Dutch Garden at Levens Hall, Westmoreland

Lxxv. Grass Path at Levens Hall, Westmoreland

Lxxvi. Yew Arbour and Arch at Levens Hall, Westmoreland

Ixxvir. Levens Hall, Westmoreland

IXXVIII. Beech Arches at Levens Hall, Westmoreland

Lxxx. The Great Yews at Levens Hall, Westmoreland

Lxxxi. Garden Entrance at Londesborough Park, Yorkshire

LXxxiI. Terrace Steps at Londesborough Park, Yorkshire

LXXXIII. Terrace at Londesborough Park, Yorkshire

Lxxxiv. Spreading Yew at Londesborough Park, Yorkshire

" "

"

" , ,

$\begin{array}{lll}\prime \prime & " 1 \\ n & n\end{array}$

Colonel J. F. Bagot

\begin{tabular}{|c|c|c|}
\hline " & $"$ & " \\
\hline " & $"$ & $"$ \\
\hline " & $"$ & " \\
\hline " & " & " \\
\hline " & ") & " \\
\hline & ") & " \\
\hline
\end{tabular}

The Earl of Londesborough

$\begin{array}{ll}n & ", \\ n & , \\ n & , \\ , & ,\end{array}$

Lxxxvi. The Lake at Londesborough Park,

Lxxxvir. Tea-house at Lowther Castle, West- The Earl of Lonsdale moreland

LxxxviII. Topiary Garden at Lowther Castle, Westmoreland

LxxxIx. The Japanese Iris Garden at Lowther viii Castle, Westmoreland 
xc. The Japanese Garden at Lowther

The Earl of Lonsdale Castle, Westmoreland

XCI. A Pagoda in the Japanese Garden at Lowther Castle, Westmoreland

xcII. "My Lady's Garden" at Lowther Castle, Westmoreland

xcIII. "Sweet-scented" Garden at Lowther Castle, Westmoreland

xciv. The Venus Garden at Lytham Hall, J. T. Clifton, Esq. Lancashire

xcv. The Lake at Lytham Hall, Lancashire

Xcvi. Topiary on Lawn at Moreby Hall, Yorkshire

xcvil. Topiary Avenue at Moreby Hall, Yorkshire

xcviII. An Old Garden at Naworth Castle, The Earl of Carlisle Cumberland

XcIx. The Rose Garden at Newton Green Hall, Yorkshire

c. Garden Entrance and Steps at Newton Green Hall, Yorkshire

CI. Steps to Forecourt at The Priory, Joseph Bibby, Esq. Bidston, Cheshire

cII. The Priory, Bidston, Cheshire

cili. The Rose Garden at The Priory, Bidston, Cheshire

civ. Ribston Hall, Yorkshire

cv. The Terrace at Ribston Hall, Yorkshire

cVI. A Fine Tree, "Picea Concolor Violacea," at Ribston Hall, Yorkshire

cviI. Herbaceous Flower Garden at Ribston Hall, Yorkshire

cvili. The Dell, with Giant Hemlock in bloom, at Ribston Hall, Yorkshire

cIx. The Terrace at Rydal Hall, Westmoreland

cx. The Terrace Garden at Rydal Hall, Westmoreland

cxi. Rustic Shelter at Sand Hutton Hall, Sir Robert Walker, Bart. Yorkshire

cxiI. Cascade at Sefton Park, Liverpool

cxiII. Stepping-stones at Sefton Park, Liverpool

cxv. Terrace Walk at Shrublands, Westmoreland

cxvi. Terrace Steps at Shrublands, Westmoreland

cxviIl. The Quadrangle at Smithills Hall, Colonel R. H. Ainsworth Lancashire

cxix. The Terrace at Smithills Hall, Lancashire

cxx. Smithills Hall, Lancashire

Major John W. Dent

$\begin{array}{lll}" & " & " \\ " & " & \\ " & "\end{array}$

S. H. le Fleming, Esq.

Corporation of Liverpool

The late R. R. Mawson, Esq.

" " , ,

\begin{tabular}{|c|c|c|}
\hline$"$ & " & $"$ \\
\hline " & $"$ & ", \\
\hline
\end{tabular}


LIST OF PHOTOGRAPHS

Plate

SUBJECT

OWNER

cxxi. Speke Hall, Lancashire

cxxil. Speke Hall, Lancashire

Miss Watt

cxxiII. The Moat at Speke Hall, Lancashire

cxxv. Box Gardening at Studley Royal, The Marquis of Ripon Yorkshire

cxxvi. A Rock Border at Thornton Manor, W. H. Lever, Esq. Cheshire

cxxviI. End of the Lake at Thornton Manor, Cheshire

cxxvili. The Lake at Thornton Manor, Cheshire

cxxix. Herbaceous Border at Underley Hall, Westmoreland

cxxx. Old Venetian Cistern at Underley Hall, Westmoreland

cxxxi. The Rose Garden at Underley Hall, Westmoreland

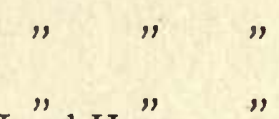

Lord Henry

Cavendish-Bentinck

cxxxII. Italian Wrought-iron Gates at Windle- Sir Wm. Eden, Bart. stone Hall, Durham

cxxxiII. Grass Walk at Windleston Hall, " " Durham

cxxxıv. The Old Walls at Wykeham Abbey, Viscount Downe Yorkshire

cxxxv. A "Pyrus Intermedia" at Wykeham Abbey, Yorkshire

cxxxvi. The Rock Garden at Messrs. Mawson's Nurseries, Windermere, Westmoreland 


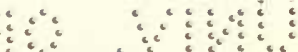

ל. (2)

\section{an}

$2 x^{2} x^{2}$

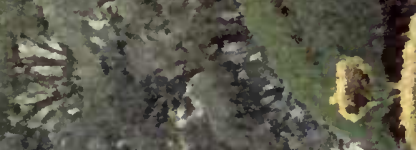

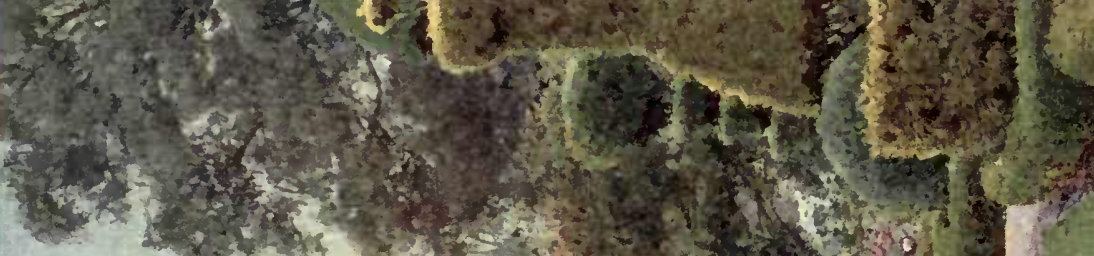

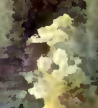

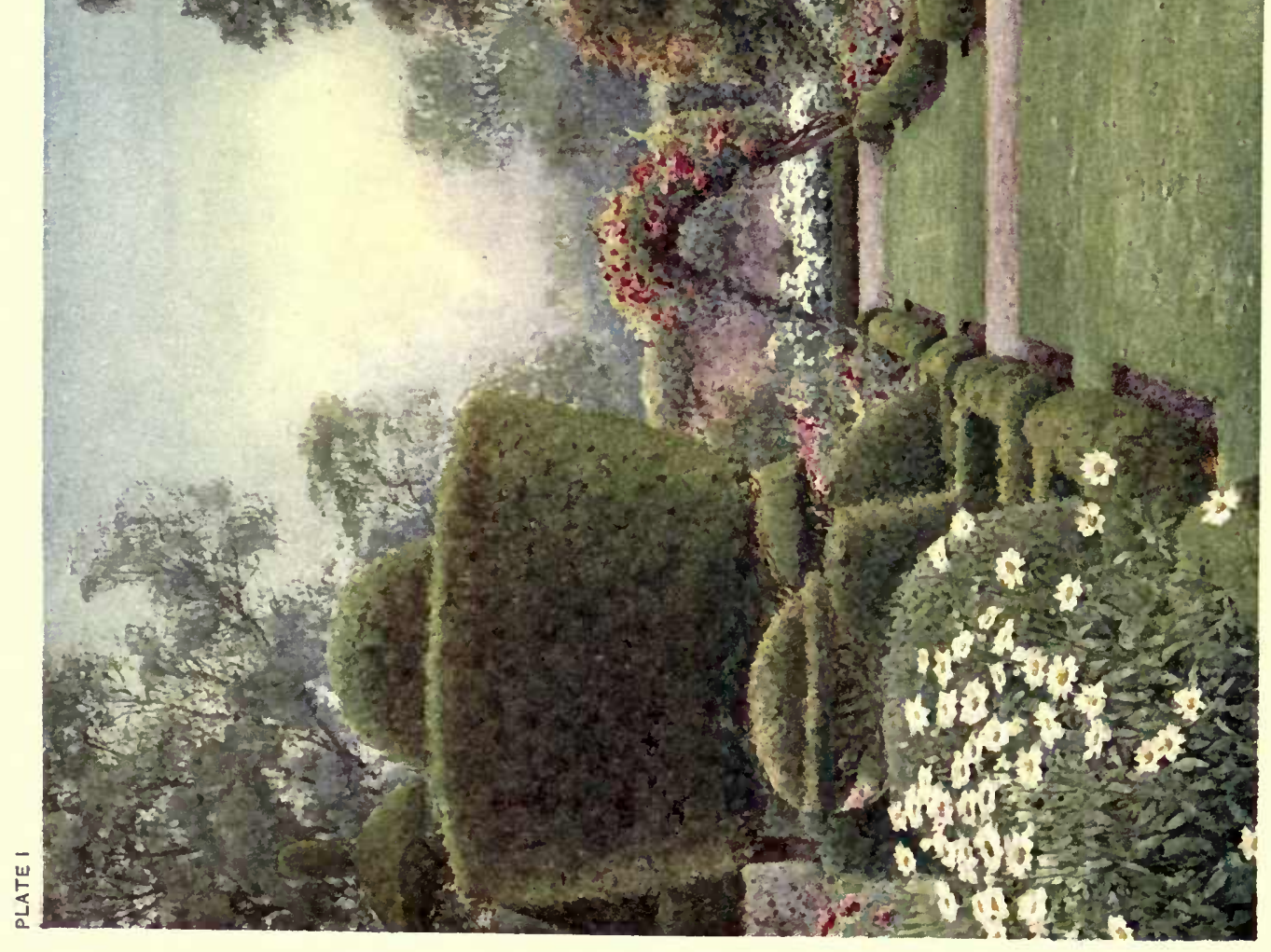




\section{TYPES OF GARDENS}

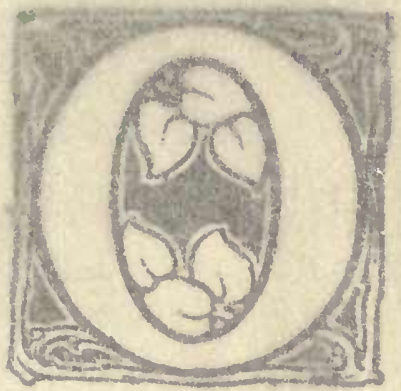

action impossible.

NE of the most obvious charms of the art of gardening is the breadth of opportunity it offers to the man with ideas who is sceking for new ways of expressing his fecling for dellign. It is a singalarly adaptable art, one in which there is endless scope for invention and for the development of original devices of arrangement; ant it is not bounded by a narrew code of rules which make freedon of In gardening, indeed, sry unconvention is permissible if only it does eat involve departure from or contradiction of nature; and cven * quite considerable degree of formal regulation can be applied to matural facts without any offence agains? artistic propricty if this regalating is done with sufficient taste and common sense

But, of courses is necestary that all the contrivances of the designer should be ygestad be reul raspest fir the spirit of garden-making.

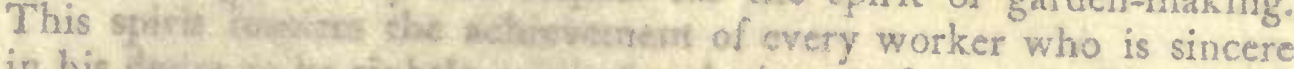

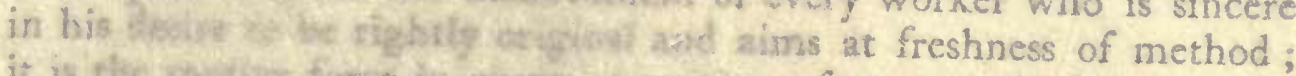
it is tike powdeg forct is . enery as powition of an art which has many

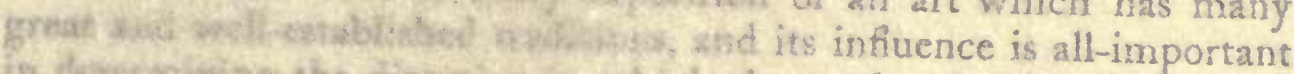

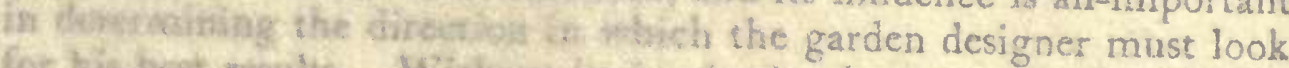
for his best revolts. Witterue its inspiration he is practically helpless and his efforts trust the incticetive; his work will be artificial and unmeaning, and its value ks az expression of a serious conviction will be practically inappreciable.

The source of this guisting spirit is nature herself. No designer of gardens can ignore uxture or pretend to work without consideration for her laws; be is really in absolute dependence upon her and must follow where the leadis. If he were to attempt to plan a garden from which she wat to be excluded and in the making of which she was to have no purt, the reoult would hardily be a garden at all. It might the an brickstiag piece of architectural construction, it might have a (सrikb thantwer as an effort in engineering, it might be remarkable

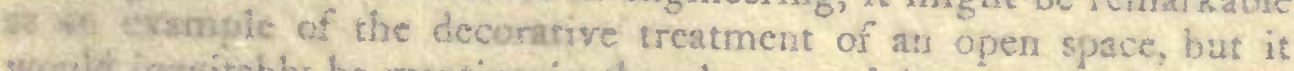
Wreld institably be wanting in the charm and beauty which belong almost as a datiter of conse to the true garden in which neture has interwened frow the first. Souner or later, however, she wotald set her mask oven upon such a perversely human attempt at gardenmaking, and, in the charity, she would try to hide the evideaces of failure due to man's conceit. Dy her magic touches, by weatheritigs, 


\section{TYPES OF GARDENS}

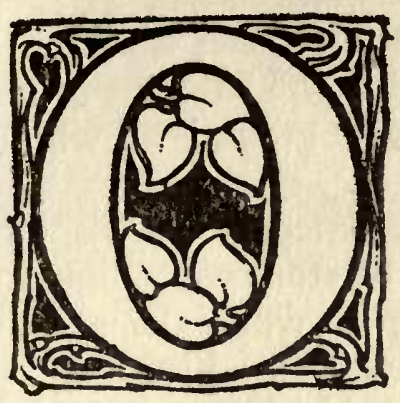

NE of the most obvious charms of the art of gardening is the breadth of opportunity it offers to the man with ideas who is seeking for new ways of expressing his feeling for design. It is a singularly adaptable art, one in which there is endless scope for invention and for the development of original devices of arrangement; and it is not bounded by a narrow code of rules which make freedom of action impossible. In gardening, indeed, any unconvention is permissible if only it does not involve departure from or contradiction of nature; and even a quite considerable degree of formal regulation can be applied to natural facts without any offence against artistic propriety if this regulating is done with sufficient taste and common sense.

But, of course, it is necessary that all the contrivances of the designer should be guided by real respect for the spirit of garden-making. This spirit inspires the achievement of every worker who is sincere in his desire to be rightly original and aims at freshness of method; it is the motive force in every exposition of an art which has many great and well-established traditions, and its influence is all-important in determining the direction in which the garden designer must look for his best results. Without its inspiration he is practically helpless and his efforts must be ineffective; his work will be artificial and unmeaning, and its value as an expression of a serious conviction will be practically inappreciable.

The source of this guiding spirit is nature herself. No designer of gardens can ignore nature or pretend to work without consideration for her laws; he is really in absolute dependence upon her and must follow where she leads. If he were to attempt to plan a garden from which she was to be excluded and in the making of which she was to have no part, the result would hardly be a garden at all. It might be an interesting piece of architectural construction, it might have a striking character as an effort in engineering, it might be remarkable as an example of the decorative treatment of an open space, but it would inevitably be wanting in the charm and beauty which belong almost as a matter of course to the true garden in which nature has intervened from the first. Sooner or later, however, she would set her mark even upon such a perversely human attempt at gardenmaking, and, in her charity, she would try to hide the evidences of failure due to man's conceit. By her magic touches, by weatherings, 
by mosses and lichens, by cunningly planted vegetation, and by endless little interferences with the designer's intentions, she would veil the crude formality of his handiwork and enrich the bareness of his plan. His architecture would become simply the ground on which she would embroider her patterns and her designs.

Indeed, he would be a foolish person who presumed to do without nature in decorating an open space undefended by stout walls and not covered by a roof. From the very beginning he would be at war with a power against which he would be helpless. Fight as he might, nature would conquer in the end and would impose upon his work the signs of the victory she had gained. Time is on her side and her limitless patience takes no account of the lapse of centuries when she has in view the ultimate working of her will upon a piece of human effort of which she disapproves. He would be a foolish person, too, because it is only by the closest alliance with nature that he can hope to score any successes worth having when he is working in the open air. If he has her on his side, and if he is sufficiently conscious of her authority and sufficiently tolerant of her wilful ways, much will be possible to him; she will help him to do even more than he realised to be within the scope of his invention, and she will amplify his schemes with wonderful additions that are all her own. He may have surprises; but if he has breadth enough of mind to understand what are the methods she employs, these surprises will be enlightening and instructive, they will give him fresh openings for the exercise of his intelligence, and they will suggest to him new modes of dealing with the problems of his art.

Happily the type of man who resents the claim of nature to have the last word in the matters that concern her most is a decided rarity; civilisation, it is true, has produced a few abnormal individuals who regard nature's freedom and dislike of any rules but her own as a sort of indecency-individuals who, whenever they can, enjoy cutting down trees and paving with flag-stones any spaces where grass might reasonably be expected to grow-but persons of this highly civilised kind usually confine their energies to borough councils and such-like municipal bodies and do not often concern themselves much with the art of garden-making. They sometimes, it must be confessed, in the exercise of an authority unwisely entrusted to them, get sadly in the way of people of more intelligence who are anxious that nature should have a better chance of showing what she could make even of the modern world; but fortunately there is still a very great majority of thinking men who love nature too well to allow those who dislike her to do any serious amount of harm.

ii 


\section{TYPES OF GARDENS}

For, certainly, it is characteristic of the people in this country to appreciate very definitely the fascination of natural beauty and to enjoy wholesomely the charm of pretty scenery. As a nation we worship nature sincerely and we take an honest pride in the way that she has lavished upon the British Isles many of her choicest favours. We respond too frankly to her generosity to be inclined to underestimate the value of what she gives us, or to wish to throw away lightly the advantages which she has enabled us to possess.

It is from this association with nature that comes our love of gardens. Our enjoyment of natural scenery implies admiration for nature in her larger manifestations, an admiration so real that it induces in us the desire to bring ourselves more closely into relation with her. We want to be constantly reminded of her, to have her works about us and to see her hand in our immediate surrroundings. Few of us, unfortunately, have the chance to live in places where she works always on a large scale; most of us, indeed, have to be content to make some small oasis in the desert which man creates and to invite nature to do what she can to help us in turning this oasis into a place of beauty. But even the small opportunity does not make us any the less inclined towards the practice and encouragement of the gardener's art ; if anything, it rouses us to greater efforts to overcome the difficulties that circumstances put in our way.

The result of this persistent pursuit of an ideal, and of this incessant struggle to maintain that intimacy with nature which in our crowded civilisation seems to verge on the impossible, is that the garden has become a very useful factor in modern existence. It is no longer the toy of the man of wealth who can spend his thousands in surrounding himself with lordly pleasure-grounds and who can give up great spaces to the working out of wonderful schemes and elaborate designs. It is, instead, the companion of men of all classes, of every one who can secure even a few square yards of ground upon which plants will grow and flowers bloom, and it brings into thousands of lives an interest and a pleasure which must be counted among the best and purest that humanity can reach.

There are many dull corners in the meanest and ugliest of our towns which are beautified to-day by little gardens which relieve delightfully the hopelessness of bare walls and contrast exquisitely in their green freshness with the drab monotony of bricks and mortar. There are many unpicturesque houses which are saved from wellmerited contempt by being set in the midst of cunningly contrived examples of the garden-maker's art, and derive dignity and character from the charm of their surroundings. There are many great cities 
which owe no small part of their attractiveness to the beauty of the parks and public gardens that occupy the open spaces among the miles of streets. The garden, in fact, in one or other of its many forms, is the influence which softens off the formalities of the world in which we live and justifies the love we have for it by the help it gives us in our endeavour to look upon the bright side of existence. Without such a link with nature we should be in very real danger of sinking into hopeless materialism and of losing what remains to us of healthy sentiment and quiet romance; the artificialities of civilisation would overwhelm us and we should degenerate from sensitive, thinking beings into mere parts of a complicated social machine. It is the love of nature, the pleasure we derive from contact with her and from observation of her works, that does most to keep us mentally alive, and it is in the garden that she visits us and whispers encouraging words as she walks with us hand in hand.

It is of vital importance that we should never forget what the art of gardening means to us and how it prevents us from descending into dull and mechanical habits of thought. It must never be allowed to become stereotyped, to lapse into the foolish repetition of a stock formula or to follow unintelligently a hard and fast code of rules. The first essential of gardening is variety; it must always be expressing new ideas, derived, of course, from nature and adapted to fit the necessities of each particular subject and locality. The true garden is essentially an inspiration, a sort of temperamental translation of nature, and the extent of its attractiveness is in direct relation to the amount of influence that nature has been allowed to exercise in bringing about the final result. There must be, too, a very apparent connection between the garden and the surroundings in which it is placed ; there must be, that is to say, a certain agreement between the type of design chosen and the situation in which the designer is called upon to work. Each kind of garden has its own character, and each one is appropriate to some spot into which it fits seemingly as a matter of course-what this character may be and how it will assort with local conditions it is the first duty of the garden-maker to find out.

For, assuredly, every type of garden that satisfies the fundamental principles of garden-making is right in its proper place. One situation demands the formal garden, another the deliberately arranged and carefully studied landscape design; another, again, simply the judicious formalising and regulating of wild nature. It would be as foolish to argue that the formal garden is the only one which deserves the attention of the designer, as to say that the ir 


\section{TYPES OF GARDENS}

deliberate landscape alone is to be counted as correct and judicious gardening. Neither is wrong when they are properly used, but both are ridiculous when they are dragged incongruously into places where they are unnatural and inappropriate, or when they are called into existence to satisfy some whim of the gardener or some dictate of fashion. In the history of gardening there are many unfortunate examples of thoughtless obedience to fashion, illustrations of the way in which a convention is often mistaken for an inspiration, and in which a principle can be misapplied by people who think that artificiality is the basis of style.

Round the formal garden there have raged endless controversies. It has had many eloquent defenders, many quite as eloquent and outspoken detractors. It has been described as the only form of garden design which can be reckoned as worthy of serious consideration on artistic grounds, because it is the only one in which every detail can be planned beforehand and in which every development can be foreseen and systematically controlled. It has been abused as the reduction of nature to a condition of dull unreality and as an example of the way in which her charm can be destroyed by applying to her the methods of the drill-sergeant. It has been defended as the best expression of the decorator's taste, and it has been attacked as the worst manifestation of the spirit of the pedant and of the man with the narrow mind who knows little and cares less about nature's ways.

Yet it neither requires defence nor merits condemnation when it is called into existence to satisfy the right kind of demand. Round about the house, which by its character and architectural style requires obviously a setting in which nature is given a sort of architectural aspect, the formal garden is very evidently suitable. A palace standing in a wild park or dropped apparently by accident into the middle of a bare expanse of turf wears an unfinished air. It looks as if the intentions of the man who designed it had failed half-way, or as if the owner, having spent more than he intended upon the building, had economised by neglecting to cultivate the ground upon which his house was erected. It is incomplete, in fact, the beginning of a great scheme which has never been carried to its logical conclusion, and it offends by its suggestion of failure.

But when the house with architectural pretensions has about it the terraces, the fountains, the flights of steps, and the paved walks, which are the delight of the maker of formal gardens, when it stands among stately clipped hedges, and makes a centre to a wellproportioned pattern of flower borders and orderly avenues, it 
acquires an added dignity and gains in artistic significance. The garden becomes then, as it were, a part of the house, an architectural adjunct which is necessary to explain the builder's intention; at the same time a frame and a background to a serious work of art. It serves, too, a very valuable purpose by separating the house itself properly from the informal landscape which lies beyond the boundaries of the grounds. The transition from the structural features of the building through the not less carefully constructed but more varied features of the garden to the untamed woods or park-lands outside is made with a certain ease and grace that satisfy the eye and with a natural sequence that seems logically correct.

It is not only the palatial house, however, that needs to be surrounded by a formal garden. At the other end of the scale can be instanced the modest suburban villa which stands in the little patch of ground assigned to it by the speculators who laid out the eligible building estate where it is herded together with many other houses of the same character. To attempt a landscape garden in this little patch would be a pitiful absurdity; the result would be pathetic rather than pleasing. But if the limitations of space are frankly accepted, if the nearness of the boundary walls is taken as an immutable fact which cannot be disguised, there is still scope enough for the designer who knows how to make the best of an apparently unpromising opportunity. He can be as formal as he pleases without getting out of relation to his surroundings; he can lay down paved walks and set up miniature pergolas or quaint trellised nooks, he may venture on a small fountain basin and distribute tidily little, definitely shaped flower beds, he may even introduce here and there a few simple pieces of topiary work, and his garden will look as if it belonged to the place and will have a due measure of that fitness which is the foundation of all good art.

Indeed, many a forecourt or backyard, in which generally a few stunted shrubs are allowed to linger miserably, or a few half-faded flowers to droop through an untidy existence, could be made into tiny formal gardens which would be quite legitimately a joy to the people who possessed them, and the designer who had grasped the necessity for dealing discreetly with such small spaces could exercise many ingenuities of planning which would be agreeably effective Of course, he would have to cultivate simplicity of style and to abandon the ambitions which spur him to sumptuousness of manner in places where he has his larger opportunities-he could not put a pretentious terrace in a city back garden or even in a suburban halfacre. But he could fill this space very pleasantly with suitable vi 


\section{TYPES OF GARDENS}

details arranged with due consideration for the sort of effect that he might fairly expect to produce, and he could certainly find ways of substituting for the dreary and hopeless gardening of the suburbs something of more permanent interest.

It is a pity that the characteristic methods of the Japanese cannot be adopted in dealing with small English gardens. The miniature landscapes which the Japanese garden designers build up often on only a few square feet of ground are delightful in their quaintness and in their ingenuity of contrivance, but they gain undeniably additional beauty from the perfect suitability of their surroundings. English domestic architecture, especially the architecture of the suburbs, would agree badly enough with the particular forms of garden-making which are so exquisitely appropriate in Japan. We have to accept a different and more obvious kind of formality, one which is as much in consonance with our manner of building as is the miniature landscape with the architecture of Japan ; but, all the same, we might learn much from the Japanese-without attempting to copy their individualities of style-as to the principles on which small scale gardening might be conducted.

For the miniature Japanese landscapes are not really examples of landscape gardening as we understand it. They are more akin to the formal garden of the British Isles than to the free adaptations of nature which are set out by our landscape gardeners. The Japanese have quite definite rules by which the placing and the character of the details out of which these little landscapes are built up are determined, and they handle their materials in accordance with specific traditions. But they are more flexible in their formality and more personal in their methods, and they have, too, a truer perception of the ways in which nature can be properly conventionalised. They have acquired the art of being artificial without being affected, of designing on nature's lines without pretending to be realistic, and of being formal without lapsing into pedantry; and as a consequence they use the means at their disposal with charming skill and in a manner that is artistic in the best sense of the word.

The danger that our designers of formal gardens have to be on their guard against is of becoming too artistic. It is the danger to which so many of our earlier gardeners succumbed during that period when the pure formality of the old gardens was abandoned for a spurious naturalism. The idea at that time was that the art of gardening consisted in planting pictures, in building up arrangements which should be purposely and professedly picturesque and in which all the details which a painter would set down upon his canvas would be 
actually collected on the ground. The men who were possessed with this delusion even went so far as to plant dead trees in their shrubberies, because the "brown tree" was a recognised accessory in the fashionable landscape painting of the time. Naturalism of this sort was obviously every bit as formal as the more honest formality of the architectural gardens in which trees were clipped into set forms, into walls with niches for statuary, into arches and gateways, and put to decorative uses such as nature never intended to assign to them; and the notion that it was artistic was far more foolish than any of the beliefs which were entertained by the frankly formal gardeners about the kind of art that they affected.

There is little risk to-day of any revival of garden designing on conventionally pictorial lines; but there is, perhaps, a possibility that the architect who is laying out a garden may be disposed to think more of the claims of his art than of the right which nature has to be taken into account in the planning of the work. Some reasonable proportion must be maintained between the features which are purely architectural and those which are, or ought to be, genuinely naturalistic. To confine nature within bounds is permissible enough, to exclude her or even to tie her down to playing an entirely minor part is an error in policy and a departure from correct taste. The designer must not be too ready to prefer the forms he can build to those which she can create, and he must not deny to her the opportunity to modify his work. All he should do is to draw the outline, the filling in he must leave to her.

Indeed, any such tendency on the part of the designer to assert the importance of his performance against that of nature would imply either that he was imperfectly equipped for the practice of his profession, or that he had misconceived the purpose of his art. It might even suggest that he was too lazy or unintelligent to think out the real meaning of the work he had undertaken, or to foresee what would be the results at which he ought to aim. There would be, decidedly, an easy evasion of the chief responsibility in gardenmaking if he were to try to make his design so fixed and immutable that it would save him from considering what would be the future developments of the garden that he had laid out. His chief and most exacting duty must be to plan for the future, to look a long way ahead, and to see clearly what his details would be like when by years of natural growth they had reached their full proportions, for it is upon these years of natural growth that he depends for the proof of the rightness of his design, and it is by them that the extent of his ability as a gardener will be tested. viii 


\section{TYPES OF GARDENS}

Another tendency to be avoided is to exalt the formal type of garden above all others, and to insist upon the architectural treatment of the garden in all situations, and under all conditions. The man who loves formality unduly is apt to yield to the temptation to view every garden site as a blank space where he has to create an effect by his own exertions; and when he chances upon a site which has already some interesting characteristics of its own he may, quite possibly, be so ill-advised as to destroy them, so as to clear the ground for the building up of his preconceived and possibly less appropriate scheme. This drastic form of preparation is objectionable; the man who resorts to it stamps himself as inefficient and as incapable of adapting himself, as an artist should, to the demands of his subject. He is cursed with a mechanical mind and he follows the engineer's instinct for construction rather than the artist's inclination to base a personal creation upon acceptable facts.

The really accomplished garden-maker must possess a rather remarkable combination of qualities. The architectural sense he must have and he must be an engineer of some skill as well, but there must be also, in his composition, a large measure of artistic imagination and of that indefinable quality which is called taste. It is only the possession of this complex endowment that will enable him to attack with certainty and to overcome with discretion the constantly varying problems which are presented to him in his professional practice. He must have no stereotyped convictions about the legitimacy of any specified form of gardening, no rigid preference for any conventional style of designing; and he must never be above taking a hint from nature when she has something to tell him that he ought to know. Indeed, he ought to be quite ready to realise that the successful carrying out of one of his designs on a certain site is a reason against rather than for the repetition of the same arrangement on another site where the conditions under which he had to work could not by any possibility be identical or even approximately the same.

There is in Mr. Thomas H. Mawson's exhaustive book on "The Art and Craft of Garden-Making," a passage which sums up exceedingly well the whole duty of the designer. He says, "Everything within the scope of the garden scheme, whether building, arrangement of trees, shrubs, expanse of water, grass lawns, or whatever it be, should be designed or planned with due consideration to its use and fitness, proportion and balance. To attain this completeness and unity of the whole implies that to a knowledge of architecture-the chief essential-must be added the study of the technique of good 
gardening and of arboriculture, and that the designer must have a love for, and a knowledge of, the many beautiful forms of plant life ready at hand, wherewith to make his garden of delight.

"The designer of the ideal garden, having no particular scruples about the lines of nature to interfere with his plans, would design in a straightforward, coherent way, considering a straight walk, if more convenient, to be the most capable of artistic treatment, and also assuming that natural objects within the garden must be drilled into position, and if necessary have their wildness tamed. Throughout, his designs would for the most part depend upon combination of line; for instance, the various flower gardens or tennis lawns would be planned with straight lines, and these would have their divisions, whether hedges or other arrangements, so treated as to express at once their use. To get shade, instead of creating it entirely by means of loose masses or clumps of trees, he would obtain it by means of alleys, covered bowers, pergolas or avenues, each of which would show at once the designer's intention. Thus, whilst enjoying the shade, the owner of the garden would cherish a kindly thought for the man who had considered his need; and who, in the disposition of every feature, had secured in an open and straightforward way so complete a grasp of his requirements.

"Although preferring invention, the true garden designer will endeavour to give a purely individual rendering to his work, having due regard for such existing natural features sufficiently interesting to warrant preservation, and requiring only a little skill to bring them into congenial harmony with the composition. The stronger a man's love of art is, the more will he appreciate nature; it is only when he tries to mimic her that artists quarrel with him. Nature may and should inspire us, but it was never meant that we should copy her weakness, or lose the teaching of her strength and dignity."

As the opinion of an expert with particular qualifications this passage deserves to be taken with all possible seriousness. Some of Mr. Mawson's greatest successes have been made in the designing of purely formal gardens, but he has the catholicity and breadth of taste to see that there are plenty of occasions on which absolute formality must be departed from or even abandoned because there are existing natural features which must be reckoned with and taken into account by the designer. These natural features may be so salient, so important, that they will dictate to the maker of the garden the course that he must follow from the very first roughing out of his plan; or they may be of only sufficient prominence to require humouring and a certain amount of adaptation to make them helpful in a more 


\section{TYPES OF GARDENS}

independent scheme; but they are not to be blotted out because they restrict the gardener's freedom of action and impose limitations upon his plan.

There are, indisputably, occasions when these natural features are so dominating that the designer, "although preferring invention," has simply to accept them as fixing the whole character of his work. All he has to do is to devise ways of making them more convincing, of amplifying them and perfecting their beauty; to interfere with them would be a scandalous piece of inartistic indiscretion. To quote $\mathrm{Mr}$. Mawson again: "Wild scenery, especially near towns, should be jealously guarded; a copse of gorse, resplendent with golden bloom ; a columnar grouping of timber trees; or a meandering stream; yet they may sometimes be enhanced and additional interest secured to them by adding touches gathered from observation of nature." It is in this process of enhancing that the skill of the designer is displayed, and it is here that he has his chance of proving how far he is capable of suiting himself to circumstances and the demands of the moment. Obviously, when work of this order has to be done he must lay aside the decorative conventions that have served him so well in his formal designing and must become for the time being a landscape gardener pure and simple, trusting to his observation of nature to help him in choosing the right touches to fill out his picture.

On this point too Mr. Mawson has something to say : "Whatever be the landscape gardener's purpose in view, or style of design to be adopted, there are so many considerations both of a local and practical nature to influence him that he finds his designs must be inspired on the spot; he must recognise, not only the special and peculiar requirements of the proprietor, but also the natural contour of the land and the characteristics of the landscape, more especially of that portion which comes within the proposed garden boundary. For instance, there may be a beautiful stream or pond, perhaps a group of silver birches or Scotch firs, rocky projections, and scores of other details which could not be destroyed, but must be made to form an integral part, in some way or other, of the garden design."

It is, then, in such a situation that landscape gardening is right, and the formal design becomes undesirable. The local and practical considerations decide the position and inspire the manner of treatment; and, as nature does not work on architectural lines, the methods of the architect cannot be accepted as artistically right in dealing with a garden site on which she has already elaborated a very definite design of the character she prefers. To cut away her groves and shrubberies so as to make space for planting rigidly ordered 
avenues and flower patterns, to level the valley she has dug out, or to fill in the stream that she has induced to wind in fascinating curves, for the sake of substituting a flat surface on which a rose garden or croquet lawn can be elaborately laid out, would be an indefensible act of vandalism, and would be as absurd as to attempt to mimic a forest glade in a London backyard. There must be real discretion exercised in every move that is made towards the final result by which the skill, the judgment, and the intelligence of the gardenmaker will in the future be estimated and his capabilities measured.

Clearly, there is necessary in landscape gardening a special degree of serious thought to prevent any wrong step being taken which it would be difficult or impossible to correct. The designer must never do things in a hurry, and never without considering fully what will be the consequences of his action. He must be able to visualise mentally all the alterations that he proposes to make in the natural scene before him, and to see exactly how by cutting away here, by planting there, by accentuating this irregularity in the ground, or by smoothing away that inconvenient piece of unevenness, he is to increase its picturesqueness without destroying its character. From experiments he is practically barred, because it is almost impossible for him to replace what he has removed-he cannot, for instance, put back a large tree he has felled with the idea of opening up a vista or improving a view-though, of course, he has the power to revise and amend his own additions, he can always take them away if they do not fit properly into the scheme.

When, however, the work is done in the right spirit it will be not only enjoyable to carry out, but very satisfying in its effect. It offers so many opportunities for contemplative study of nature, for the careful balancing of the merits of this or that expedient, for the intelligent anticipation of nature's intentions, that from beginning to end the gardener is able to keep his interest fully alive and to avoid any tendency to do obvious things in a mechanical manner. $\mathrm{He}$ need never be at a loss for ideas, because wherever he looks new suggestions are being made to him, and fresh ways of overcoming difficulties are being demonstrated by practical proof; and he need never hesitate to accept the hints that are offered him, because they come from the one teacher whose authority he cannot question.

Still, it is very important that he should cultivate his sense of selection as well as his power of observation. It would be no use to store his memory with a great variety of impressions if he could not produce at the right moment the one he wanted. It is upon this stock of impressions that he must draw when he wishes to be xii 


\section{TYPES OF GARDENS}

equal to some emergency which has arisen in connection with his treatment of the subject that he has to handle. He must be able to choose from among his memories of nature's way of dealing with a similar situation the one which will best meet the exigencies of his particular case, and he must be able to make this choice with the confidence which comes from the knowledge that he has equipped himself against all possible contingencies. What he learns he must sort out and classify so that there may be no confusion in his mind about the way in which he should use his experience and apply practically the various kinds of information he has collected.

It must never be forgotten that the main purpose of the landscape garden is to look as if it had grown up by a natural sequence of events and not by the deliberate direction of the designer. The evidences of human occupation which have to be introduced should not be too emphatic; they should seem to some extent accidental, and as if they had been brought in simply to enable the occupier to enjoy the beauty of the scenery in the midst of which he has chosen to live. The paths must be placed where they would naturally be trodden out by people passing backwards and forwards over the ground and must follow consistently the configuration of the surface; their curves should not be arranged on any arbitrary system, but should seem to have been determined by the necessity of avoiding some impassable piece of shrubbery, or by the need for making at an easy gradient a way up some awkward slope. They should not be forced to wriggle about simply to avoid straight lines in places where, as often as not, a straight walk would be the obvious thing to expect. Seats, again, or summer-houses, should be put where the shelter of the trees or the attractiveness of the view would be likely to induce a wanderer to linger and rest. Lawns and flower borders should be laid out only where the absence of dense masses of overhanging foliage would suggest the possibility of grass growing or flowers flourishing -in natural clearings and open spaces.

Indeed, in a logical piece of gardening there would be nothing done which could hint that the designer had set up his own preferences against nature's intentions; it would rather be implied that he had tried to avoid any appreciable interference with her. Yet this reticence of effect is by no means gained by leaving the garden to take care of itself and to evolve a design, as it were, automatically. The more complete the seeming unconsciousness of the scheme, the more careful and considerate must be the methods of the gardenmaker, and the more scrupulous must be his observation of the details by which the ultimate result is made interesting. If his 
artistic devices are to be properly veiled, he must have his art at his finger-tips and be able to do the right thing by infallible instinct, and he must possess fully the cunning to efface himself even while he is playing a part of no little importance in the management of affairs.

There is, nevertheless, no need in making this effort after reticence and self-effacement, and in seeking thus for consistent naturalism, to disregard the value of a certain measure of formality in even a pure landscape design. Nature is often quite formal in her repetition of forms and in her way of arranging the facts of a landscape. A piece of wild forest scenery not infrequently suggests the intervention of a human designer, so preciseiy is it planned and so well balanced are the parts of which it is composed. Instances, indeed, are not uncommon of her carrying balance into absolute symmetry; spacing her forms with regularity, and keeping an exact proportion of mass to mass.

Therefore, to mix intelligently formality with naturalism is quite permissible, so long as it does not involve any actual contradiction of facts or any attempt to create impossibilities. To edge a stream with a brick wall would be unpleasant and wrong in a wild valley, because bricks are essentially man's handiwork and could not have got into such a situation without human agency; but to define the course of the stream with pieces of rock arranged with sufficient sense of the picturesque would not be objectionable, and a sloping grass bank would equally be in keeping with the surroundings-the stream can be kept within bounds and its course can be regulated without blatantly advertising the fact that its liberty to carve its channel where it pleases has been taken away. Again, to plant an avenue of clipped yews through a piece of natural woodland would be to introduce a rather ridiculous incongruity, but an avenue that would be quite effective and yet look pleasantly unintentional could be made by choosing a part of the wood where the trees grew for the most part in some sort of order and by cutting away those which confused the design. A rocky slope, too, could be terraced and diversified with sheltered walks by judicious building up here and there with natural stone, in reasonable imitation of nature's manner of shaping a craggy hill-side into ledges and steeps.

In the same way, a wooded garden can be brought into correct order by observing and reproducing the natural alternations of thicket and open glade, which in a forest come automatically from variations in the soil or from the killing of the undergrowth under the shadow of some wide-spreading tree. Effects of light and shade can be xiv 


\section{TYPES OF GARDENS}

obtained by opening up vistas from the shadowed places where the branches are thick to the glades where the sunlight is free to play; and the illusion of wildness can be increased by planting in suitable nooks and corners the woodland flowers which flourish in the halfveiled light that gleams through the foliage overhead. In a wild garden of this kind the scientific gardener who grows specimen blooms for exhibition purposes will, no doubt, be exceedingly unhappy; and the man who has an affection for ribbon borders, and for floral devices which wriggle and sprawl over vast expanses of flat lawn, will feel the utmost contempt for nature's untidiness; but the lover of charming unconventionality will enjoy unreservedly the persuasiveness of surroundings which remind him pleasantly of those remoter spots in the world where human improvements have not as yet exercised their disfiguring influence.

And, after all, the lover of unconventionality has as much right to be heard on the subject of garden-making as the man to whom the seriousness of stately formality makes a strong appeal. It would be a pity, indeed, if the art of gardening were ever to be hedged round by rigid rules which sought to define exactly what should or should not be the line it should take. Nothing could be more undesirable than any attempt to fix immutably what is legitimate in gardening. Everything is legitimate that can be defended as artistically correct and that has the necessary quality of fitness; nothing is illegitimate unless it is contrary to good taste or opposed to nature's laws. The range of possibilities is so wide, the chances of success are open in so many directions, that to impose any but the most obviously necessary limitations would be to contradict the whole genius of the art and to destroy its vitality.

Between the two extremes of fantastic topiary work which takes hardly any account of nature at all and contorts natural growths into entirely arbitrary forms, and the naturalistic gardening which simply accepts a piece of purely wild scenery and accentuates its characteristics, almost every type of design has a claim to be recognised. Each one is right if it satisfies the essential condition of suitability to its surroundings, and each one can be made to reflect fully the personality of the designer. But, of course, it is necessary that the designer should maintain always the capacity to receive new impressions, the power to observe and understand what he sees, and the ability to select with shrewdness and discretion. Of all artists he must be the most adaptable and the least inclined to substitute a formula for independent thought ; directly he becomes stereotyped, his claim to rank among the leading lights of his profession is gone, 
and he stands in the way of the men who are still working sincerely on the side of progress and development.

Fortunately, we have amongst us at the present time a very large number of garden designers who have the fullest possible appreciation of their responsibilities and a thorough perception of the need for not only keeping alive the better traditions of their art, but also for establishing new principles which will be in accord with the change in conditions that has been brought about by the change in our modes of life. A few generations ago garden-making was in danger of sinking into a very dull convention which took nothing into account except the dictates of a fashion which was based neither upon artistic reason or practical common sense; and while this fashion lasted, much was done that seems to us to-day to have been inexpressibly foolish. But now there is no prevailing fashion, and there is no fixed dogma to which conformity is demanded by popular opinion. The people who want gardens are quite as ready to welcome new ideas as the designers are to supply them; and with the experience of the past to draw upon, with many enlightening suggestions and useful warnings to be obtained from the performances of our predecessors, we are witnessing a revival of garden-making which promises to carry the art further than it has ever gone before.

There are not, it is true, many opportunities to-day for laying out vast pleasure grounds round some royal palace or lordly mansion; there is, if anything, a tendency to allow the great gardens which have survived from the past to go out of cultivation and to lose their character through neglect. But social changes have brought into existence a large class of moderately wealthy men who are building themselves houses of some pretensions, and to whom the idea of possessing a garden which will do credit to their taste commends itself as important. These men have the good sense to recognise that the modern house needs a setting which will sufficiently reflect the modern spirit, and that to try to put round a piece of twentiethcentury architecture the sort of garden which agrees well enough with a mediæval castle or a Georgian country house would lead to a very evident misfitting of styles. So they call in the services of the garden designer, who has his own way of solving the difficulty, and he, knowing what is wanted, gives them something which is entirely congruous and right in its expression of its purpose.

But the creation of this new and essentially modern type of garden, this delicately finished design worked out within a comparatively limited space, should not make us forget the debt we owe to the xvi 


\section{TYPES OF GARDENS}

greater garden-makers of other centuries who established the traditions of an art which we are now applying in ways that they scarcely contemplated. They taught us the principles which we must follow, they provided us with examples which are inspiring and instructive, and they pointed the way along which we are finding so much that is worth gathering. Even the fact that some of our predecessors misconceived the art of garden-making and did things which now we honestly deplore, is not without value; at least it takes away from us any excuse for making similar mistakes. The moral of it is that subservience to a fashion is destructive of true artistic understanding, and that the vitality of any art can only be maintained by keeping it free and untrammelled by conventions. So we must never forget how wide a scope is offered by the art of gardening for the exercise of the designer's individuality, and we must do all that lies in our power to encourage him to practise the art in the broadest spirit and with the fullest perception of its endless possibilities. 


\section{NOTES ON THE ILLUSTRATIONS}

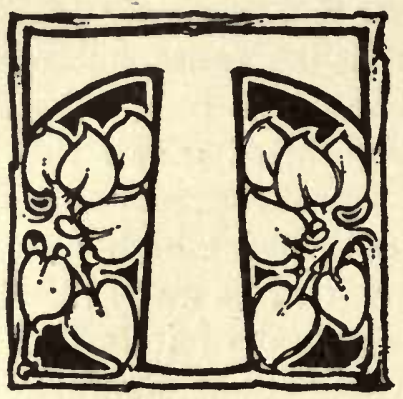

O compare the gardens in the north of England with those in the south, and to note in how many ways local conditions affect the style and character of the garden-maker's work, is decidedly interesting. The influence of locality is very evident in gardening : it determines not only the working out of minor details but, as well, the arrangement of those fundamental principles upon which all the larger facts of the work that is to be done must necessarily depend. The nature of the soil and the quality of the climate naturally have to be taken seriously into consideration by the designer, because they decide what are to be the trees, the shrubs and the flowers that he will plant in the garden that he is projecting; but the configuration of the ground and the particular surroundings in which it happens to be situated claim not less consideration, for they give him the leading lines of the plan that he must develop, and, in great measure, define what is to be the style of gardening that he must adopt.

In the southern counties formal gardening is more general than in the north; the stately Italian garden, with its regular lines, its fountains and groups of statuary, and its carefully ordered beds of flowers and ornamental plants, is a type that finds much favour with designers. But in the north this kind of work is not nearly so popular, because it is far more difficult to carry out properly. The Italian garden is best when it is laid out upon ground that is flat or only gently undulating, and sites of this character are more often available in the south than in the north of England. Again, in many of the northern districts there are great industrial cities which poison the air for miles round with the smoke from a host of factory chimneys, and create an atmosphere that destroys open-air statuary and kills off many of the trees and plants necessary for effective garden-making of the formal type.

The smoke difficulty, indeed, is a serious one, and has not only interfered with the development of formal gardening in northern districts which might otherwise have been suitable, but has also caused some gardens, which once were of the highest importance as examples of graceful and elaborate design, to lose their character and to be shorn of their best features. There is one great place which was originally situated in the open country between two towns, but which by the spreading of these towns is now surrounded by streets and shadowed xviii 
by a pall of smoke. It had formerly a magnificent Italian garden with noble fountains and fine groups of statuary and other ornaments; but these, to save them from complete destruction, have had to be removed, and the garden has in consequence been deprived of the greater part of its beauty and interest. Smoke is a deadly foe, too, to even the simple flower garden which does not depend for its effect upon architectural ornamentation, for the flowers are choked and stunted by the sulphurous deposit which descends upon them, and refuse to grow under such disheartening conditions.

Necessarily, the task of the gardener is greatly complicated by these interferences, and the cost of forming and maintaining a garden on elaborately formal lines is considerably increased. Architectural embellishments and garden ornaments must be made of carefully selected materials and must be constantly cleaned ; trees and flowers which suffer as little as possible in a smoky atmosphere must be chosen, and even these must be incessantly syringed to keep them reasonably fresh, and generally much more attention must be given to details of upkeep than is required in places where the surroundings are more agreeable and the inconveniences less disconcerting. Even when all this trouble is taken it is almost impossible to prevent the garden looking rather bedraggled and unkempt, and of all gardens that in the Italian style needs most to be kept in perfect order and to have always the air of being sedulously cared for.

It is not surprising that the designers, finding the local conditions so unsuitable for one particular kind of garden-making, should have adopted another which is less troublesome to carry out and from which more satisfactory results are obtainable. Even in the districts where the smoke difficulty has not to be contended with, the site available is often very ill adapted for a formal garden and demands quite a different mode of treatment. The irregularities of the ground have to be taken into account and accepted as facts which determine the character of the design that is to be worked out, and in a large number of cases there are already existing natural features which are so definitely important that the garden has necessarily to be built round them and made to agree with them.

Therefore, the preference for landscape gardening which is shown by the designers in the north is the logical consequence of the influences by which they find themselves directed. To their credit it may be said that in a very large number of cases they have used with remarkable skill the opportunities offered them of developing picturesquely garden sites which had attractive possibilities, and they have overcome admirably the difficulties involved in converting 
bits of wild nature into reasonably ordered pleasure grounds. Frequently the north country houses are built upon the edge of a glen, which by judicious adaptation is given all the charm and interest of a well-planned garden, and often a natural stream is used to supply happily placed lakes and pools, or is itself treated as an important factor in the design. Fine lawns, diversified by wellproportioned shrubberies, are found in many gardens, and herbaceous borders arranged with a due sense of colour-effect are much favoured. One characteristic of the northern gardens must be noted - the ingenious application of all sorts of materials for paving the footpaths and walks so as to obtain a dry surface and yet one which will be pleasantly in keeping with its surroundings.

In all these details there is evidence enough that the garden-makers, even when they have to avoid the formalities of a set design, do not by any means relax their efforts to deal with the problems of their art in an individual and intelligent manner. They seek to give character to their work, to make it right in feeling and effective in its results, and they show much readiness of resource in the way they adapt themselves to the exigencies of the position in which they may happen to be placed. The northern gardens, indeed, illustrate what may be called the impressionist style of gardening-the style, that is to say, which is fixed not by tradition, nor by regular rules of design, but by the necessity of responding to the suggestions of a particular locality or a special phase of nature.

The garden which comes first in this series of illustrations is at Bishop Auckland, the palace of the Bishop of Durham (Plate II.). The palace, a dignified building with a fine chapel, stands on the top of a hill which slopes steeply to the south and east, and the ground round about it is laid out in broad lawns bordered with shrubberies and surrounded on two sides by a walled walk, from which extensive views of the country beyond are obtained.

2. Blagdon, the seat of Viscount Ridley (Plates III. to VII.), is a place with many striking features, to which important additions are being made from Lady Ridley's designs. The house is approached from the main road by a bridge, flanked at each end by colossal marble statues, which crosses a deep, narrow valley. On the south side of the house is a large terrace lawn, and on the western side a steep slope leading to the grounds beyond. On the eastern and western sides of the large lawn are rectangular beds, well spaced and filled with various kinds of flowers; and at the southern end is placed a colossal bronze statue. Among the special features of the gardens are the rectangular lily pond and the new circular rose garden, both $\overline{\mathbf{x}} \mathbf{X}$ 
of which were designed by Lady Ridley. The lily pond has a stone edging, which is broken at regular intervals by flights of steps leading from the water to the walk above, and is surrounded by a terrace wall, and round it is placed a series of some sixty grotesque stone figures. The rose garden is enclosed by a pergola, built of old red bricks, which is an unusually ingenious and picturesque piece of construction; and the path beneath the pergola is also made of red bricks arranged in geometrical patterns. Other attractions at Blagdon are the lake, a sheet of water prettily overhung with trees; and the dene-the valley spanned by the entrance bridge-which is laid out with winding walks through a tangle of wild woodland.

At Bramham Park (Plates VIII. to XIV.), there are unusually extensive gardens and pleasure grounds which were laid out in the style of the gardens at Versailles by a French designer in the time of Queen Anne. A particular characteristic of the place is the series of broad walks, many of them grass paths, running through groves of beech-trees, which in some places are trained to form arches over the paths. These paths are from twenty to thirty feet wide and lie between walls of close-clipped beech-trees some twenty feet high; they run in all directions and form avenues through which are seen vistas of the surrounding country. At one point four walks radiate from a centre where a large group of statuary is placed. Lakes and lily ponds are used with good effect in the design, and temples and garden pavilions-sometimes placed at the end of a vista-are introduced with excellent judgment. There is a sunk rose garden in front of the house, and there are other flower gardens in different parts of the grounds. In many respects Bramham Park is a unique example of garden-making; there is no other place of the same character in England.

Brancepeth Castle, the seat of Viscount Boyne (Plates XV. and XVI.), is an imposing building, a large mediæval castle standing on high ground which on two sides slopes to a deep glen. Through this glen runs a stream along the course of which are waterfalls and steppingstones, and bridges which connect different parts of the grounds. Round the castle are lawns and shrubberies with winding paths; the flower gardens are arranged at some little distance from the building. In the kitchen garden there is a feature of a very attractive kind, a broad gravelled walk, bordered with flowers and enclosed within yew hedges, which has in its centre a stone fountain and at the end a pair of finely wrought iron gates leading into the park.

Brockhole (Plates XVIII. and XIX.) is a characteristic lake-side garden which was designed and planted by Mr. Mawson some ten xxi 
years ago. The house stands on a small plateau on the side of a hill between Windermere and Ambleside and commands lovely views of Lake Windermere and of the hills beyond. The gardens are not large, but they are laid out with admirable judgment and with complete appreciation of the manner in which the beauty of the site chosen could be most adequately developed. They make an entirely appropriate foreground to a singularly charming picture. In Sir William Forwood's gardens at Bromborough Hall, Cheshire (Plates XX. and XXI.), there are noteworthy illustrations of more than one type of design. On the south front of the house is a very well-planned Dutch garden, at the end of which stands a large conservatory; the flower beds, bordered with dwarf box-edging, are filled with begonias and other bright-hued flowers which make an exquisitely brilliant colour harmony, and they are arranged on a formal plan which has suitable regularity without stiffness. In another part of the grounds is a Japanese garden planted with appropriate shrubs and flowers and furnished with garden ornaments which help much to give distinctive character to the design. This garden is mainly a reproduction of one which was laid out at the Chicago Exhibition.

v. Brougham Hall (Plates XXII. and XXIII.), a picturesque building of much architectural importance, is surrounded with lawns bordered and diversified by beds of flowering plants; on the western side of the house the lawn forms a terrace which overlooks a wide stretch of country leading in the distance to the hills at the foot of which lies Lake Ullswater - a view of remarkable beauty. The chief characteristic of the garden is the profusion of flowers grown in it. The Bungalow, Rivington (Plates XXIV. and XXV.), is a place still in the making, which promises to be, when completed, one of the most remarkable of the northern gardens. The bungalow itself has been built by $\mathrm{Mr}$. W. H. Lever on a hill known as Rivington Pike, from which amazing views are obtained in all directions, and the gardens are being laid out by Mr. Mawson, who is using all the resources of garden-making to accentuate the natural attractions of the site. A notable piece of construction is the terrace upon which are erected stone sheiters and from which steps lead to a stone-built pergola and to garden houses commanding a wonderful outlook over the country round. Already a great variety of plants, and of alpine plants particulariy, are growing in the garden. The Rivington estate, which is about seven miles from Bolton-le-Moors, includes both the high moorland hills and a large stretch of pasture land in the valley below ; it was bought by Mr. Lever some little while ago.

One of the best features of the stately garden at Byram Hall (Plates xxii 


\section{NOTES ON THE ILLUSTRATIONS}

XXVI. and XXVII.), is the triangular rose garden enclosed by high walls of clipped yew, along the foot of which are placed terra cotta busts on ornamental pedestals; but the orangery on the terrace, approached by steps from the garden below, is also of interest. On one side of these steps grows a fine cedar of Lebanon, on the other an acacia-tree-the contrast of form and foliage texture is pleasantly effective. Carnatic Hall (Plates XXVIII. and XXIX.) has a modern garden of much beauty, pleasantly arranged and well kept ; it does not, however, provide examples of any new methods of design. At Castle Eden (Plates XXX. and XXXI.) the gardens are' not very extensive, but they are important because they show a great deal of well-applied ingenuity in the adaptation of the natural character of the site. From the lawns on the north side of the castle there are fine views of woodland scenery overlooking the masses of foliage in the Castle Eden Dene, which is one of the famous beauty-spots in the county of Durham. In some places there are perpendicular rocky cliffs, eighty to a hundred feet high, and clothed with ferns and other vegetation growing in the crevices; and there are walks, winding along the Dene and over rustic bridges, which give many glimpses of exquisite wild nature. At its western end the Dene is crossed by a bridge from which the valley, with its rocky sides half hidden by masses of shrubs and with a streamlet winding along the bottom some eighty feet below, is seen to perfection.

Castle Howard (Plates XXXII. to XXXV.), a magnificent mansion built by Vanbrugh, has gardens laid out on an imposing scale which are not, however, maintained now in perfect order. This is a matter for regret, because they have unusual dignity of design and breadth of effect and are memorable as examples of the grand style in gardenmaking. A very interesting feature is the temple which stands on high ground on the eastern slope, and is approached by a wide grass walk along which are placed a number of colossal statues. Fine pieces of sculpture, fountains, and so on, ornament other parts of the grounds. Chevet Park, near Wakefield (Plate XXXVI.), provides a good example of the manner in which a pleasant garden can be made and maintained despite certain disadvantages of situation - the house stands on high ground and, though it is to some extent protected by surrounding beech woods, it is a good deal exposed, particularly to westerly winds. The rock garden is, perhaps, the most successful bit of arrangement in the place, but the kitchen garden, with its central walk bordered by herbaceous plants, and leading to a large well, is also worthy of note. At Cragside (Plates XXXVIII. and XXXIX.), 
the possibilities of landscape gardening, when directed by sound taste and a proper sense of artistic proprieties, are singularly well illustrated. Some years ago the late Lord Armstrong bought a large stretch of moorland hills and valleys near Rothbury with the idea of building a shooting-box there, but, before he died, he had converted this estate into an unusually beautiful place with a character and charm entirely its own. Behind the house is a high hill clothed with trees amongst which great grey rocks stand out like the ruins of a castle. At the foot of the hill is a dene through which wind paths that open up delightful vistas of woods and streams and waterfalls, with here and there rustic bridges spanning the water. At one point a bridge crosses the valley at a high level; at another point the stream runs through thickets of trees and shrubs between tall, perpendicular cliffs of rock which are overgrown with ferns and partly veiled with ivy. Cragside is especially famous for its wonderful show of rhododendrons -three or four million bushes have been planted about the grounds, and in the early summer, when the bushes are in flower, the display of colour is exceptionally beautiful.

$\checkmark$ Croxteth Park, the seat of the Earl of Sefton (Plates XL., XLI., and XLII.), has a great deal of sumptuousness and dignity of effect, and the gardens make an admirable setting for the house. This is built on a high, broad terrace, paved with flagstones, from which a large flight of steps descends to a long gravelled path that intersects the garden in front of the house. Another path, below the terrace, leads to the eastern and western lawns. The grounds are mostly laid out in lawns studded with beds of flowering plants and with fine trees. A winding walk runs on one side to a small lake, and there are other walks, prettily placed, which connect the different parts of the garden. Eller How (Plate XLIII.) deserves attention because it represents a real achievement in garden-making. The house, which stands on the side of a hill at the back of Ambleside, was built by the late $\mathrm{Mr}$. Boyle, who bought a couple of acres of meadow land and, having a hobby for gardening, devoted himself to laying them out in accordance with his own ideas. He planted a great variety of trees and shrubs, he constructed miniature lakes and pools, and built rustic bridges; and by judiciously planning his winding walks he succeeded in creating an impression that the garden covers a much greater space than it actually occupies. The pools, in which grow many varieties of water-lilies, are made quite charming by being set in masses of greenery and surrounded by clumps of fine ferns.

$\checkmark \quad$ For the present arrangement of the gardens at Farfield Hall (Plate XLIV.), Mr. Mawson is responsible; his assistance was obtained for xxiv 


\section{NOTES ON THE ILLUSTRATIONS}

the reconstruction and improvement of a previously existing design. His intervention has certainly been most successful, for the place as it is now has a considerable degree of distinction and possesses many features of interest. Well-proportioned terraces and other architectural details have been introduced, and advantage has been taken of the situation of the house to provide standpoints from which fine views of the surrounding country can be obtained. Ford Castle (Plates XLV. and XLVI.), a place of much historical importance, was purchased a few years ago from the Marquis of Waterford by Lord Joicey, who has since spent large sums of money in improving the grounds and the village which adjoins the castle. Like so many of the northern places, Ford Castle stands on a high plateau above a wooded valley which is laid out as a wild garden and crossed by bridges from which there are charming views of the slopes and streams below. In the north-west corner of the plateau is a small but well-designed formal garden that makes a pleasant foreground to a vista which stretches away into the far distance. A large fountain, designed by Louisa, Marchioness of Waterford, and erected as a memorial to her husband, the fourth Marquis, stands in another part of the grounds; and another important architectural addition, which has been made by Lord Joicey, is the new entrance from the main road, an open stone wall with fine gates and bronze horses on the top of the gate piers. Ford Castle is known in history as the place where King James of Scotland spent the night before the battle of Flodden Field.

Fulford Hall (Plate XLVII.) is an old house which has been in the family of the present owner for at least two centuries. The gardens are apparently of the same date as the house, and are good as examples of the earlier fashion in design. Old trimmed yews give a quaint picturesqueness to the place and assort well with the architectural character of the building with which they are associated. The most striking thing at Gledhow Hall (Plate XLVIII.) is the fuchsia garden, which is also called "My Lady's Garden"; a charming nook enclosed by shrubberies which is planted with fuchsia-bushes that have grown to several feet high and are covered by masses of bloom. The grounds are laid out in a simple and unpretentious manner, but full advantage has been taken of the undulating character of the site, and the whole place has been planned with taste and judgment. There is in the garden a remarkable piece of topiary work, a boxtree which has been trained and trimmed into the shape of an oldfashioned rush-bottomed chair. At Grimston Park (Plates XLIX., L., and LI.) is one of the best examples of the Italian type of garden 
that can be found in the north of England. This garden, which covers some forty acres, was laid out about half a century ago by Nesfield, who was one of the chief of the Early Victorian garden designers, and it quite adequately represents his methods. Much use has been made of marble statuary, most of which is by Italian artists; and there is one path particularly - the Emperors' walk-which shows very effectively how sculpture can be introduced into a garden design. This walk has at one end a statue of Paris offering the apple and at the other a temple in which stands a colossal bust of Napoleon I., and on either side are placed busts of Roman Emperors. The house itself, which is in the classical style, replaced an early building in 1840 .

Nesfield was also responsible for the fine terrace and formal garden on the south front of Harewood House (Plates LII. and LIII.), in the centre of which there is a large and imposing fountain executed by Raymond Smith. The house overlooks a wide expanse of country; in the middle distance is a lake, surrounded by trees, which was constructed by Capability Brown, and beyond is a vista of hills and valleys, diversified by masses of woodland. On the eastern side is a small square garden bounded by a dwarf hedge of trimmed yew and surrounding a basin in which stands a green bronze figure of Venus. Beyond the formal garden on the south is an unusually fine herbaceous flower garden, and below this again is a grass terrace which runs along the whole width of the garden above. A walk along the margin of the lake leads to a charming little rose garden, and other walks wind through the woods beyond. In the kitchen garden is a herbaceous flower walk, with a rustic pergola covered with climbing roses, and in the centre of this walk is a circular grass plat upon which stands an old stone sun-dial.

Heslington Hall (Plates LIV. to LVII.), an old Tudor mansion which was restored about seventy years ago, has considerable interest as a good specimen of domestic architecture. The garden in which it stands is not elaborate in design, but in character and manner of treatment it is admirably in keeping with the house, and it has a kind of old-world atmosphere that is more than usually satisfying. It is, fortunately, exceedingly well cared for, and has not been allowed to lose any of its trim and stately formality through neglect. Its chief feature is a series of clipped yew-trees cut into all sorts of curious shapes; these trees are mostly of great age, and are of unusual height and girth, and have not only been well shaped from the beginning, but have also been kept in the best of order. In the grounds is a lake which is used for boating. Trimmed yew-trees xxvi 


\section{NOTES ON THE ILLUSTRATIONS}

some centuries old are also to be found at Hovingham Hall (Plate LVIII.) ; they make a sheltering wall round the rose garden, and provide with their dark foliage a singularly effective background for the masses of delicately coloured flowers with which the garden is filled - the contrast is undeniably pleasing. Another interesting feature at Hovingham Hall is a walk through an avenue of yew-trees which have been left to grow in their natural form.

At Hutton John (Plates LIX. and LX.), the seat of the Speaker of the House of Commons, another good illustration is provided of the harmonious relation which exists between an old house and the old gardens by which it is surrounded. The whole place is pervaded by the sentiments of quiet and restful age, and it has an air of remoteness from the noise and bustle of the modern world that is curiously persuasive. The quaintness of the garden is due in great measure to the use that is made in it of topiary work of a large and simple type ; on the terrace in front of the house is a row of ancient yews, trimmed into definite and massive shapes without any grotesqueness of form, and in other parts of the grounds clipped trees are introduced with excellent appreciation of their decorative value. The small sundial garden with its profusion of flowers is a very pleasant nook; and there are in the grounds many pretty walks from which fascinating peeps of the Cumberland Hills can be obtained. Jesmond Dene House (Plates LXI. and LXII.) stands about two miles from the city of Newcastle-on-Tyne beside the famous valley known as Jesmond Dene. Through the grounds runs a deep ravine with wooded sides and a stream at the bottom which is crossed by two rustic bridges; and at the end of the gardens by the Dene is a high stone bridge with a single arch which tells as a fact of much importance in the general plan of the place. In another part an arched subway leads to an old stone quarry which has been converted into an exquisite garden ; and there is elsewhere a "dell garden" which is very well seen from a walk above. The whole of this place is absolutely informal: the natural characteristics of the ground have been very cleverly turned to account in working out a scheme of wild gardening on thoroughly appropriate lines.

At Kirklees (Plates LXIII. and LXIV.) the gardens are neither large nor elaborately arranged but they have the merit of being suited in their natural character to the place in which they are situated and to the house to which they belong. The pool in the lower garden is skilfully contrived and has a picturesqueness that can be frankly admired, and there is a grass walk bordered with flowers which is, in a very quaint, old-fashioned way, of quite noteworthy beauty. 
$\checkmark$ Knowsley Park, near Prescot (Plates LXV. to LXVIII.), is a place of greater pretensions. It covers a good deal of space and has much variety of treatment. The principal flower garden is designed for bedding-out plants, and the whole group of beds in it is filled with scarlet geraniums, an old-fashioned flower, but one which, used as it is here, gives wonderful effects of gorgeous colour. It is certainly seen to perfection at Knowsley. The lake and lily pond are examples of the best kind of wild gardening, and there are in the grounds many pretty walks and some well-placed rustic bridges.

$\checkmark \quad$ The gardens at Lambton Castle (Plates LXIX., LXX., and LXXI.) are finely designed and have been planted with excellent judgment. In front of the Castle is a broad gravelled terrace, with a parapet wall, from which there are fine views of the River Wear (on the banks of which the building stands) and of the lovely country beyond. On the eastern side is a succession of grass terraces leading down to a formal flower garden about eighty yards long, which is laid out in scroll patterns of different coloured flowers. On the western side there is a pair of magnificent wrought-iron gates through which the gardens are approached. In the surrounding woods are a number of shady walks which lead up and down the slopes of the river bank; and in one part of the grounds is a pretty ravine crossed by a suspension bridge. Lambton Castle is a modern building but it is interesting architecturally and its surroundings give it ample dignity.

$\checkmark$ Levens Hall, in Westmoreland (Plates LXXII. to LXXX.), is quite the most famous of all the English houses for the remarkable character of its gardens and for the large amount of fine topiary work that is to be seen in them. They were laid out originally with much ingenuity of design, and as they are kept in scrupulous order all the beauties of this design and all its remarkable variety of detail can be fully enjoyed. As an exercise in formal planning and clever space-filling the whole place deserves the closest study; and the way in which trimmed trees have been used in the scheme of garden-making to increase the picturesqueness of the general effect, and to give it the right note or studied quaintness, is singularly fortunate. In the summer-time when the beds are filled with a gay profusion of bright-coloured flowers, which tell brilliantly against the dark foliage of the clipped yews, the Levens Hall gardens are a wonderful sight and abound with subjects for the painter. The Hall itself has many notable architectural features and its oak-panelled rooms are entirely delightful.

$\checkmark$ Lord Londesborough's shooting-box, Londesborough Park (Plates LXXXI. to LXXXVI.), provides a good illustration of the way in which the configuration of the ground can be utilised to guide the xxviii 


\section{NOTES ON THE ILLUSTRATIONS}

garden designer in making his plan for laying out a selected site. The house stands at the top of a fairly steep slope along the brow of which has been constructed a terrace with flights of steps leading down to a stretch of grass-land below, and the part of the slope immediately beneath the terrace has been converted into a wild rock garden instead of being rigidly formalised, so that the terrace, while serving well its purpose as a sort of base for the house, is not in any way out of relation to the open park in which it is placed. In the lower part of the grounds is a small lake overhung with trees and planted round with a variety of shrubs and free-growing plants; and on' the high ground at a little distance from the house is a walk running beside a row of large yew-trees and bordered by a dwarf terrace wall.

Lowther Castle, the Westmoreland seat of the Earl of Lonsdale (Plates LXXXVII. to XCIII.), ranks among the greatest of the English country houses and has gardens which are comparable with those in even such famous show-places as Wilton or Blenheim. Within its boundaries are examples of a great variety of types of garden-making, and each one is a complete working out of the motive chosen as well as an expression of a particular style. The most remarkable of these gardens are "My Lady's Laurel Garden," a sunk lawn laid out with flower beds which has at one end a terrace and on either side high, sloping banks of trimmed laurels backed up by tall trees; a very large rose garden with a walk at its margin bordered with herbaceous flower beds; a "sweet-scented" garden planted with all kinds of sweet-smelling herbs; a topiary garden, a lawn with clipped yewtrees on either side; a Japanese garden; and a Japanese iris garden. In the Japanese garden the lakes, canals, bridges, trees, and other details are all on a small scale but perfect in their relative proportion, and the scheme of the whole thing is exquisitely carried out. Each of these gardens is in a separate enclosure, so that there is no unpleasant jarring of styles. Other features of the Lowther Castle grounds are a fine avenue of beeches and sycamores, an avenue of old yew-trees, left in their natural growth, which make an arch over the path beneath, and a great grass terrace thirty feet wide and about three-quarters of a mile long and backed by fine woods. From this terrace is seen a wonderful panorama of the valleys and hills of Cumberland-a vast expanse of some of the loveliest country in the north of England.

At Lytharn Hall (Plates XCIV, and XCV.) there is a somewhat similar arrangement of gardens kept separate from one another and placed in different parts of the grounds. There is a flower garden 
on an island in a pretty lily pond surrounded by a grove of trees; on the north-east side of the house and in front of the house is a pleasantly planned rose garden. Farther off, in a secluded spot, is a phlox garden which is especially attractive in effect; and at a little distance from the lily pond, but also in a place quite by itself, is the Venus garden, an open space in a ring of trees which is laid out with paths and flower borders round a marble statue. One of the better characteristics of these gardens is their informality-it is an informality, however, in which there is no lack of order.

An air of antiquity pervades the garden at Moreby Hall (Plates XCVI. and XCVII.), an antiquity, however, which has in it no hint of decay. The garden, ancient as it is, has gained rather than lost in beauty and charm of effect by the lapse of years. Laid out originally with much care and much originality of design it has been kept up perfectly and has never been allowed to degenerate into a condition of irregularity or want of proper order. It occupies the southern slope below the house, and is planned with luxuriant grass terraces and shaded walks. Much use is made of clipped yew-trees formally arranged, and there are fine lawns surrounded with masses of foliage.

At Naworth Castle, the Cumberland seat of the Earl of Carlisle (Plate XCVIII.), the gardens are comparatively small and unpretending, though the estate in which the Castle stands is of considerable extent. They are in an enclosure at the back of the Castle, and are surrounded by a red brick wall with huge buttresses on the inner side. Within this area are both flower and vegetable gardens; it is divided by two narrow grass walks which cross one another in the centre, at which point is placed an old sundial. These paths are bordered by beds of flowers, and in the spaces between the buttresses are other flower beds; while on the wall are trained rambler roses and other climbing plants. Near the Castle is a grass terrace overlooking a sunk lawn, and on and below it are more flower beds and borders. There is an old-world charm about the whole place which can be thoroughly enjoyed.

$\checkmark$ It is interesting to compare with the old garden at Naworth Castle the exceedingly new one at Newton Green Hall (Plates XCIX. and C.). Until last year it was of no special note, but early in I 910 the owner, Sir Wilfred Hepton, having decided to create some special features in his garden, invoked the aid of Mr. Thomas Mawson to rearrange the place. The work was commenced on February 10, and completed by April 28-all the stonework was built, the turf laid, the flower beds dug, and some hundreds of rose-trees planted-and in this short $\mathbf{X x X}$ 


\section{NOTES ON THE ILLUSTRATIONS}

time an old kitchen garden was converted into a delightful circular rose garden with beds of flowers radiating from a central point on which stands a sundial. The design is in Mr. Mawson's most characteristic manner, and the way in which it has been carried out does the utmost credit both to him and to Mr. Tingle, the head gardener at the Hall, who was responsible for the gardening details. The photographs from which these illustrations were reproduced were taken at the beginning of September, and they show well the condition of the garden, hardly more than six months after the work on it was begun - they record clearly the success of a wonderful piece of garden-making.

The Priory, Bidston, Cheshire (Plates CI., CII., and CIII.), is another new garden and by the same admirable designer-it is a noteworthy example of the treatment of a site by an artist who is in touch with the modern point of view. The house was built in 1902 in the middle of a fir plantation, and originally the cutting of some drives and walks among the trees was all that was attempted in the way of laying out the ground. But about two years ago the owner, Mr. Bibby, commissioned Mr. Mawson to remodel the whole place on a well-considered plan, and the garden, as it is now, is very attractive as a piece of thoughtful arrangement. Its natural character has not been radically altered, but many features of great interest have been added and brought pleasantly into relation with their surroundings.

Ribston Park (Plates CIV. to CVIII.) is famous in the horticultural world as the place where the Ribston pippin was first grown. The stem of the original apple-tree-some two hundred years old-is still standing, but it is a shoot from the parent tree which is now growing and bearing fruit. The pleasure gardens at Ribston Hall show considerable variety of treatment, and in planning them advantage has been fully taken of the inequalities of the ground by which departures from set convention have been made possible. The nature of the site, indeed, has helped appreciably to make the gardens markedly interesting because it has allowed the designer scope for the exercise of the right kind of ingenuity. In front of the house is a terrace with a small formal garden, and from this terrace woodland paths lead to the principal flower garden, which is prettily situated and surrounded by trees and shrubberies. In another part is a pinetum which contains some rare and remarkable specimen trees; and there is a dell which is quite exquisite in its tangle of foliage. In it grow plants of giant hemlock, which in this sheltered spot reach a height of twelve or fifteen feet and carry enormous heads of bloom.

xxxi 
$\checkmark$ At Rydal Hall (Plates CIX. and CX.) there is another example of $\mathrm{Mr}$. Thomas Mawson's versatility as a garden-maker, an essay in formal designing very different in character from the general run of his work, but one which shows all his usual sense of proportion and grasp of appropriate technicalities. The house is built on the slope of a hill overlooking Rydal Water, and this slope has been converted into a series of splendid terraces with excellently planned formal gardens which have an ample measure of dignity and spaciousness of effect. These terraces are not only fine features in the design, but they afford many standpoints from which the beautiful country round can be viewed under the pleasantest conditions. At the back of the house is a romantic wild garden, a dell into which falls a stream with a considerable volume of water. At the foot of the falls, a rustic, stonebuilt tea-house has been erected; and the dell, by the accentuation of its natural beauties, has been made into an exquisite piece of landscape gardening with a character entirely its own. The contrast between this wild scene and the studied, formal laying out of the ground in front of the house is as striking as it is agreeable.

Sand Hutton Hall (Plate CXI.) looks out upon a lake which was made by a former owner of the place and is in the midst of grounds that have much beauty and picturesqueness of arrangement. There is not much in the way of formal designing about the gardens, but they are made gay by pretty flower beds, and there are in them many quiet nooks and many walks which wind through the shrubberies and under the trees. The thatched pagoda is well situated and is a good example of garden architecture of the rustic kind. The illustrations of the cascade in Sefton Park (Plates CXII. and CXIII.) are worth studying as instances of the way in which nature's wildness and fascinating irregularity can be suggested by the deliberate contrivances of the garden-maker who has a right instinct in the practice of his art. The combination of rugged rock forms and tangled foliage in this exquisite little bit of water-gardening is singularly well controlled, and the result is one which in its general effectiveness and its charm of detail could hardly be surpassed. Sefton Park, which is the property of the Corporation of Liverpool, is one of the most valued possessions of that northern city; the extent of the park is two hundred and sixty-nine acres; the land was acquired in 1867 from the Earl of Sefton at a cost of over $\oint_{0} 260,000$, and over $f_{0} 146,000$ was spent in laying it out.

$\checkmark \quad$ The garden of the late Mr. R. R. Mawson's house at Windermere (Plates CXIV. to CXVII.) is not large, but it is of great interest as an illustration of the application of Mr. Thomas Mawson's methods of xxxii 


\section{NOTES ON THE ILLUSTRATIONS}

design to a place where an elaborate and extensive scheme of gardenmaking was not required. Mr. Mawson has done so much ambitious work, so many things on a large scale in which he has had to grapple with difficulties of a complicated kind, that this comparatively small villa garden must have seemed to him quite an easy undertaking. But he has not, because it was easy, dealt with it in any careless mood; it shows, indeed, a kind of exquisite delicacy in treatment and is finished in all its details with delightful precision-and it has stamped upon it that individuality of manner which distinguishes all his productions. The entrance gate with its broad steps and rough stone walls is excellently planned; the terrace in front of the house with its beds of flowers, and, at the end, a little pergola, has exactly the right touch of homely simplicity; and the steps which lead from this terrace to the tennis lawn below are given a rustic character that is wholly appropriate and entirely free from any touch of affectation. In this garden, indeed, is revealed the secret of the success of Mr. Mawson's art-his capacity to recognise what are the special needs of the subject presented to him and his power of adapting himself to the demands made upon him by circumstances.

Smithills (Plates CXVIII., CXIX., and CXX.), which is just outside Bolton, is one of the largest and most picturesque of the old English half-timbered houses, and its gabled front, quaintly irregular and partly veiled with creeping plants, has a quite unusual beauty. Such a house requires an appropriate setting and this has been provided by the planning of gardens which are perfectly in keeping with the building to which they are attached. The lawn in front, with its terrace wall and the long flower bed which borders the path to which the steps from the terrace lead, is admirably spaced, and its proportions are excellently related to the height and length of the house. Its simplicity of design is not the least of its merits, for a more elaborate arrangement would have clashed to some extent with the architectural details of the building and would have produced a certain confusion of effect. In the other parts of the gardens the same air of congruity has been maintained; they are orderly and restful and never complicated by unnecessary features, and they are full of flowering plants of the kinds that fit best into such surroundings.

Another beautiful half-timbered house is Speke Hall (Plates CXXI. to CXXIV.), which, as an inscription over the entrance porch implies, was built in the latter part of the sixteenth century, when it replaced an earlier stone house which stood on the same site. The porch, which is on the north side, is approached by a bridge twenty-five yards long over what was formerly a moat spanned 
by a drawbridge. On the western side of the Hall is a large sunk lawn some two hundred feet long by about sixty feet wide with two grass terraces rising from it, and this is continued at right angles along part of the north side and is crossed by the entrance bridgethis lawn has evidently taken the place of the old moat. On the south front is another lawn planted with evergreen trees and shrubs; and at the western end of the house is a small enclosed flower garden. Generally, the arrangement of the grounds suggests rather a kind of evolution guided by circumstances and by the necessity for altering features, like the moat, which were inconvenient or no longer worth maintaining, than the working out of a deliberately prepared plan ; but this evolution has been judiciously controlled and has led to very acceptable results.

$\checkmark \quad$ The illustration of a garden seat at Studley Royal (Plate CXXV.) is important because it shows a method of garden ornamentation by the use of plants in boxes, which is applicable in situations where the laying out of regular flower beds is not convenient and where a variation on the more usual method of tub gardening is desired. The garden seat is interesting as a piece of quaint wood construction. The main gardens at Studley Royal lie about a mile from the house on the way to Fountains Abbey and are now semi-public-an admission fee is charged to visitors.

Thornton Manor (Plates CXXVI., CXXVII., and CXXVIII.) is another place which owes its beauties to Mr. Mawson's intervention. The gardens are practically still in the making and have been in progress for only about four years. But already they have a very great charm and they promise as they develop to become singularly attractive. There is a circular rose garden which has much effectiveness of design; and the lake, which has been formed in a grove of well-grown trees, is a particularly successful piece of planning and is very happily placed in its woodland setting. At one end of this lake is a swimming pool with a paved margin. The rock walk is another feature which does credit to Mr. Mawson's sense of artistic fitness and in which the marked individuality of his methods is well displayed. The fruit and vegetable garden has also been laid out with full consideration for its future picturesqueness; it is intersected by broad walks shaded by rose arches and bordered with beds filled with a great variety of blossoms.

One of the most pleasant parts of the grounds at Underley Hall (Plates CXXIX., CXXX., and CXXXI.) is the wild garden, which is situated on the farther bank of the River Lune, on the south front of the house but at some little distance from it. This garden with its netxxxiv 


\section{NOTES ON THE ILLUSTRATIONS}

work of winding walks which run up and down the steep slope of the river bank, below which the turbulent stream flows with unusual velocity, is extraordinarily picturesque, and many beautiful spots are to be found among its tangled masses of foliage and thickets of flowering plants. It is a wonderful example of apparently unpremeditated garden-making. The gardens which immediately surround the house are planned with a great deal of taste and with full consideration for the relation they should bear to the building itself. There are large tennis and croquet lawns round which flower borders are laid out, and there is a very fine rose garden which at the proper séason is a blaze of colour. Another charming spot is a raised, circular lawn in the centre of which is placed a rectangular cistern, a piece of old Venetian carving, with golden yew-trees grouped round about it. Throughout these gardens the intention of the designer to arrive at a dignified spaciousness of effect is very clearly revealed, and that this intention has been fully realised is quite beyond dispute.

Windlestone Hall, the seat of Sir William Eden (Plates CXXXII. and CXXXIII.), is especially noteworthy for the profusion of flowers which are grown in the gardens. This profusion is the more remarkable because in the immediate neighbourhood of the house are several collieries, which might not unreasonably have been expected to have such an effect upon the atmosphere that anything like success in keeping up a garden would have been impossible. But so well is the place maintained that it does not in any way suggest that it has been prejudiced by the local conditions. Sir William Eden, as an artist of ability and experience, and as an expert in horticulture, has naturally influenced greatly the character of these gardens; he has made many alterations in their arrangement and has added a number of features which are valuable in enhancing the attractiveness of the general design-his direction and supervision, wisely exercised, have led to important results. Around the Hall are many large trees-a group of ilexes particularly must be mentioned-and there are numerous wellplanned walks which are edged with beds filled with an astonishing variety of flowering plants. These gardens provide a series of colour harmonies schemed with unusually good taste.

At Wykeham Abbey (Plates CXXXIV. and CXXXV.) the gardens are not only excellent in design but they have also the advantage of including within their boundaries the ruins of the old abbey building. These ruins in one part of the grounds are used with charming effect as a background to a prettily laid-out lawn, and as the old stone walls are partly covered with masses of climbing roses their pictorial value in a delightfully arranged composition is inestimable. The spacing 
of the gardens, with their winding paths and expanses of smooth turf, is exceedingly judicious, and the whole place has a very attractive air of shady seclusion. Some fine cedars of Lebanon and other specimen trees of mature growth are planted in suitable places on the lawns, where they have had room to develop their greatest beauties of form and proportion.

$\checkmark$ The rock garden in Messrs. Mawson's Nurseries (Plate CXXXVI.) claims attention as an example of the deliberate planning of a piece of wild scenery. The relation of the garden to its surroundings has been well thought out, and good use has been made of suitable materials. This rockery has been filled with rare Alpine plants. In these nurseries, there are many other cleverly arranged bits of garden design, which afford the fullest possible evidence of Mr. Mawson's understanding of the art in which he has attained so much success.

This is the last of the northern gardens which have been selected for record in these pages. Like so many others in the same neighbourhood it shows the ability of the designer to adapt himself to some particular conditions which the locality imposes and to use existing features as the basis of his work. There are, however, in the series of illustrations instances which prove even more effectively how the site determines the manner of treatment which must be applied to it, and how much readiness of resource the gardener must have who wishes to make the most of the material at his disposal in places where nature asserts herself in a vigorous and definite manner. The rocky valley or the steep hill-side cannot be coaxed into a state of placid beauty as easily as the gently undulating surface of a chalk down or the level expanse of a river-side meadow, and the designer has not the same freedom of action where hard facts are against him as he has where his path is made easy in whatever direction he pleases.

Indeed, in many parts of the north the gardener who wished to disregard nature's arrangement and do things absolutely in his own way, would have to call in the services of an engineer to prepare the ground for him by blasting away crags and levelling up deep depressions, by diverting the courses of rivers and by draining lakes. He would have to change with infinite trouble and at vast expense the whole face of the country, and to make a blank expanse with nothing in it to remind him of what had been there, before he could begin to work out any design of his own. To such drastic measures there would be, of course, endless objections, practical and æsthetic, and happily no one has had the mistaken courage to undertake a task of such unnecessary magnitude.

xxxvi 


\section{NOTES ON THE ILLUSTRATIONS}

There is evident, instead, all through these districts of England a very frank and sincere respect for nature-a respect, no doubt, which she demands in a rather robustious and uncompromising fashion-and to it is due in large measure the peculiar charm of much of the gardenmaking which in this part of the world appeals so strongly to students of the art. The cleverness of the designer in using what he finds on the spot where he has to work, and in handling it judiciously without destroying its character or diminishing its interest is at least as commendable as the capacity of the man who can turn a plain field into a place of beauty by building up upon it something that is entirely of his inventing. It is never difficult for the tactless person to vulgarise even the most alluring piece of wild nature if he has not the taste to see what will come appropriately into certain given surroundings, but it takes an artist to deal with something that is already beautiful and to add to it further beauties of his own devising -and it is only the great artist who can realise what subtle touches are required to perfect a picture which has been drawn exquisitely by a master hand. But of these northern gardens a proportion that is, perhaps, surprisingly large does show that this high quality of artistic appreciation has not been lacking and that the right degree both of taste and power has been applied to the solution of the problems which have been presented in rather alarming complexity. That they have been solved is the best possible proof of the care with which the designers of gardens have studied the principles of their art and of the admirable spirit in which they have carried on its practice.

A. L. BALDRY 
a

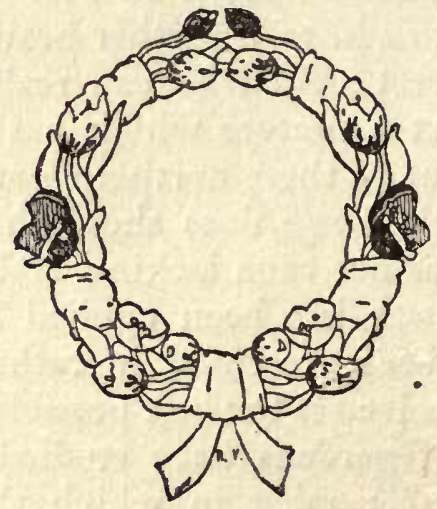




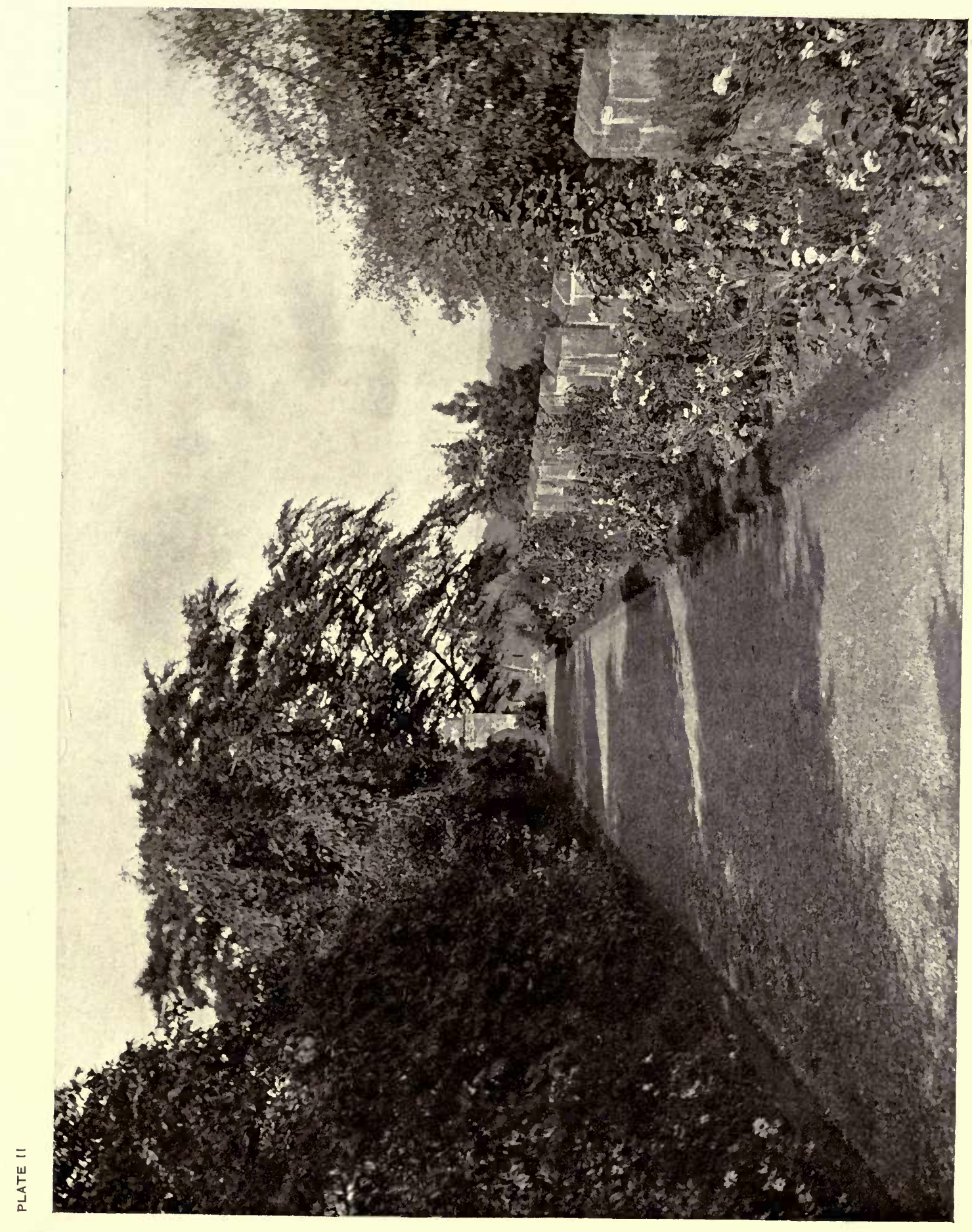

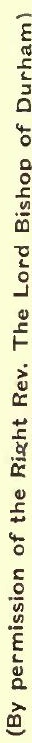




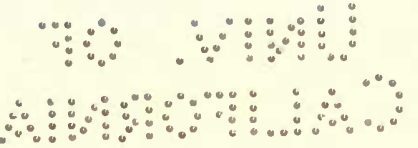

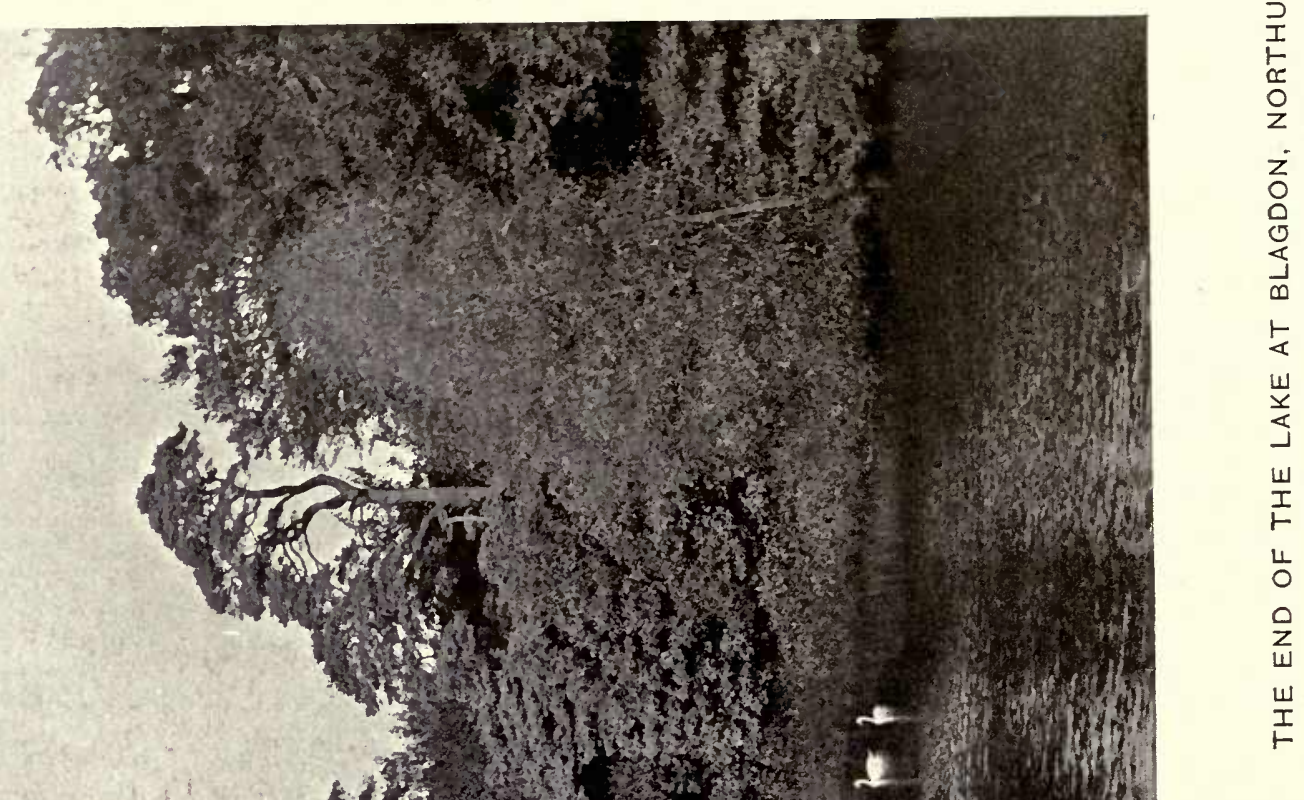

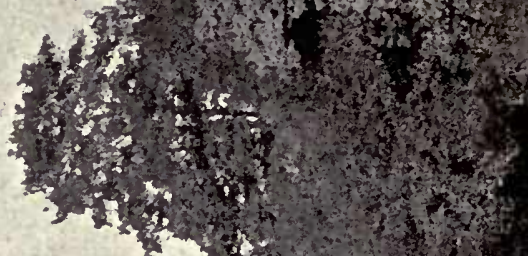

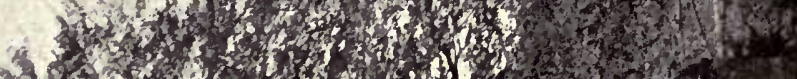

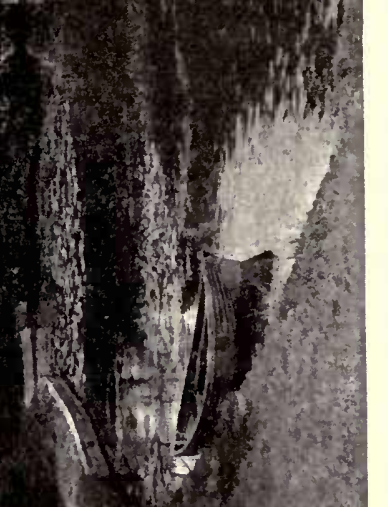

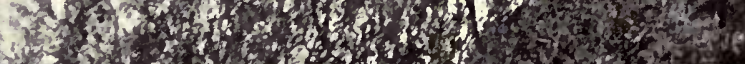

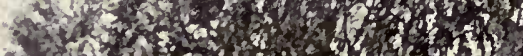

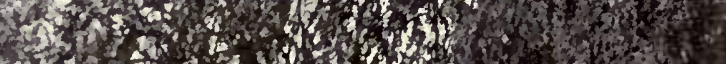

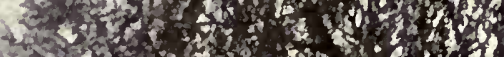

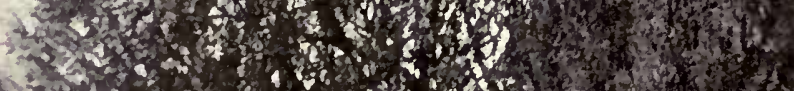
S.

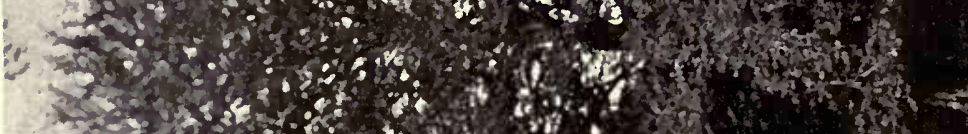
3.

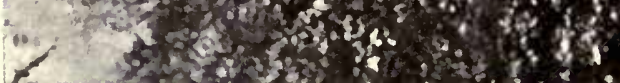




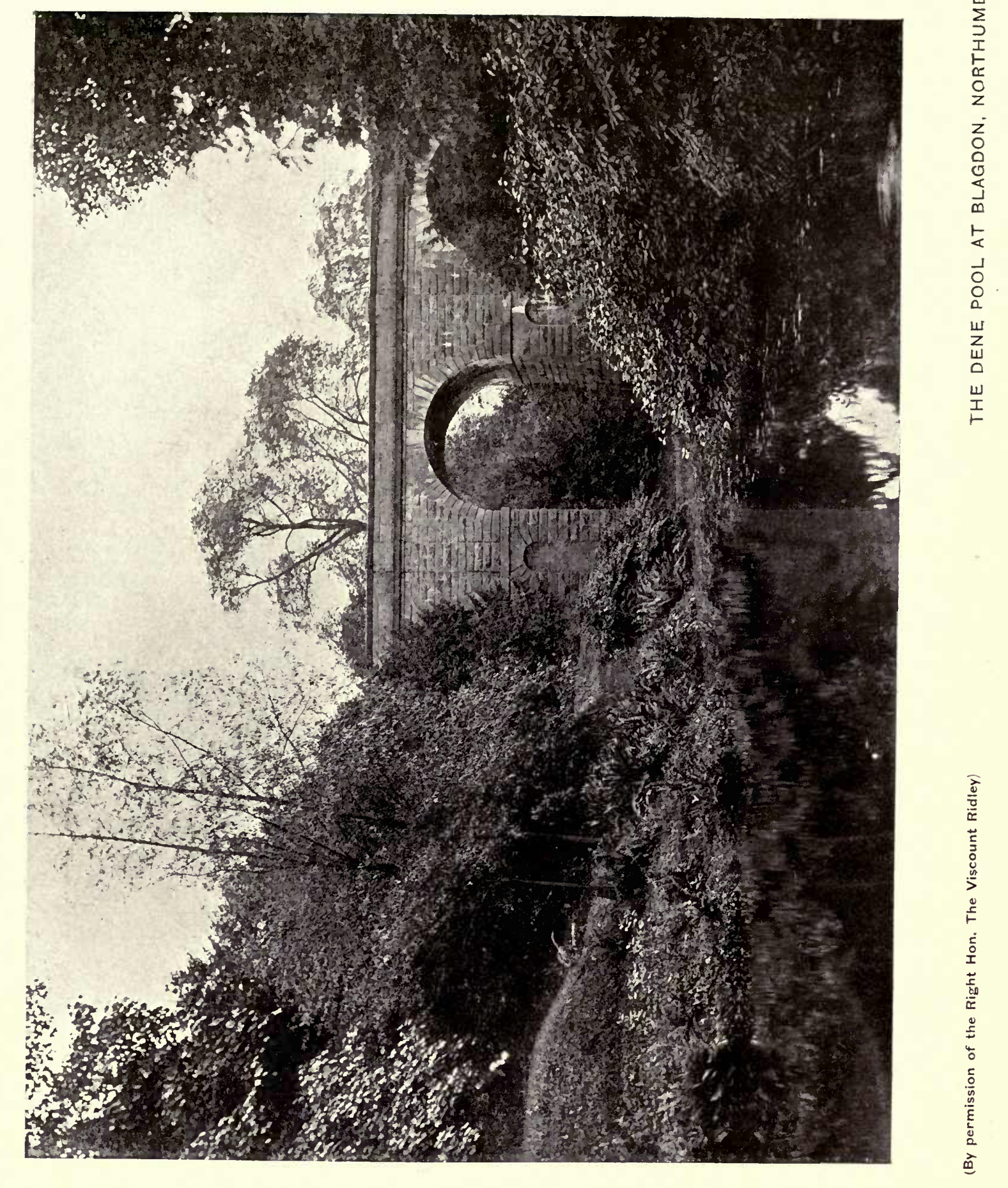




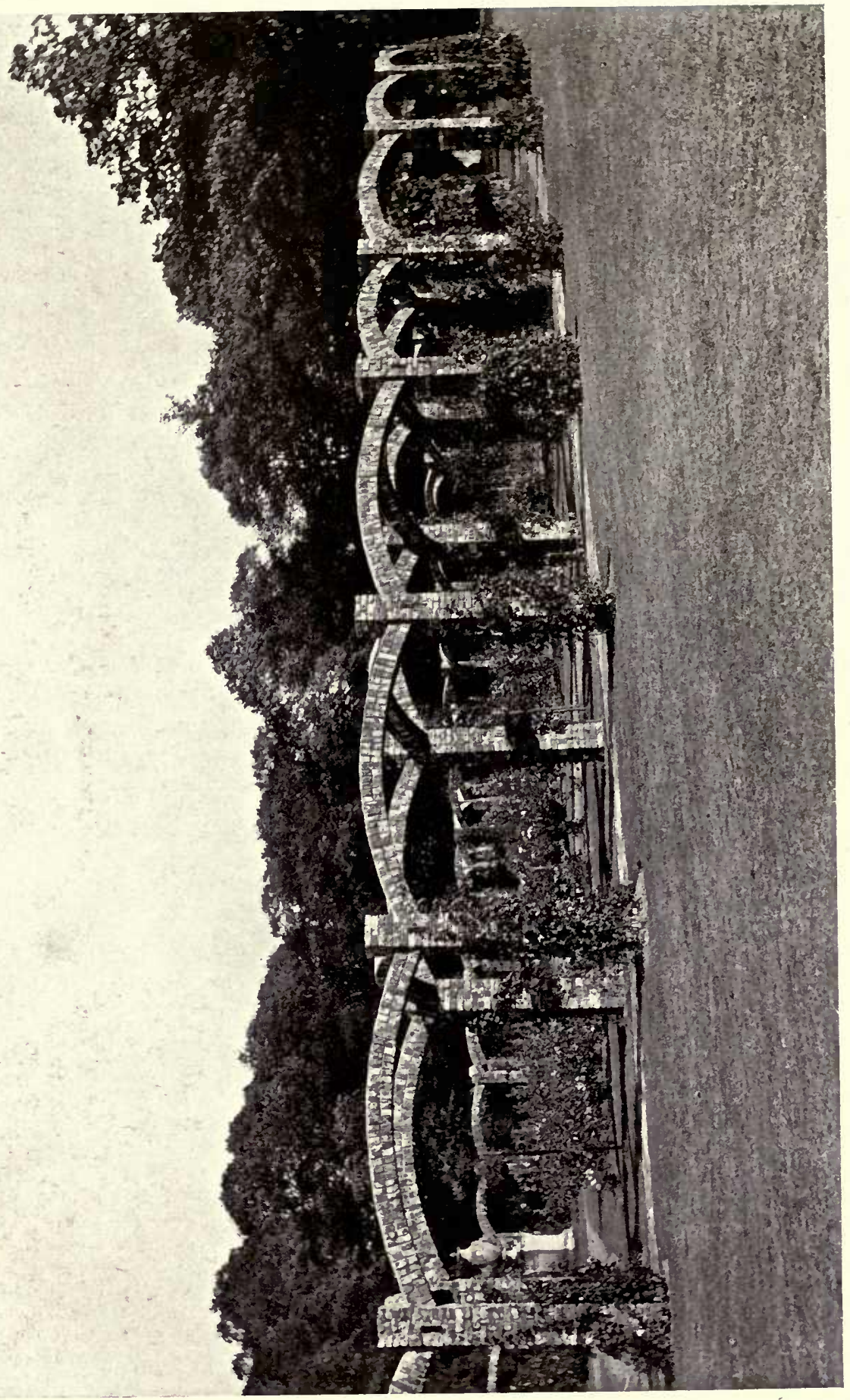

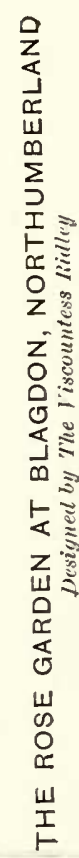

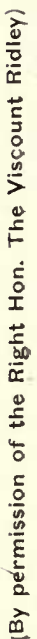




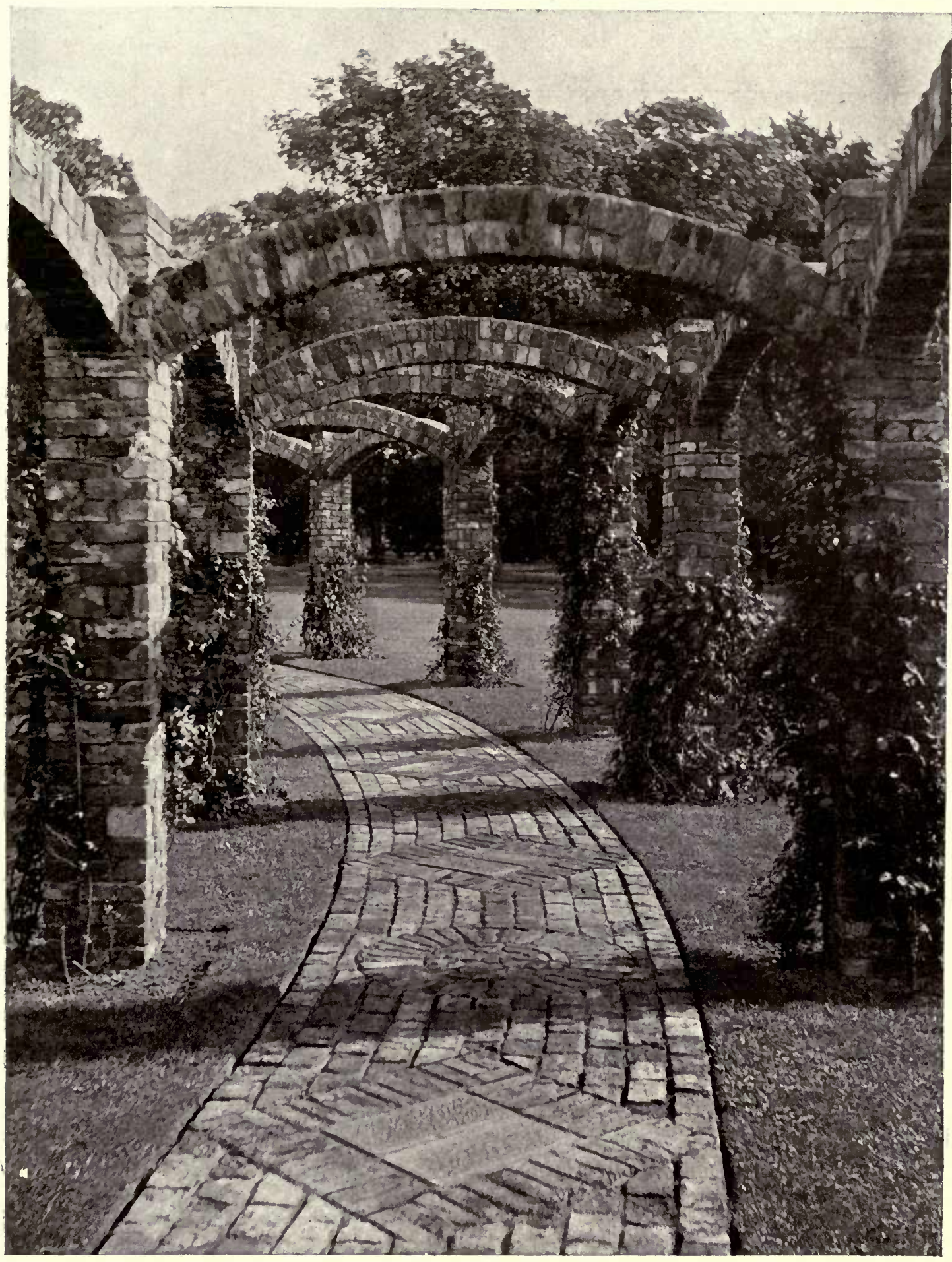


$\because \vdots \because \div \div \div \div$

$\therefore \vdots \because \vdots \because \vdots \div \vdots \vdots \vdots \therefore \therefore, \therefore$

$+1$ 1.7. (3) $2 x-1,4,13$

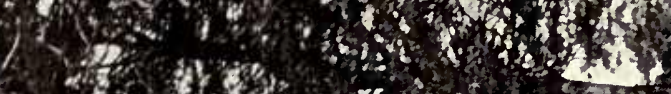

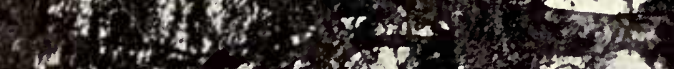

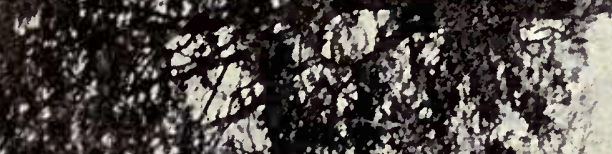
20.7.

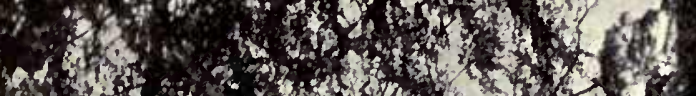

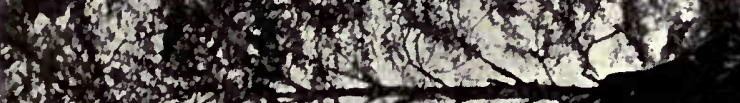

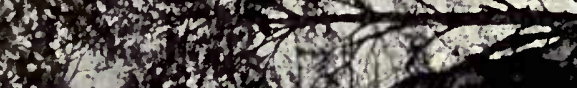

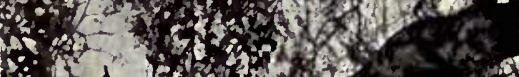

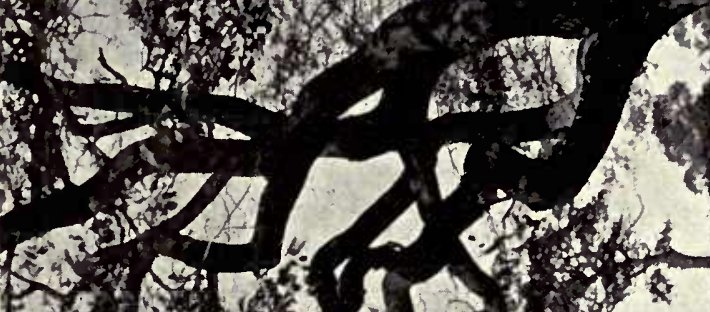

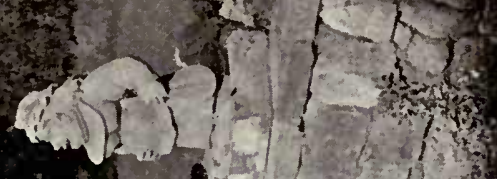

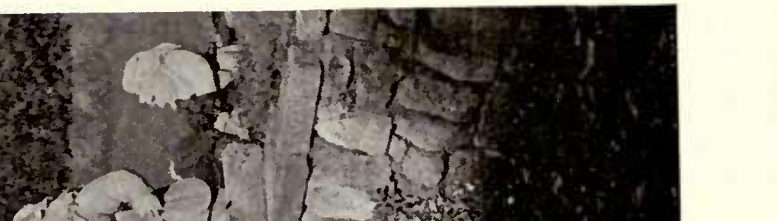

운

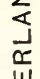

山

$\sum_{\text {I }}$

采

$z$

ż

莲

要

产

을

Z

さ

$(x+y)$ of

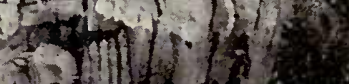

2 . Fen

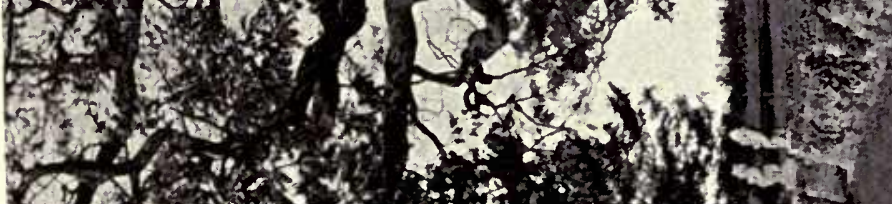

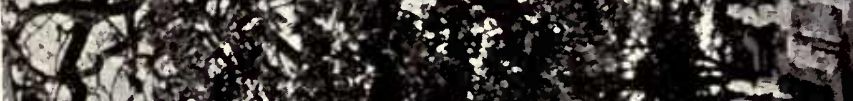
17 (3)

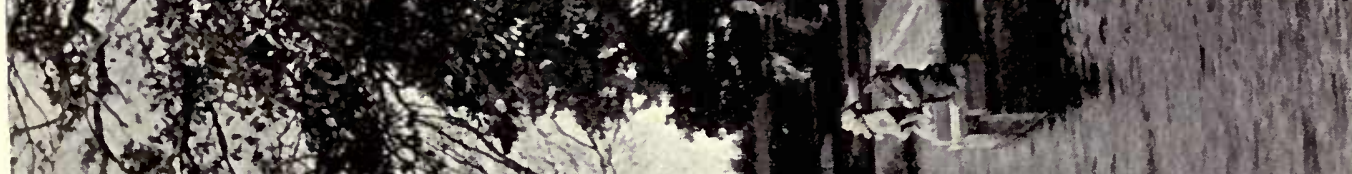
2) 10 an

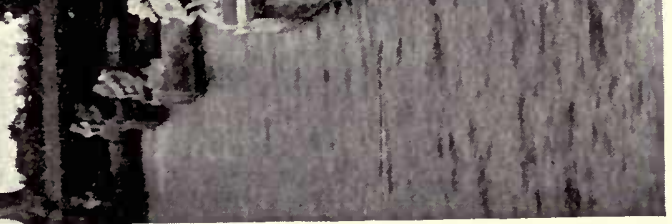




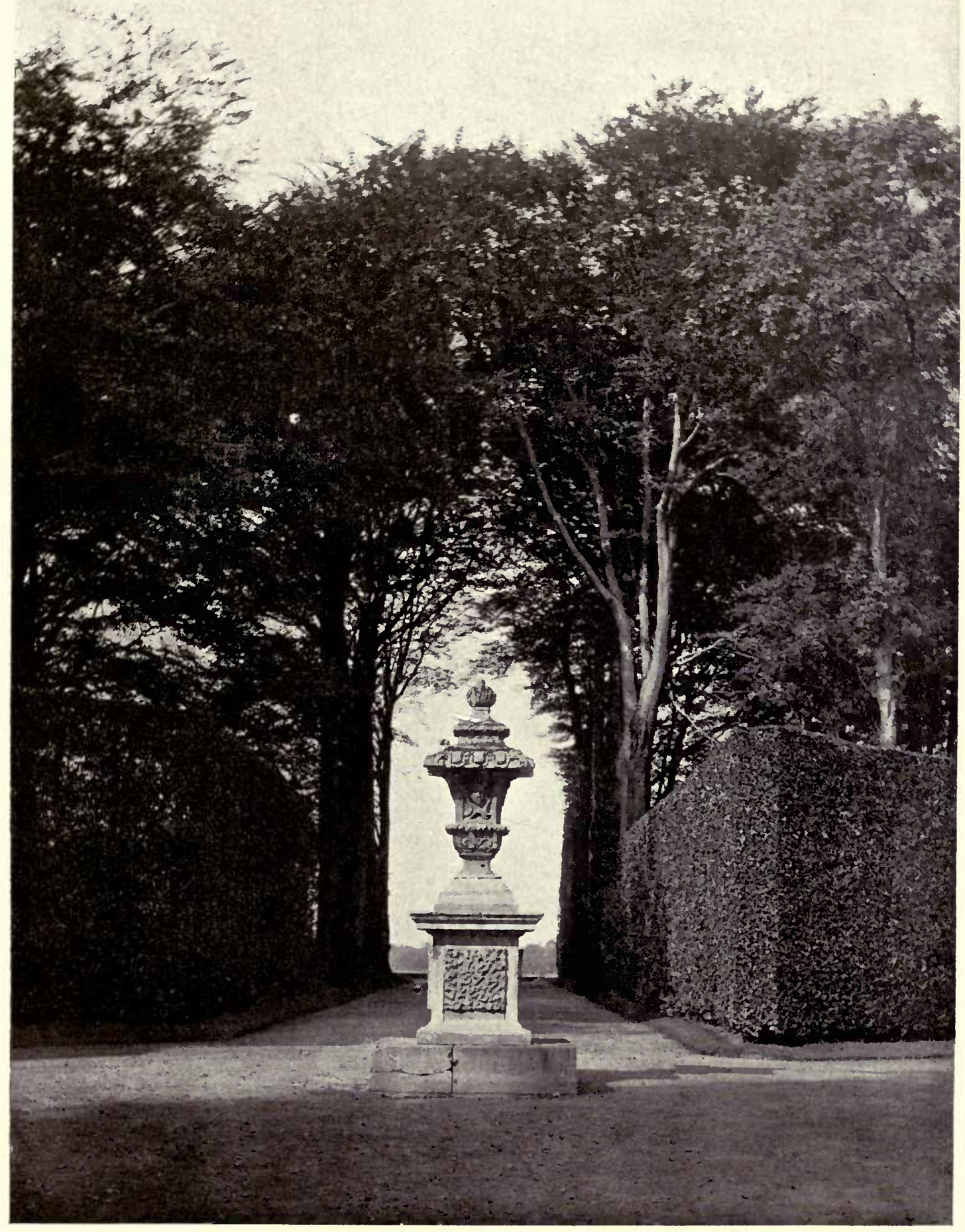




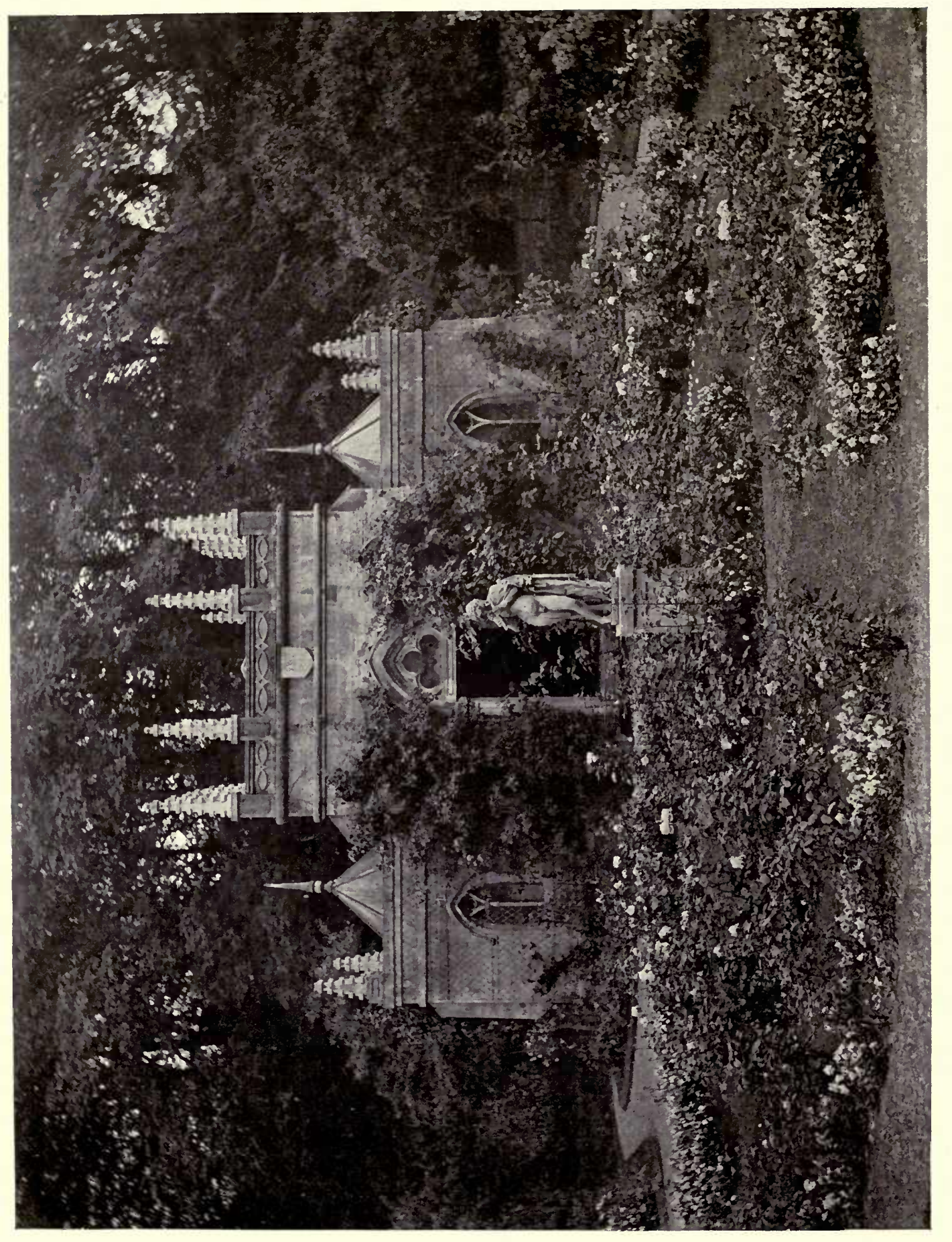

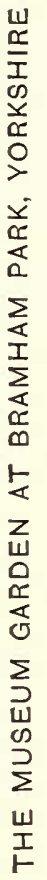



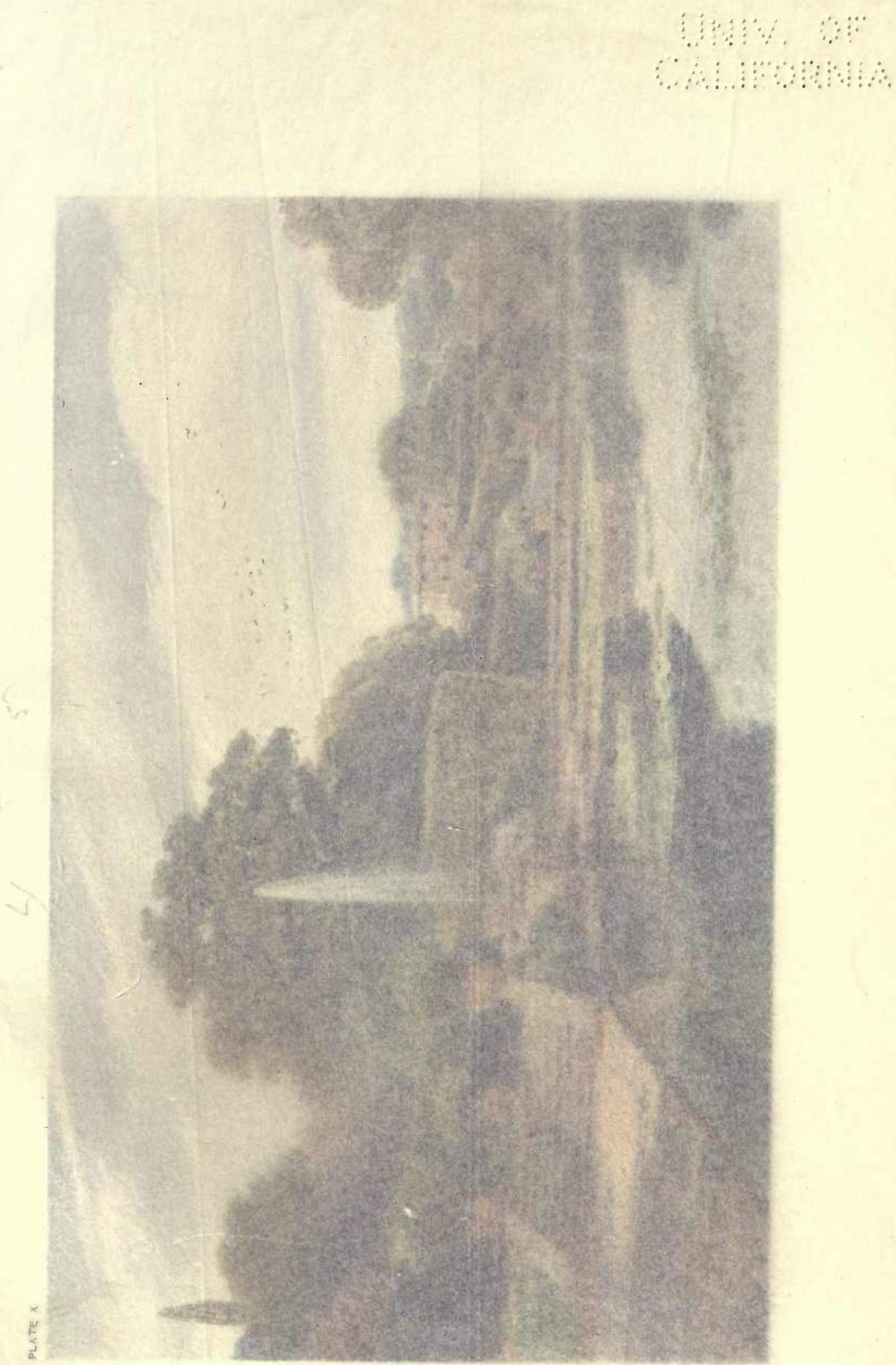


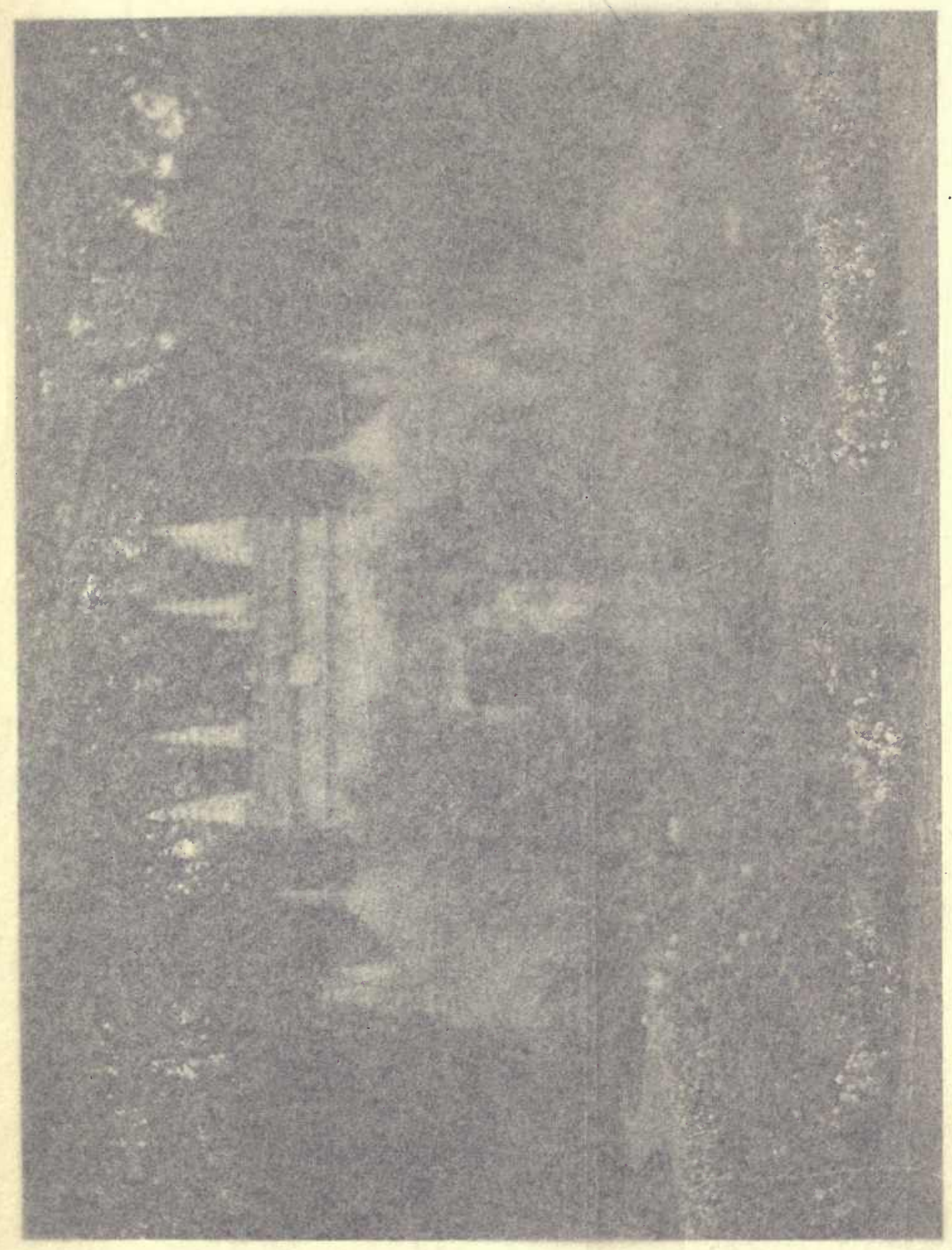

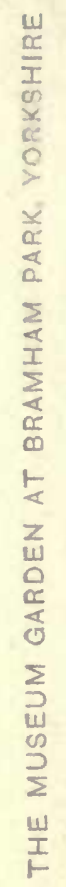

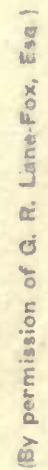



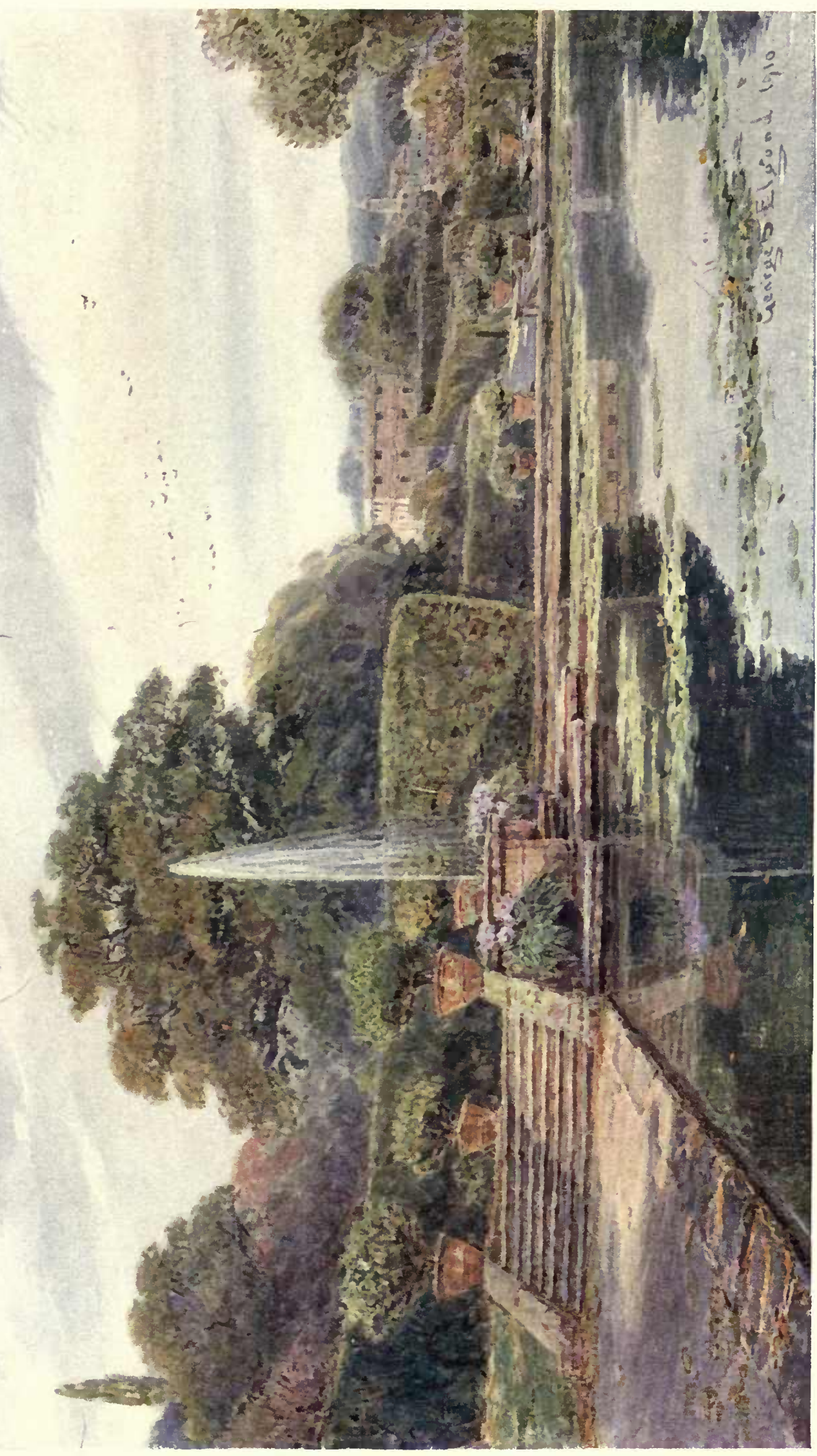
$x_{1}=$
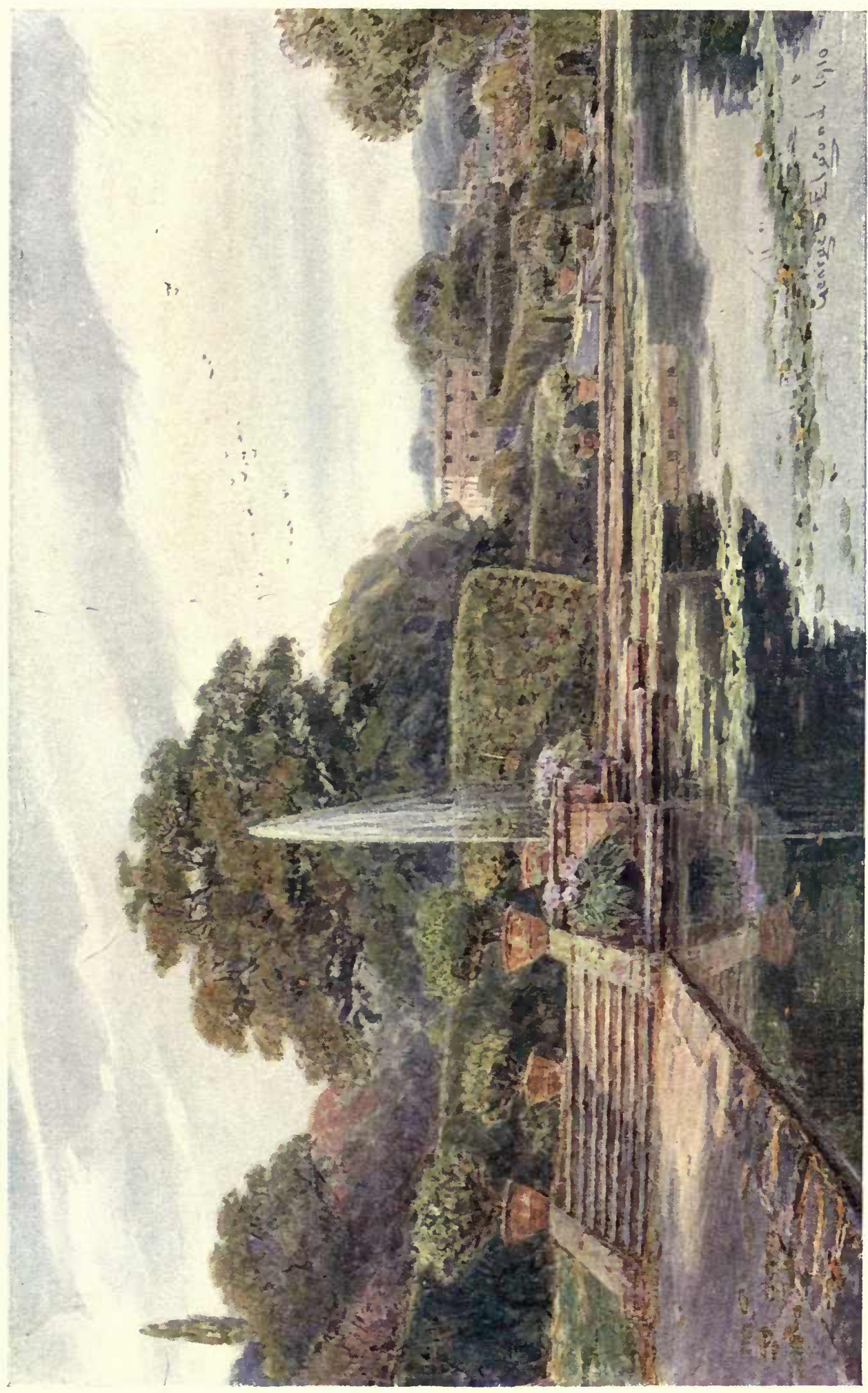

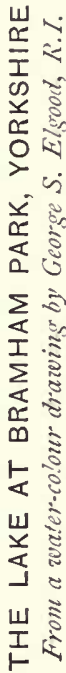
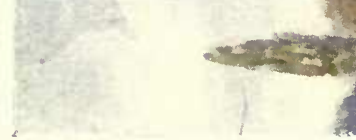
$\because 40$

ano 


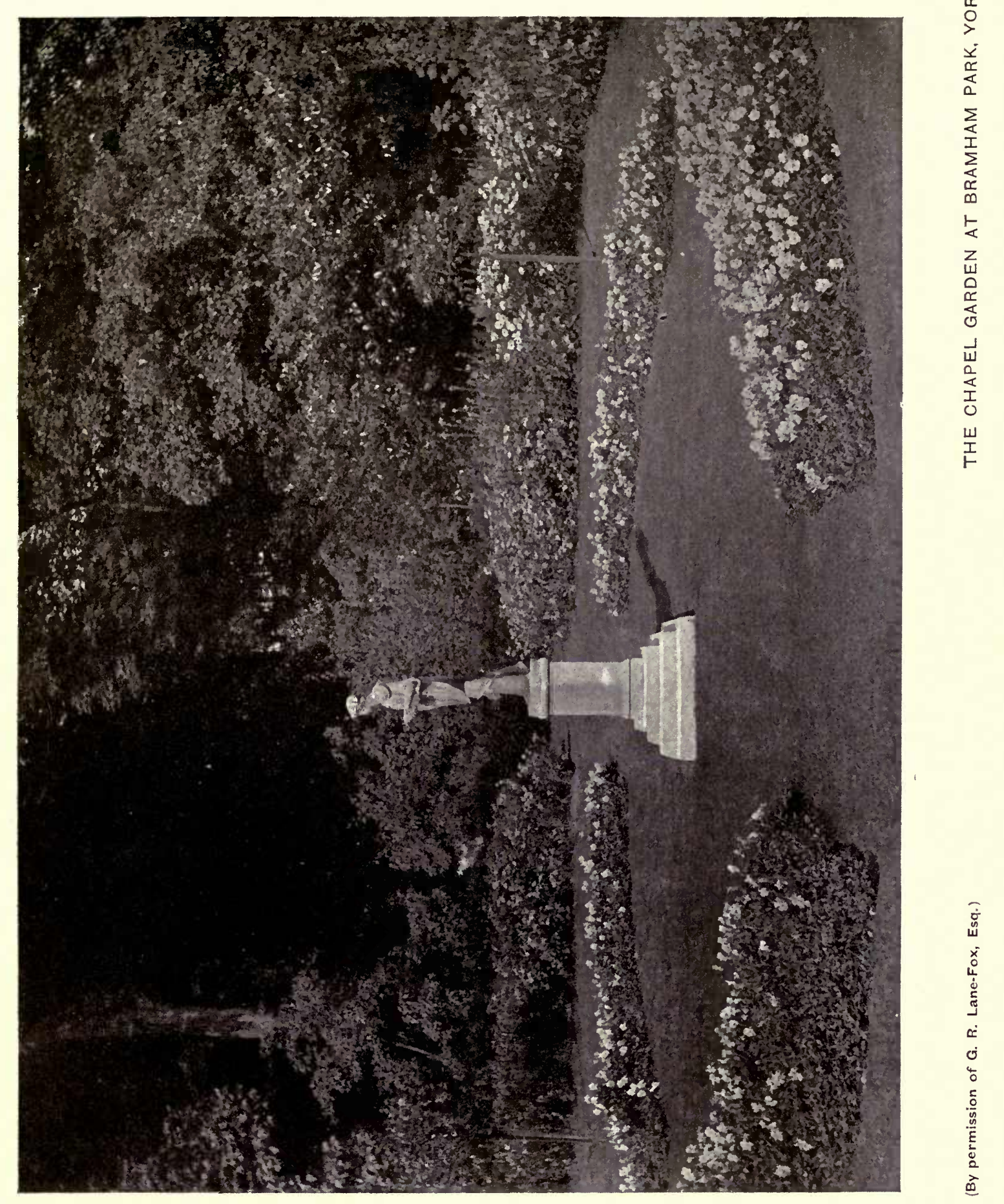




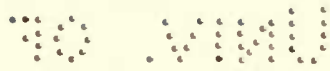

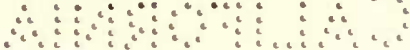

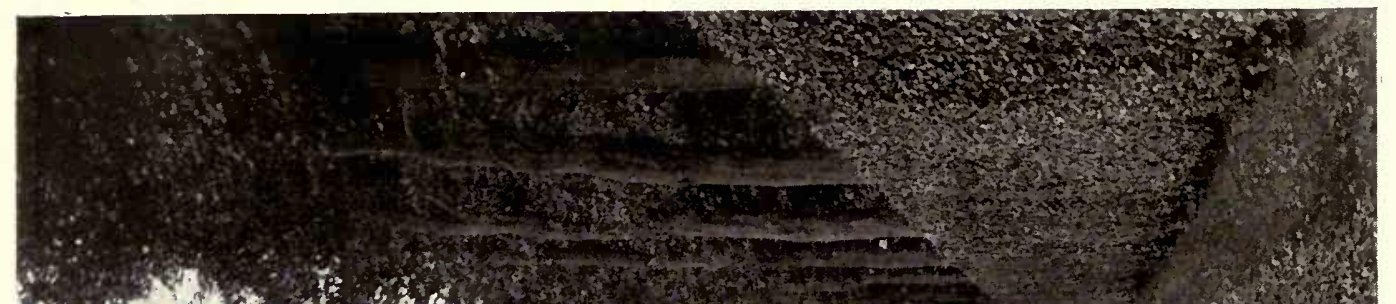

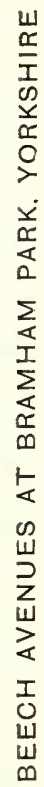

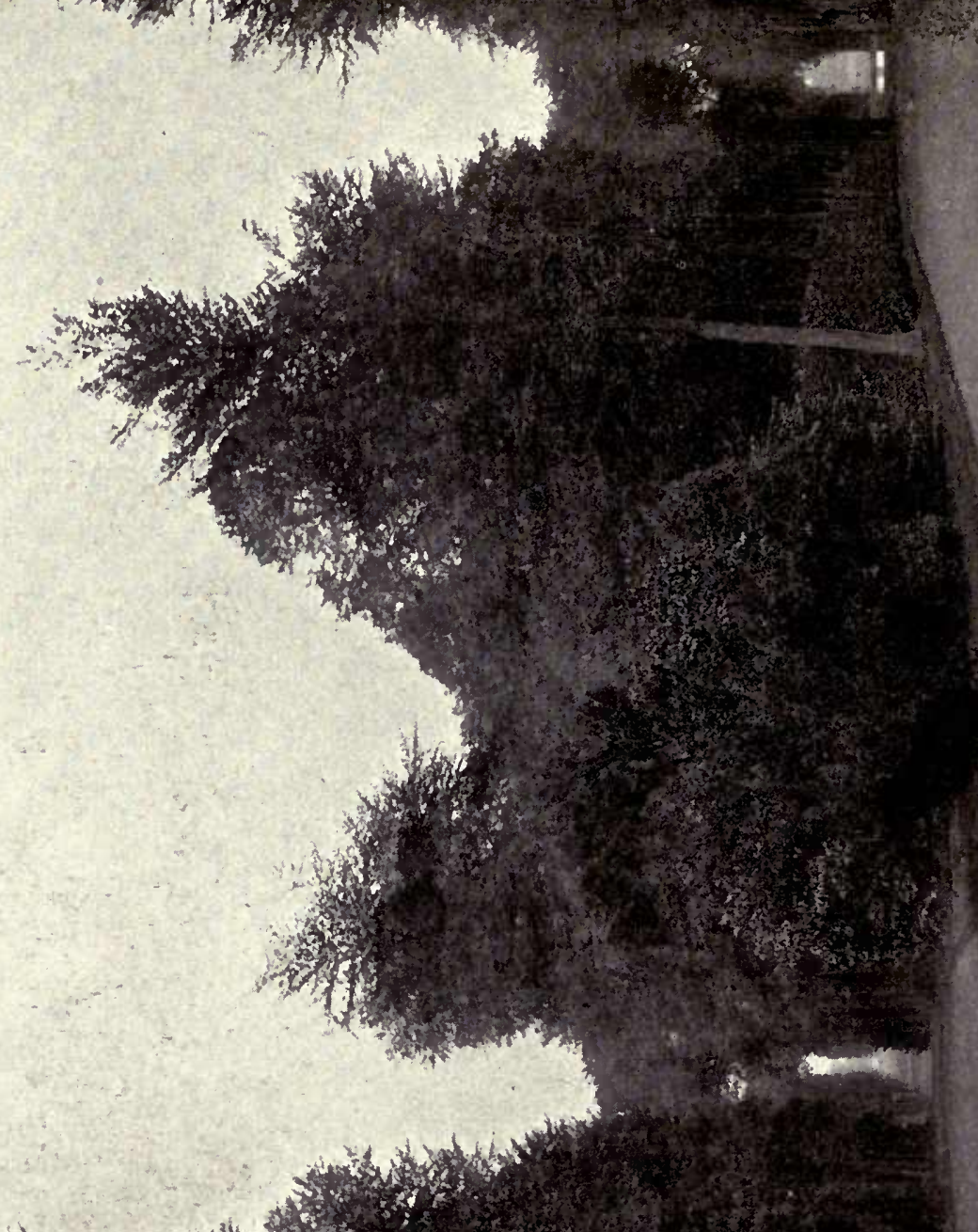

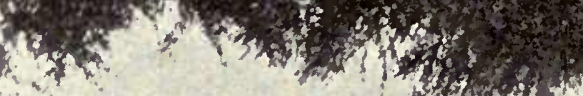

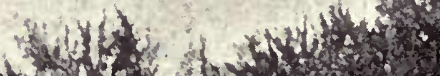

(4)

$=$

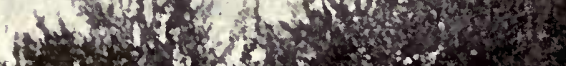

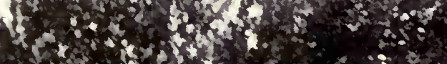

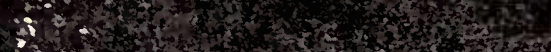




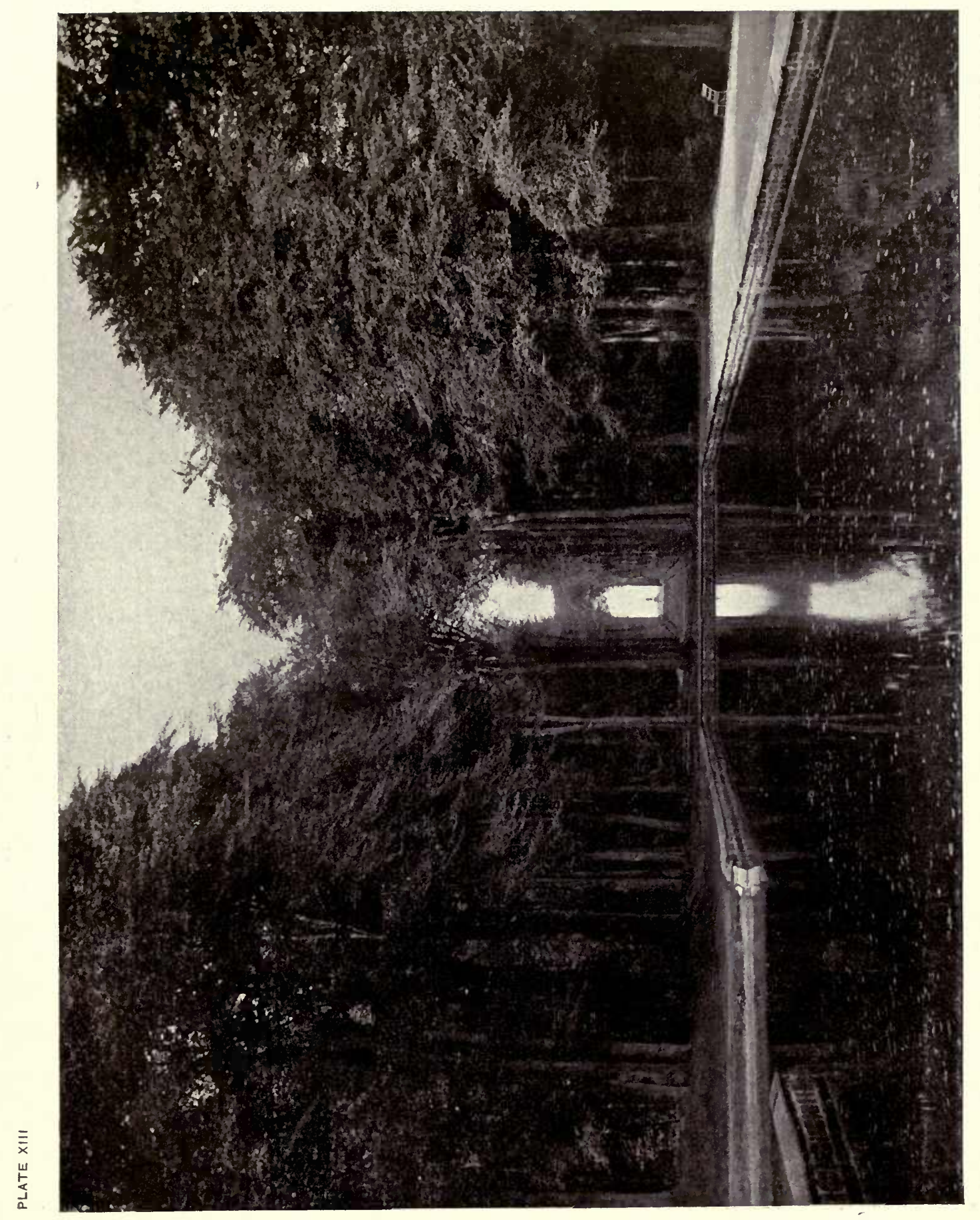

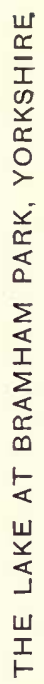




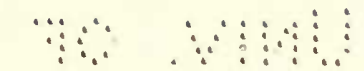

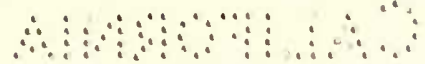

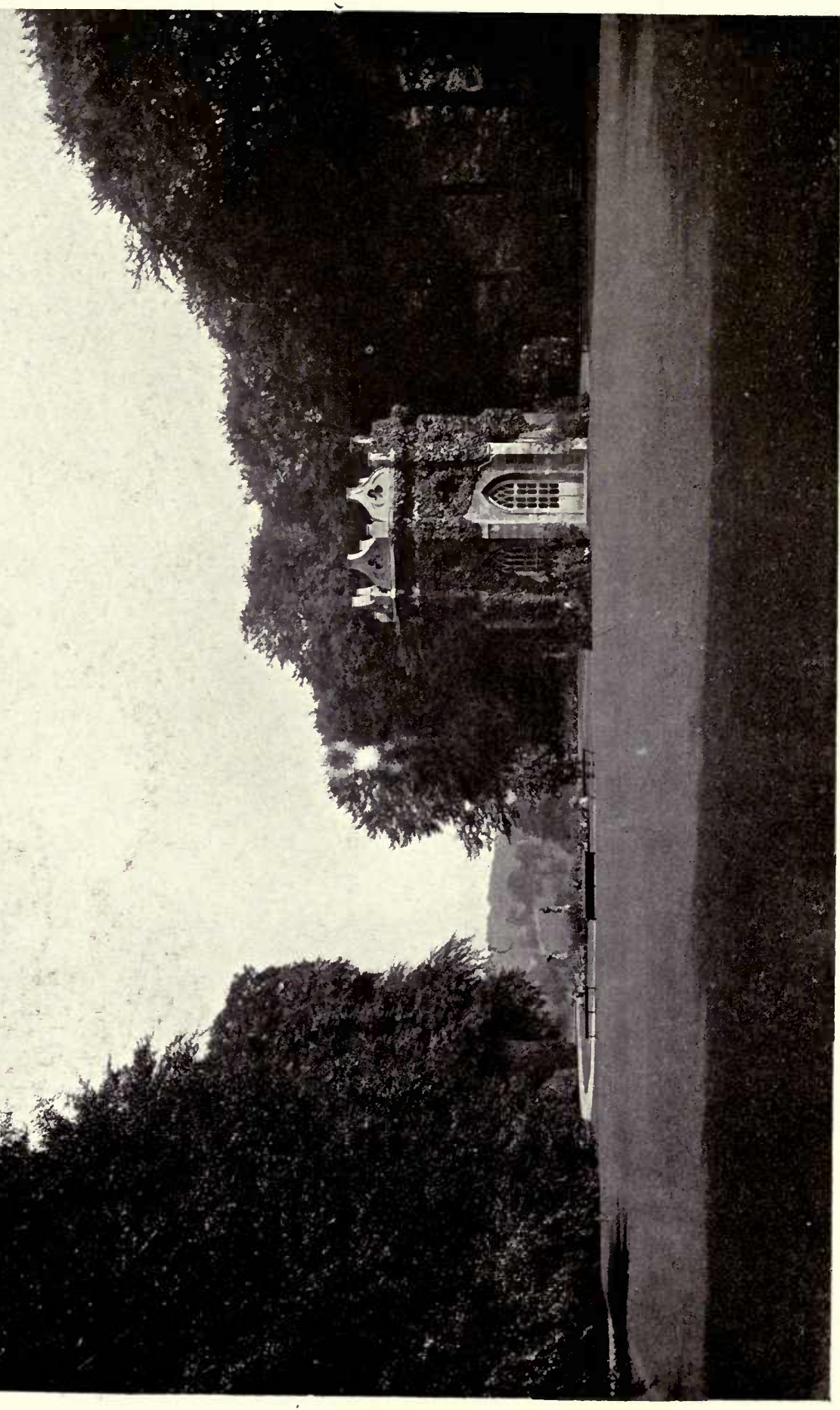

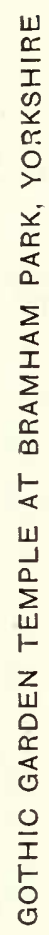



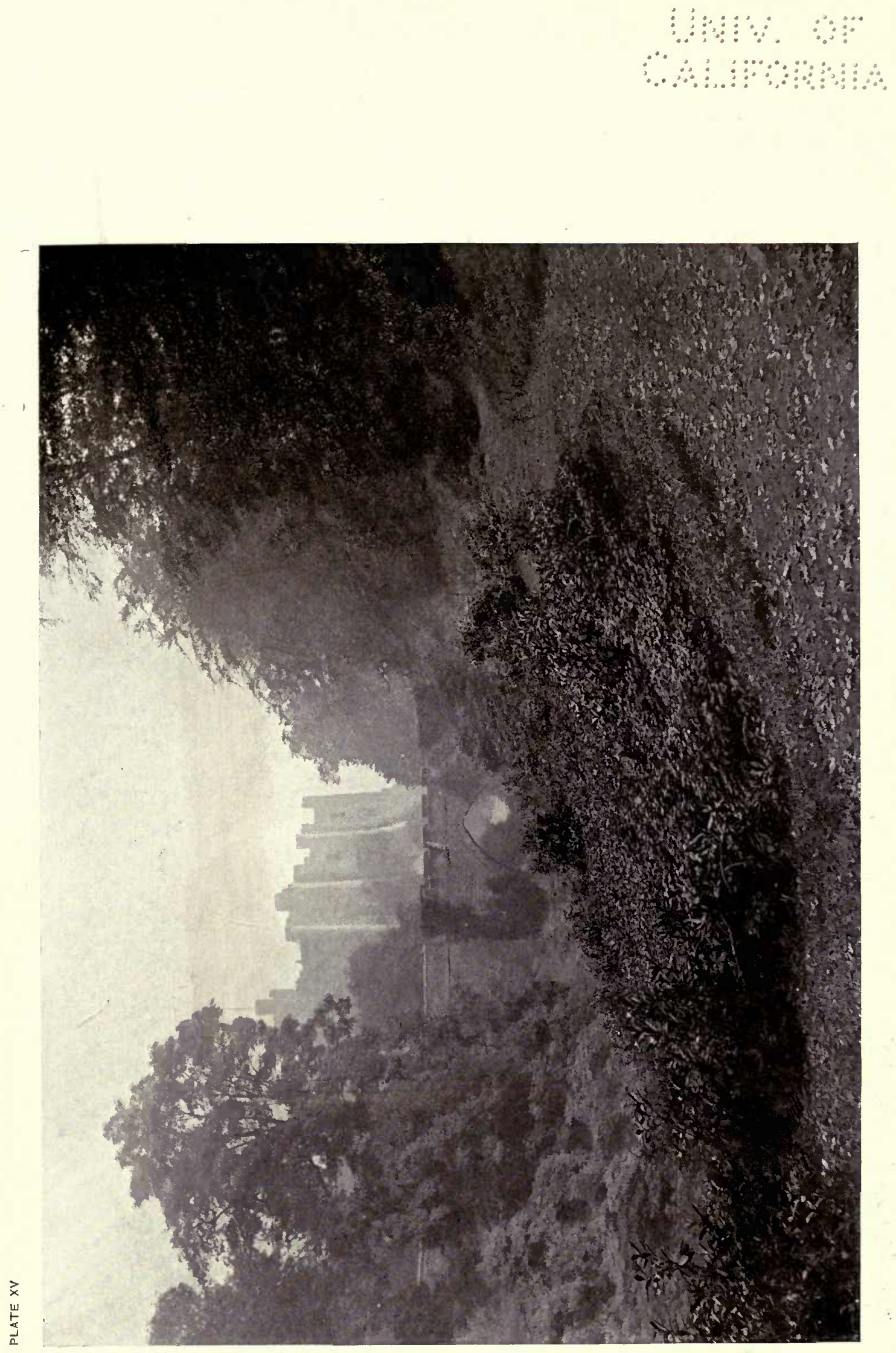

$\frac{5}{5}$
$\frac{1}{\pi}$
$\frac{0}{2}$
0

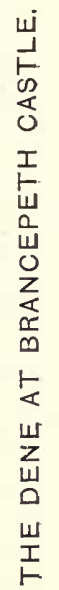


$\because \vdots \vdots \quad \because \therefore \vdots \vdots \therefore \vdots$

$\therefore$

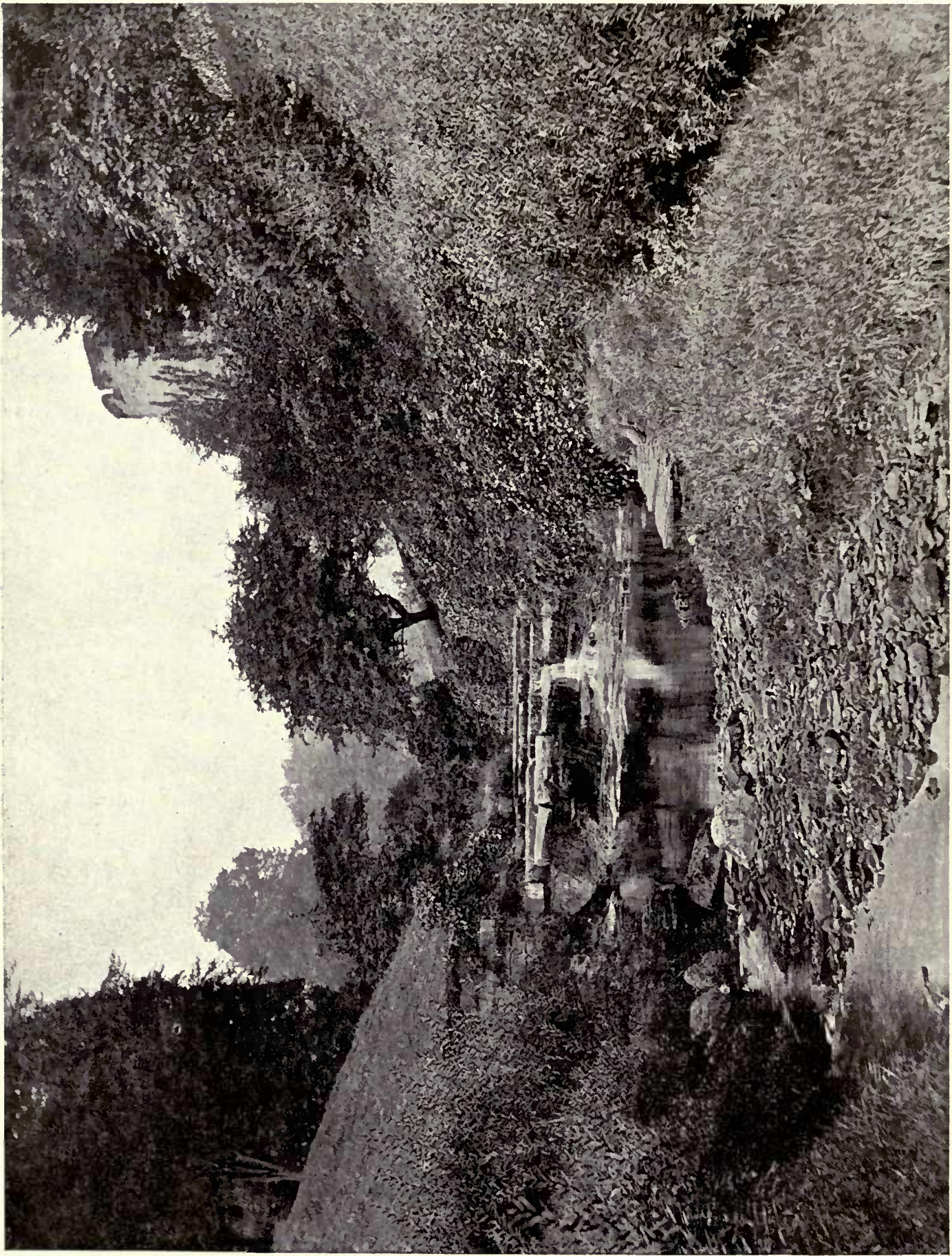



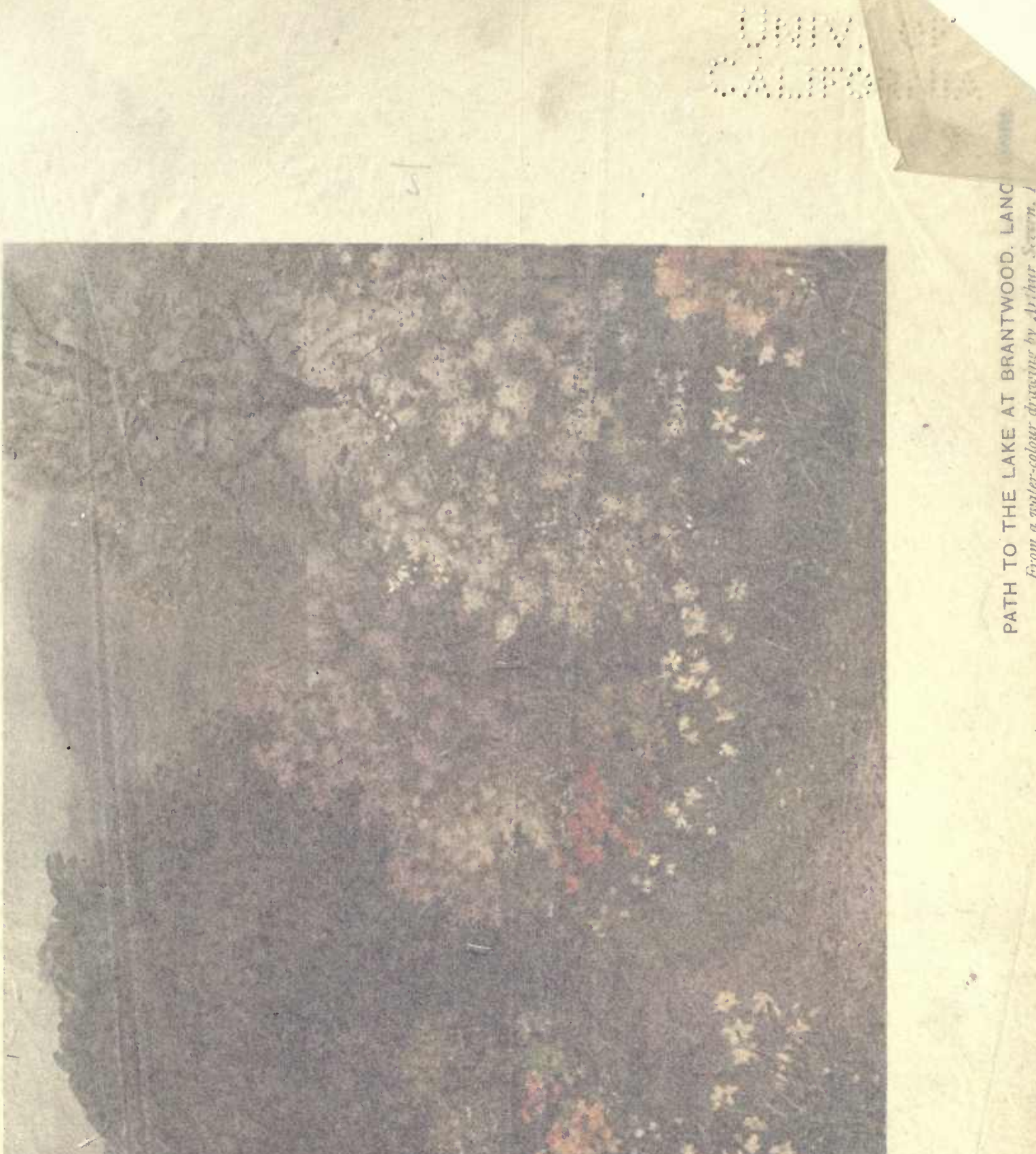

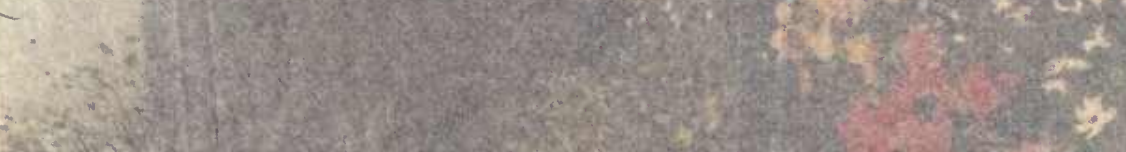

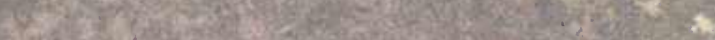

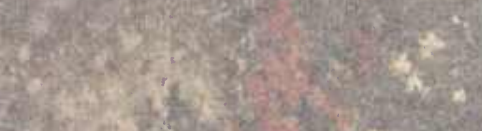

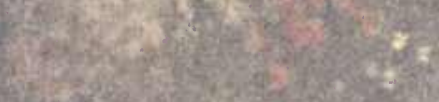

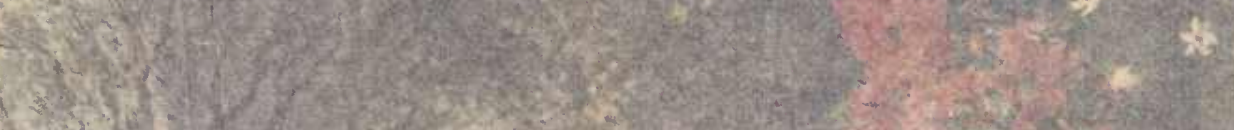

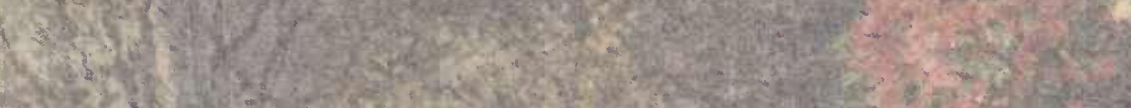

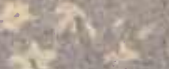

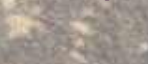
5 S.



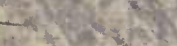
$x^{2}+x+2 y+2$ 


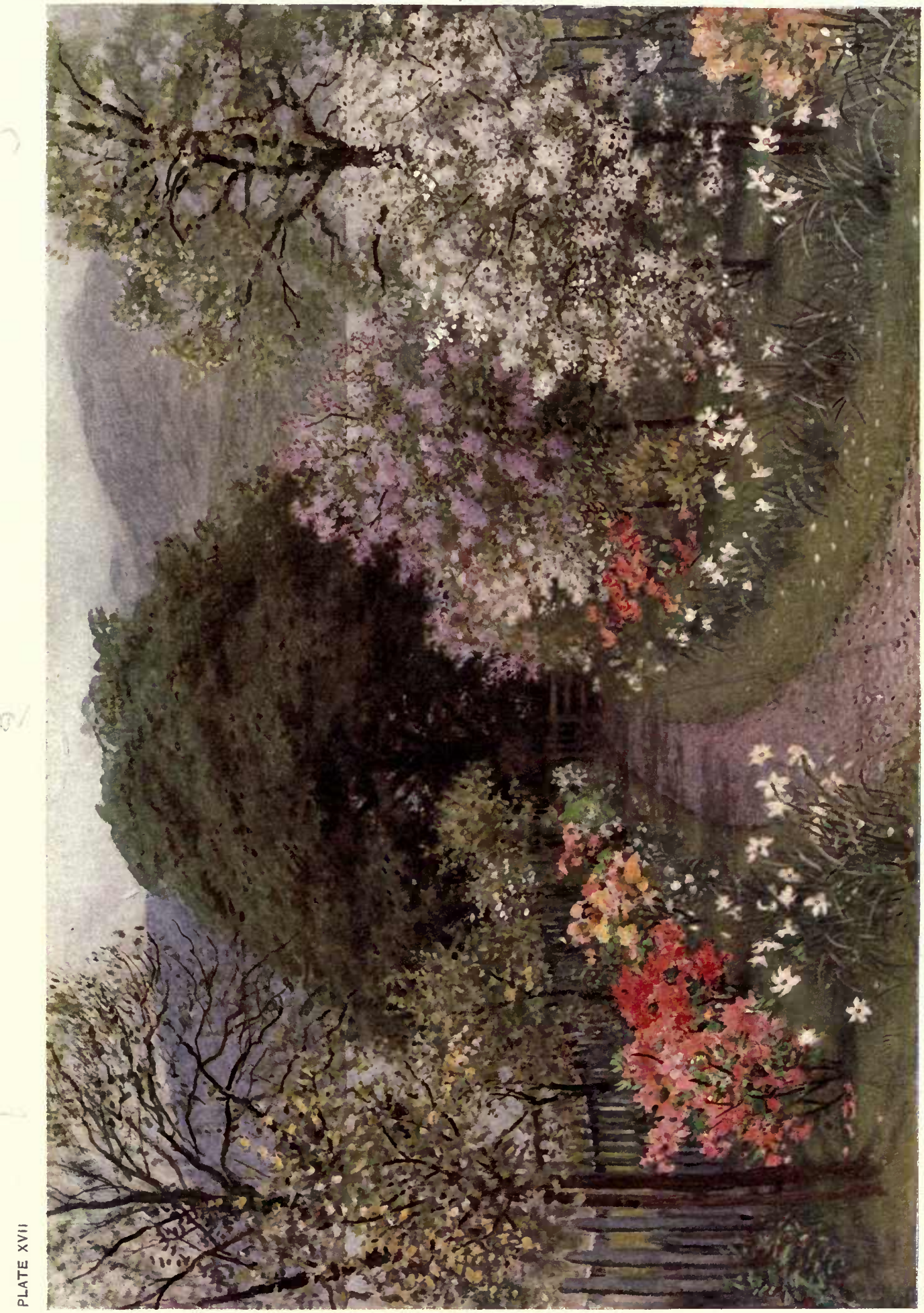


$\because \quad \because \vdots \vdots$ 


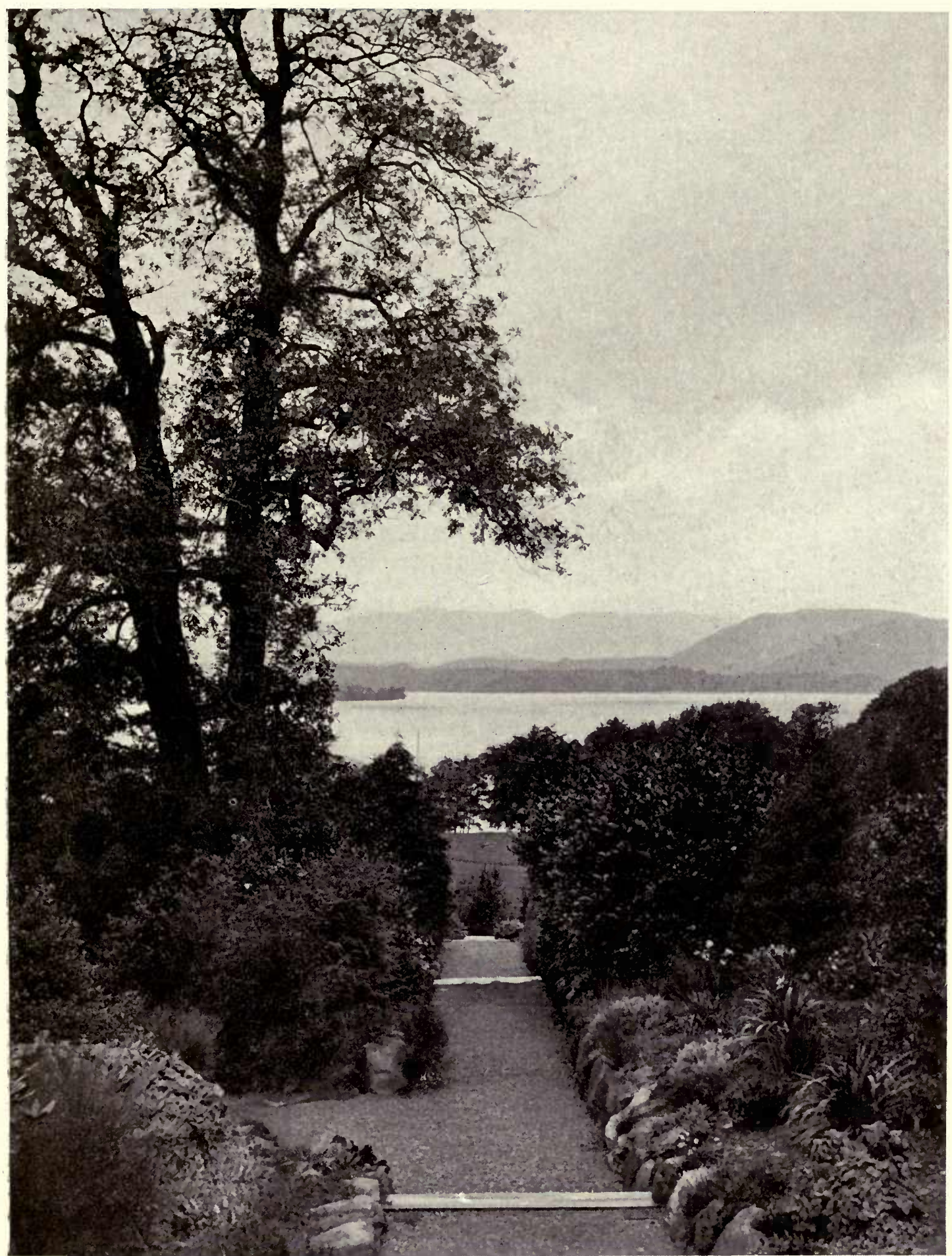




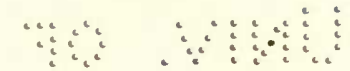

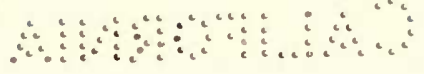

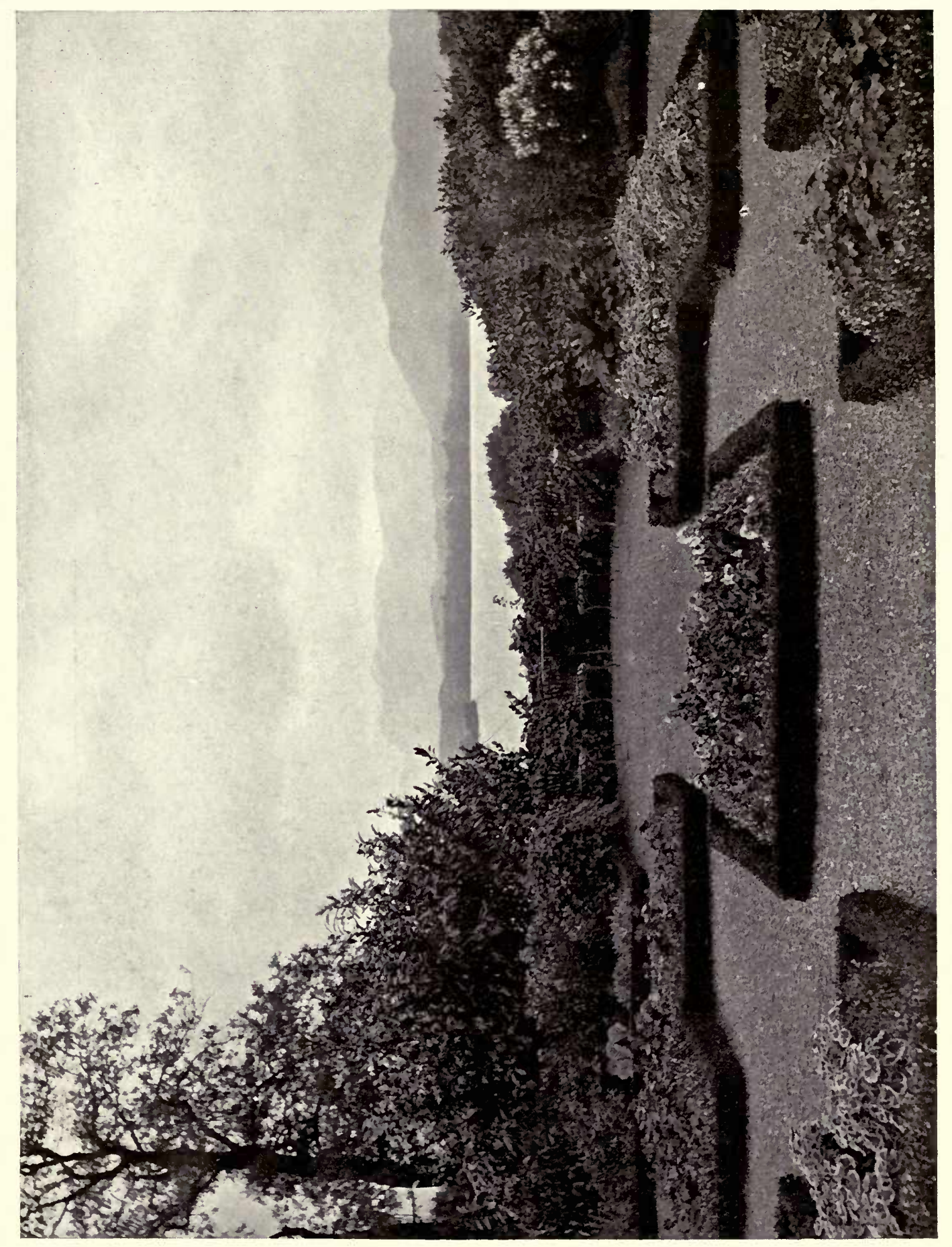

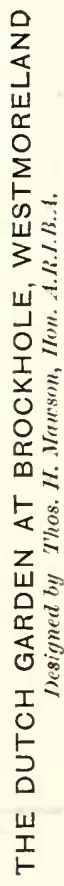




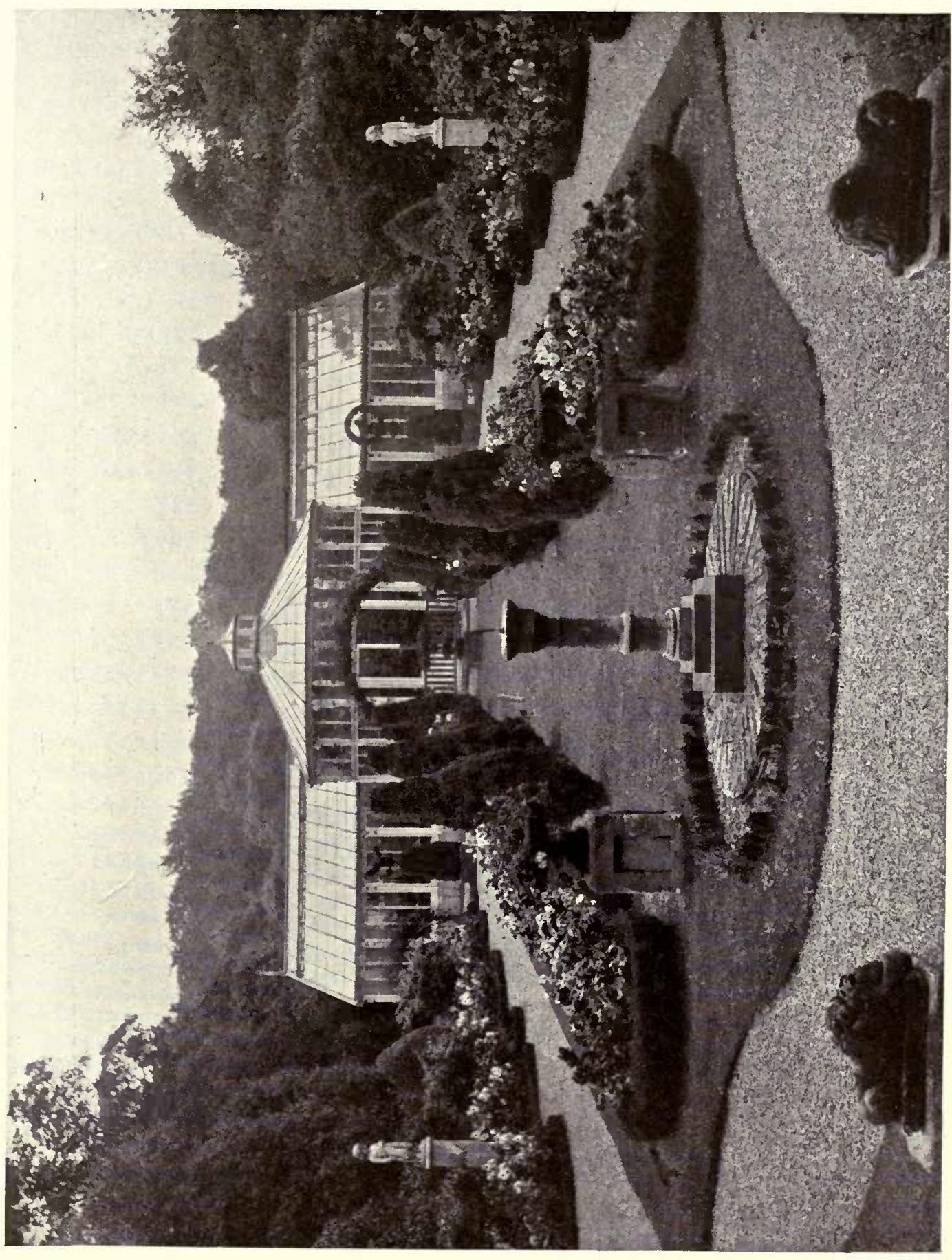




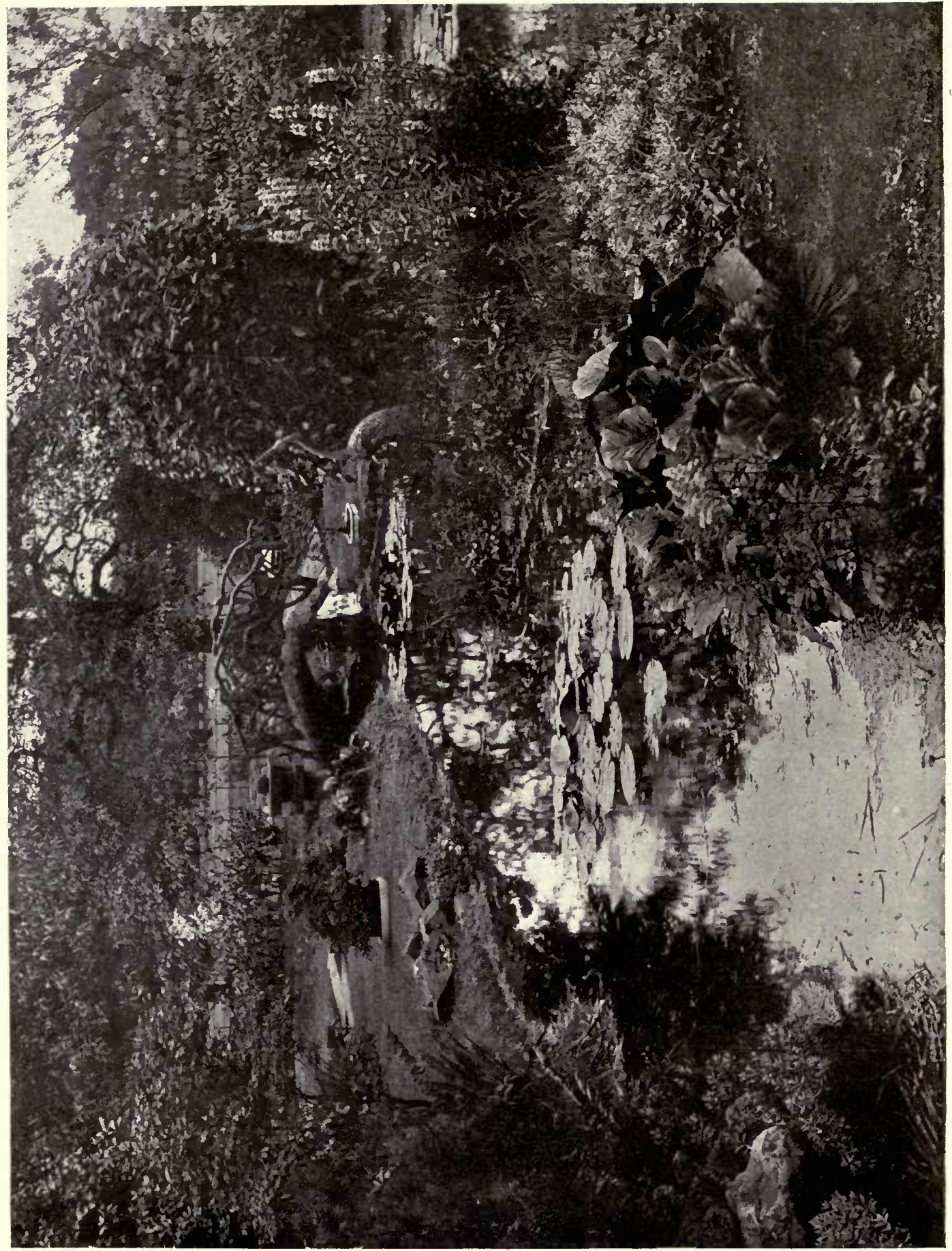




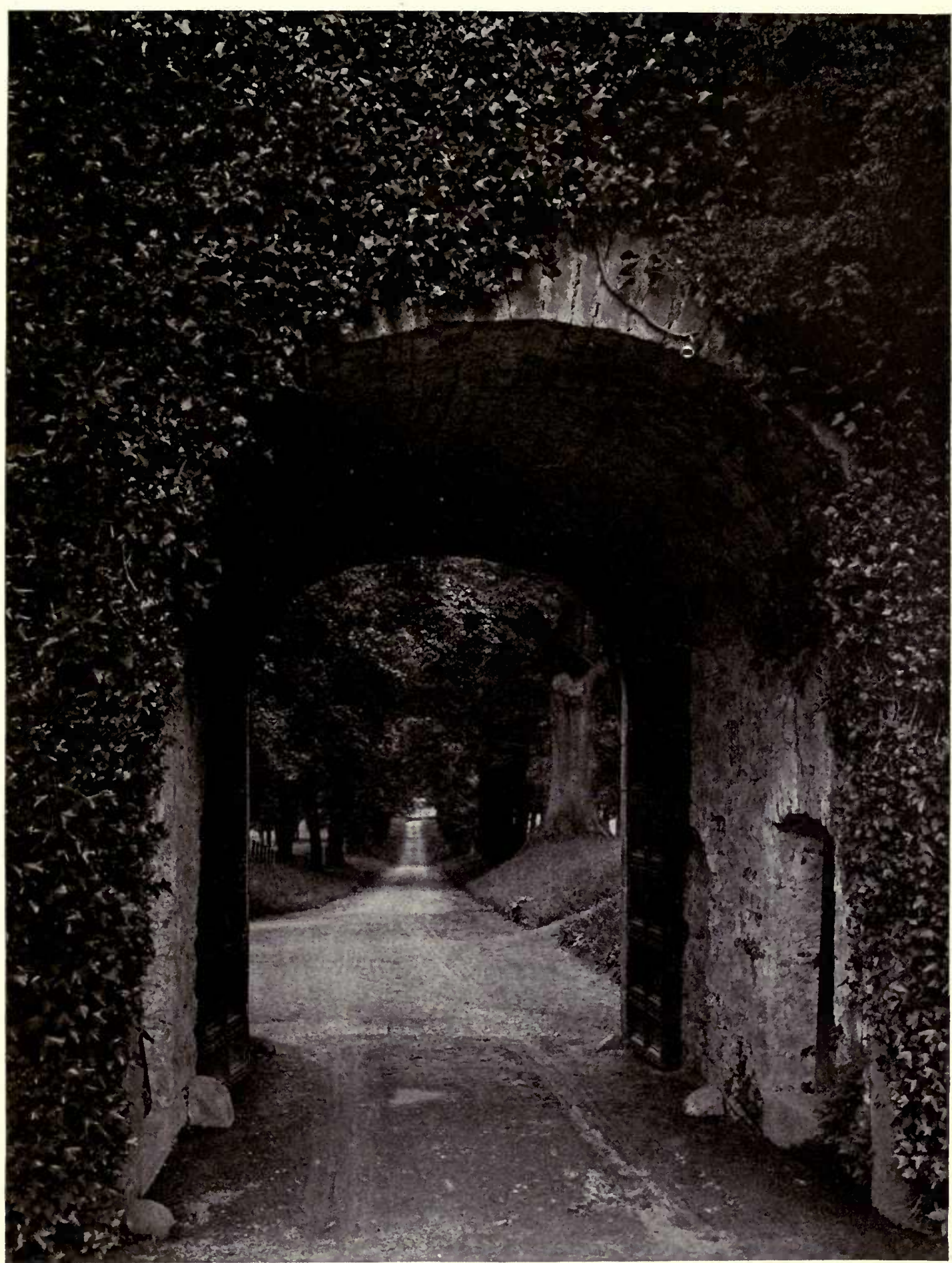




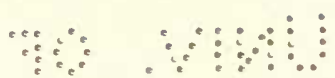

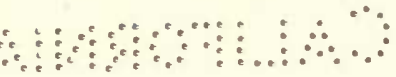

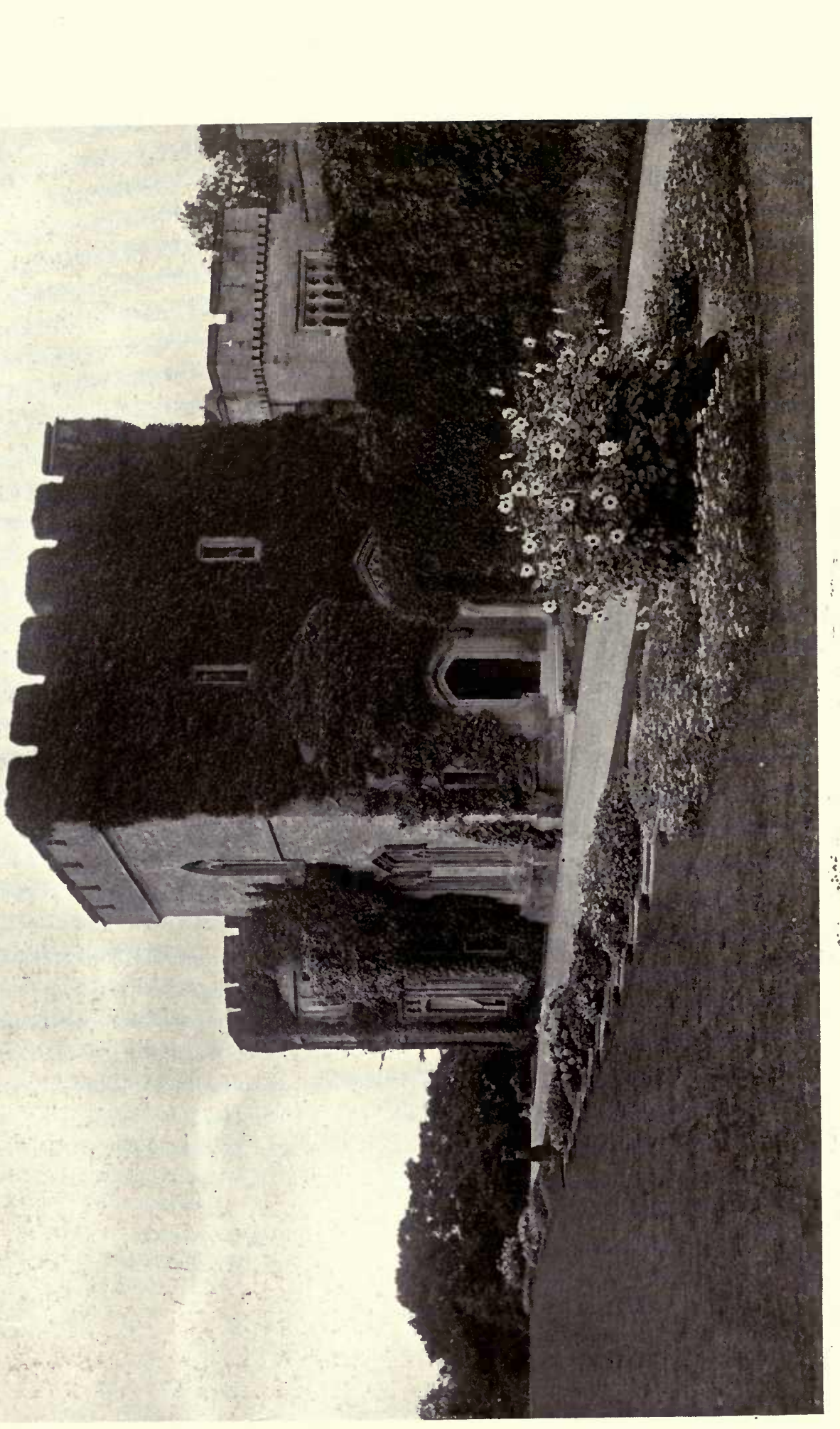

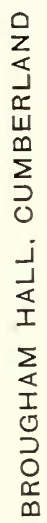




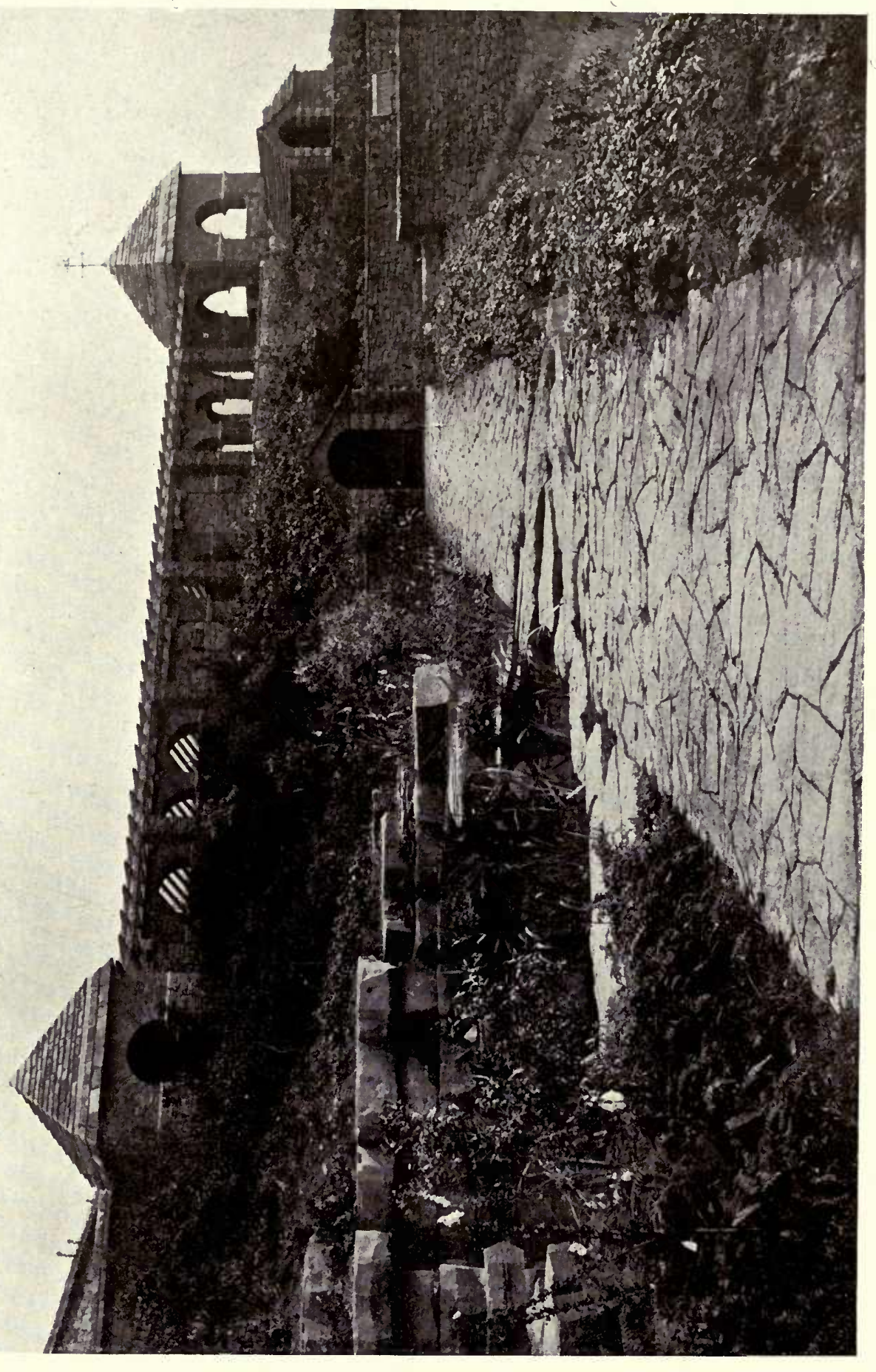

崩

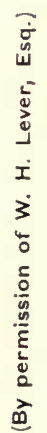




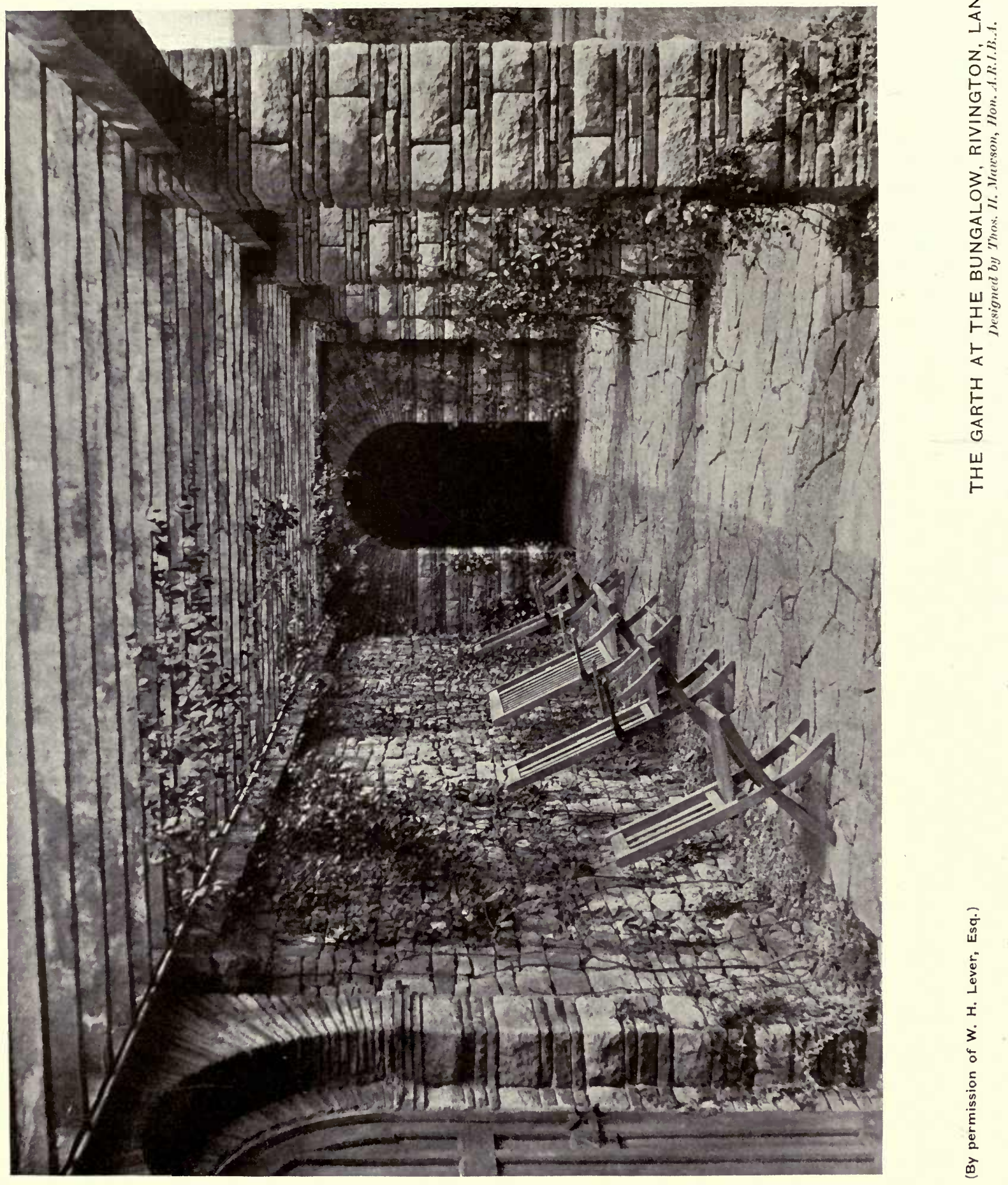




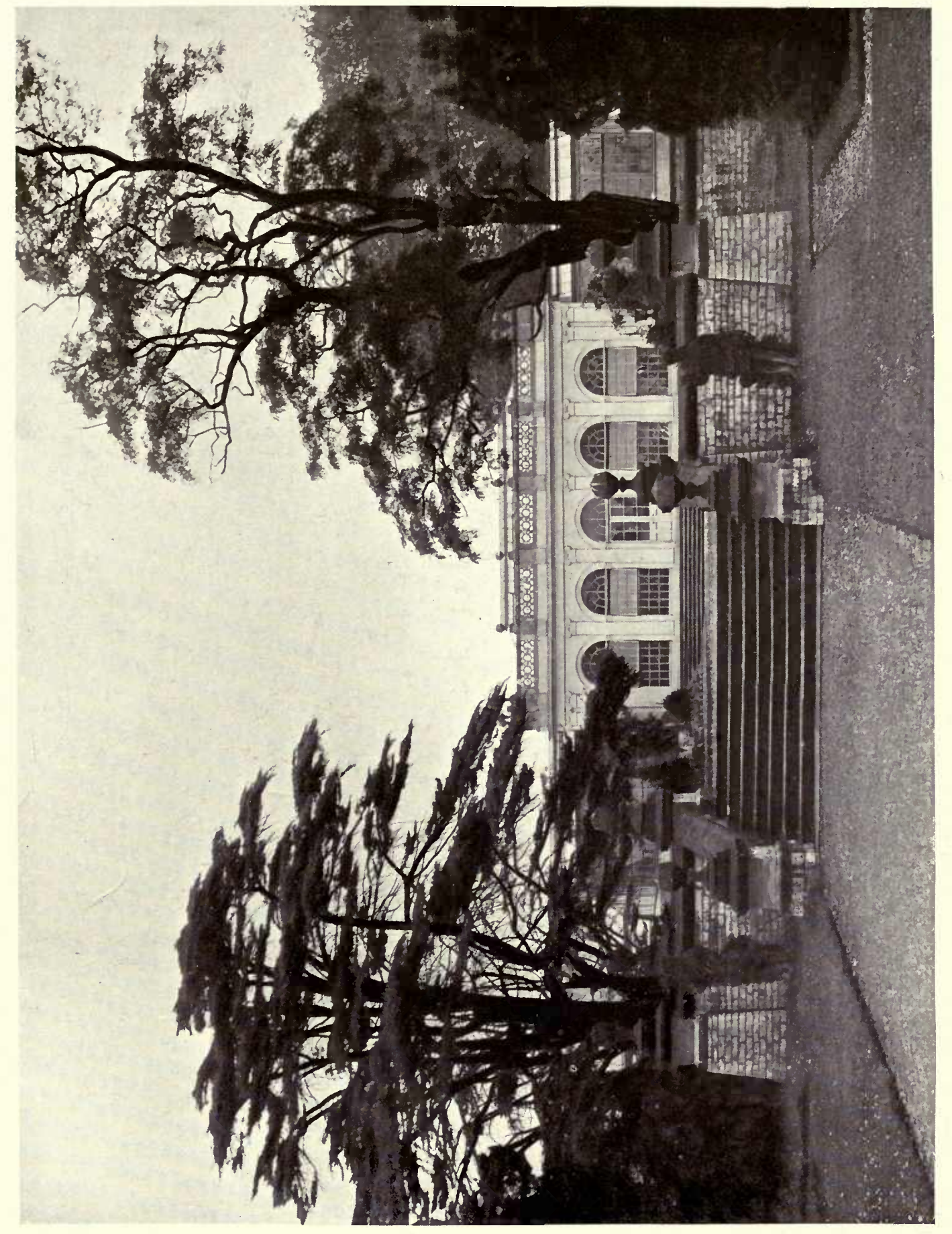

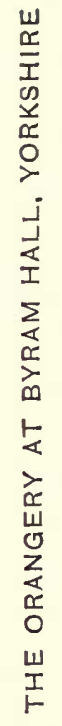

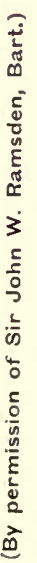




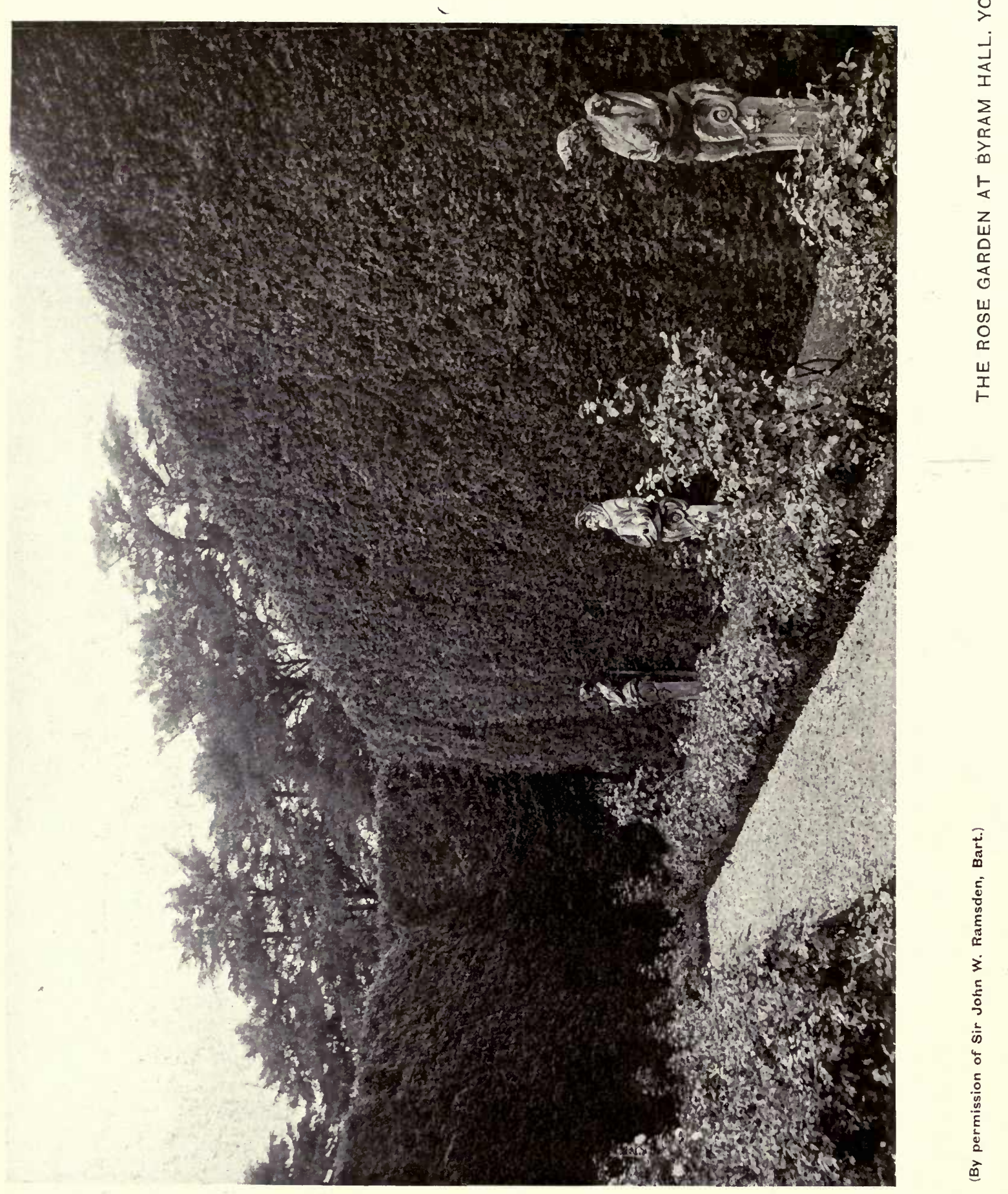




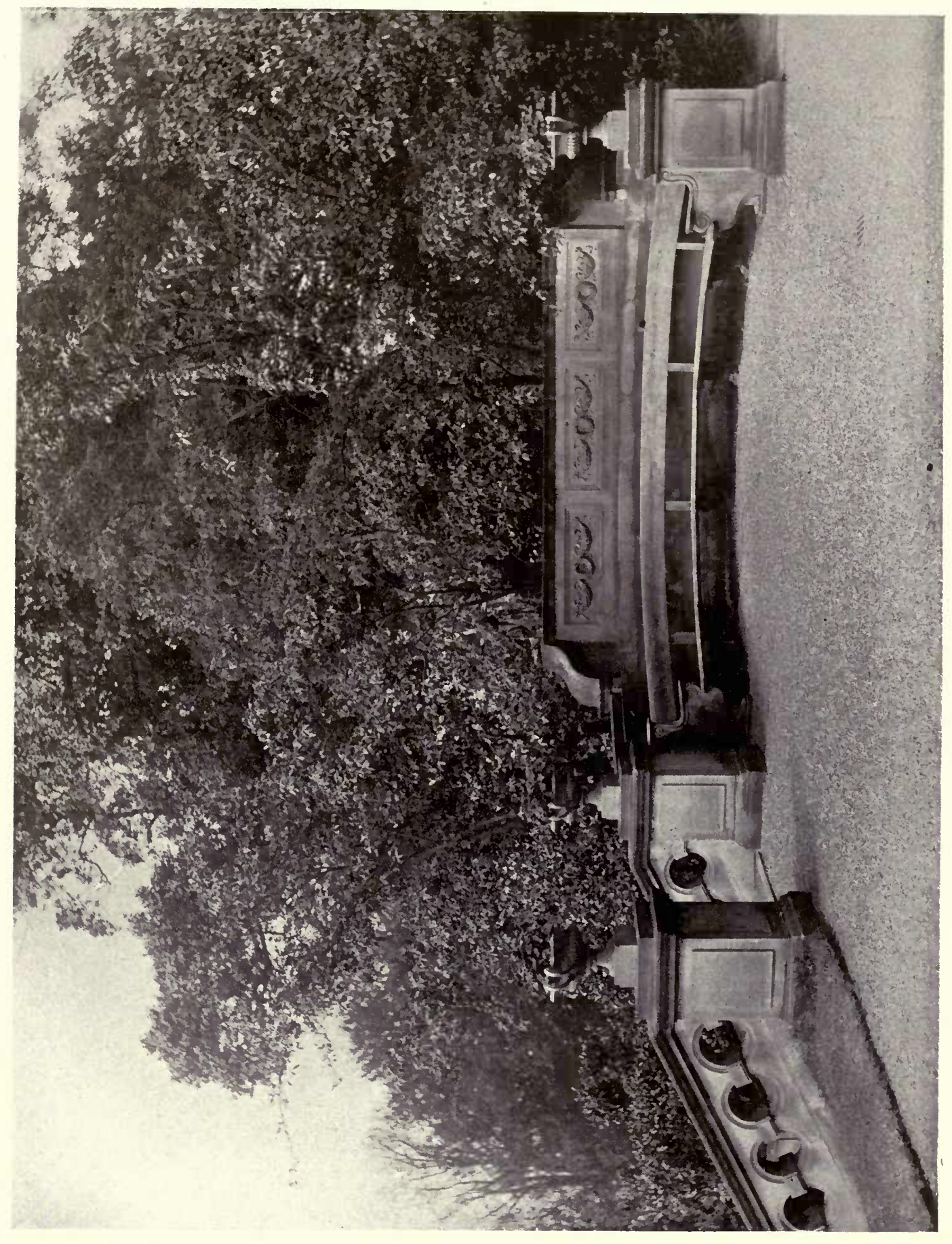

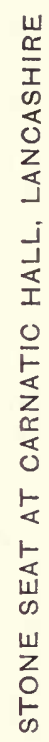

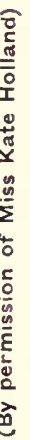




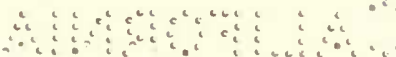

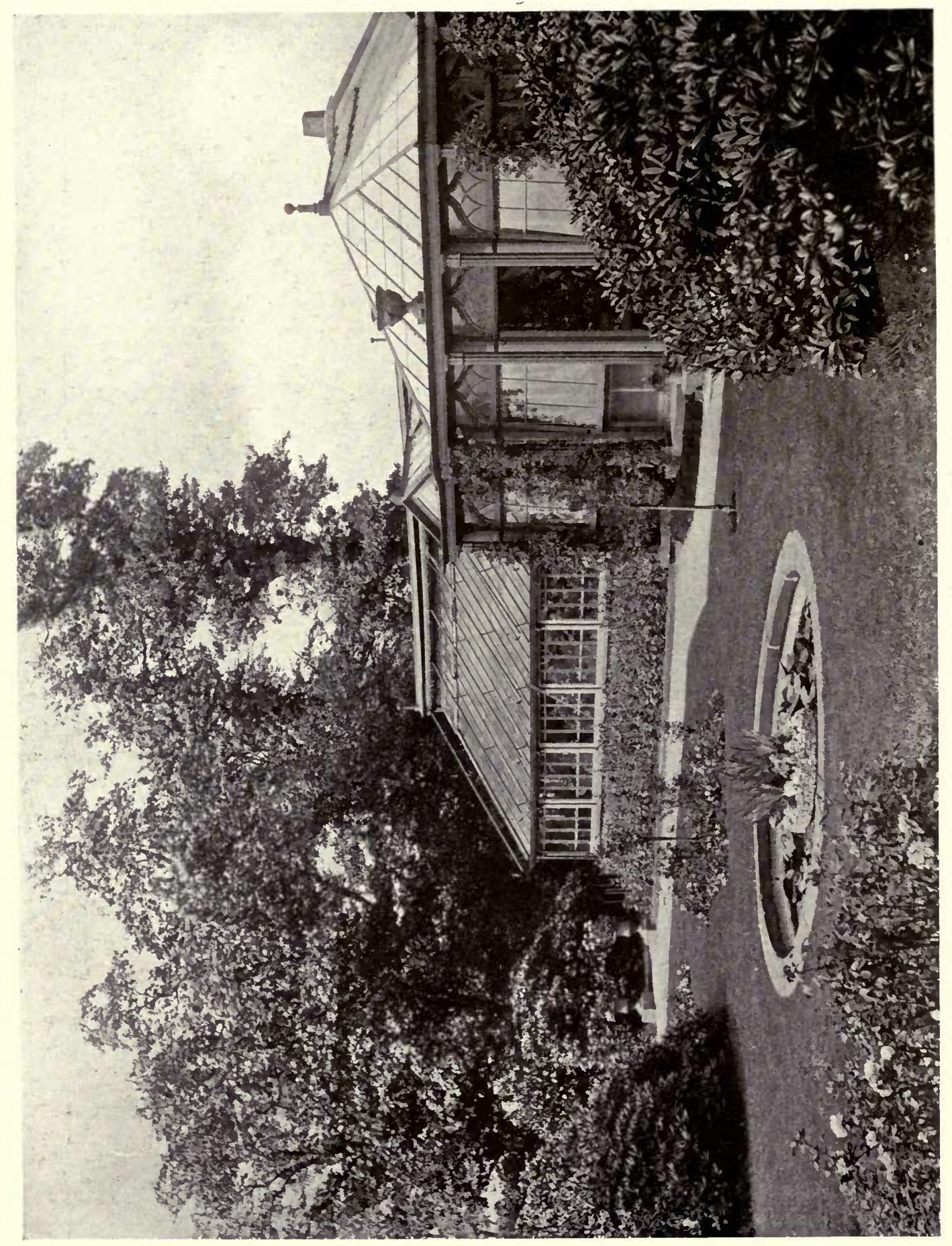

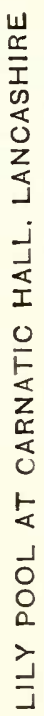




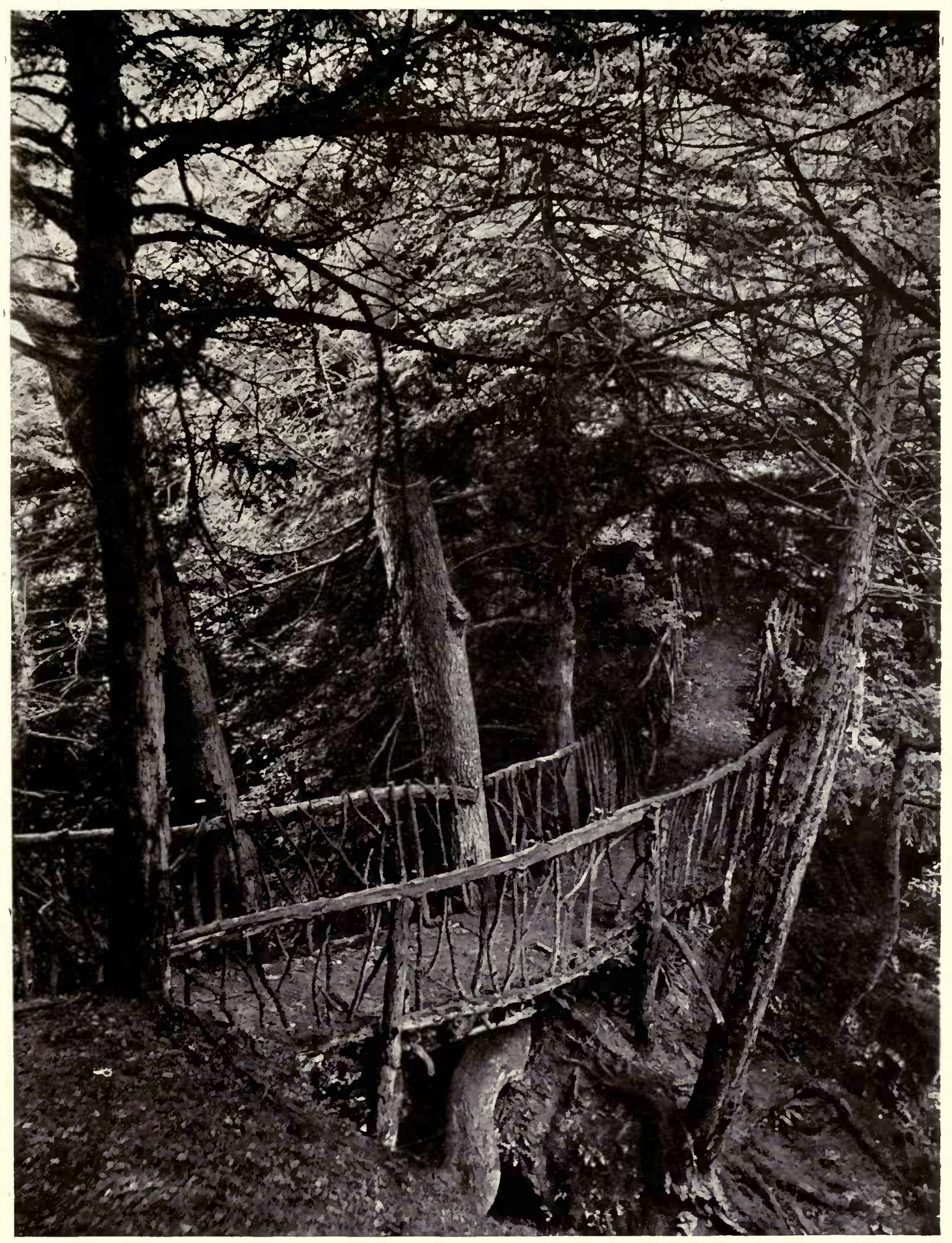




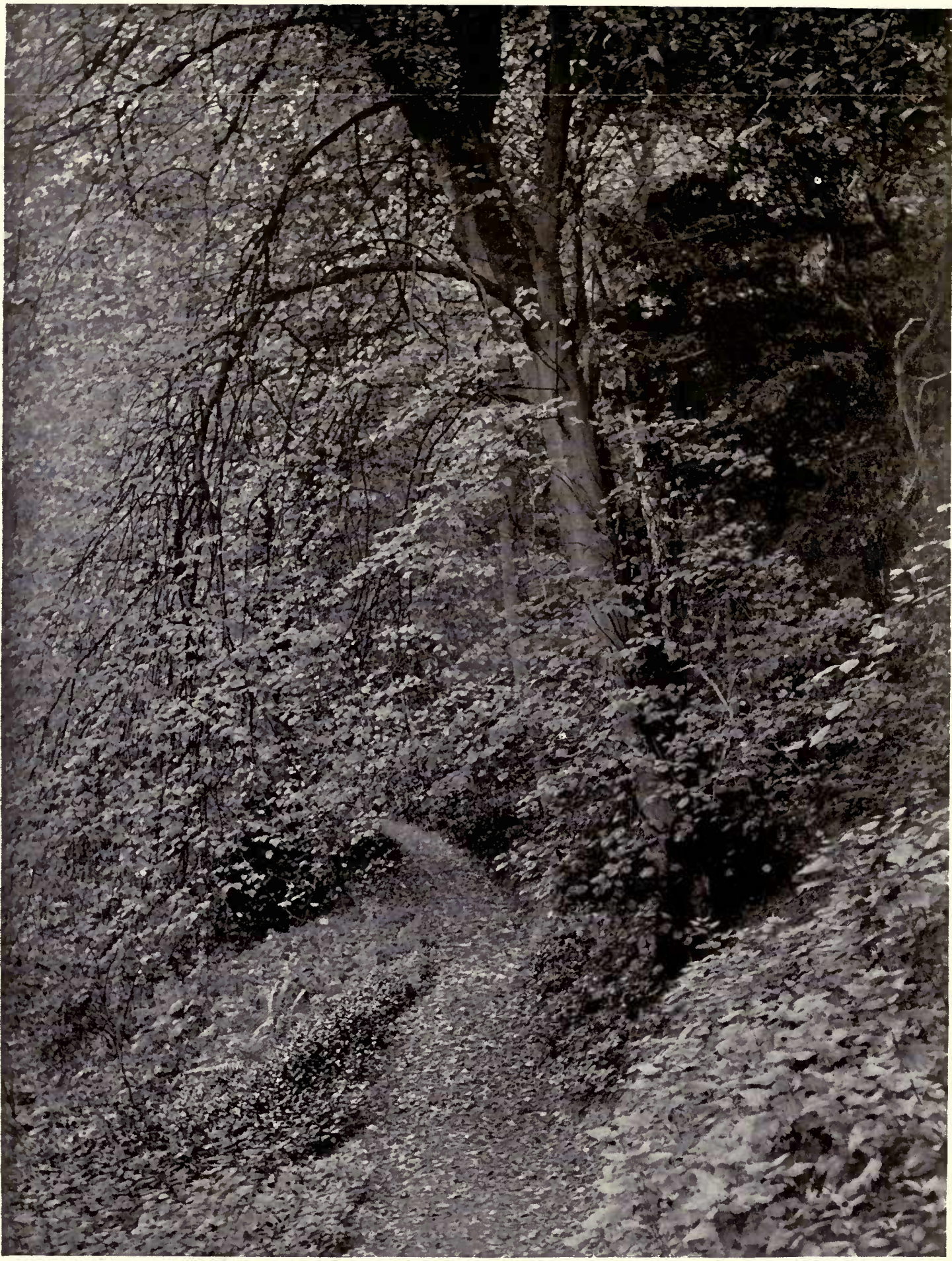




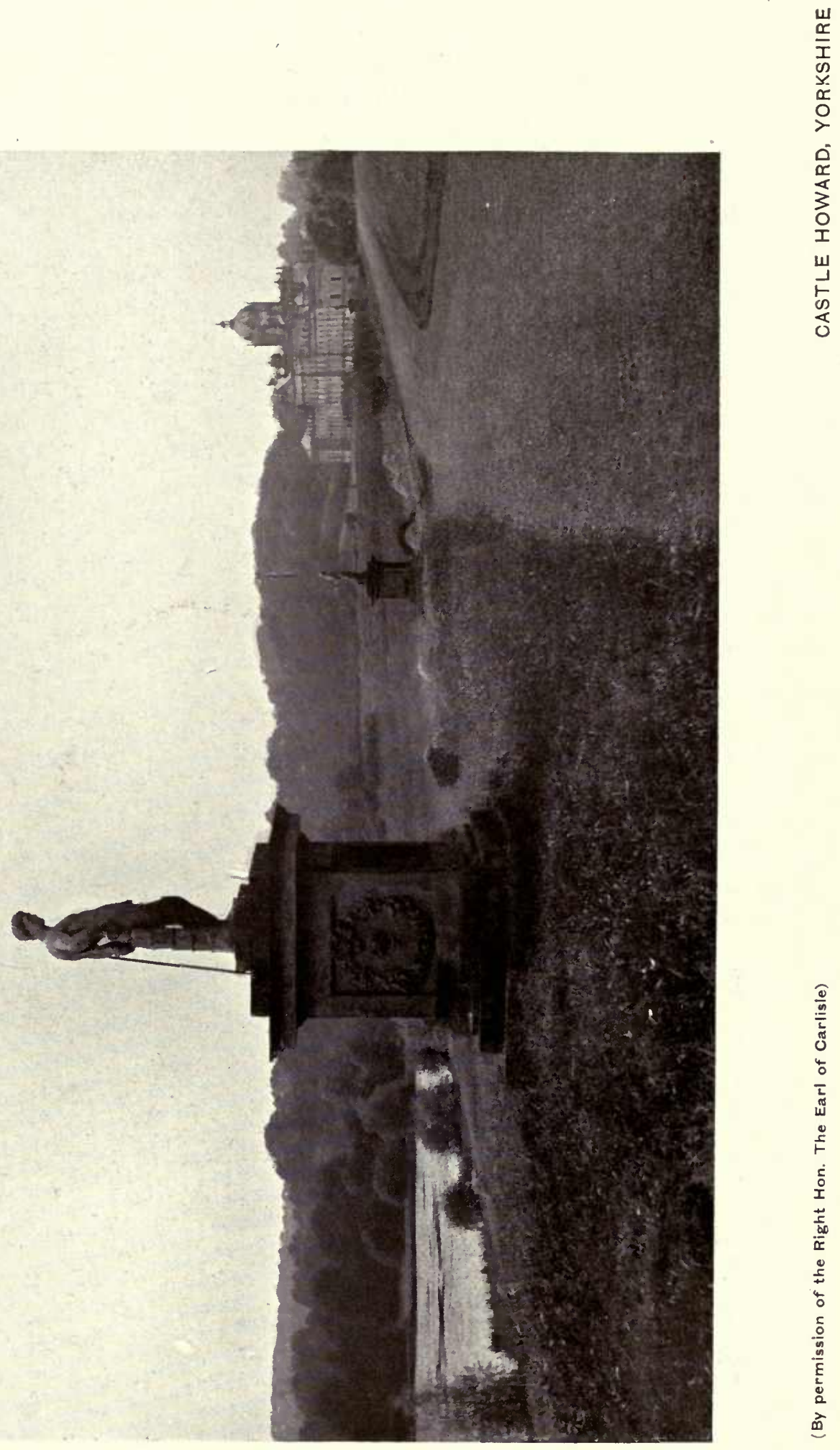




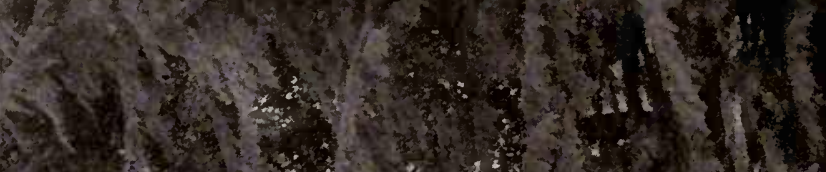

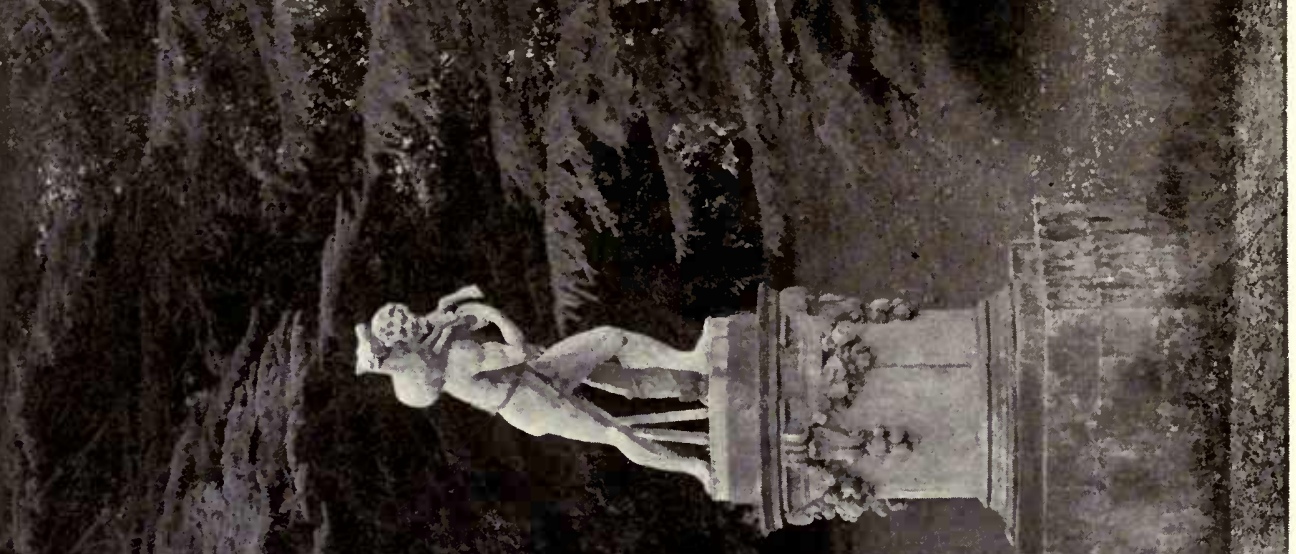

(2)

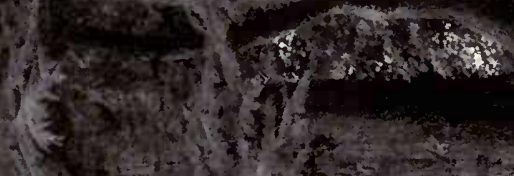

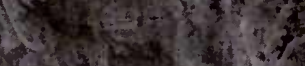

1045
1

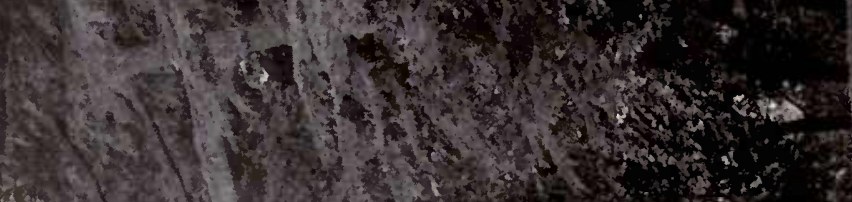

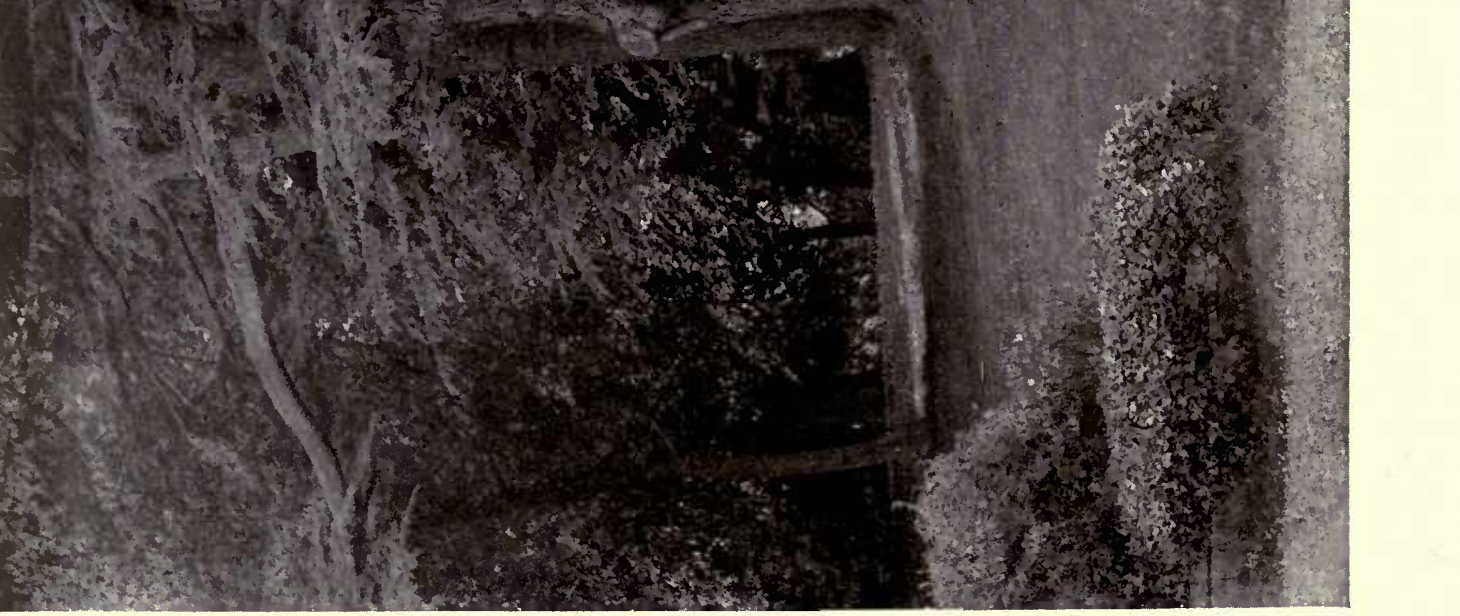

$x^{2}$ 


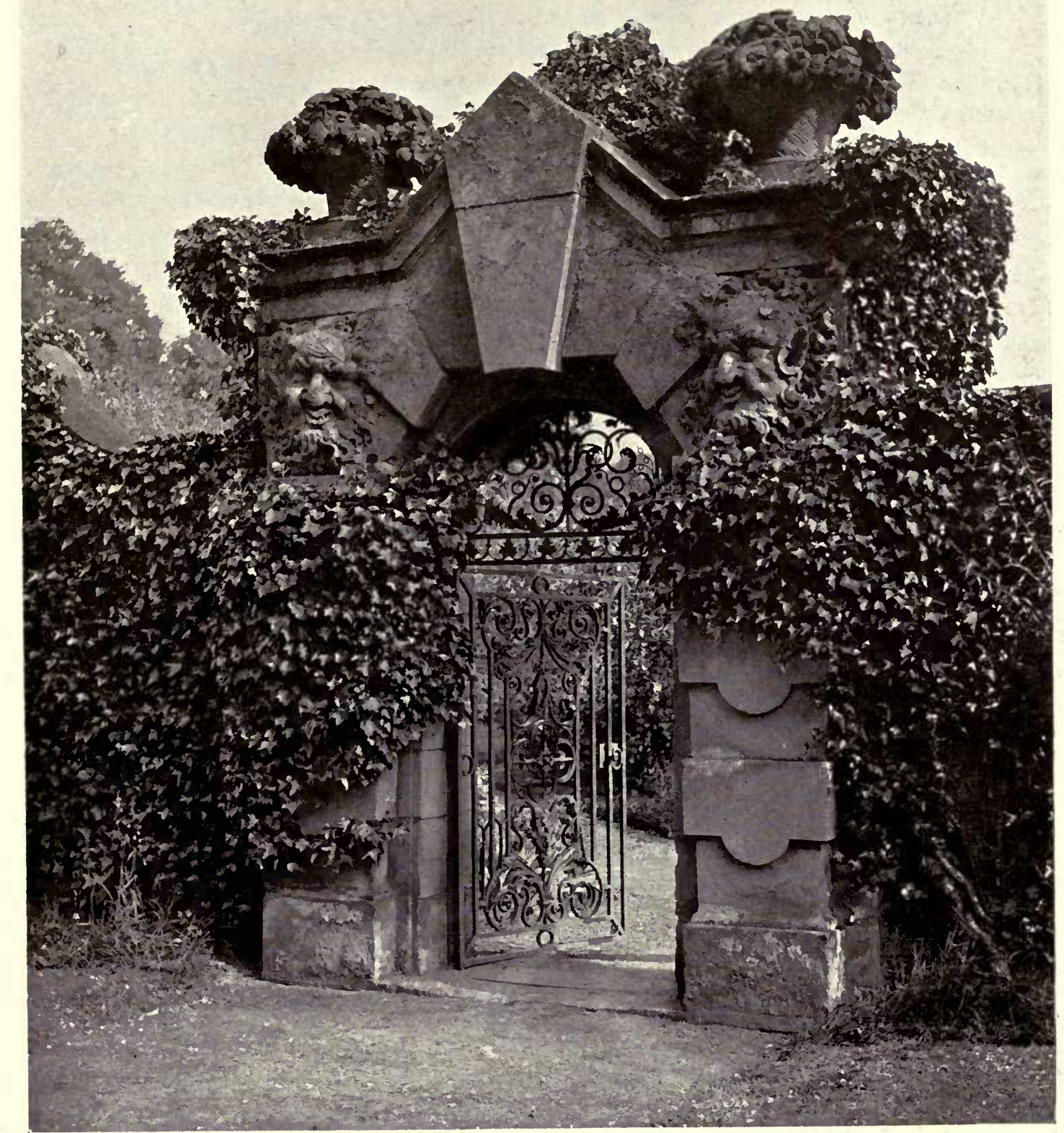




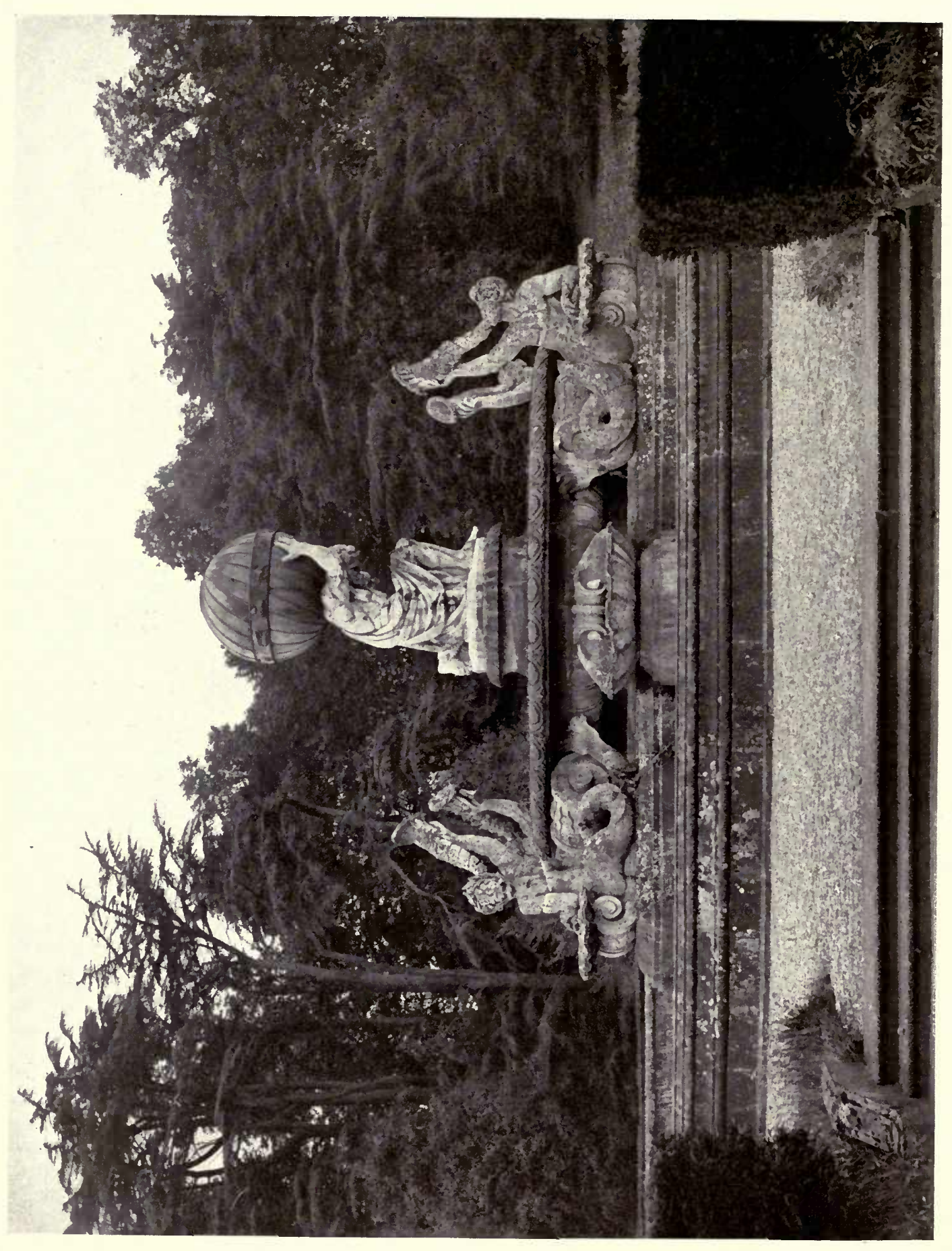

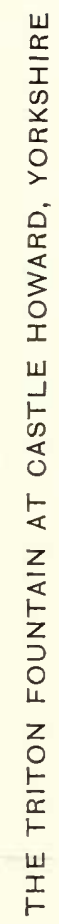




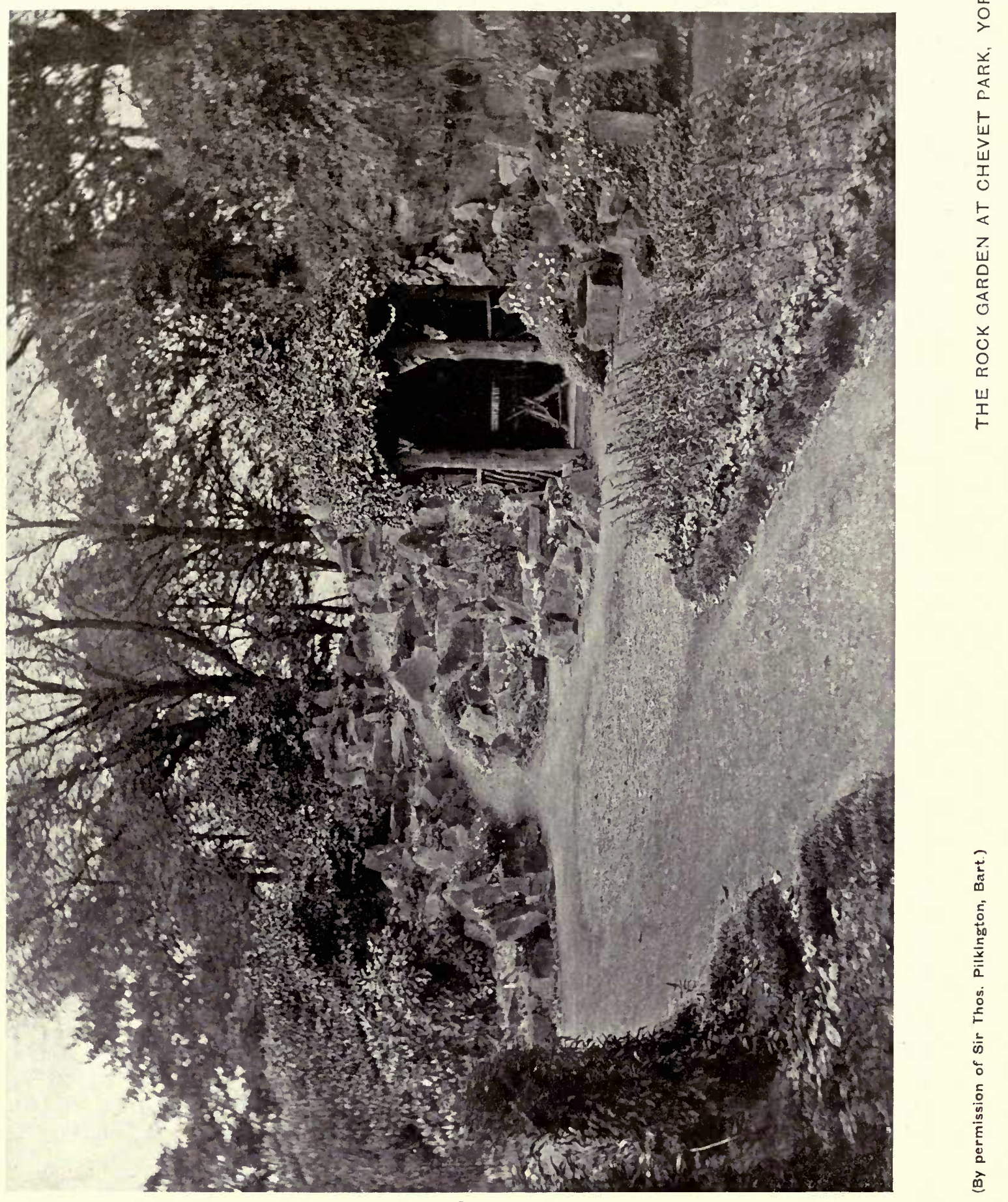




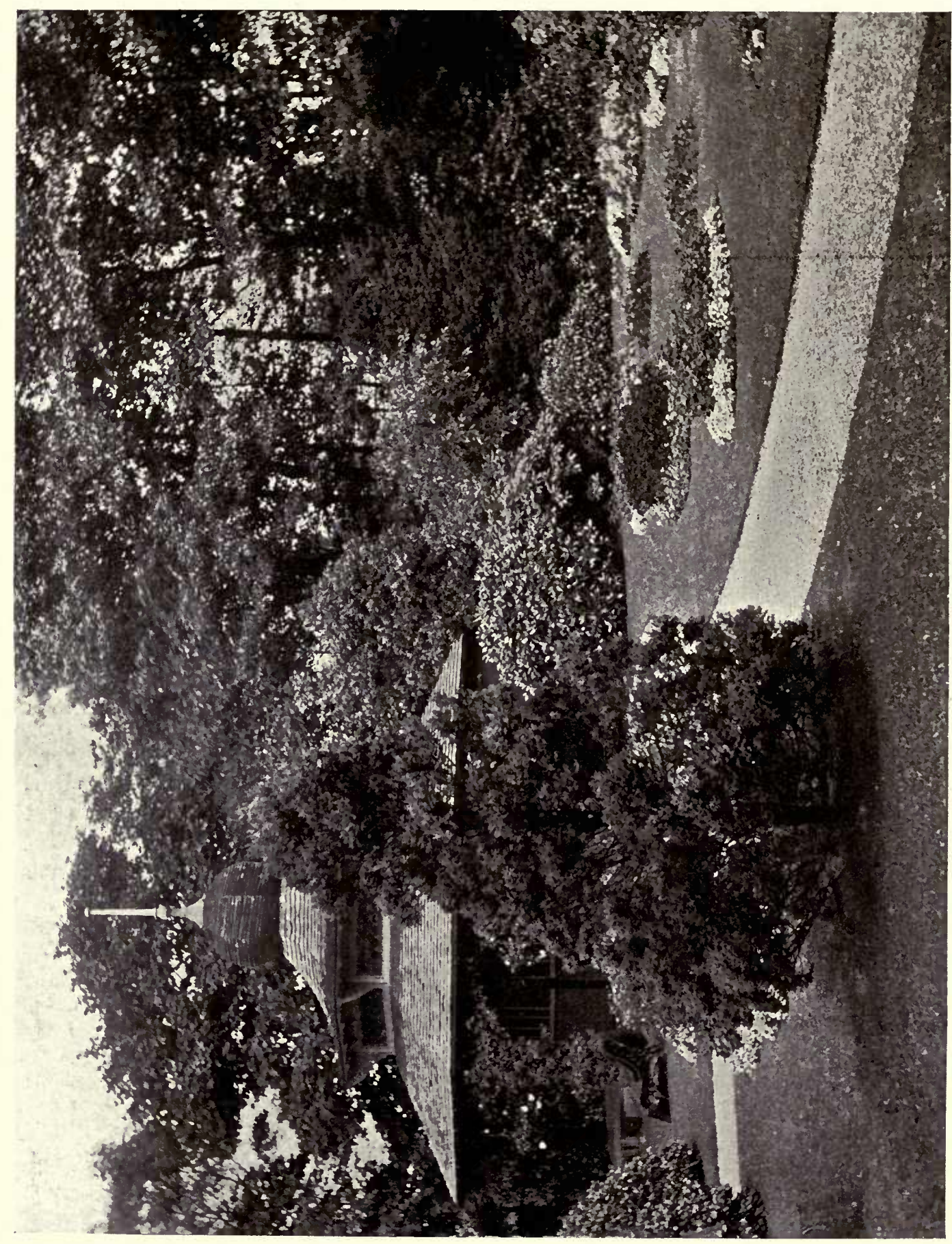




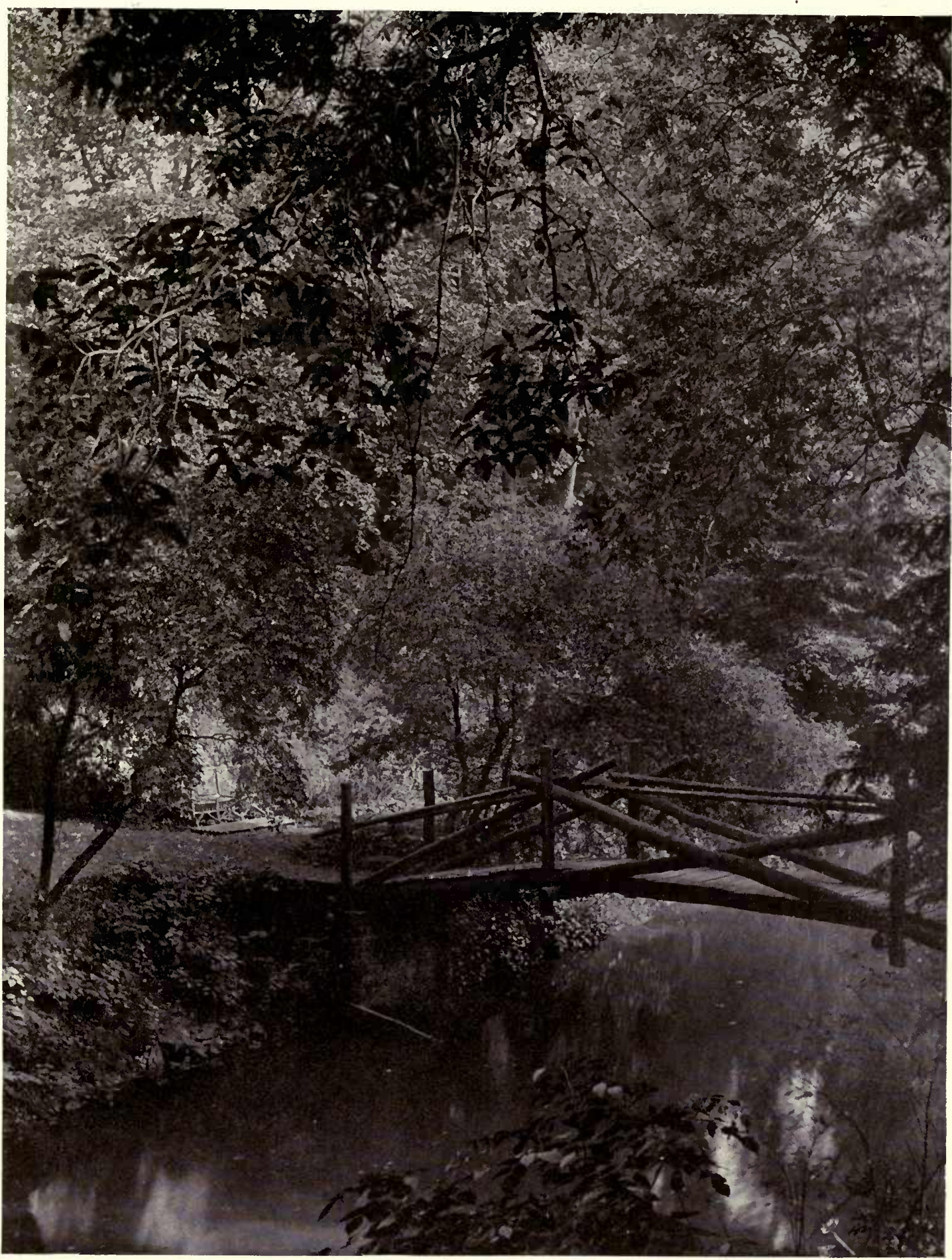




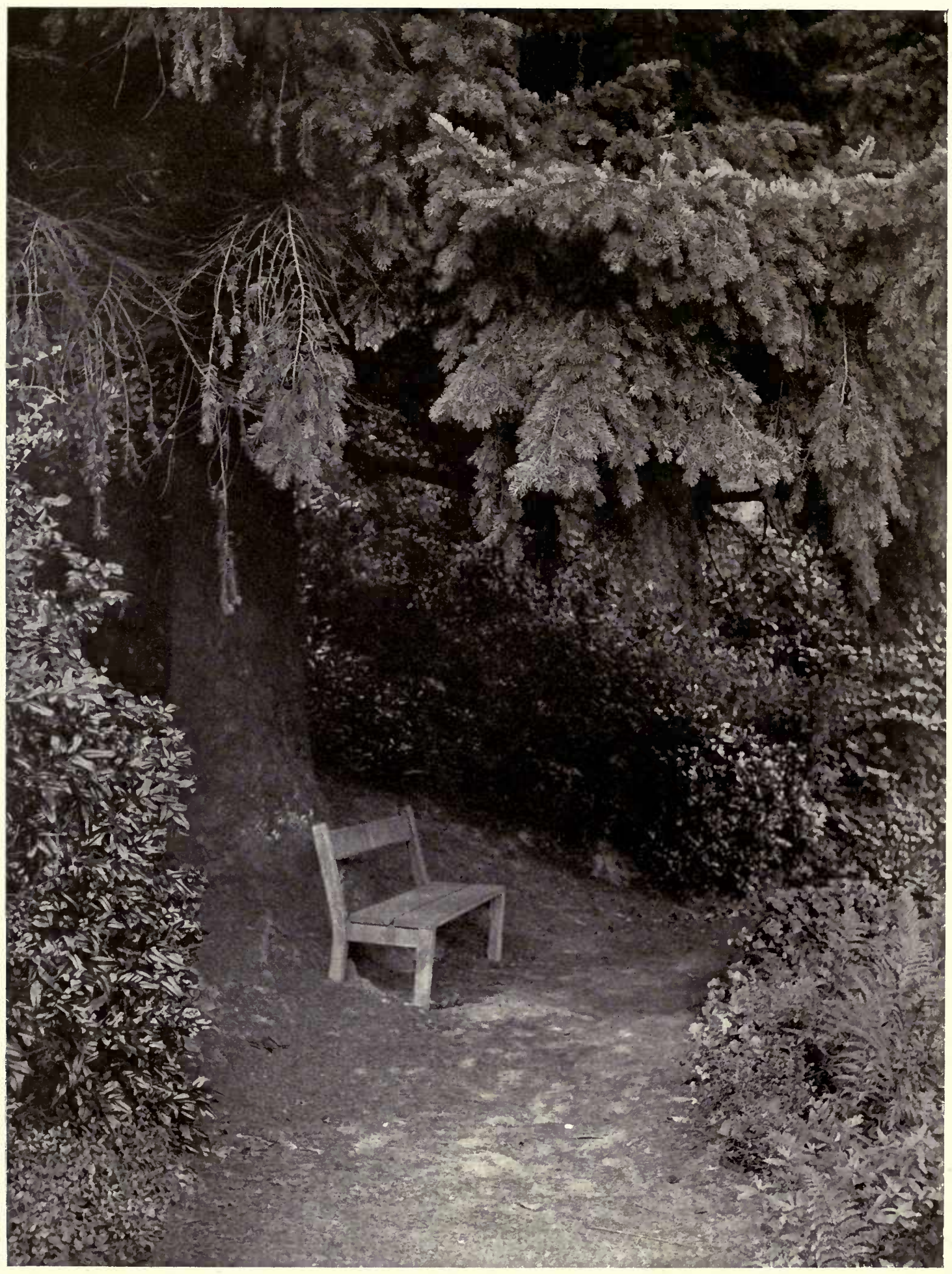




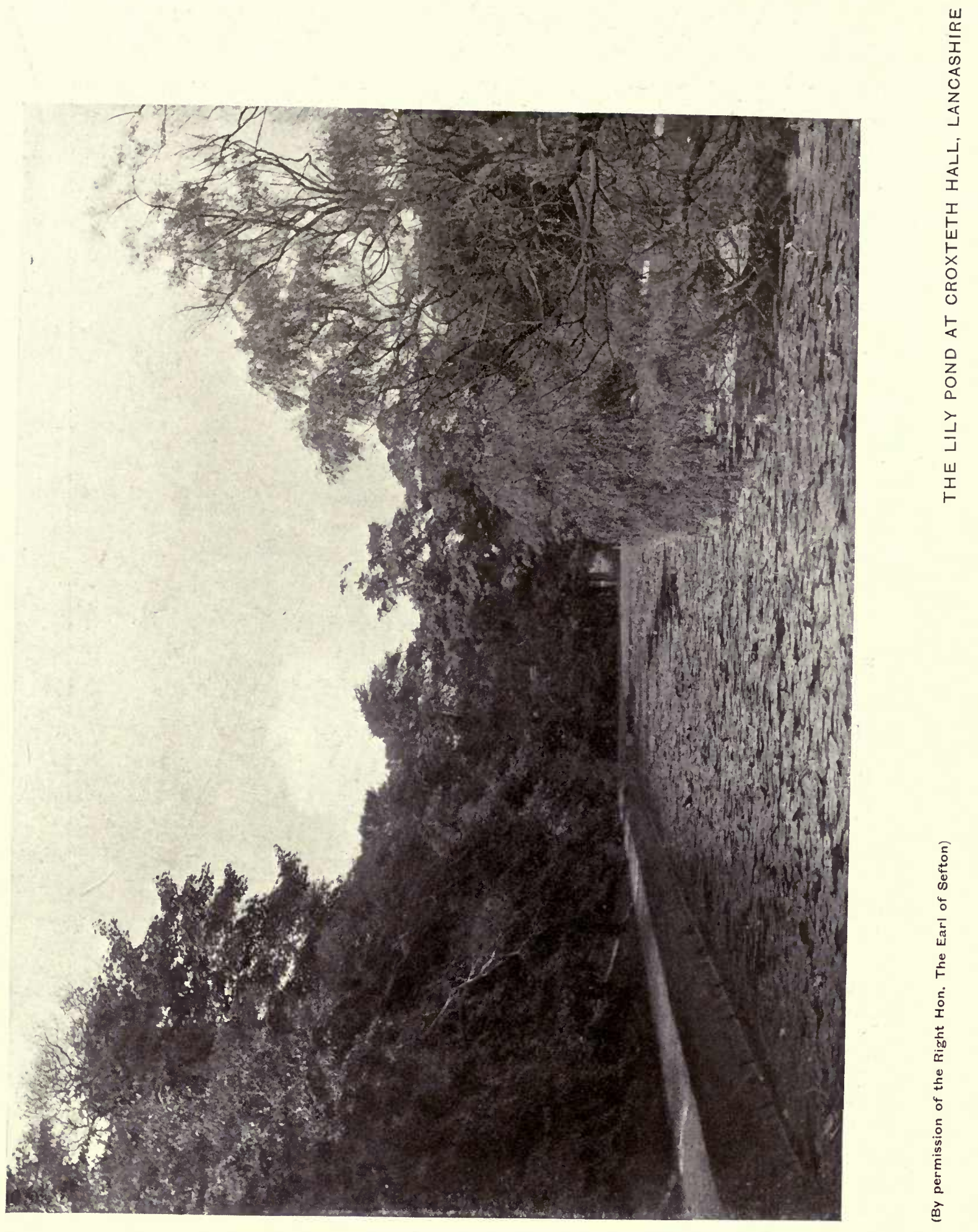




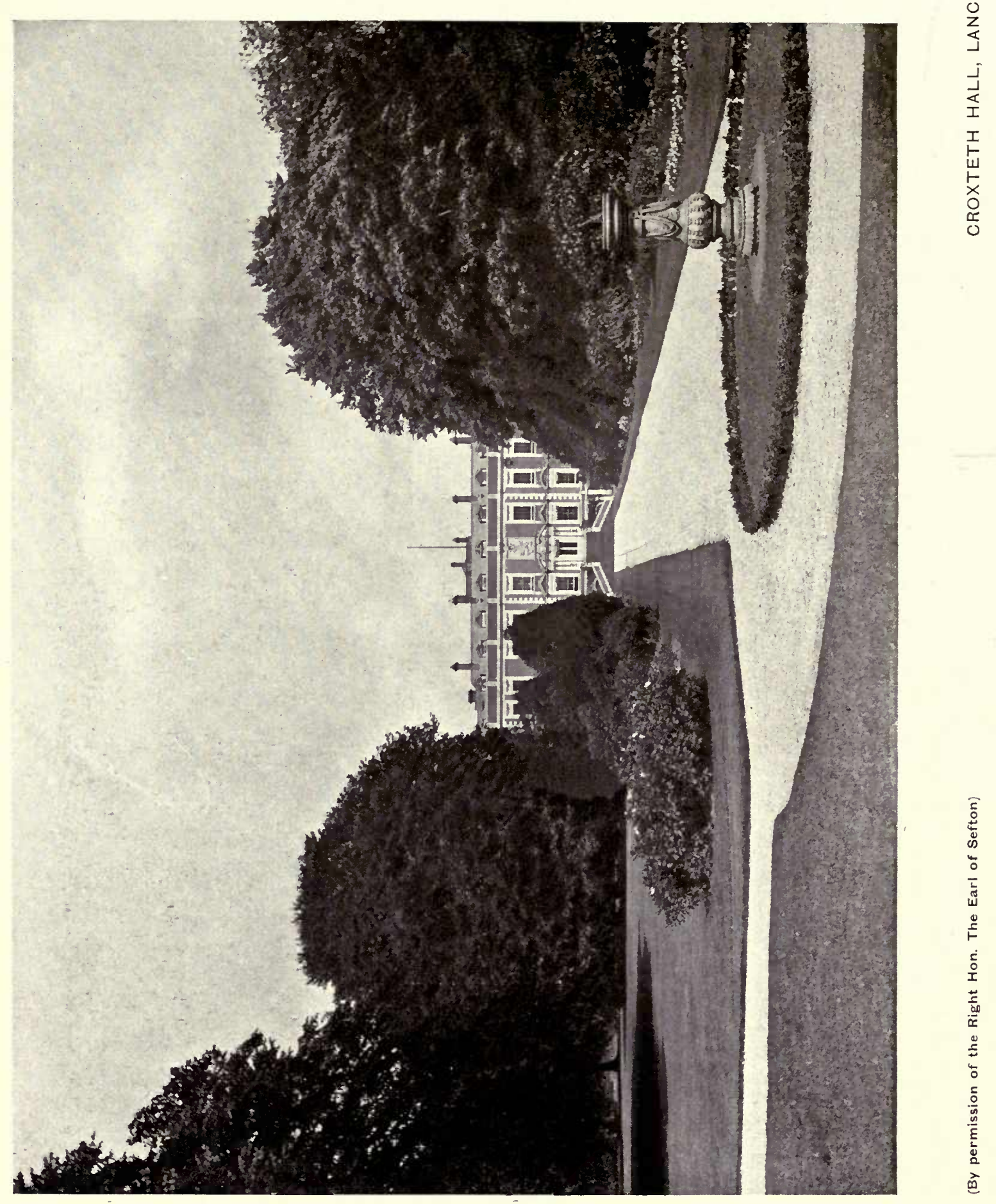




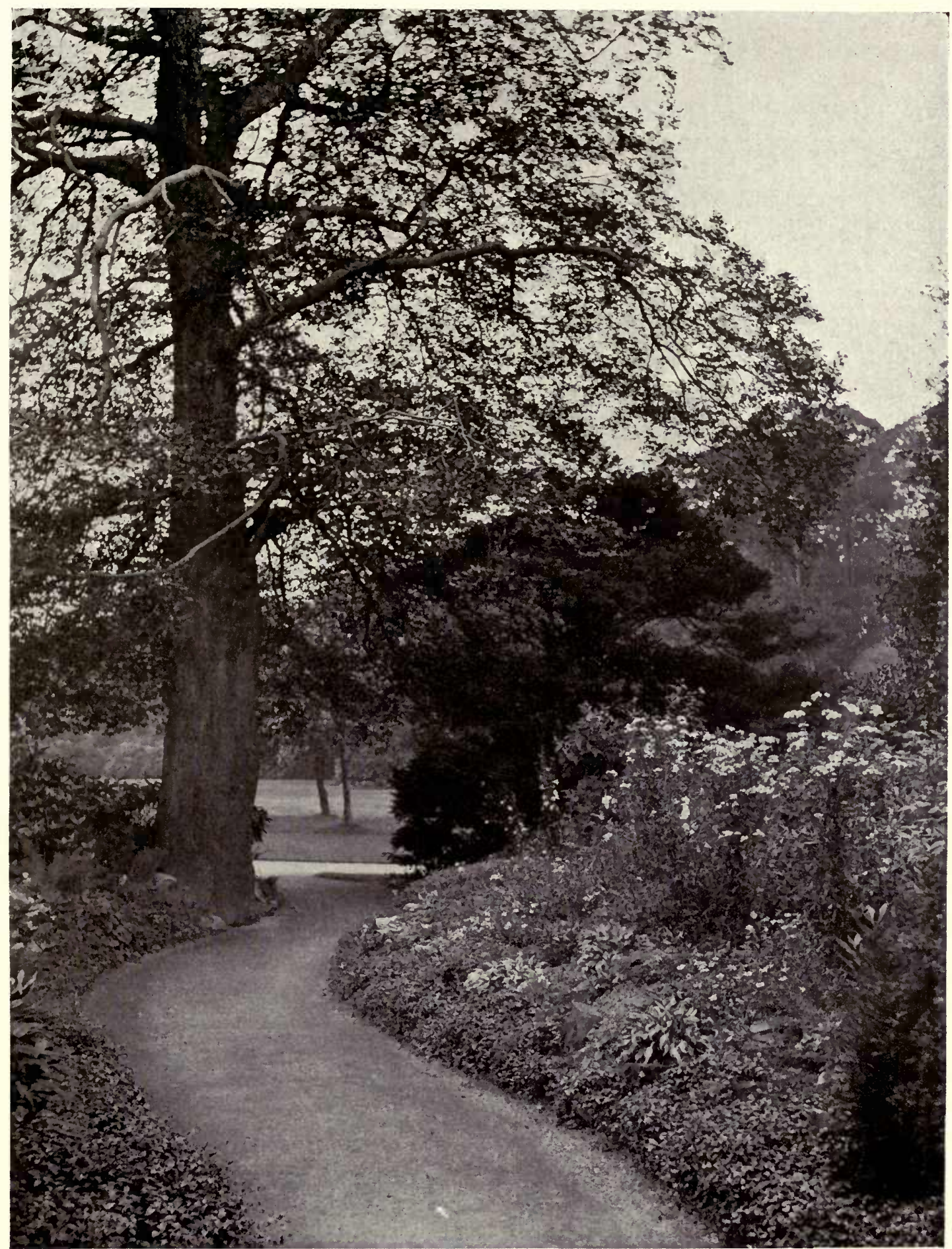




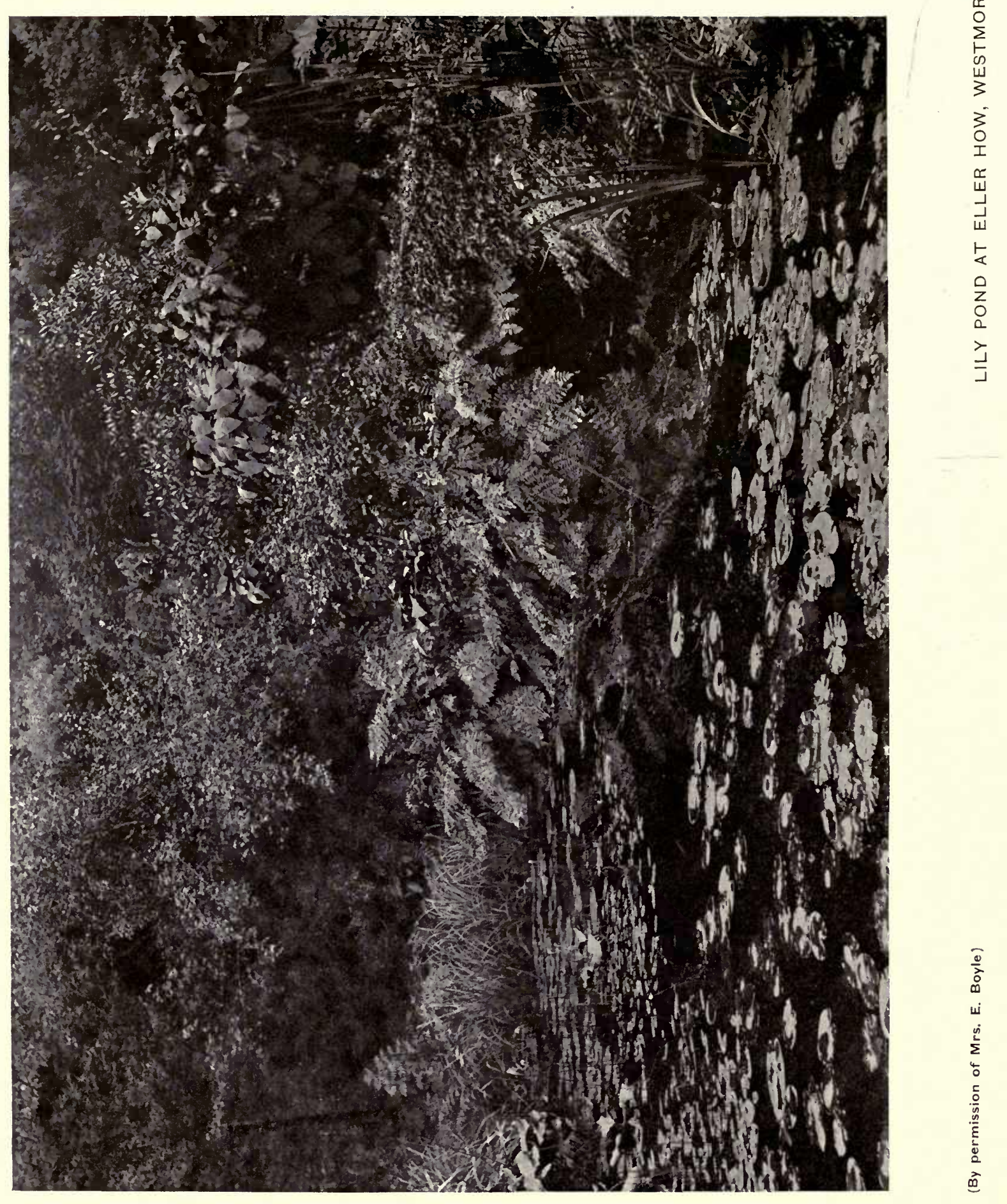




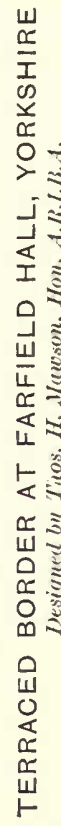

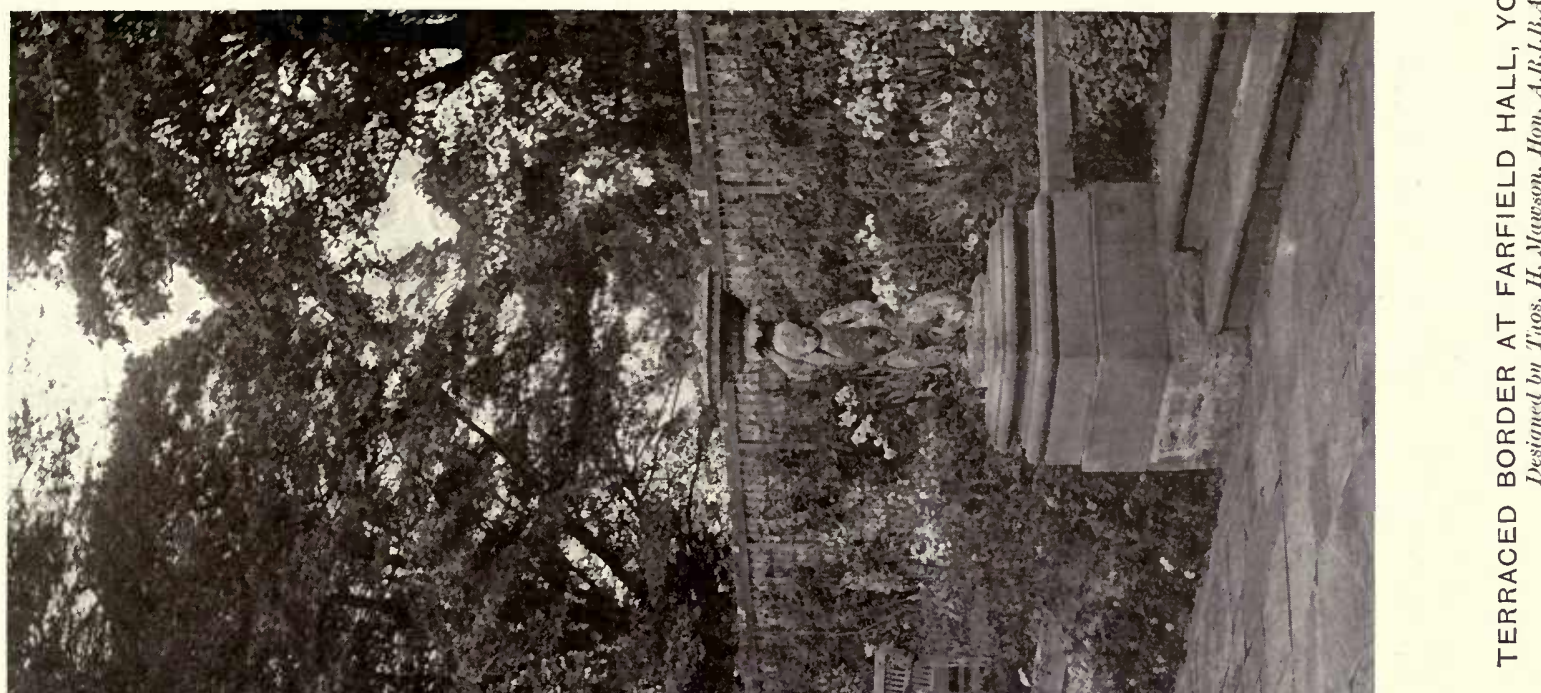

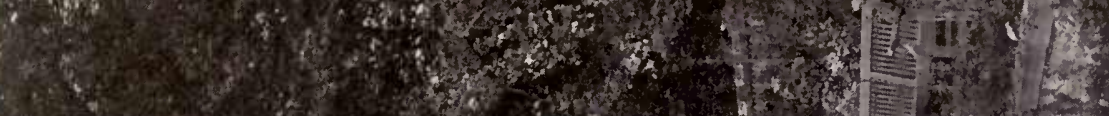

1.15)

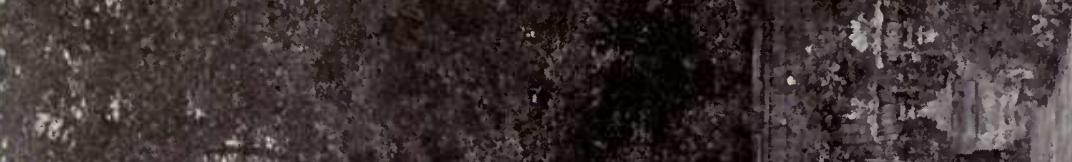

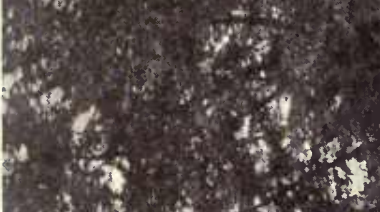

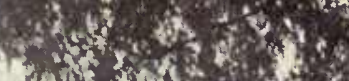

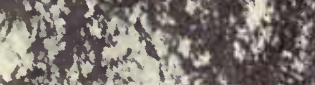

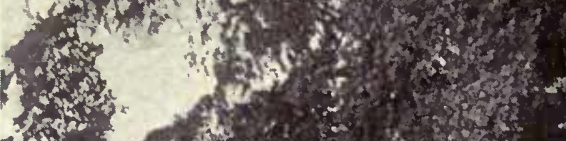

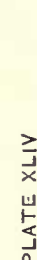

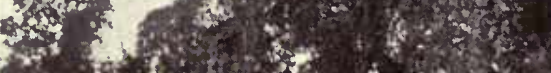

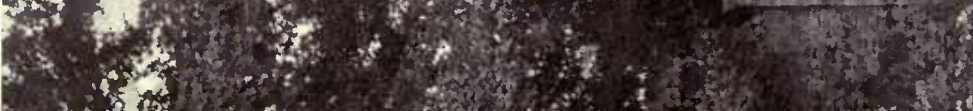

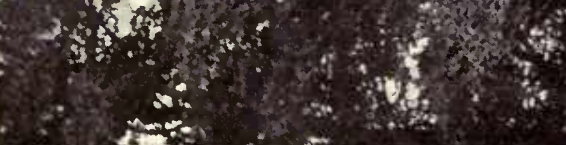

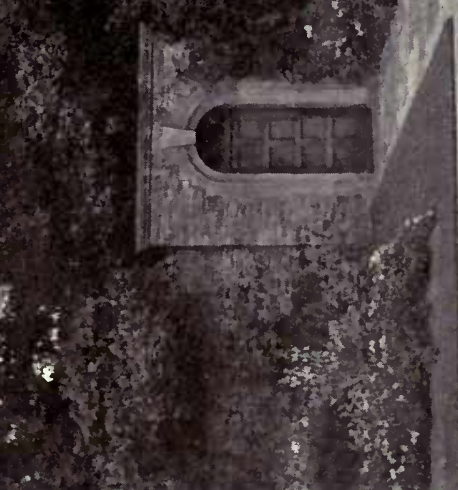




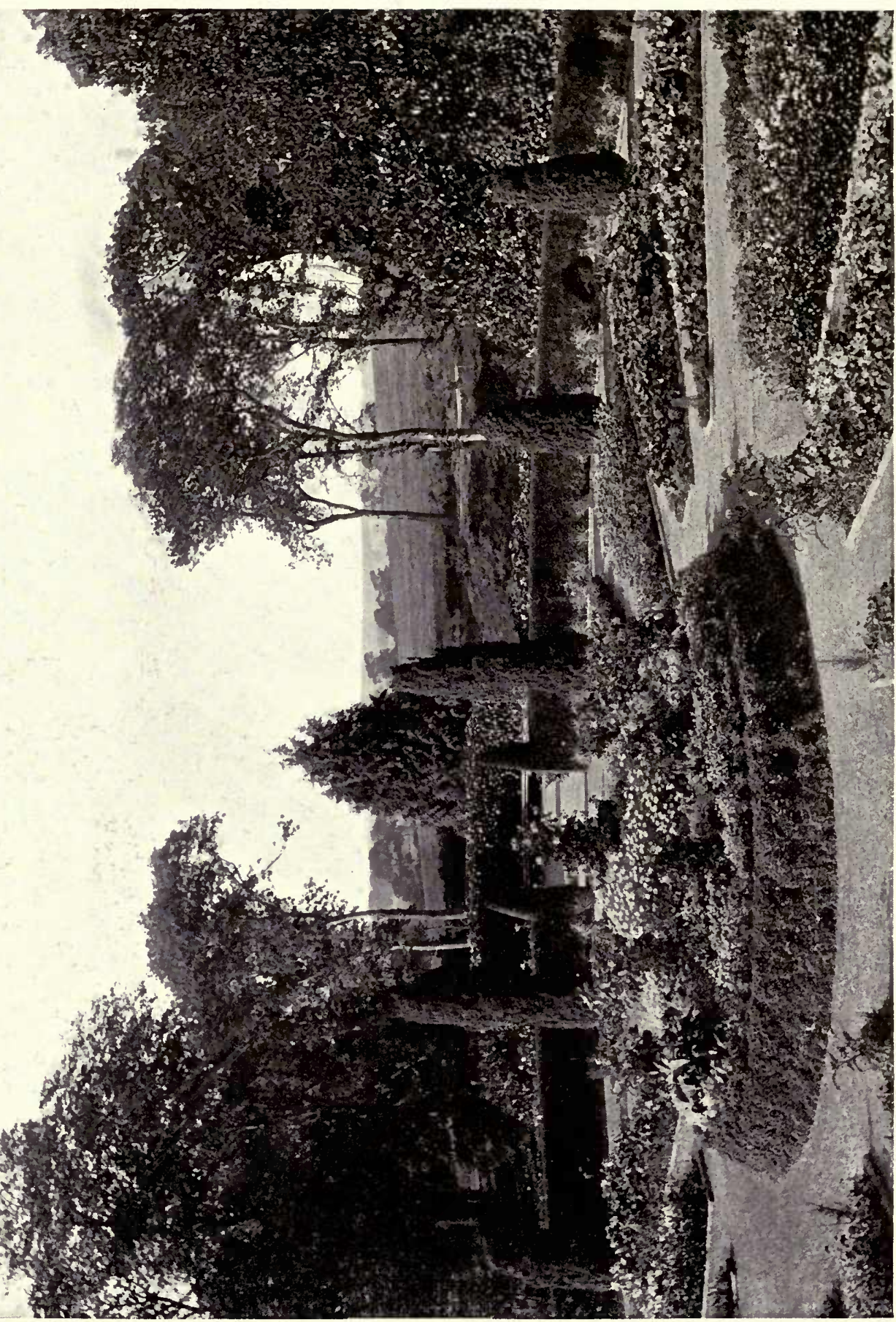

o

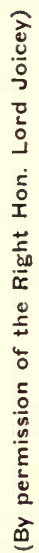




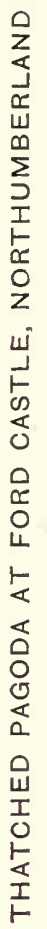

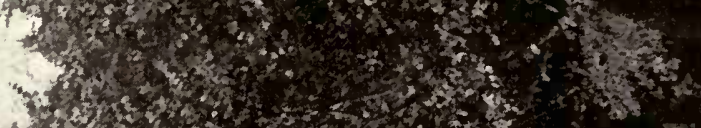

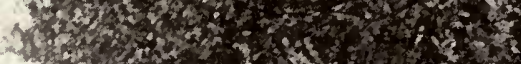

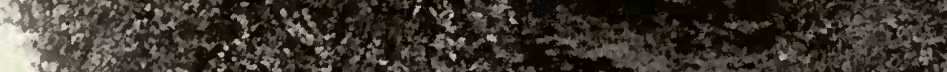

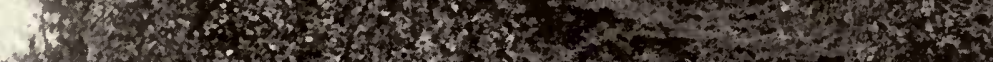

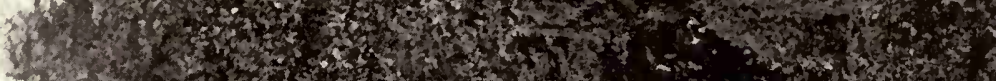

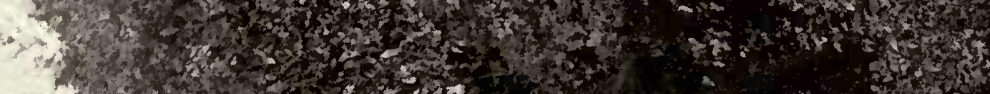

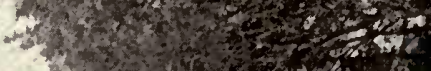
Anth sen

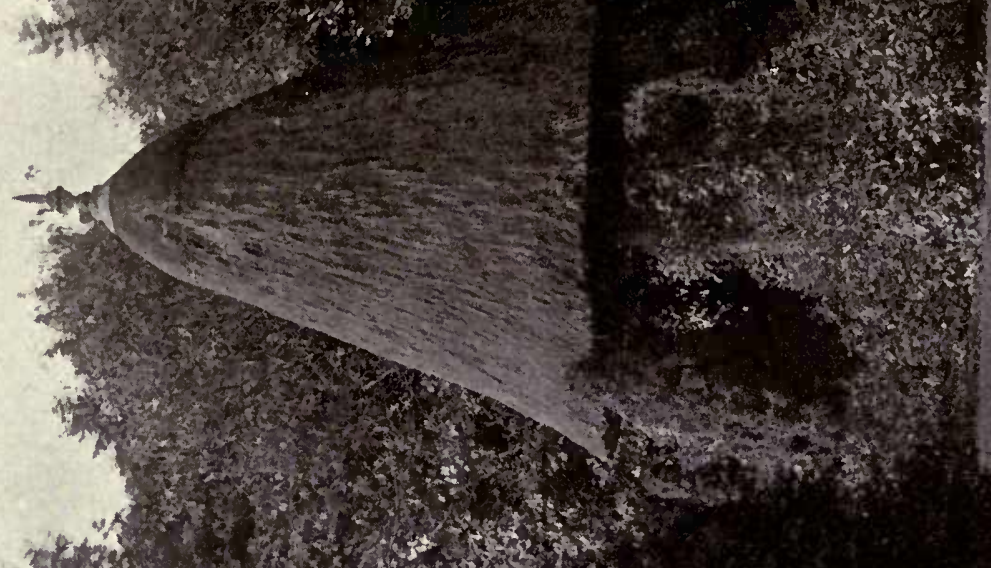

\section{$+x^{2}$}

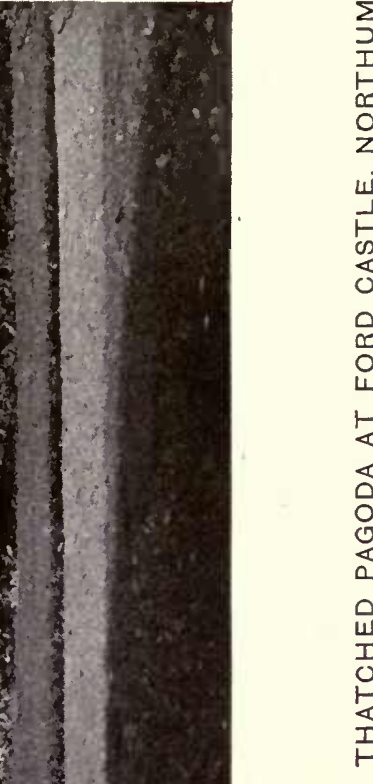

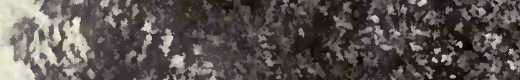

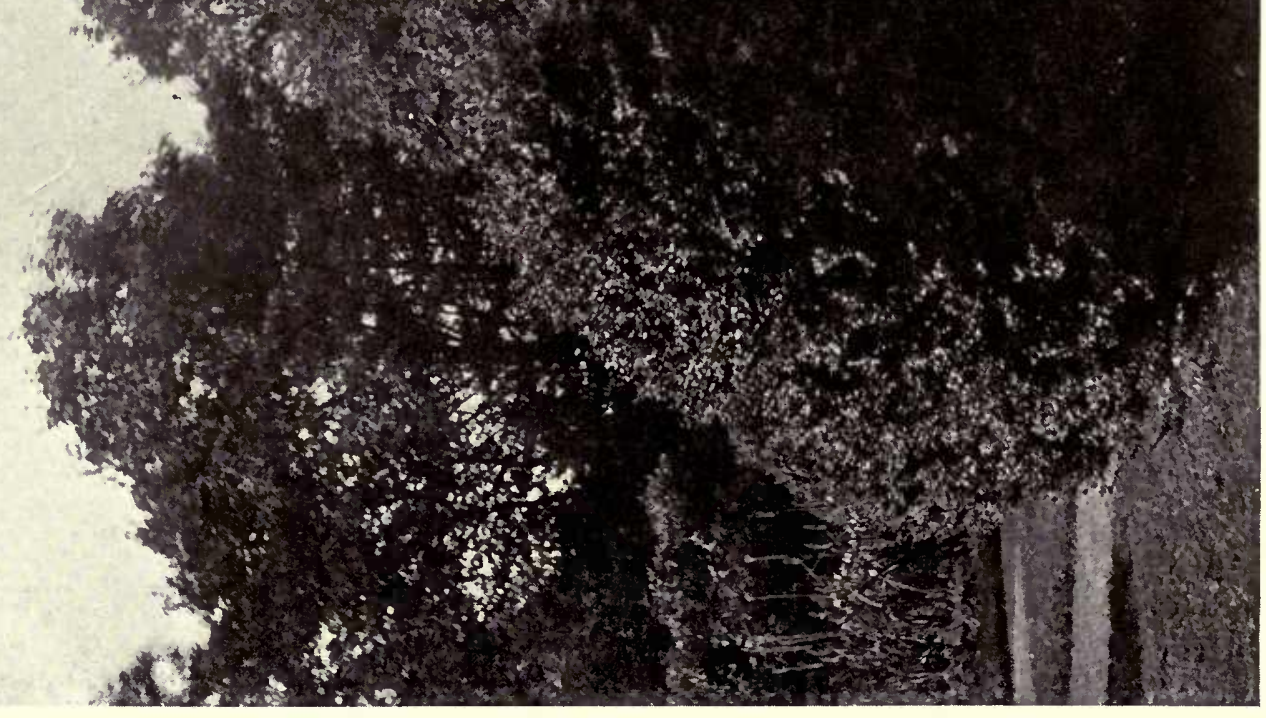


$\because \because \because \vdots \vdots \vdots \vdots \vdots$

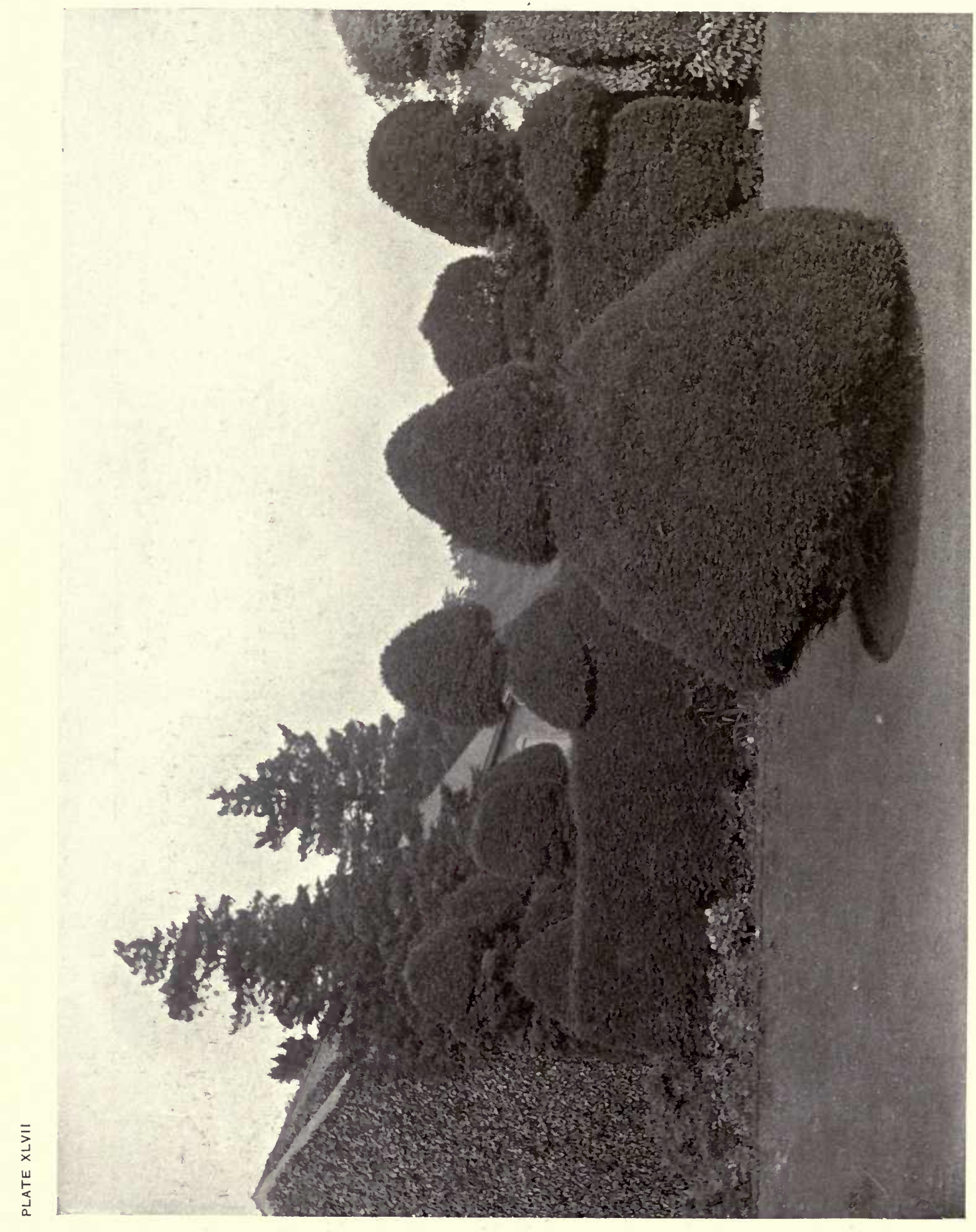

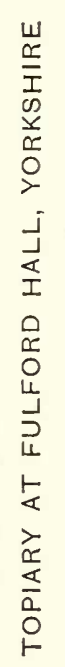




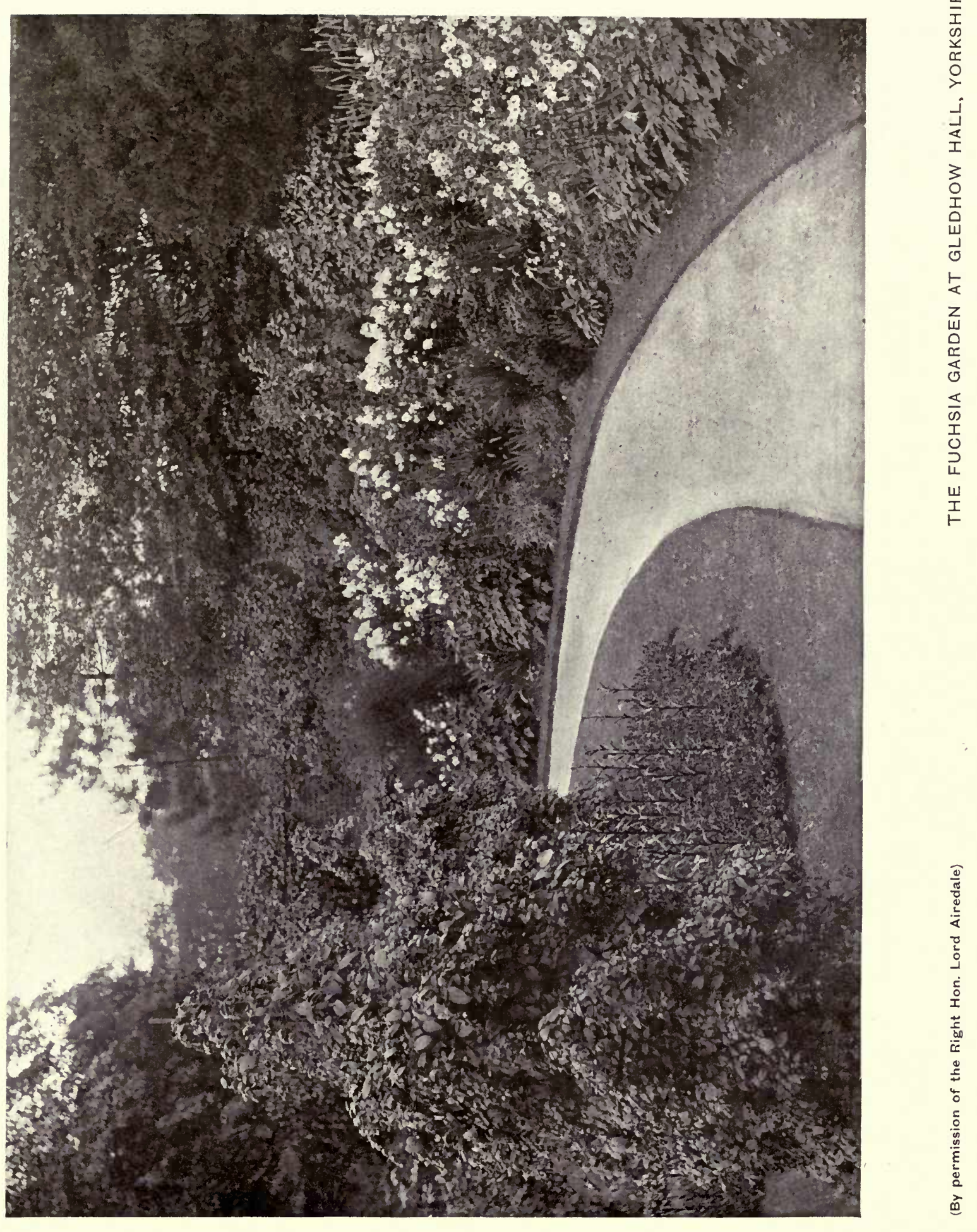




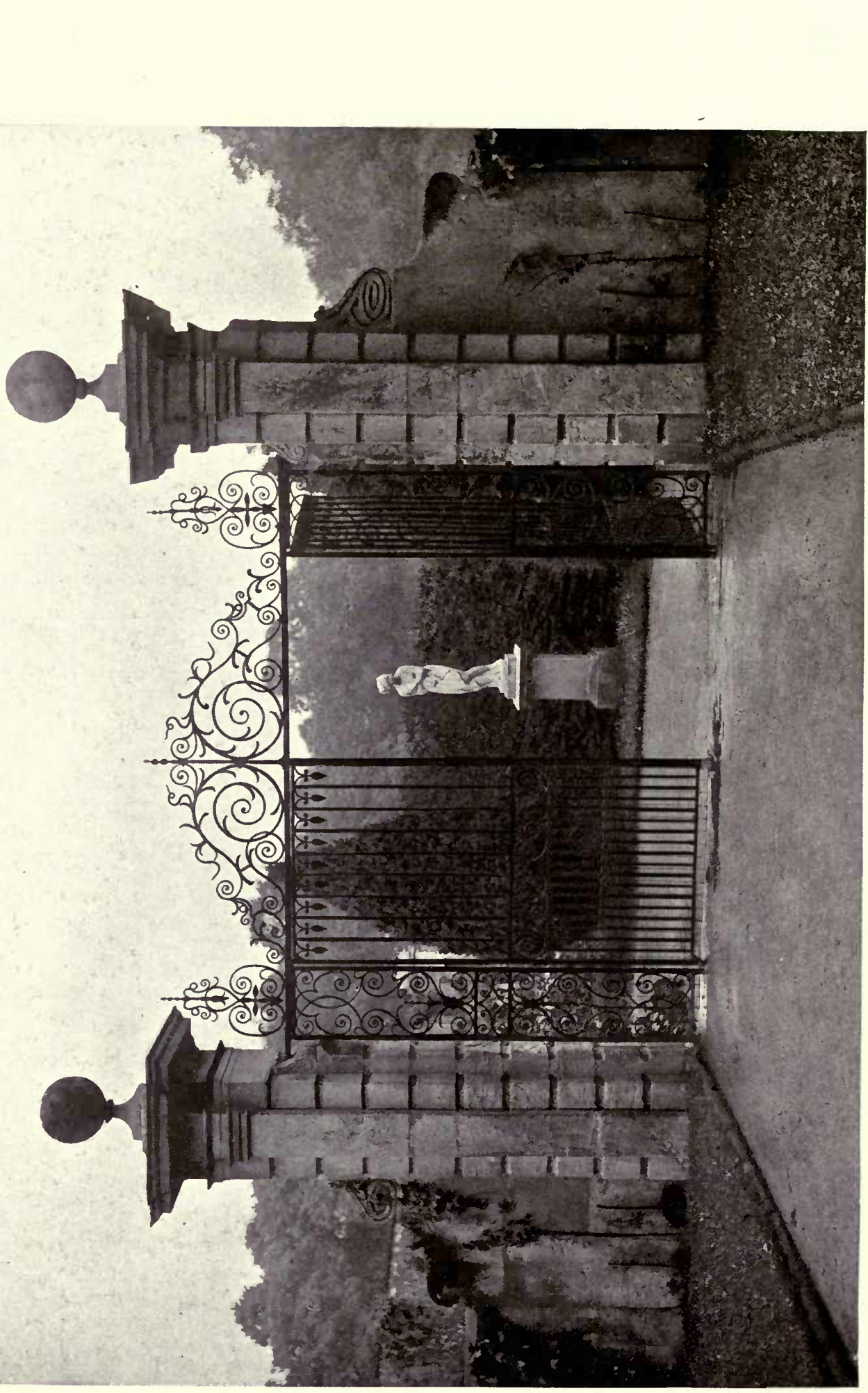

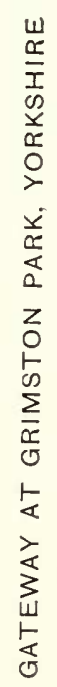



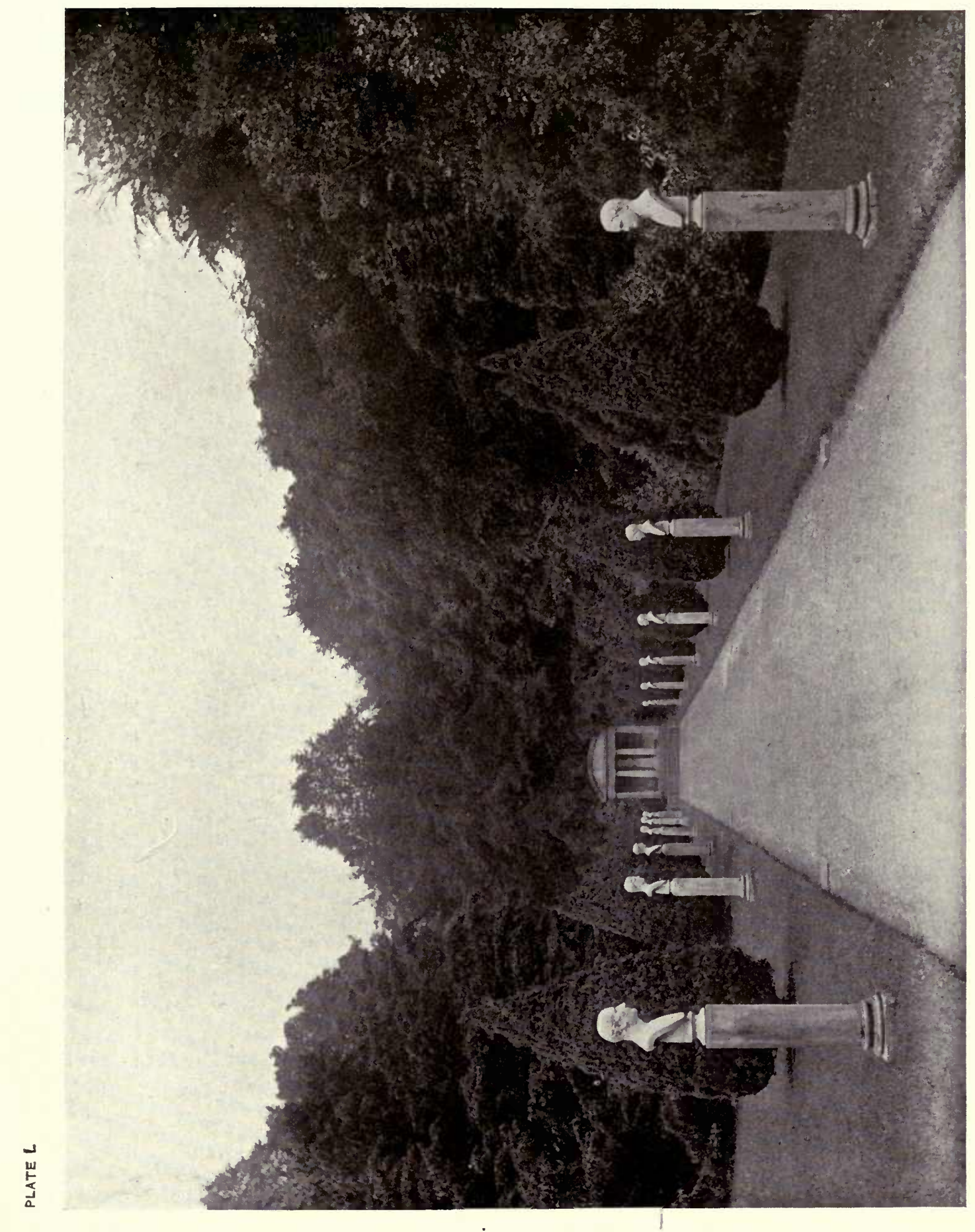

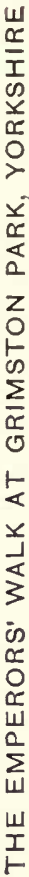

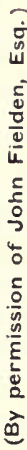




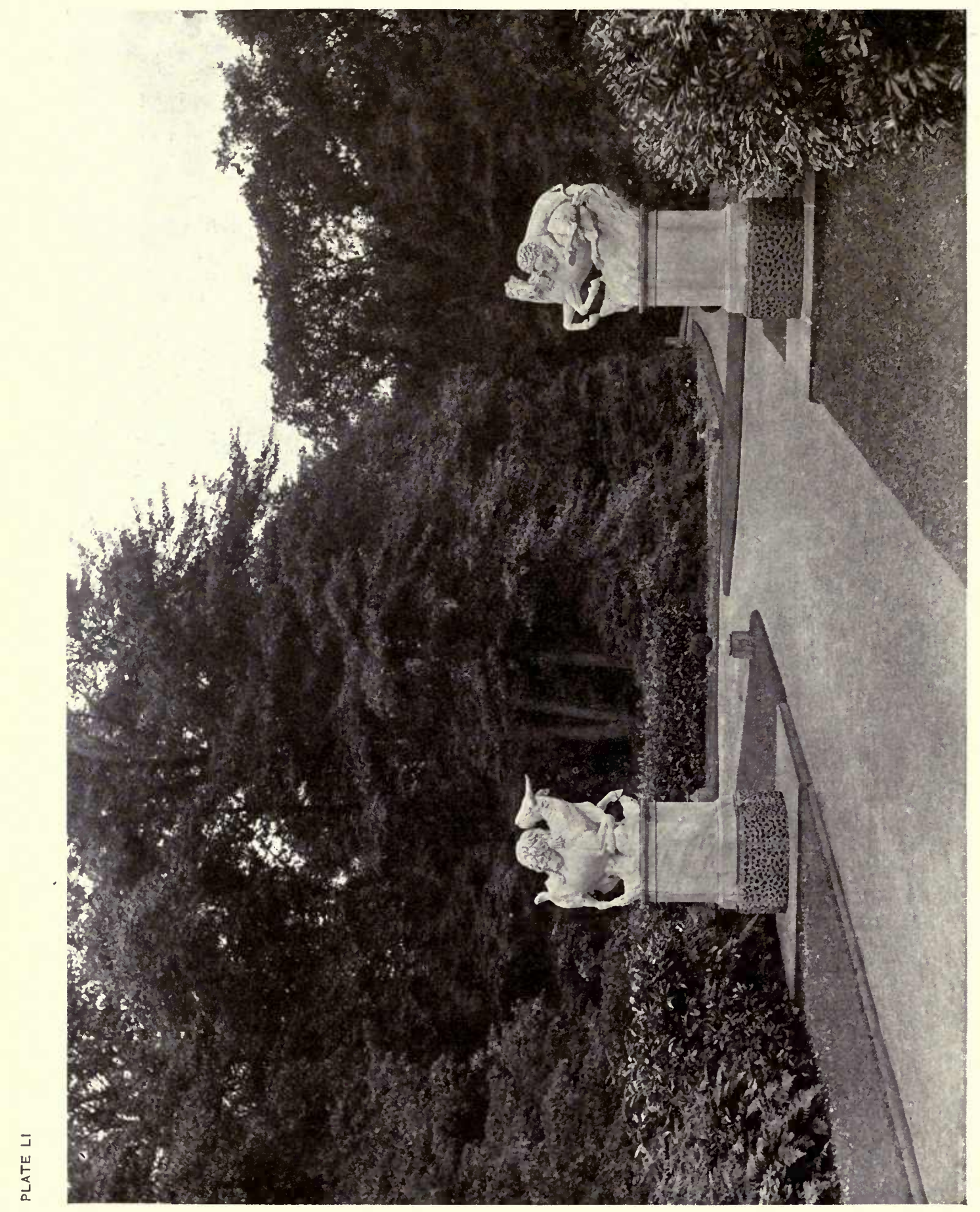

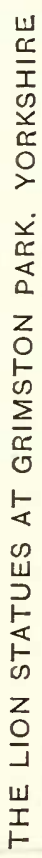




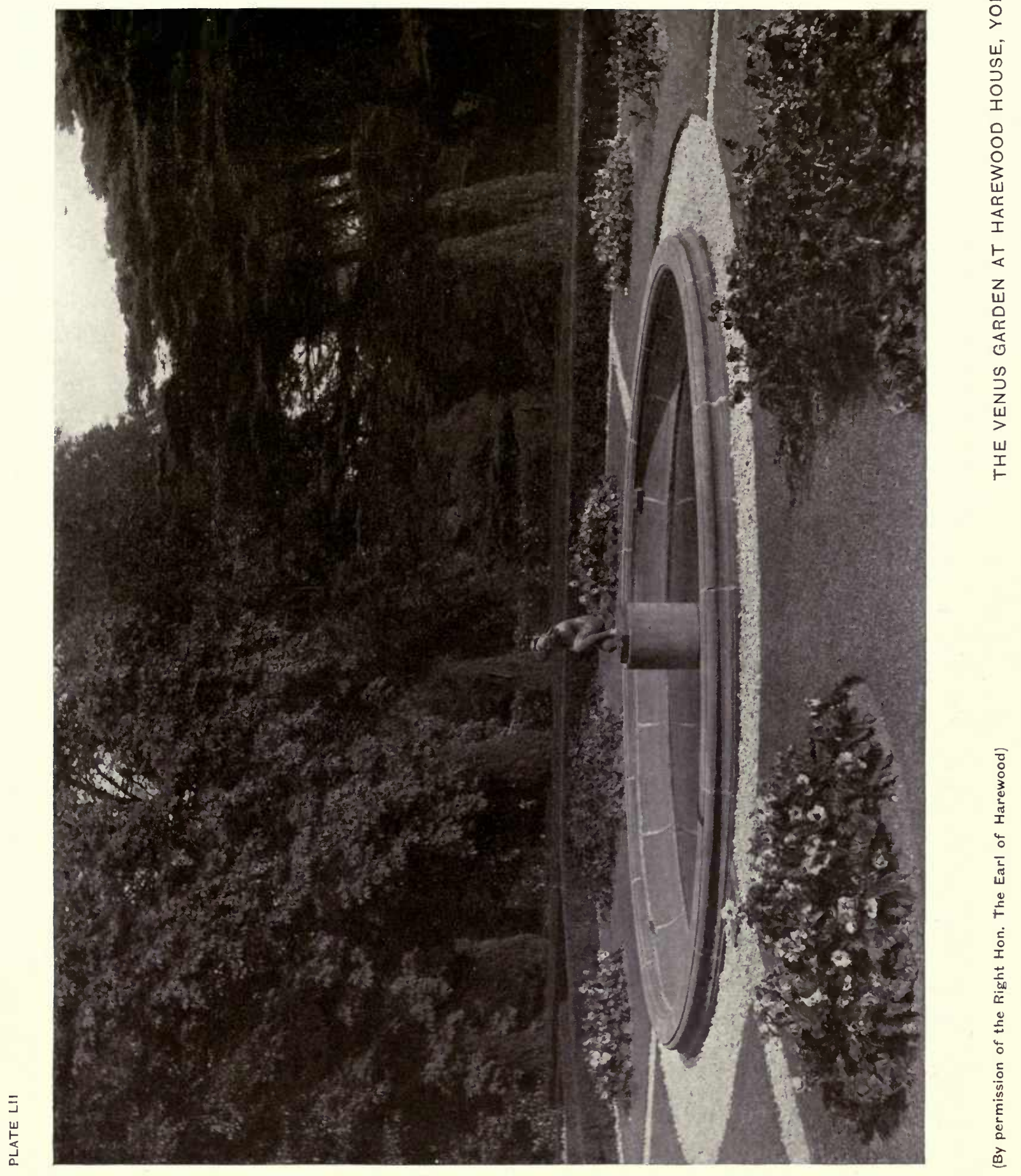




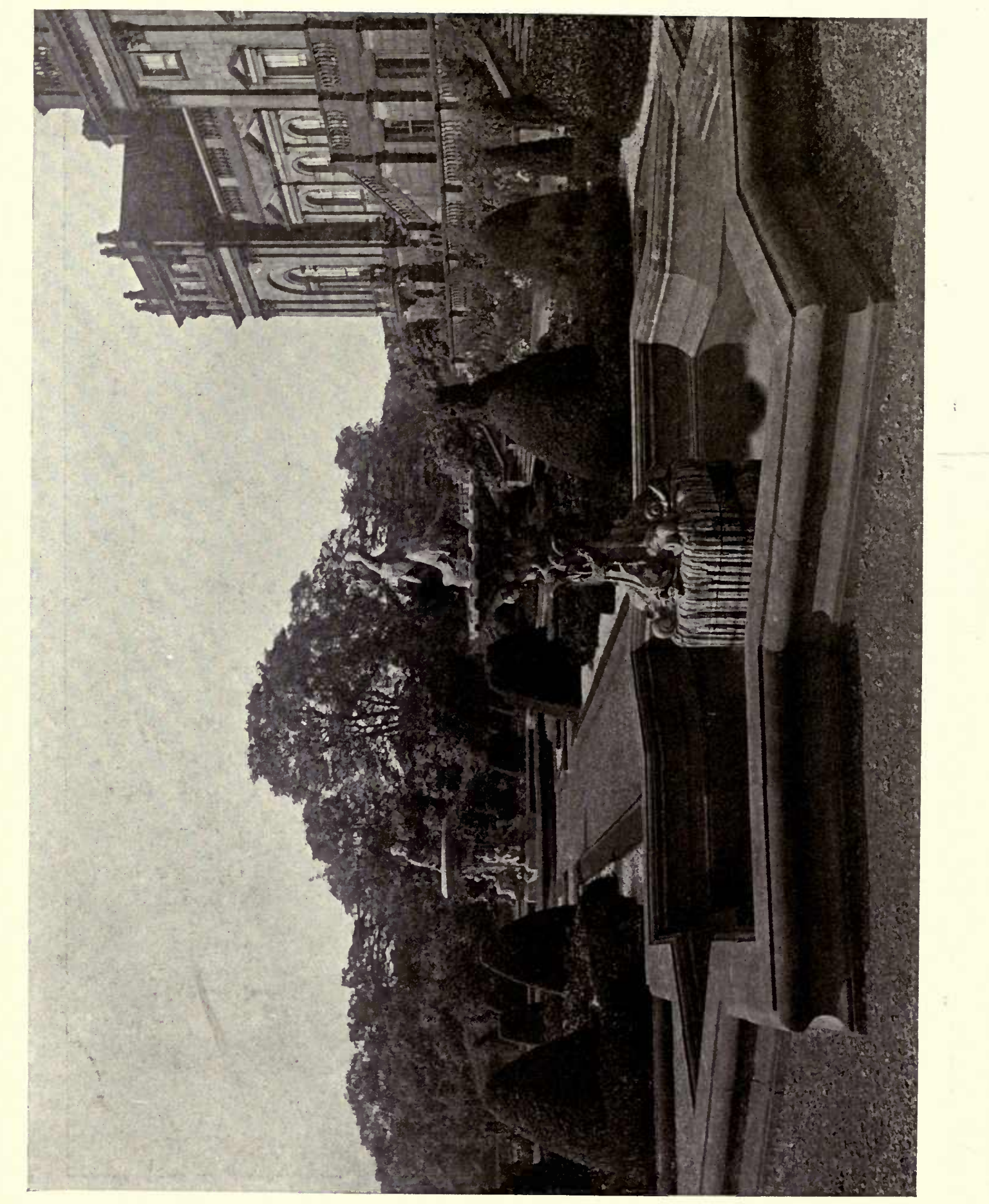

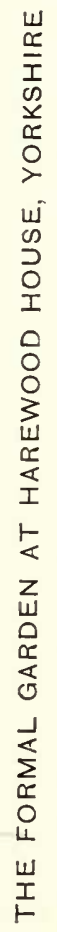




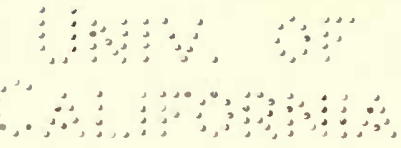

PLATE LIV

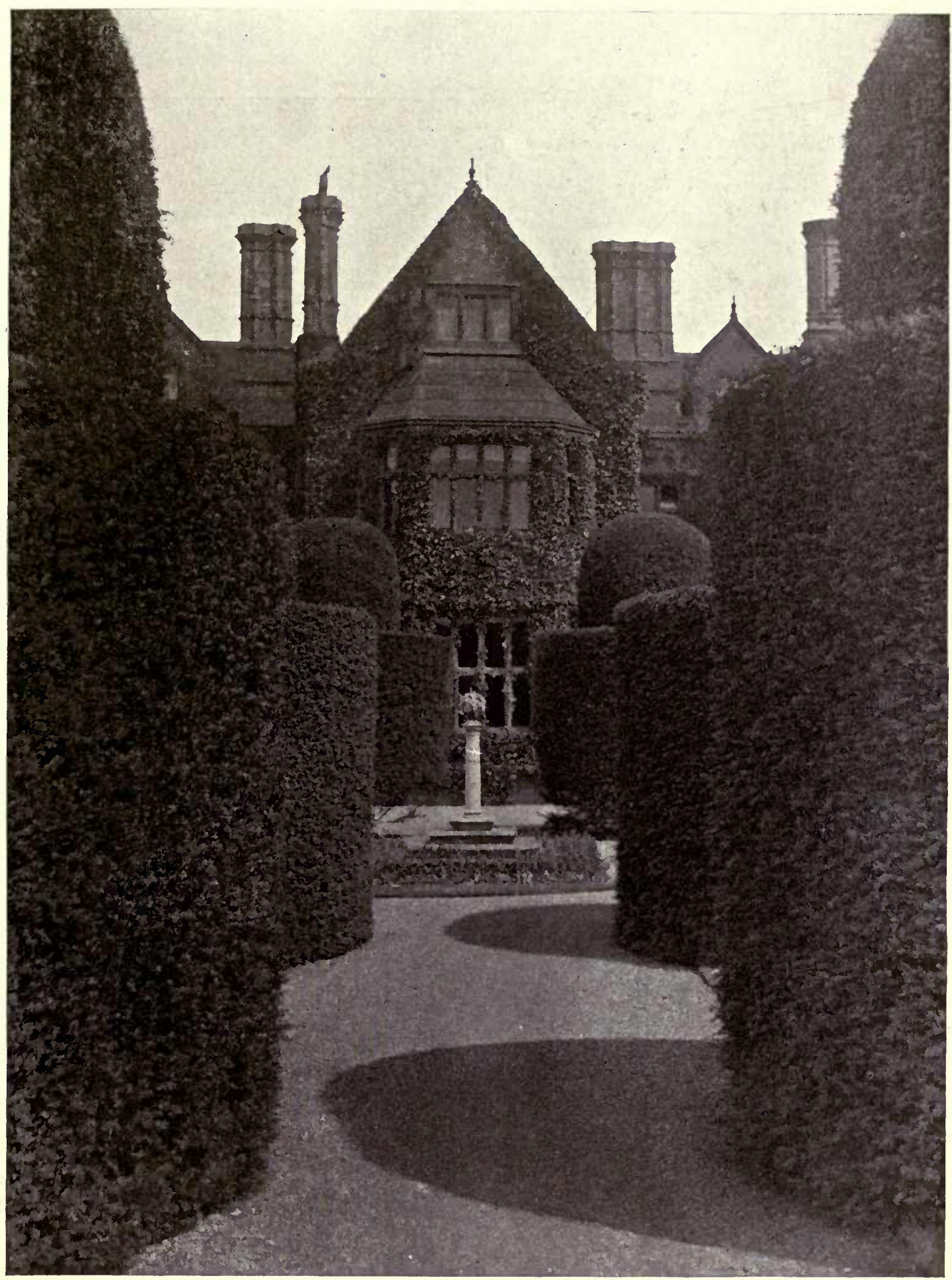


\begin{tabular}{l}
3 \\
\hdashline \\
\hdashline
\end{tabular}

a

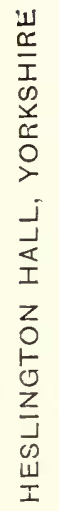

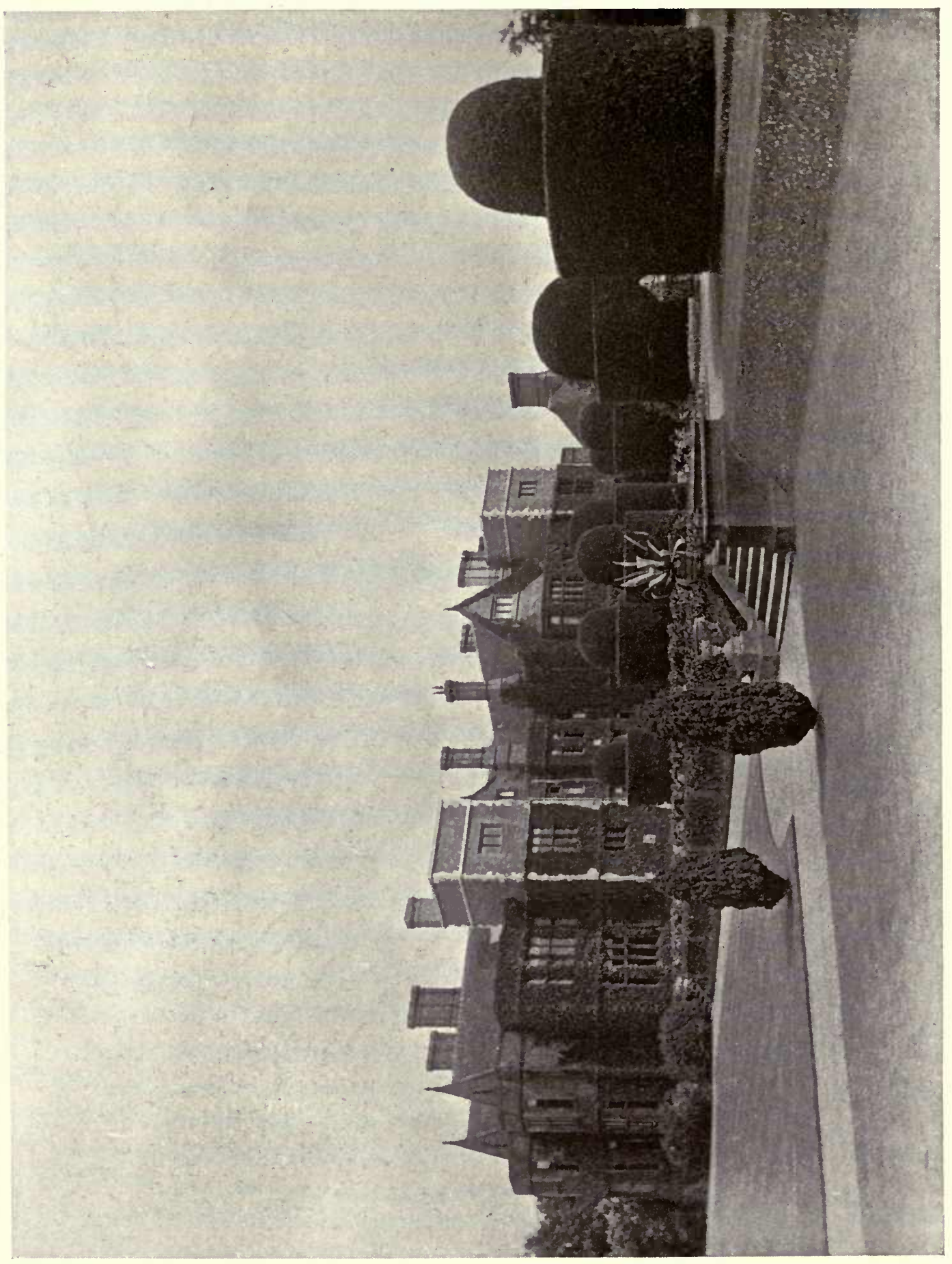



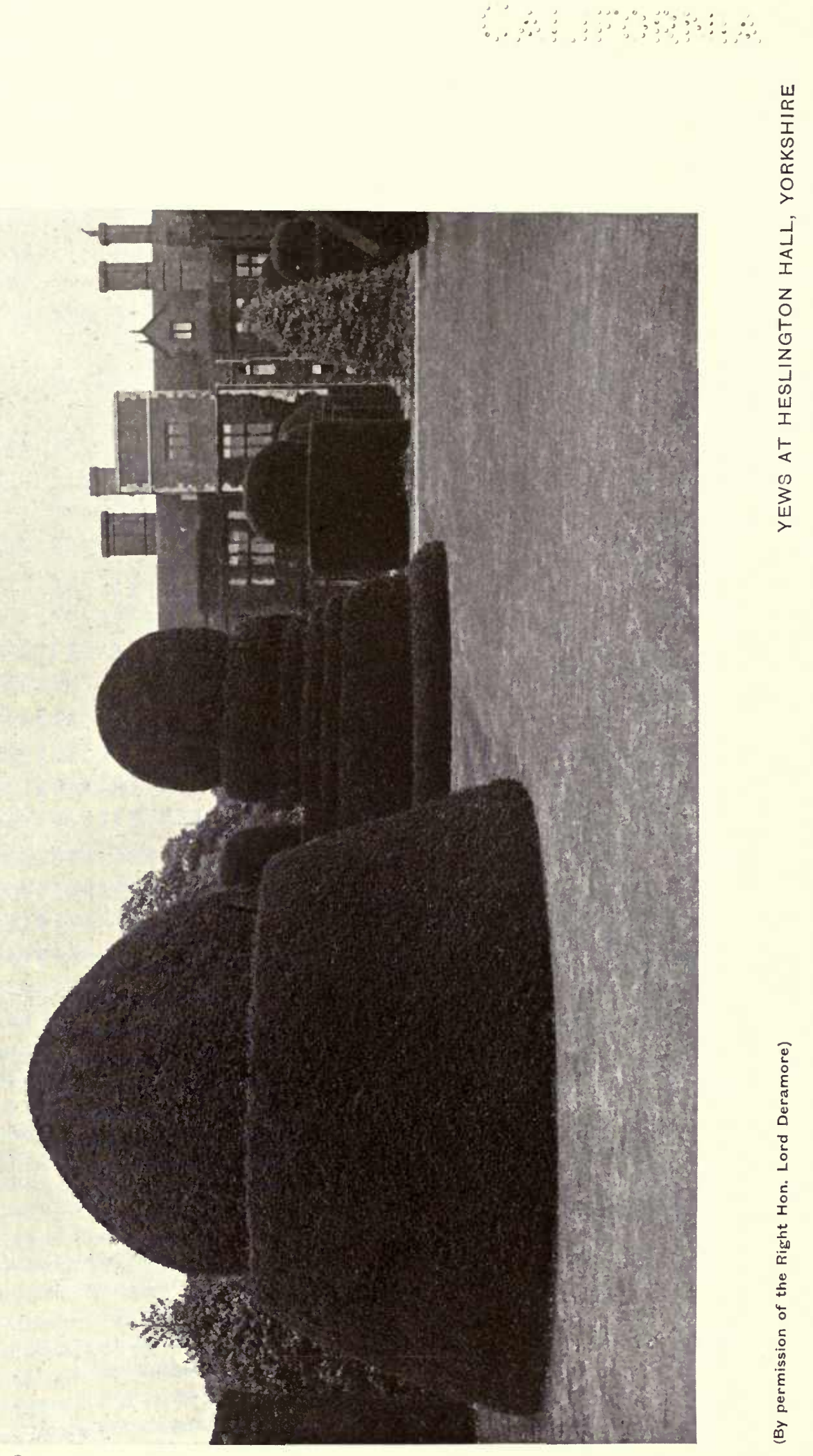

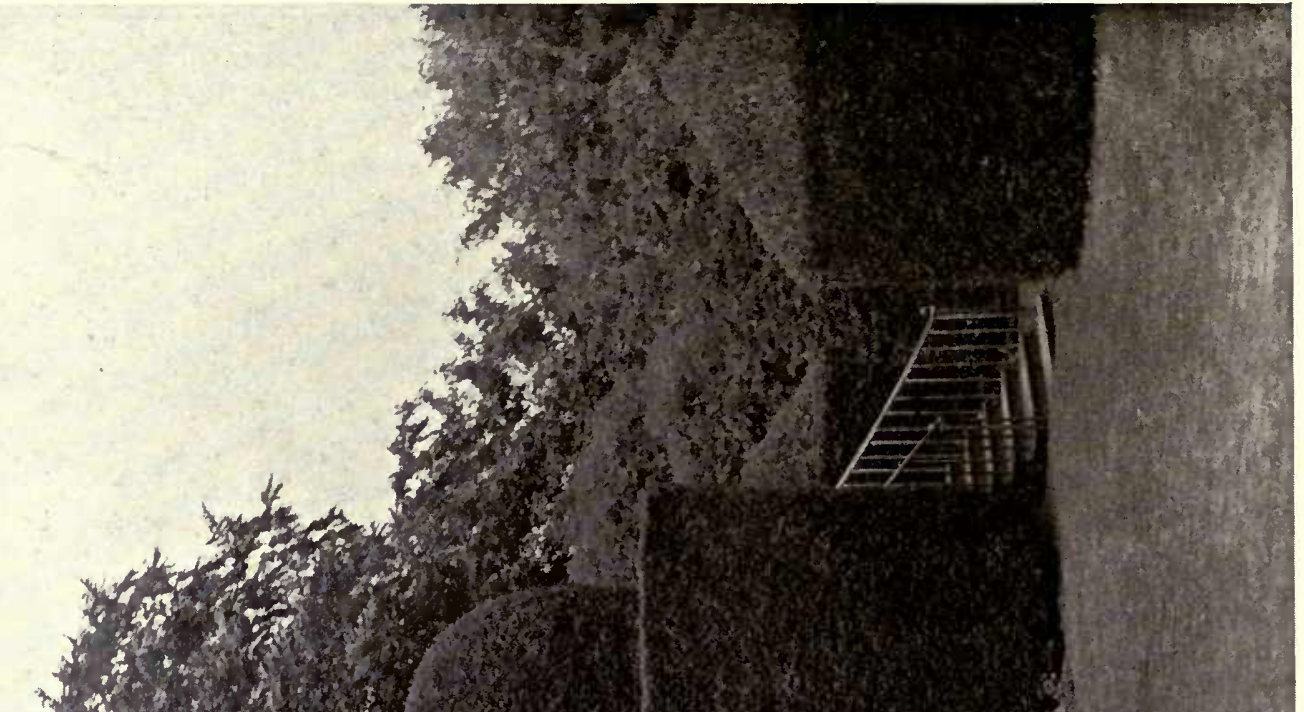

I) $\rightarrow$ to

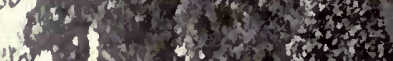

H.

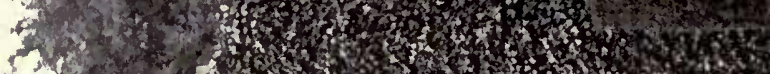

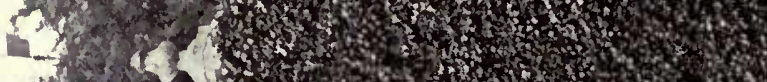

3010 (6)

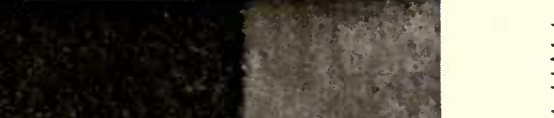

2

$\underline{z}$

岌

选

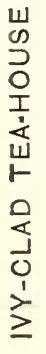

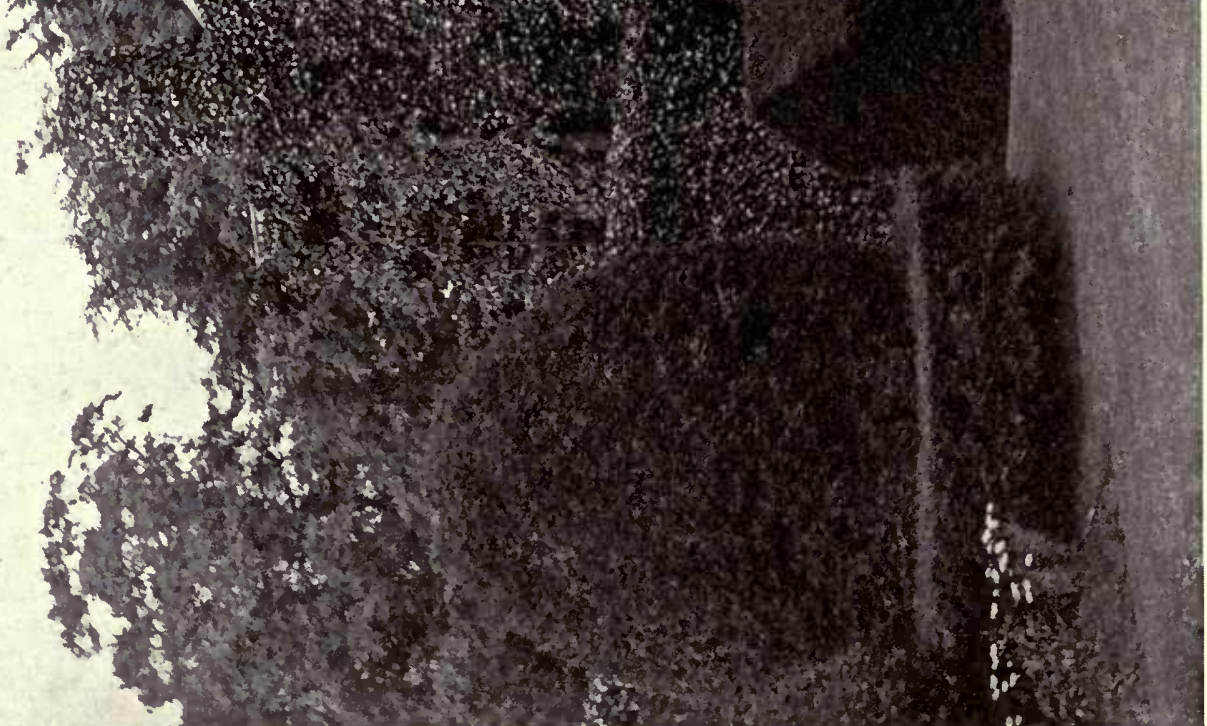



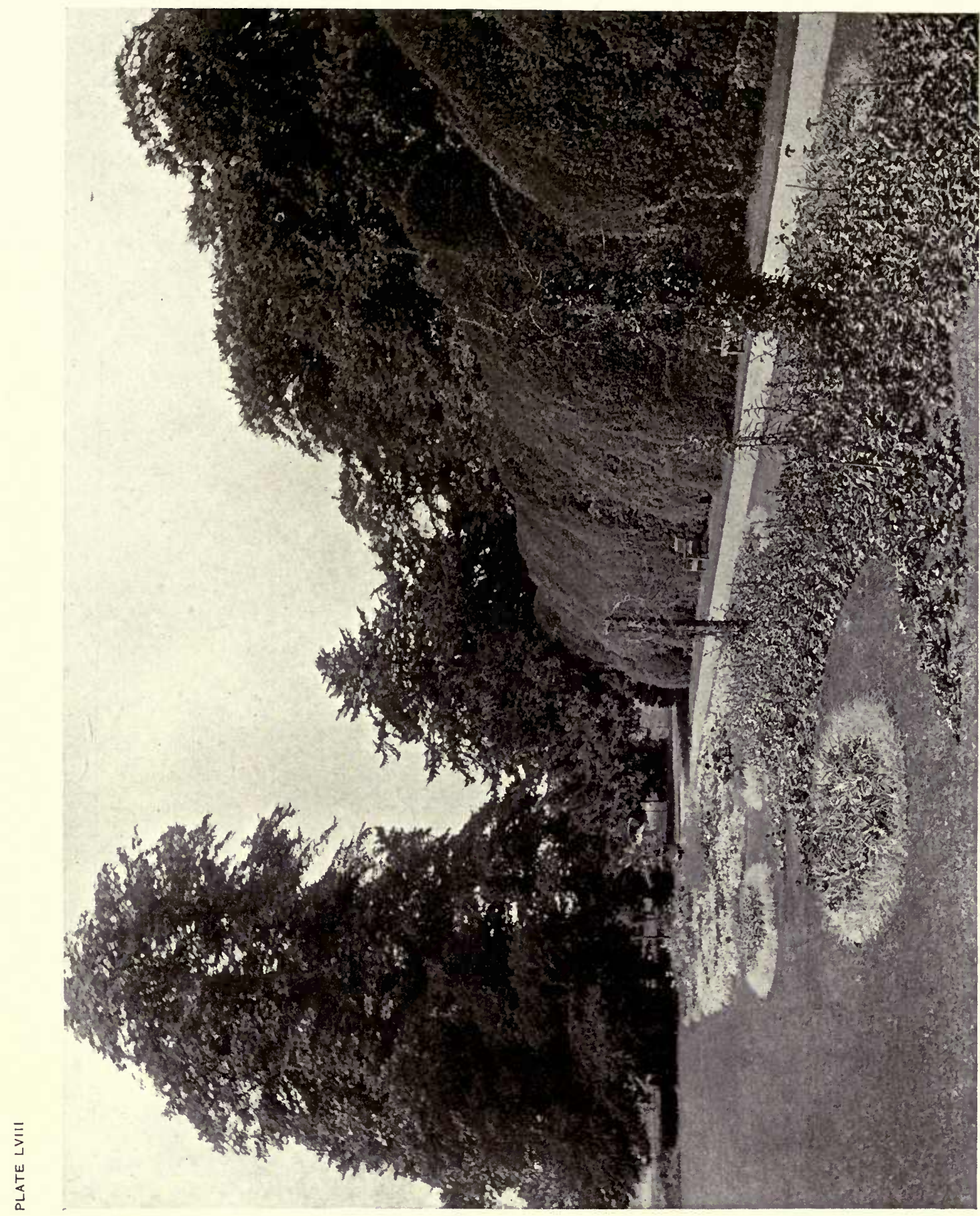

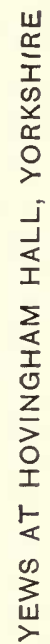

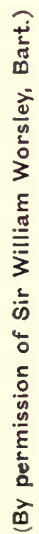




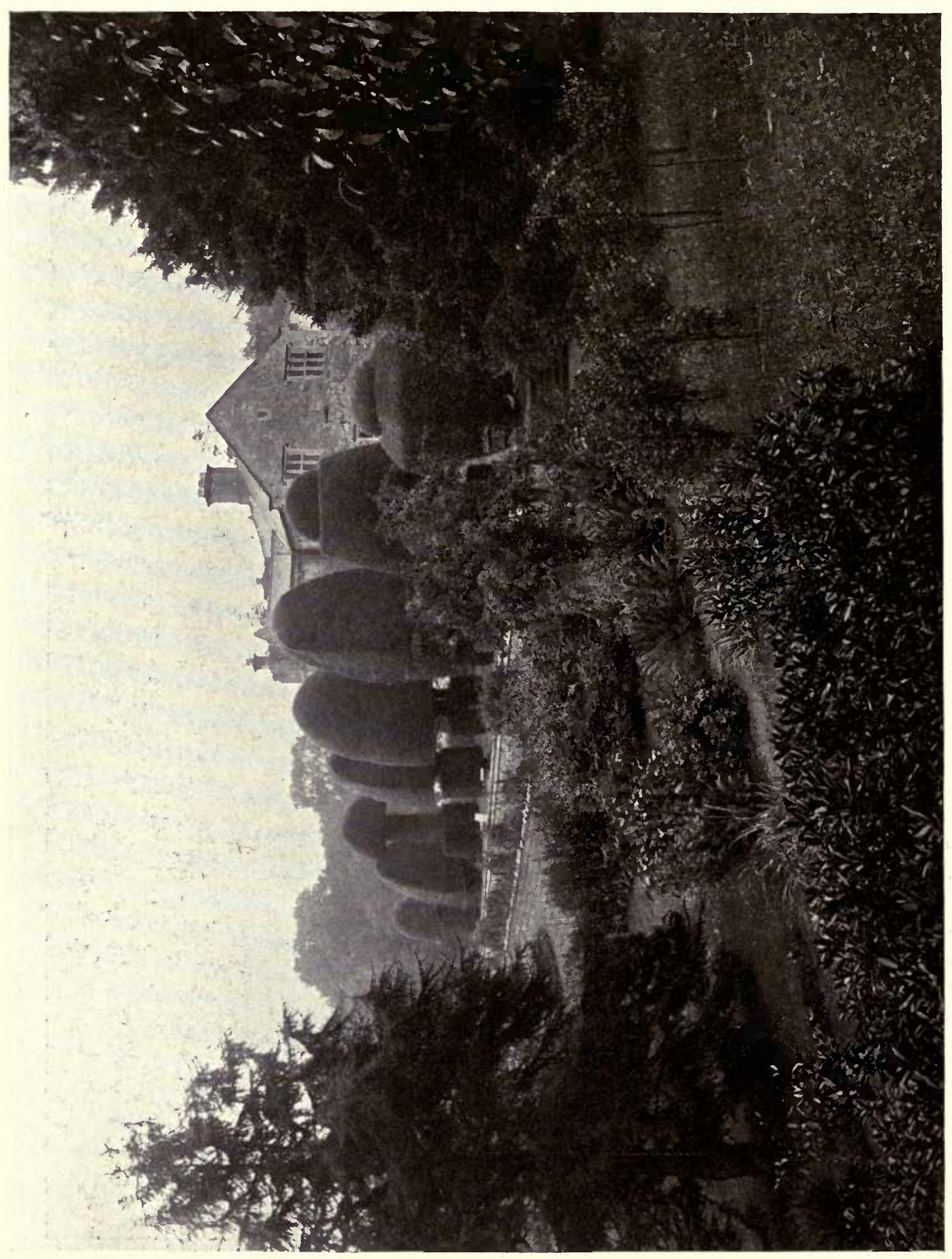

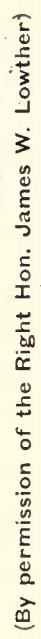




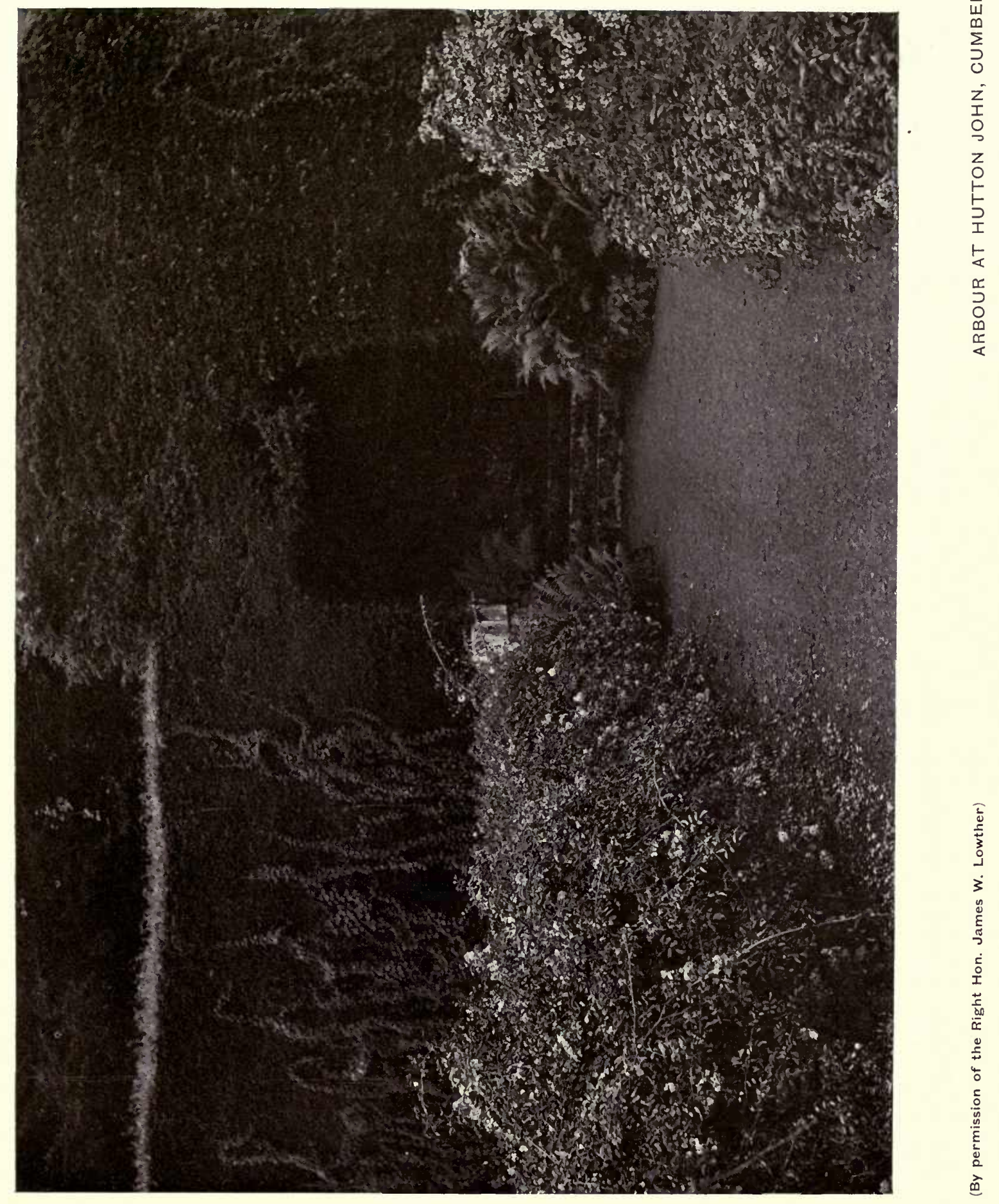




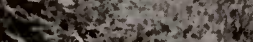

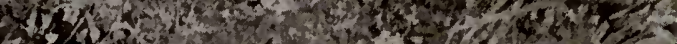

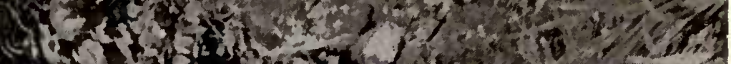

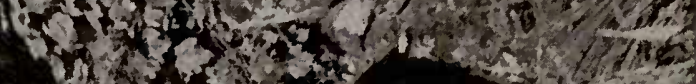

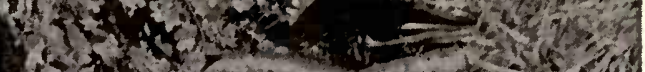

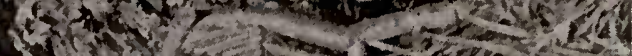
1.

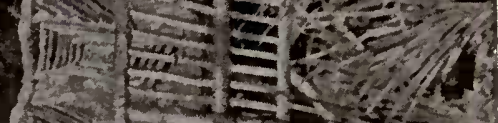

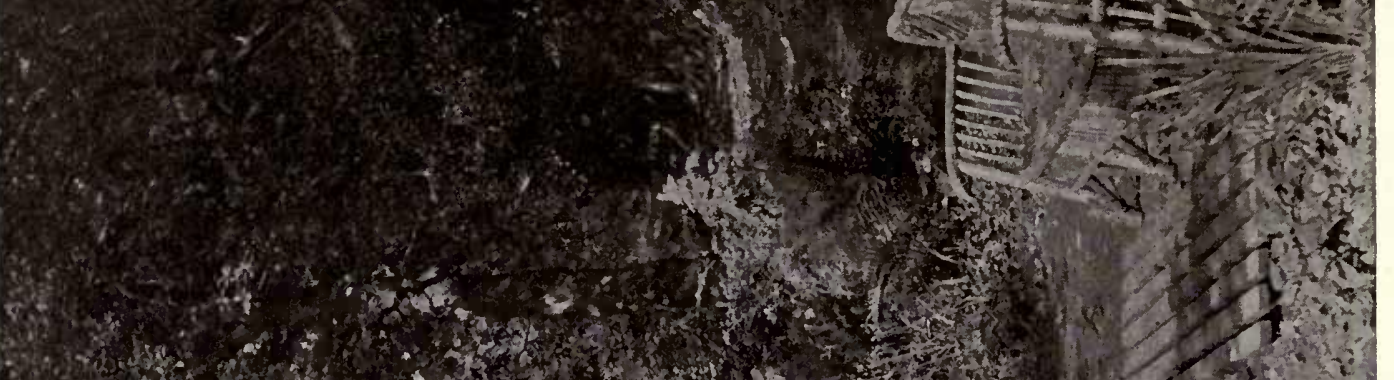

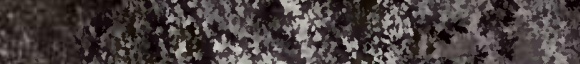

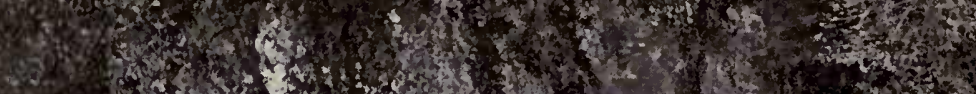
2.

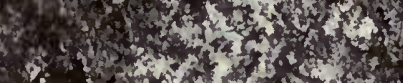

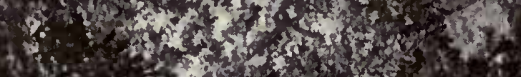

4.8.

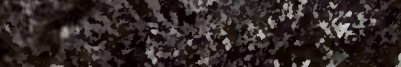

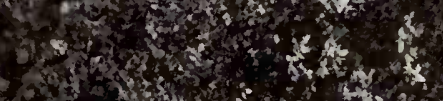

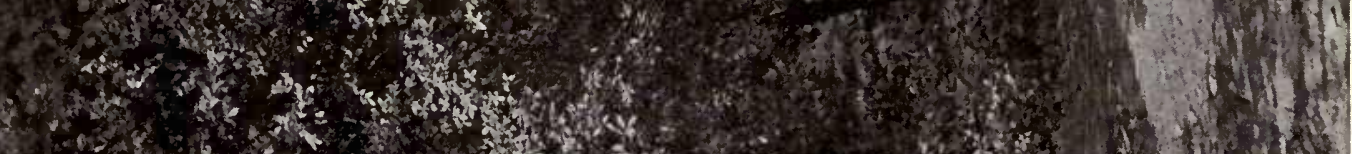

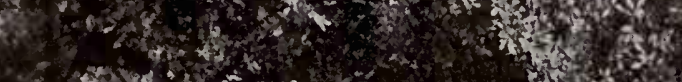

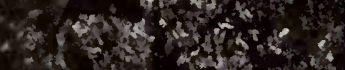

(4)

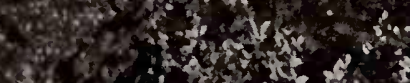

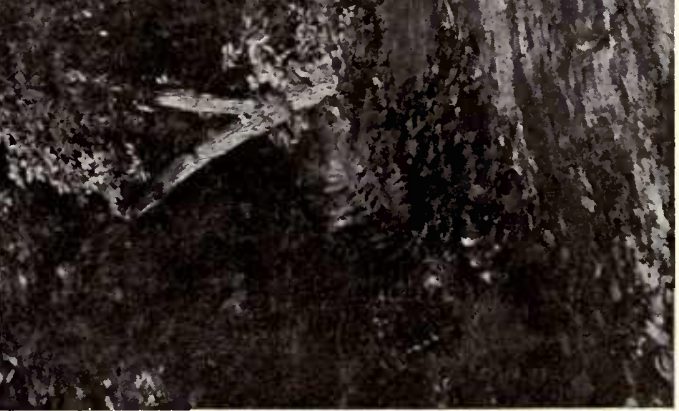




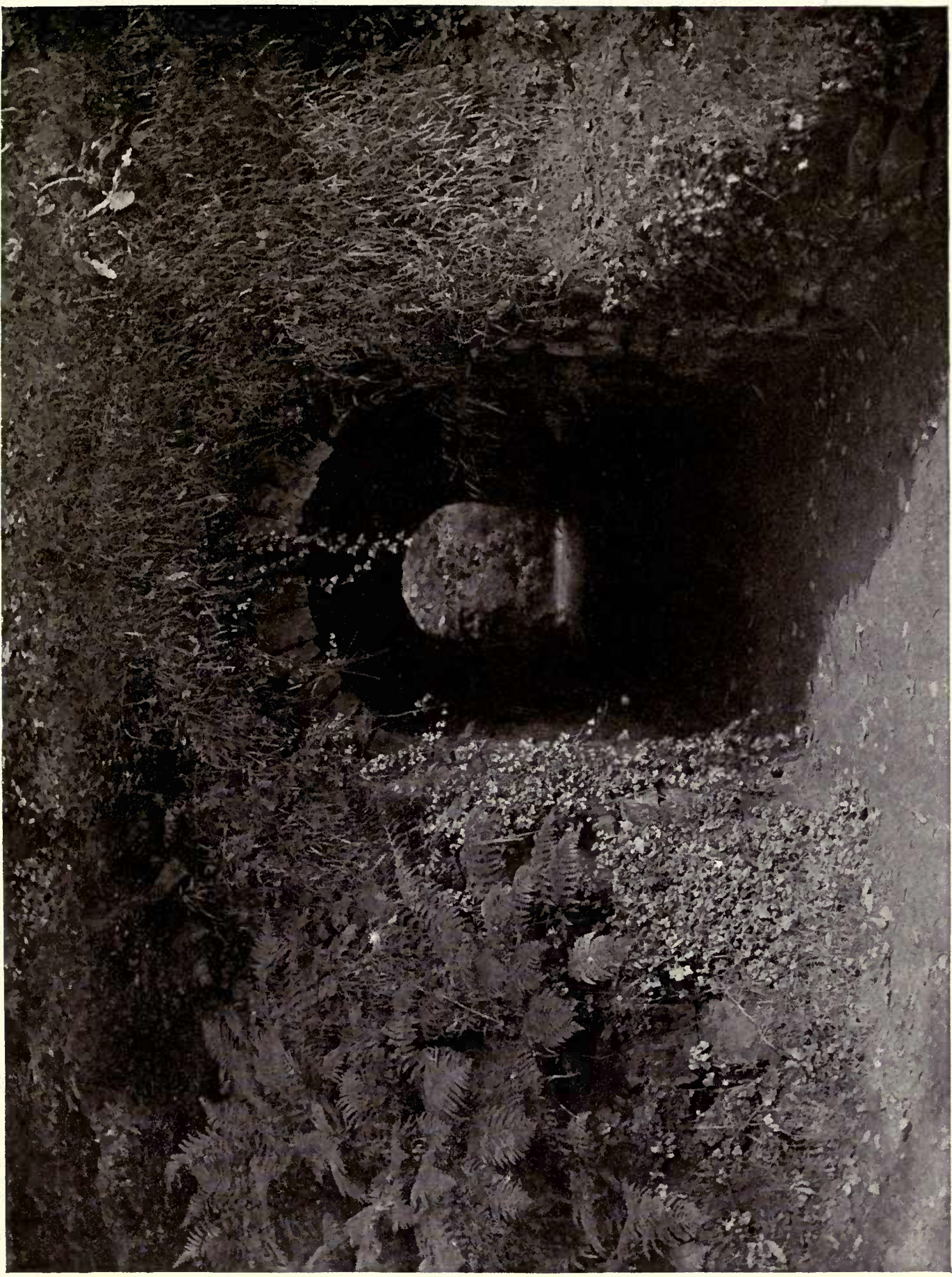

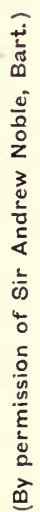





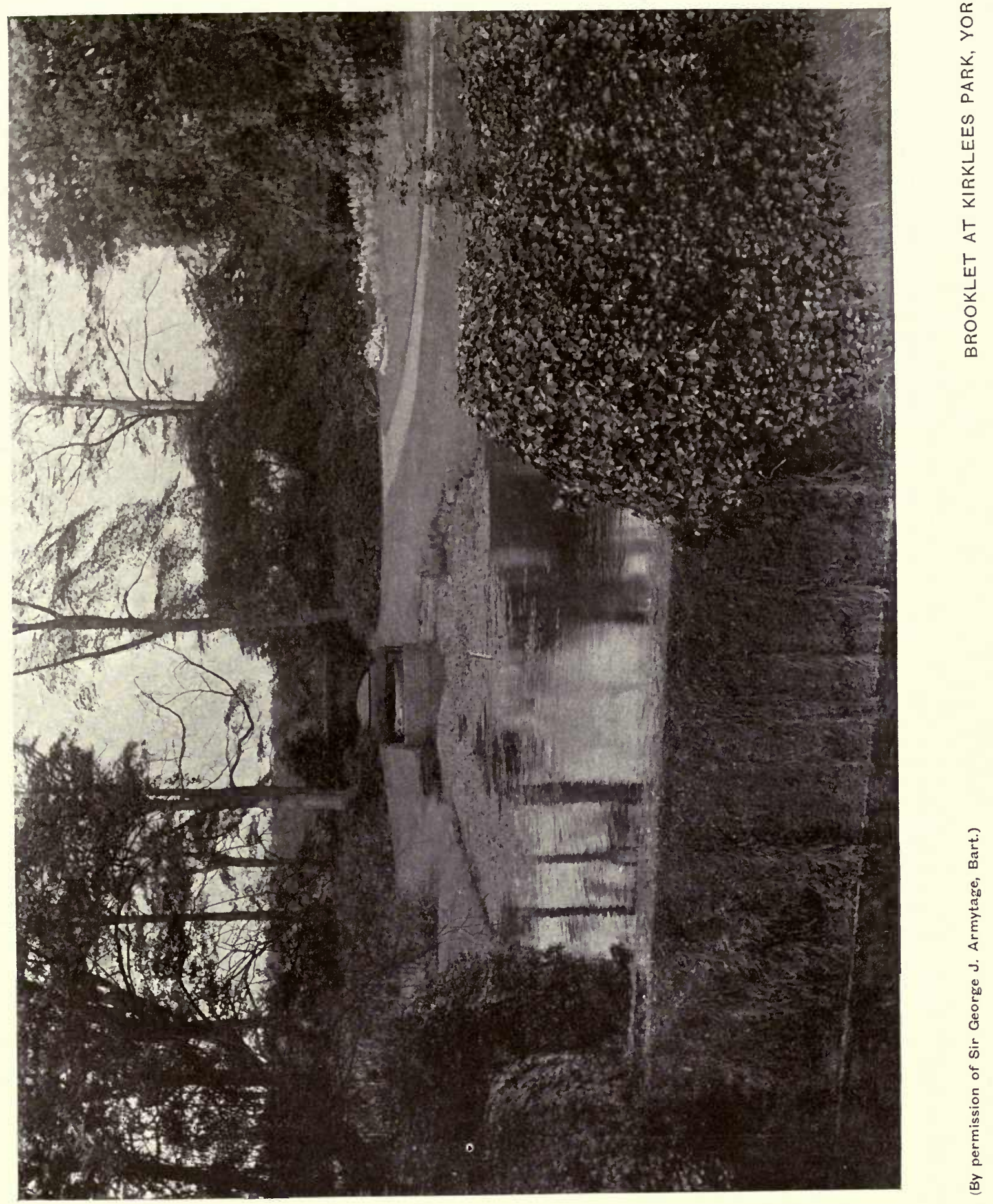




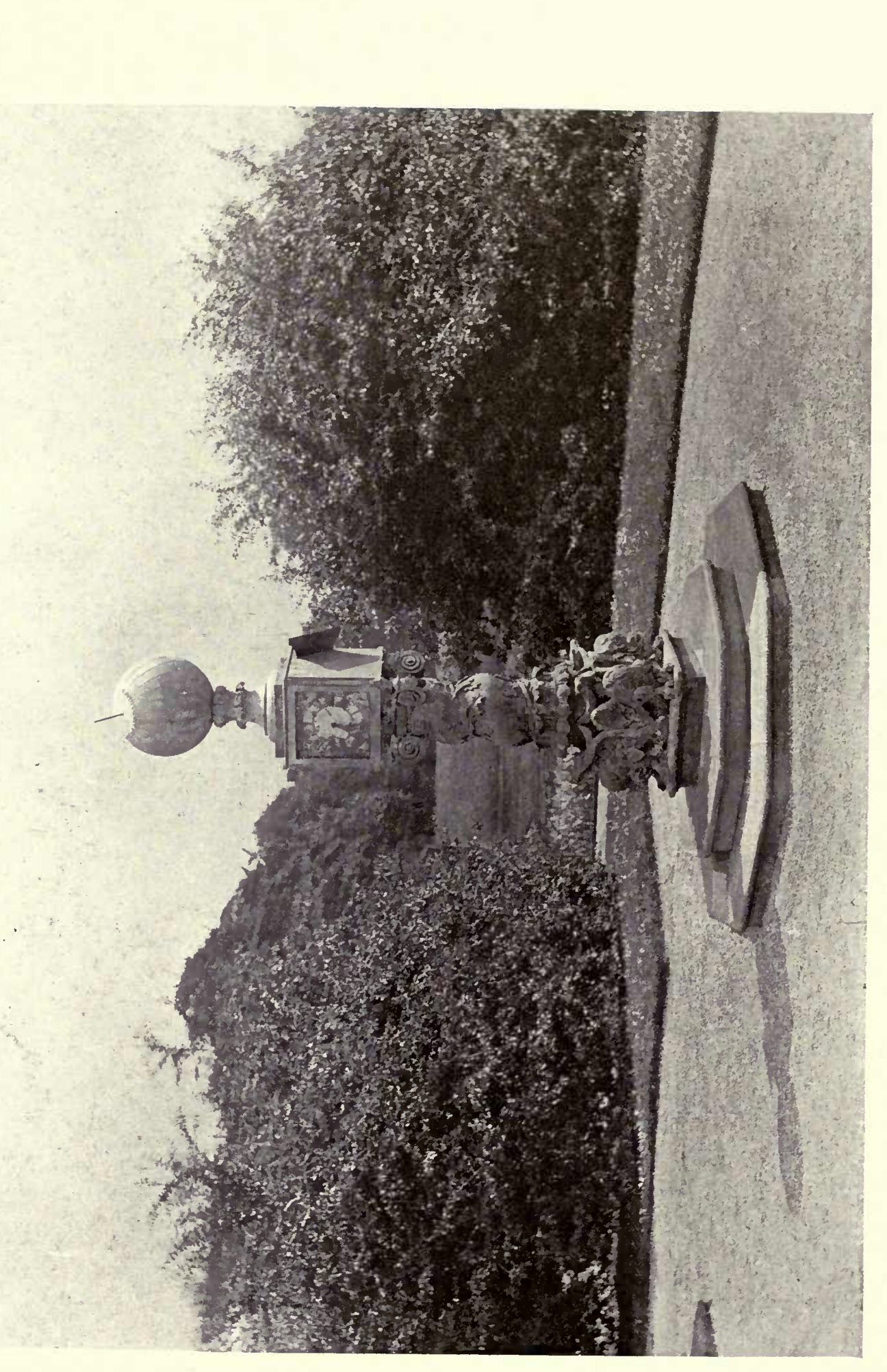

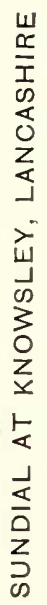




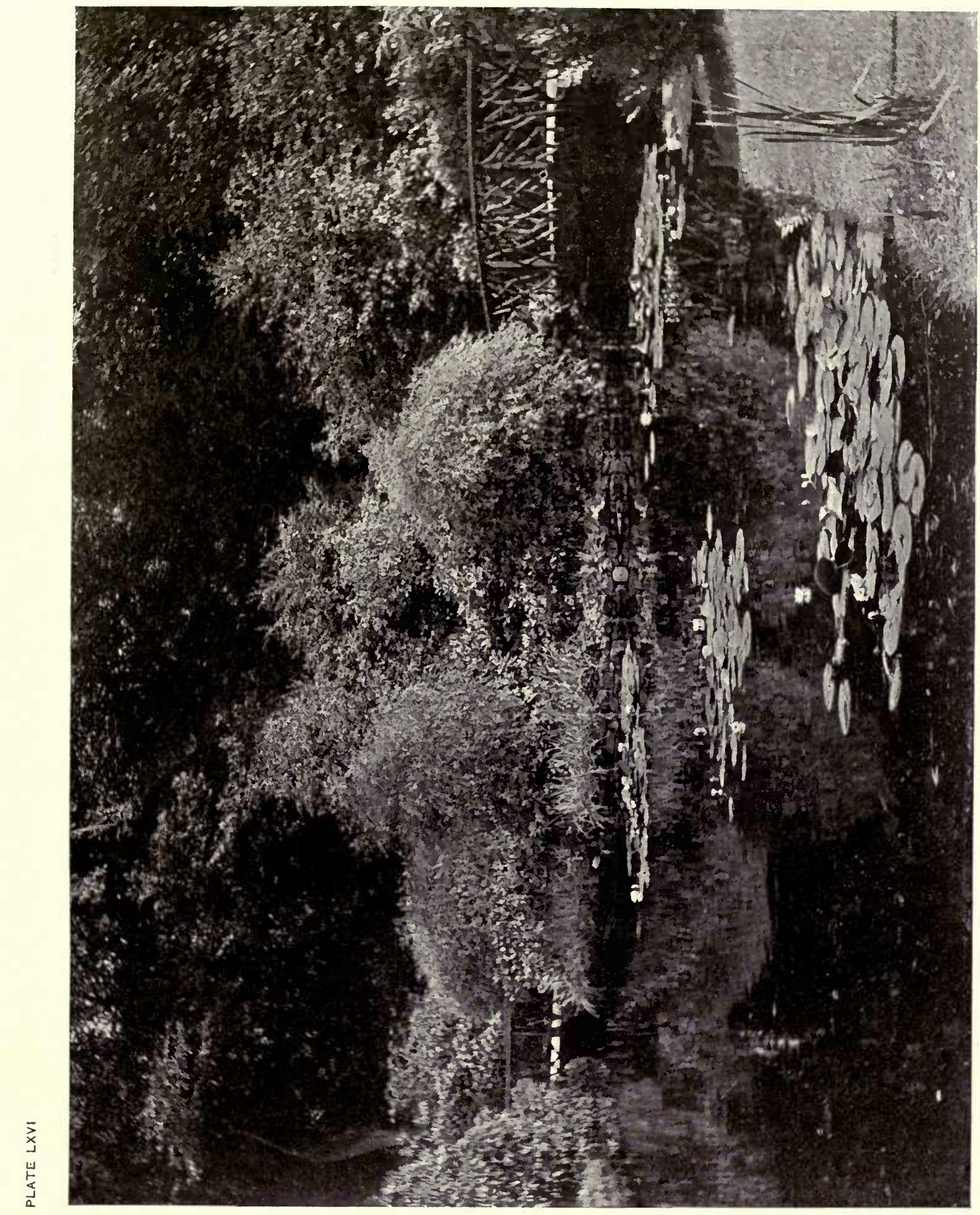

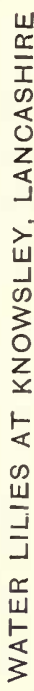

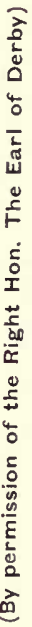




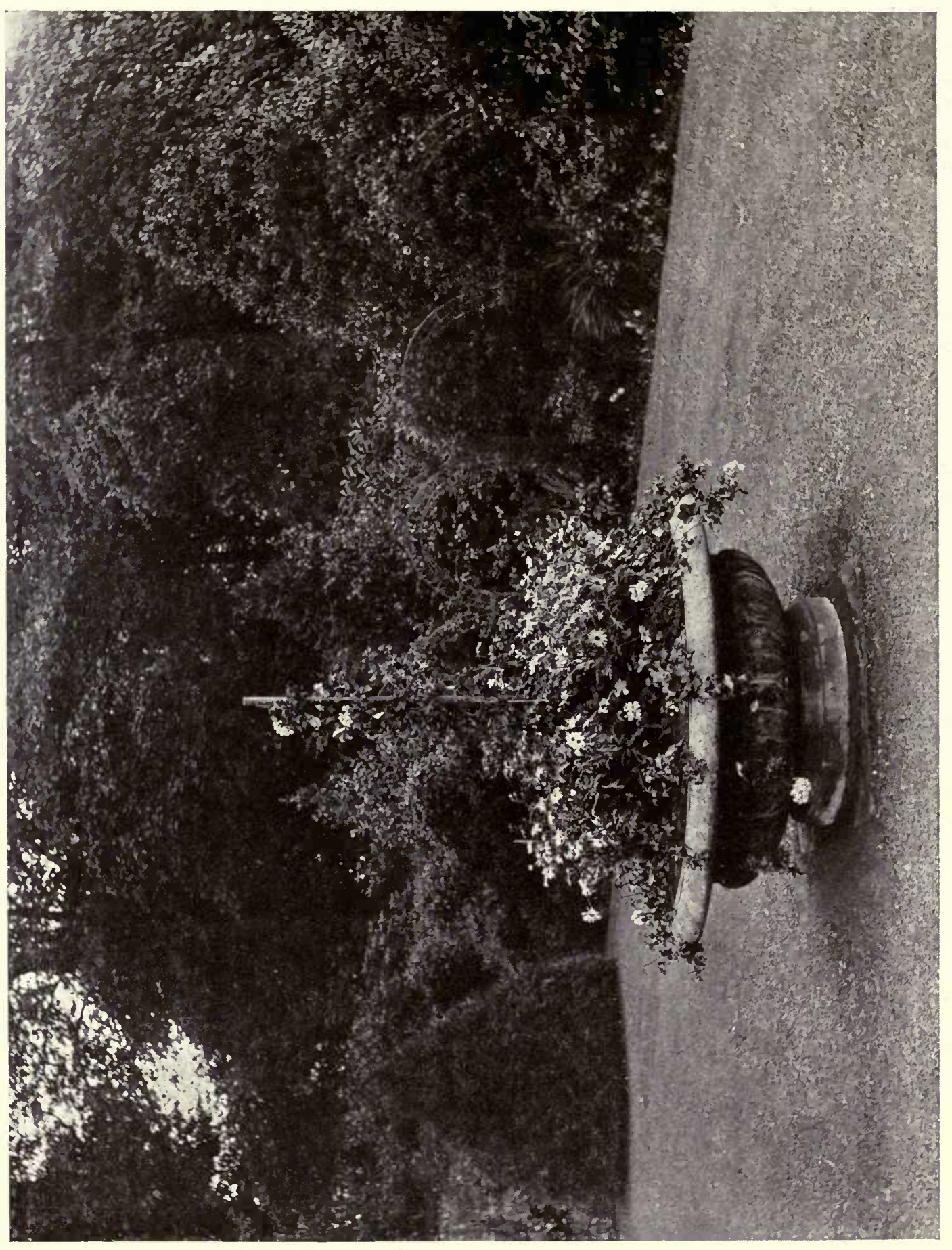

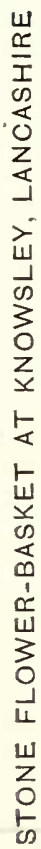




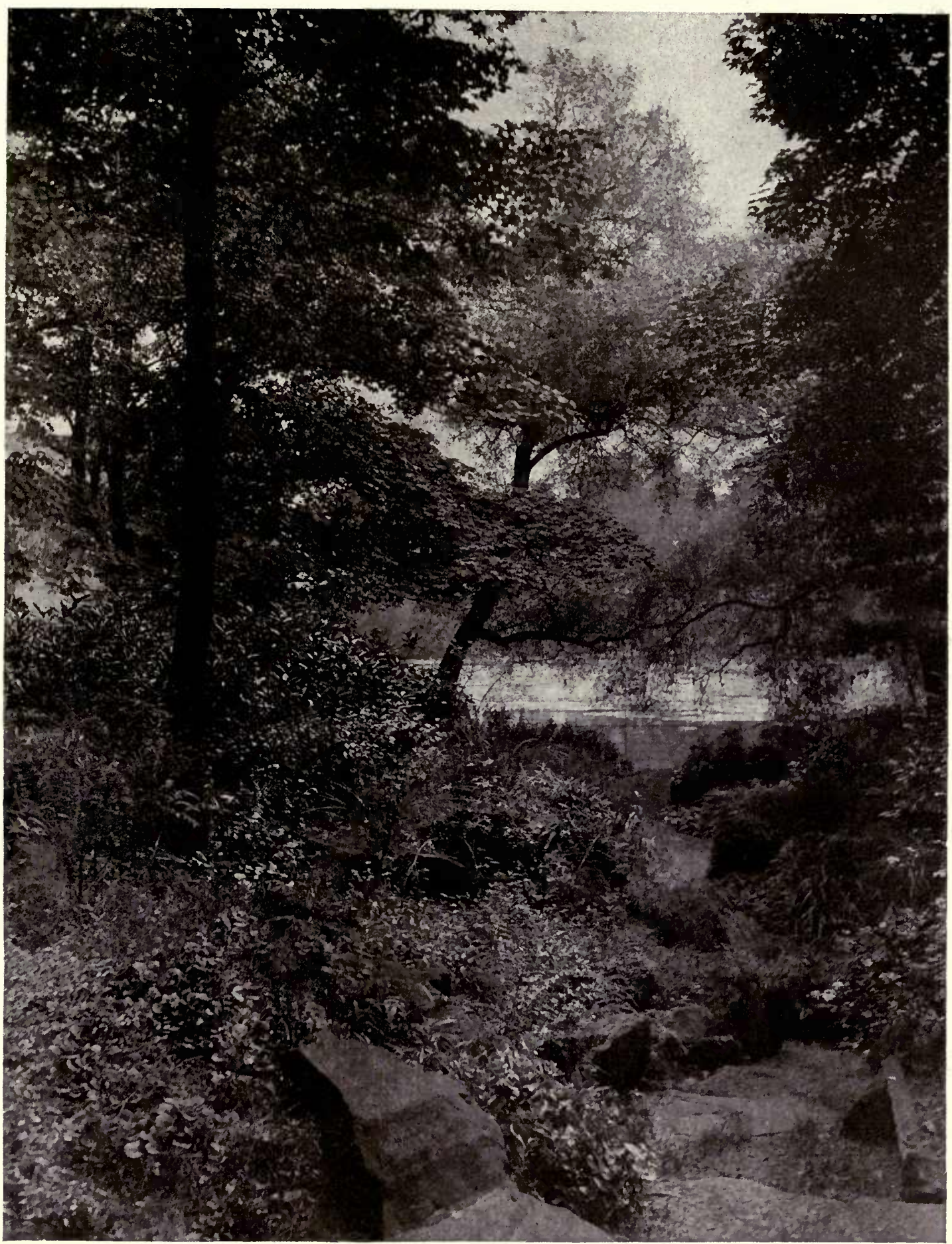




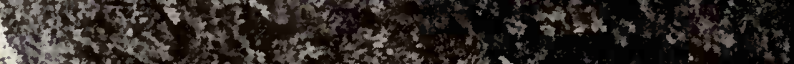

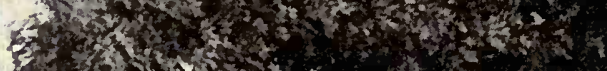

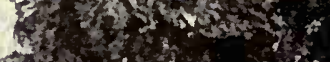

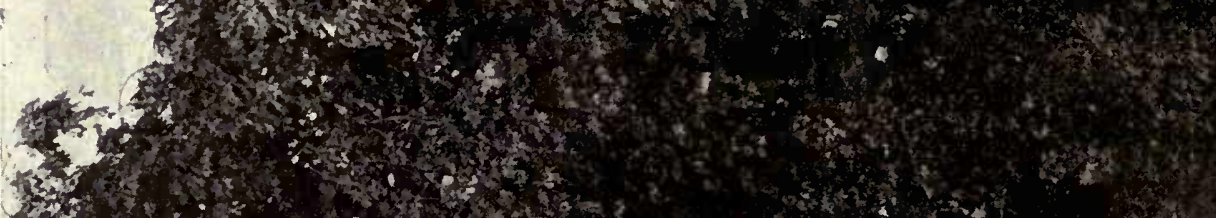

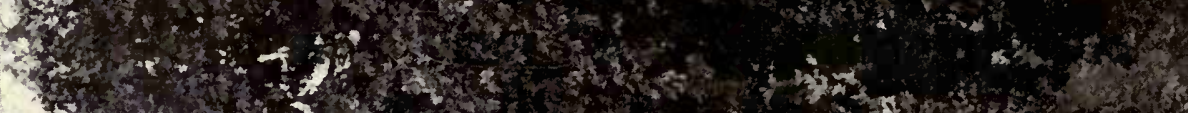

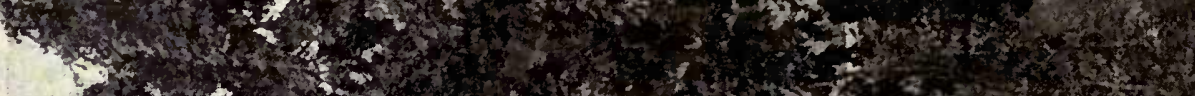

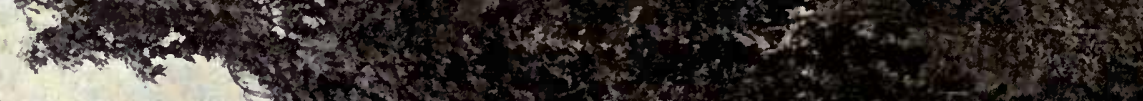

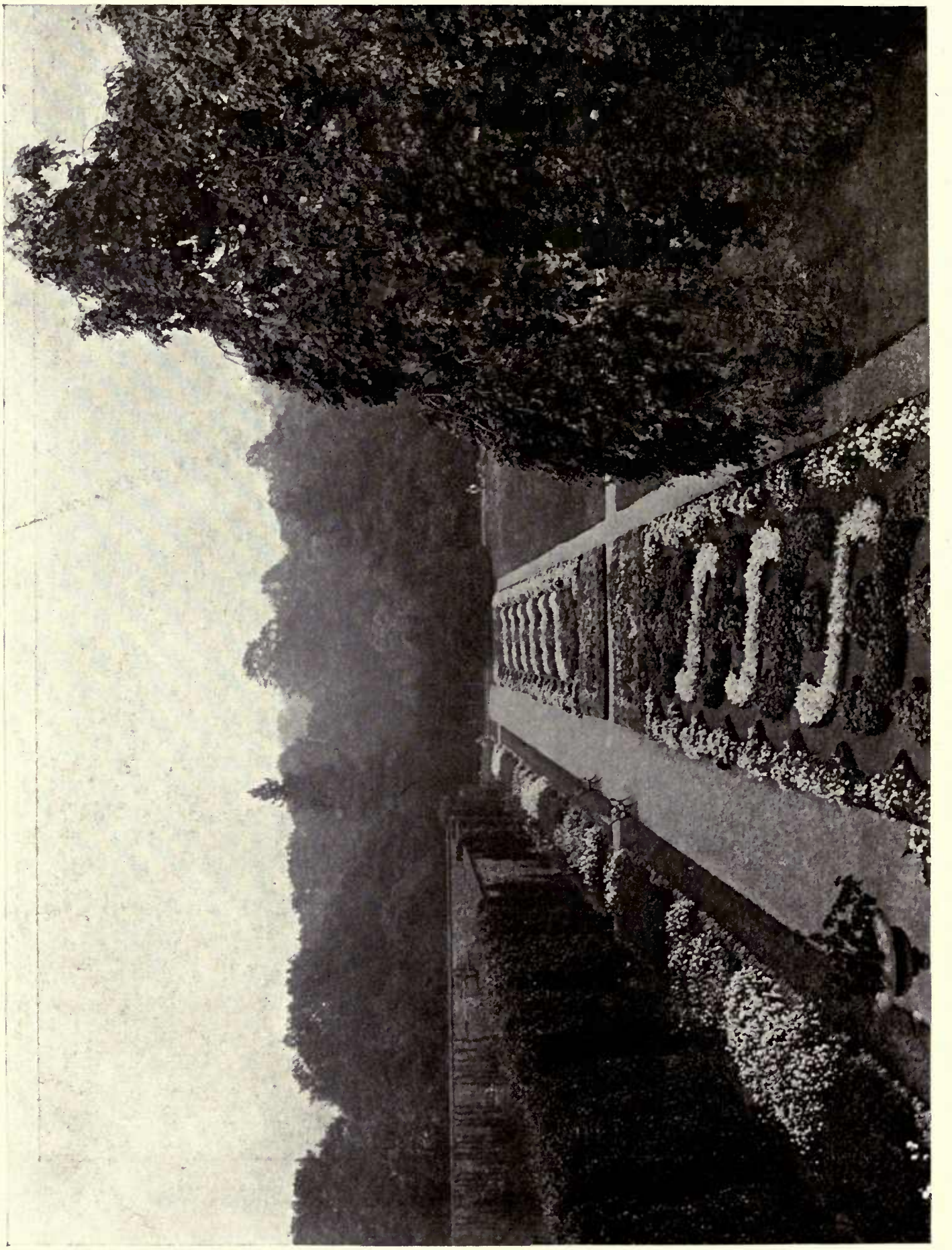

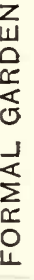

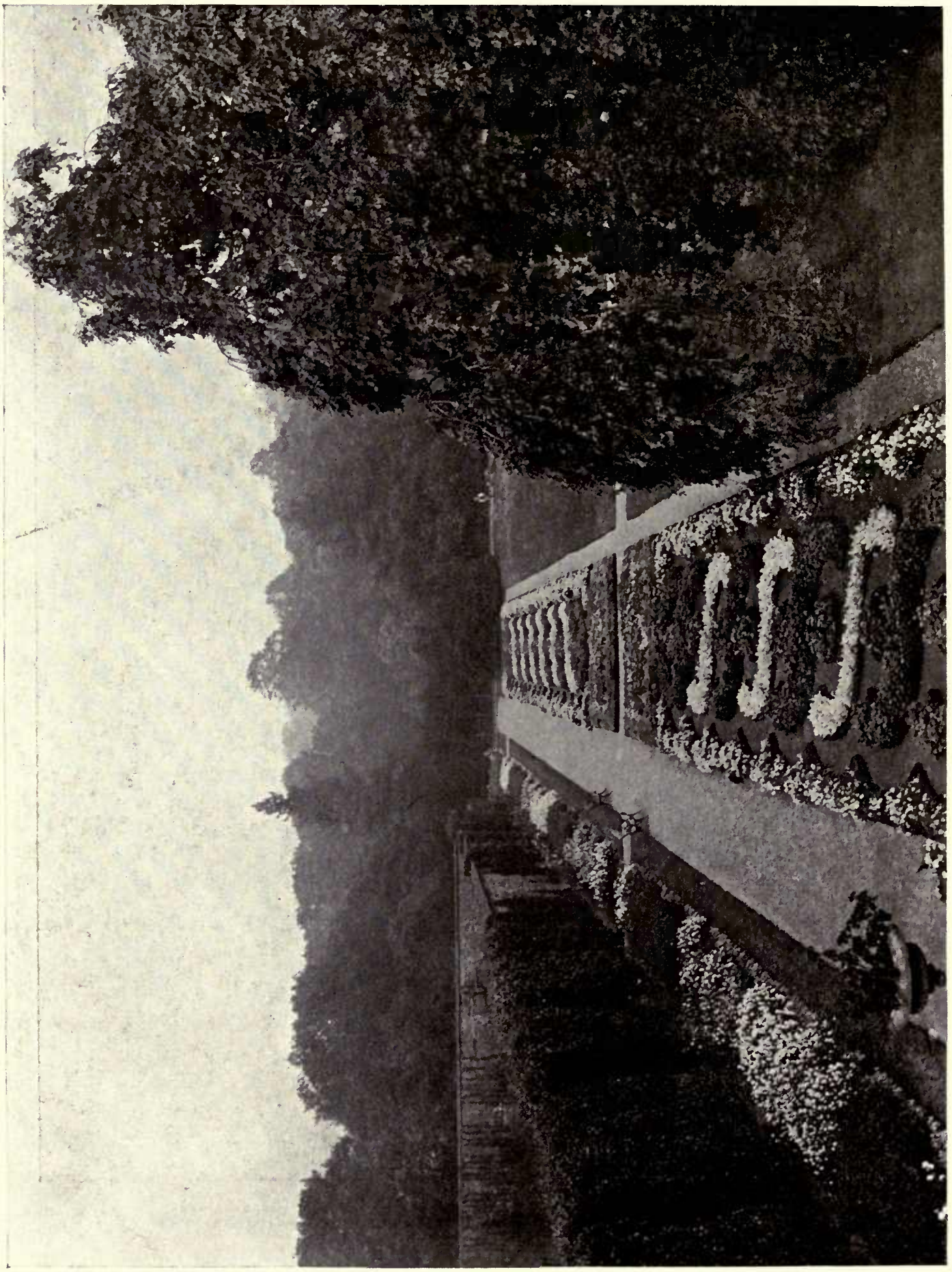
$4 t^{2}, t^{2}$

4 ,

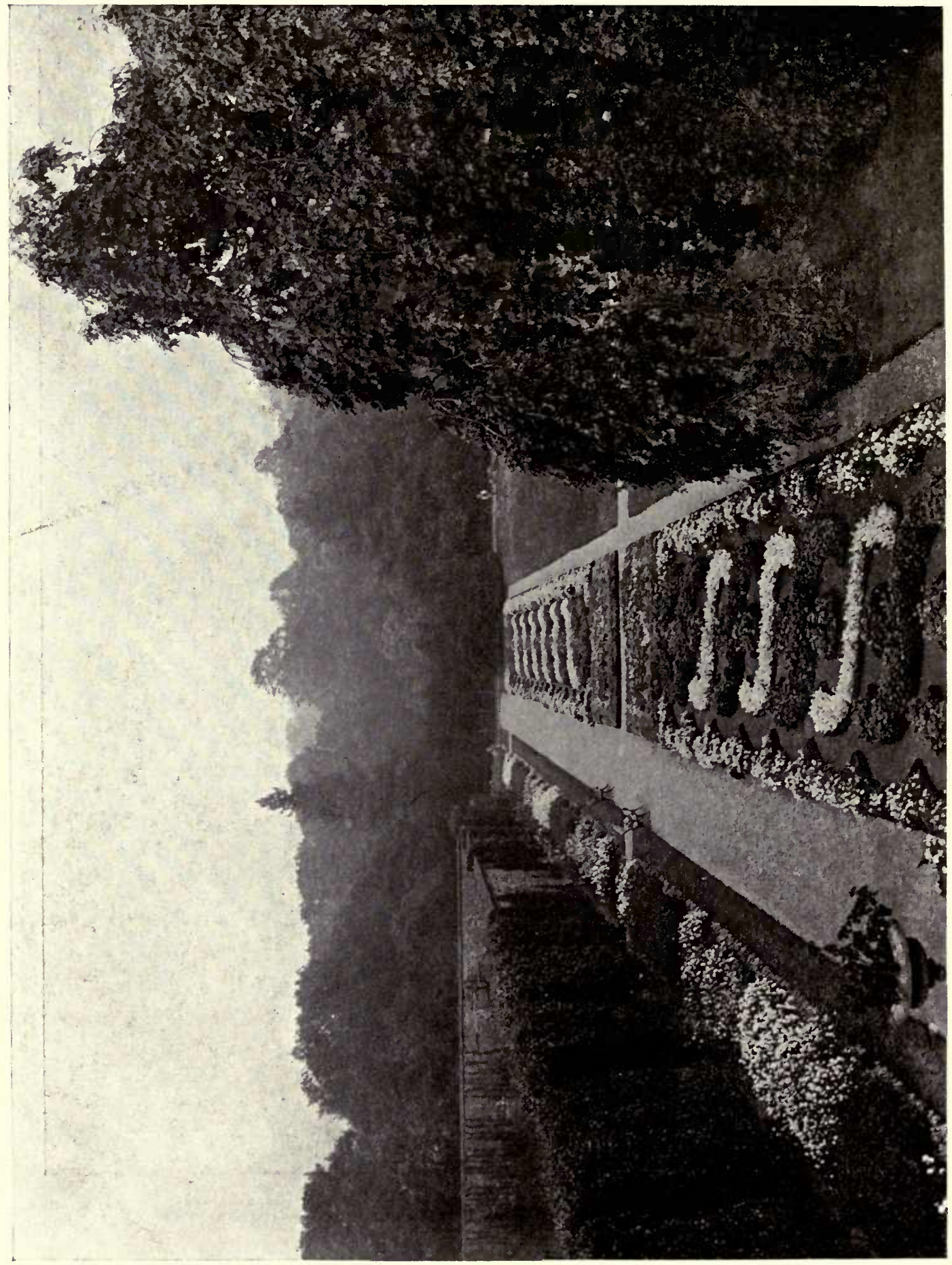

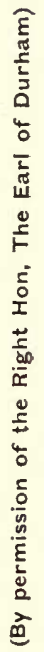




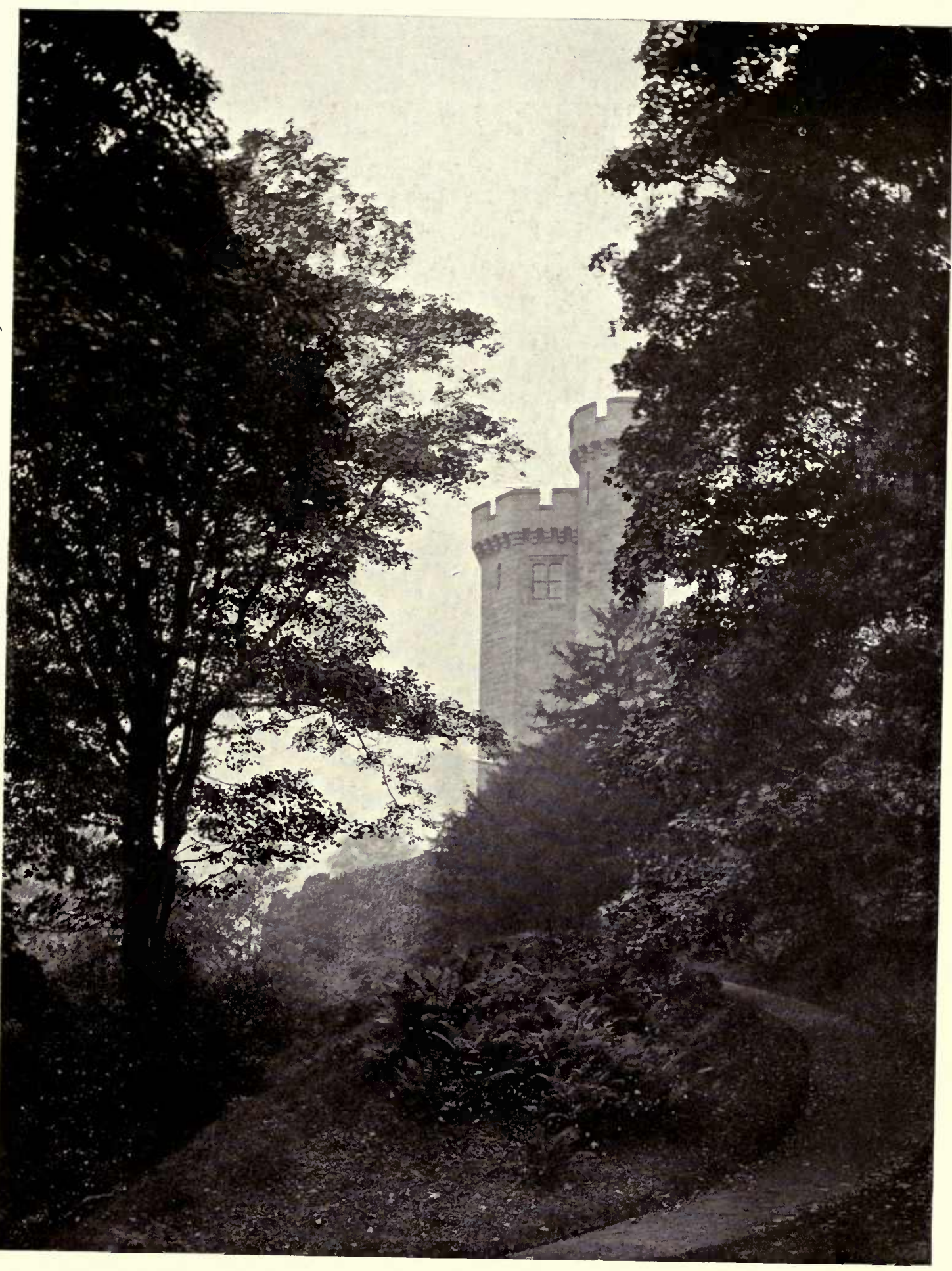




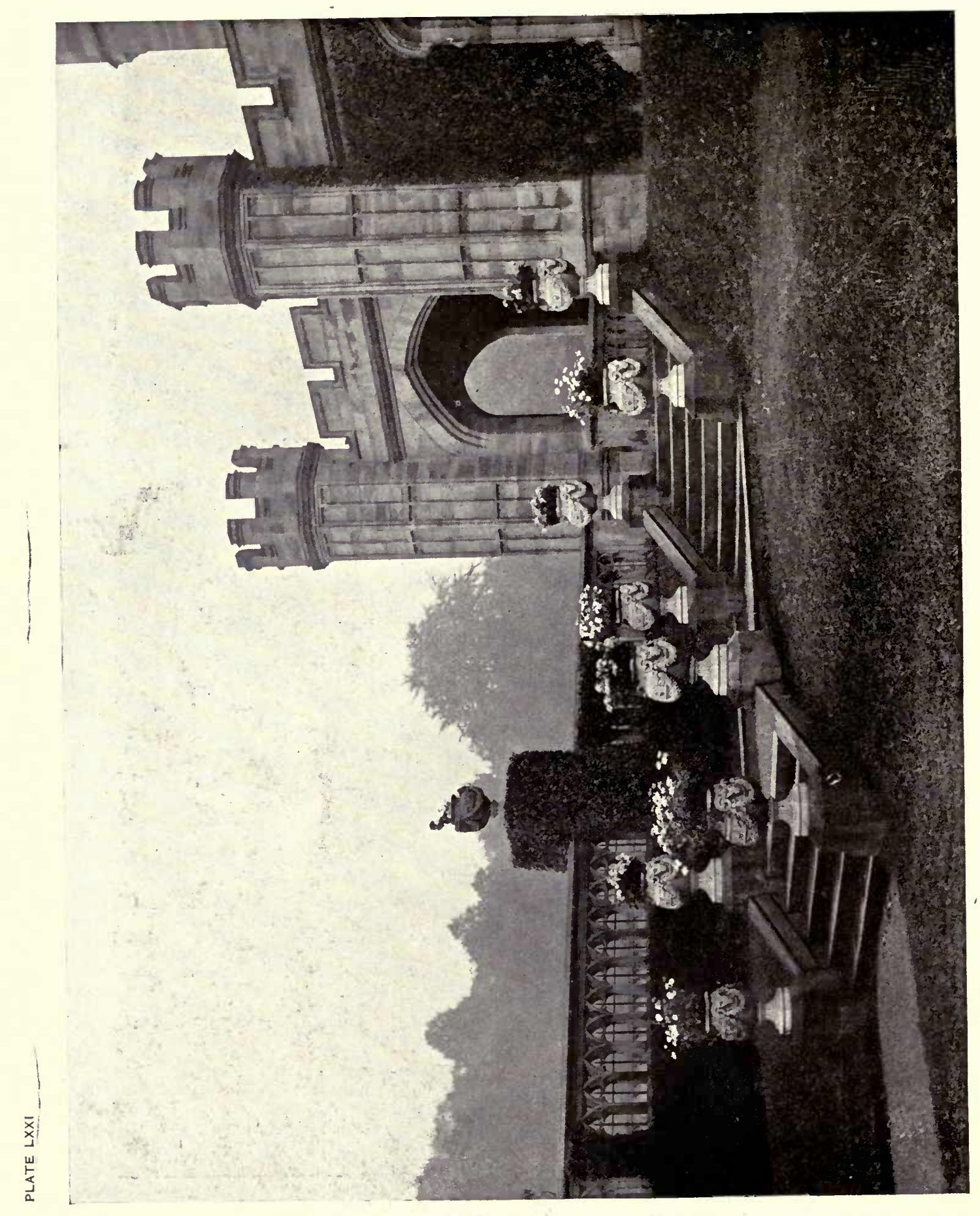

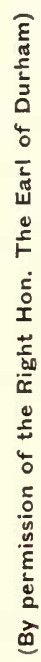




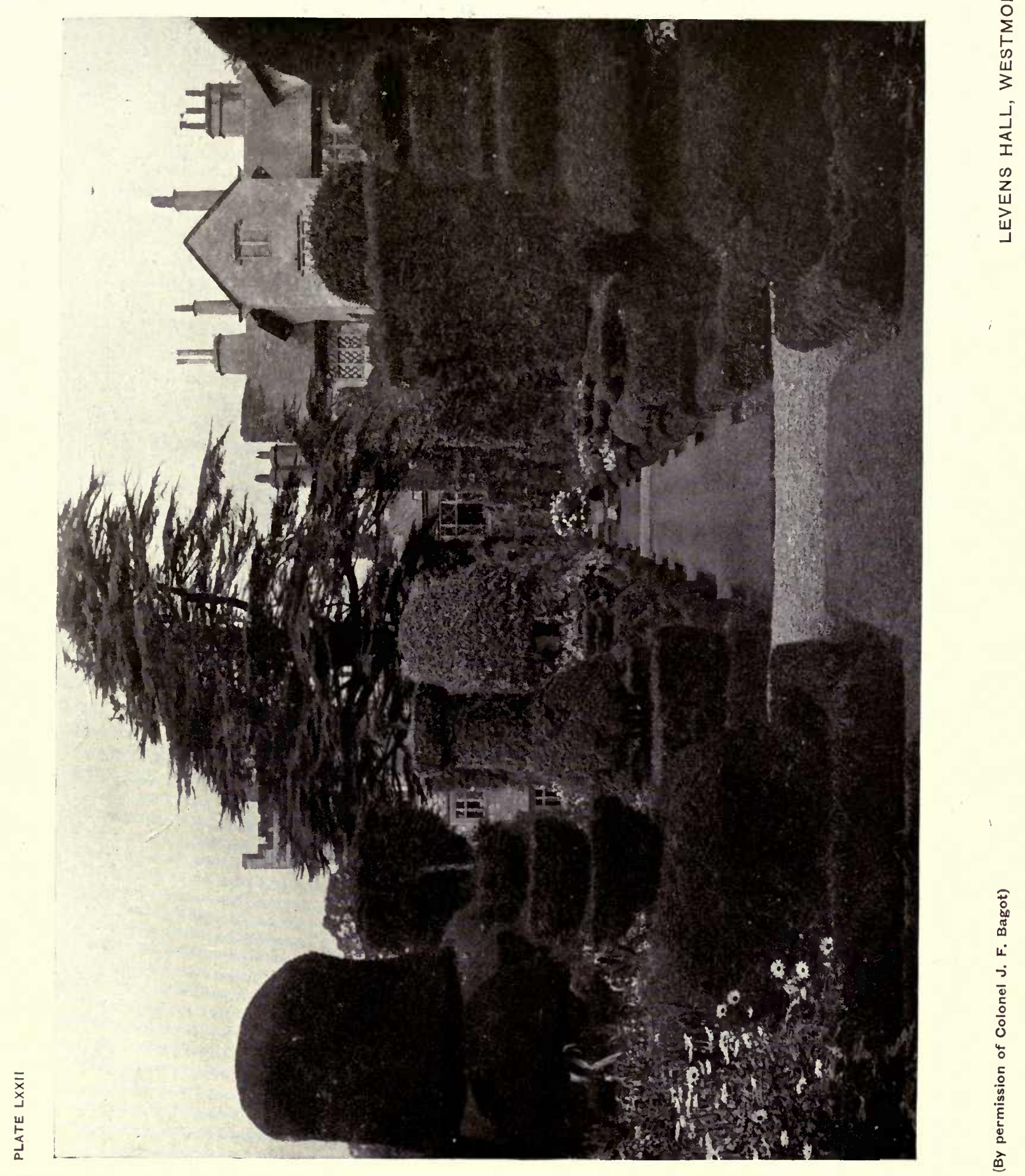




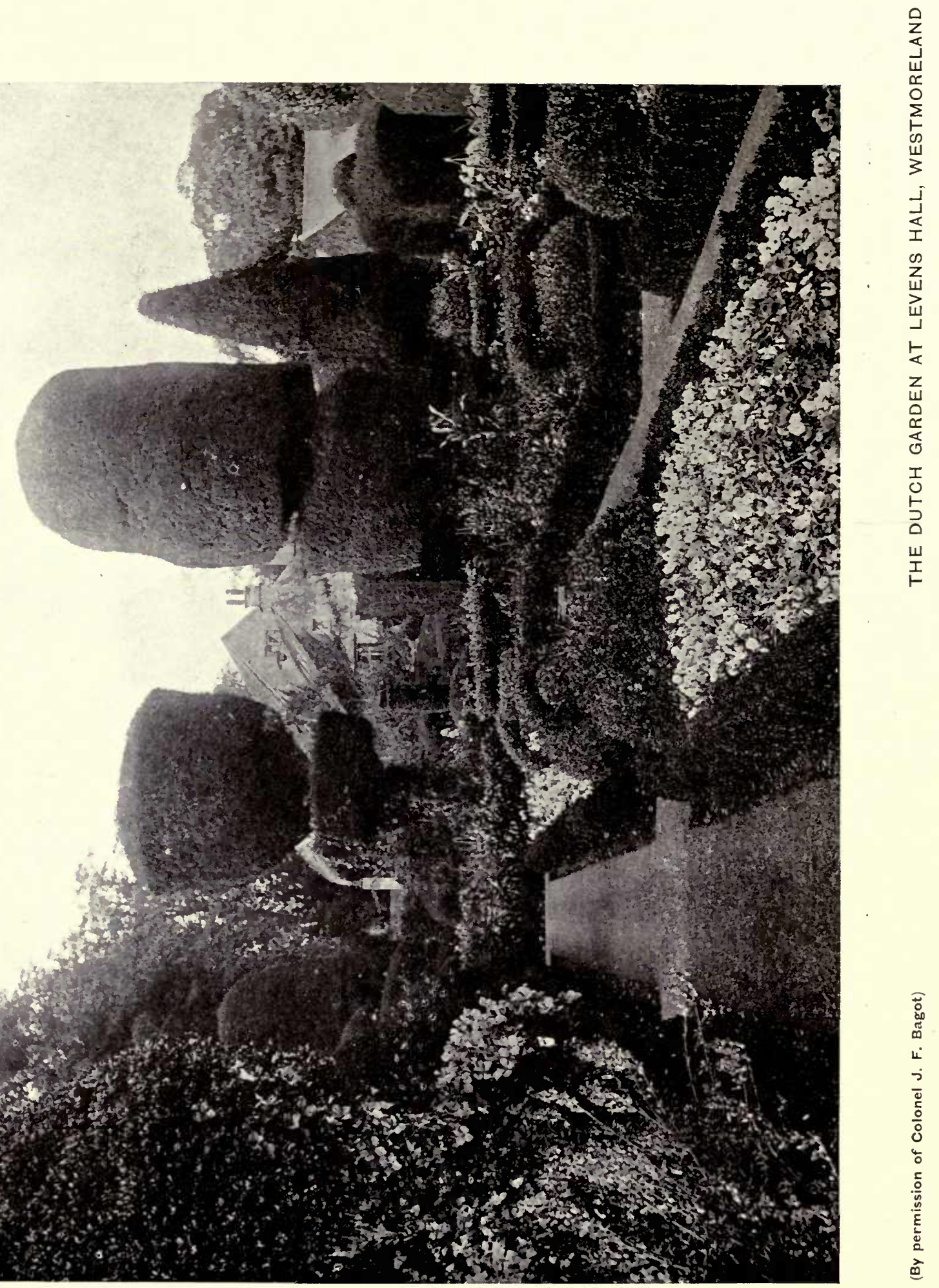




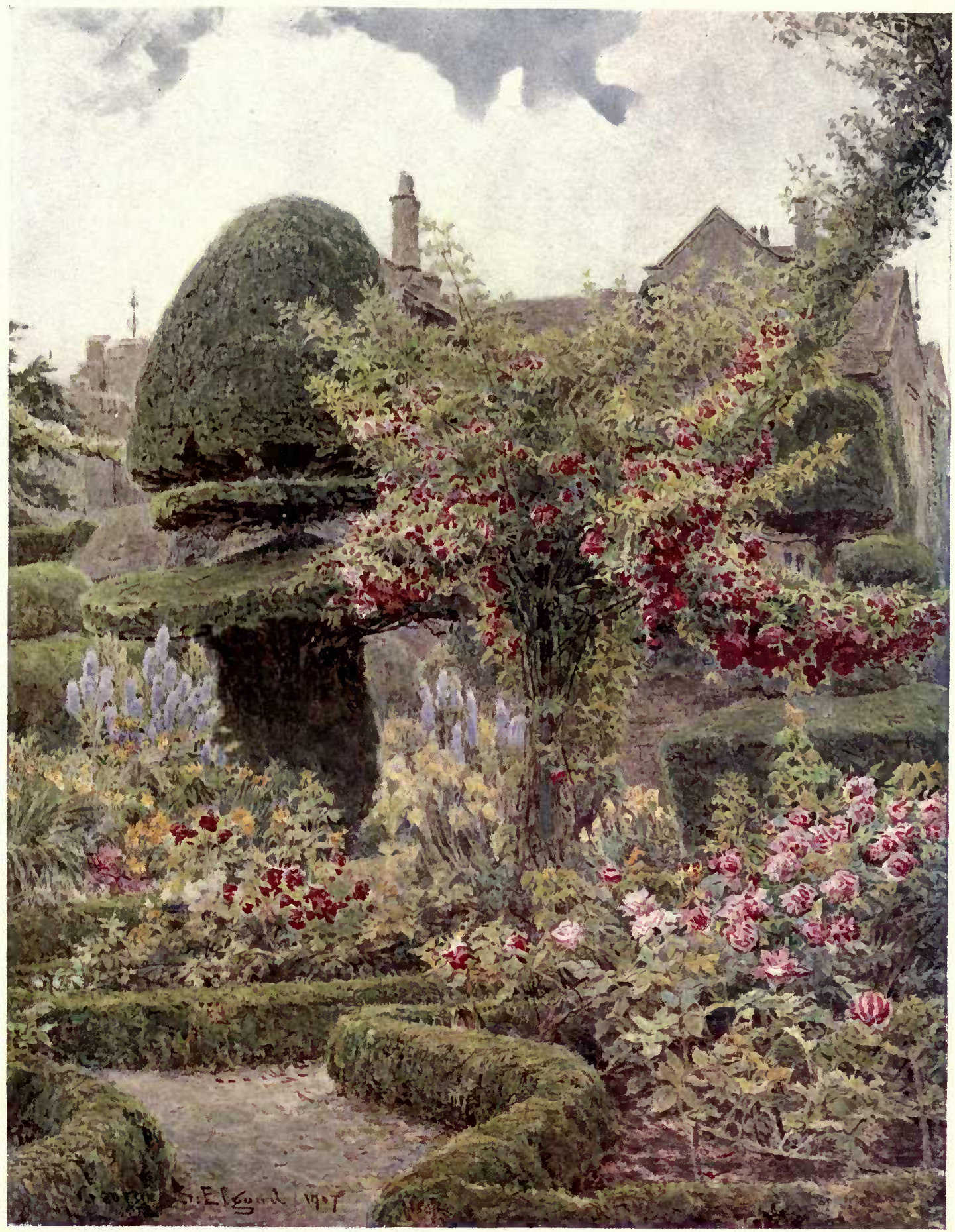




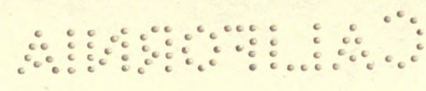




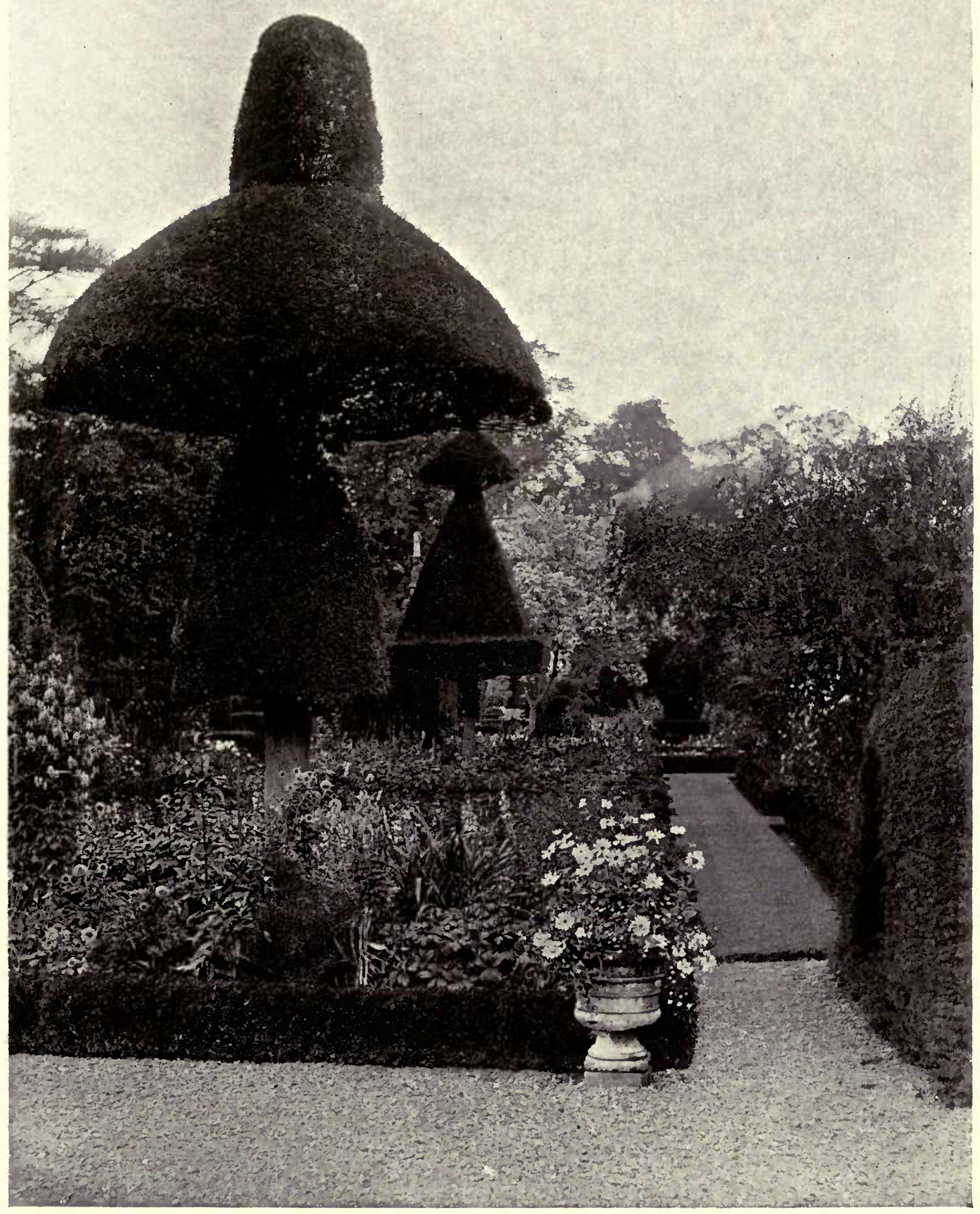




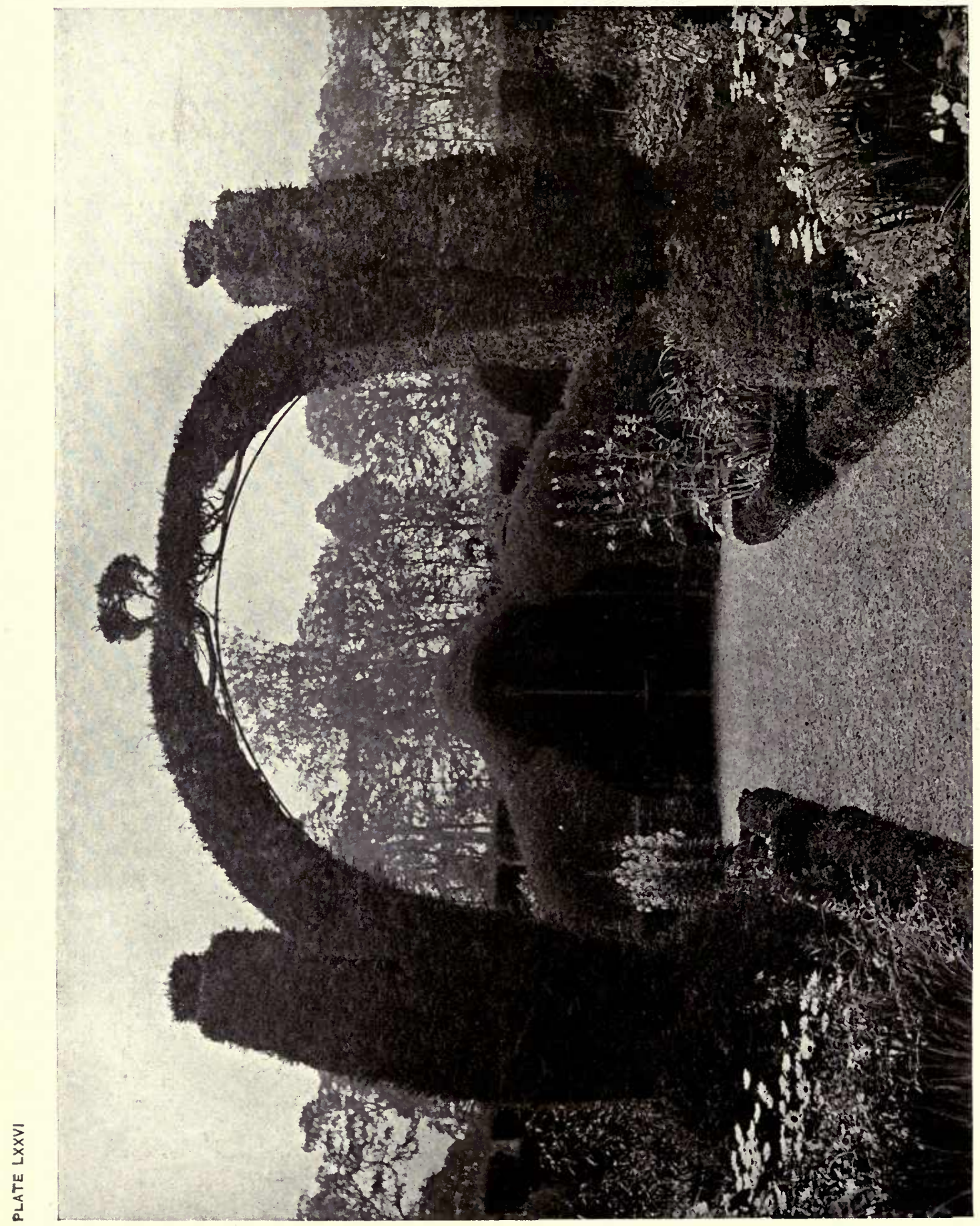

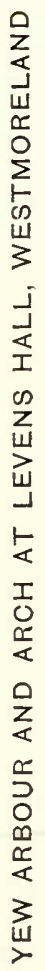

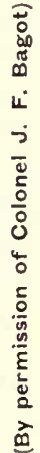




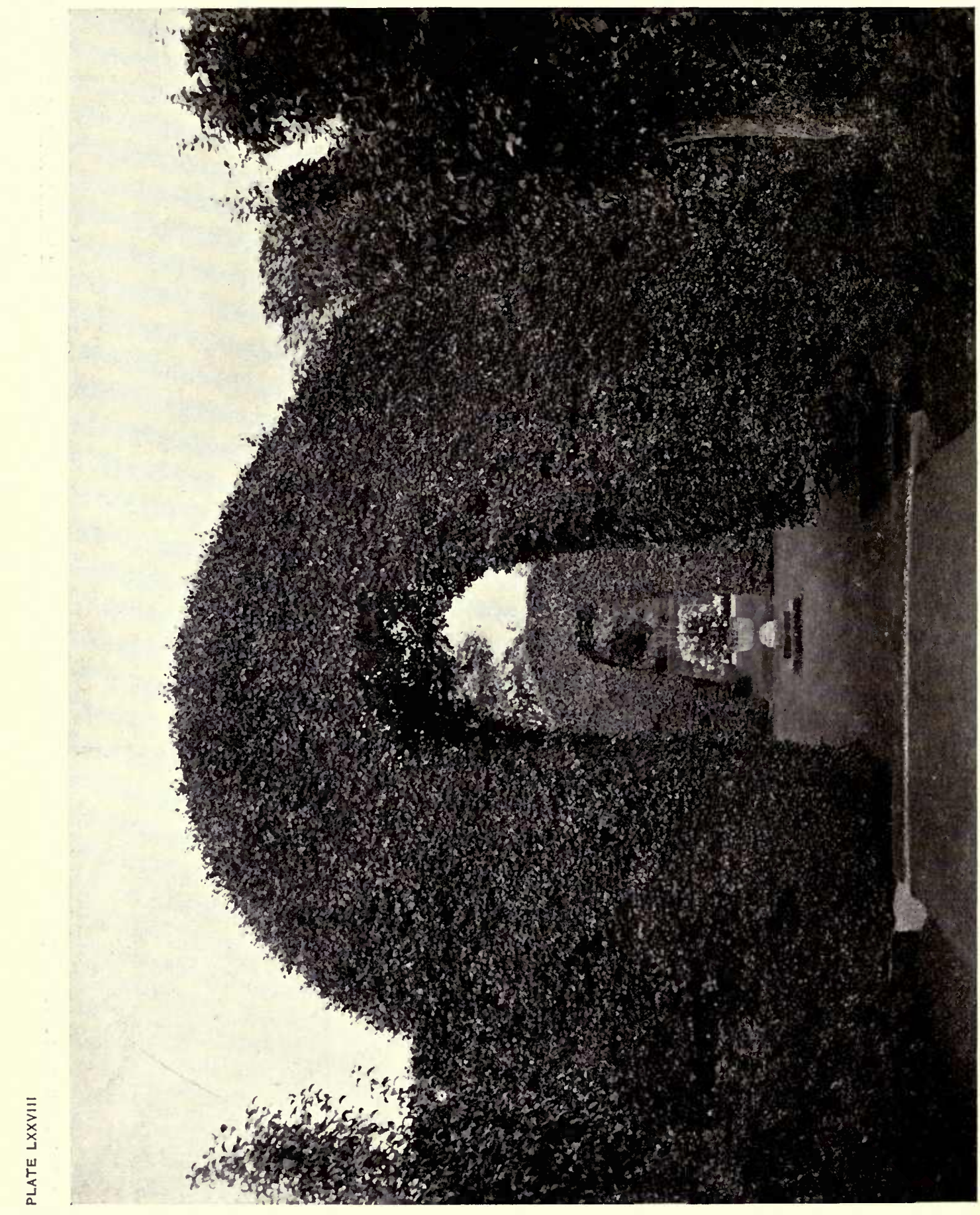




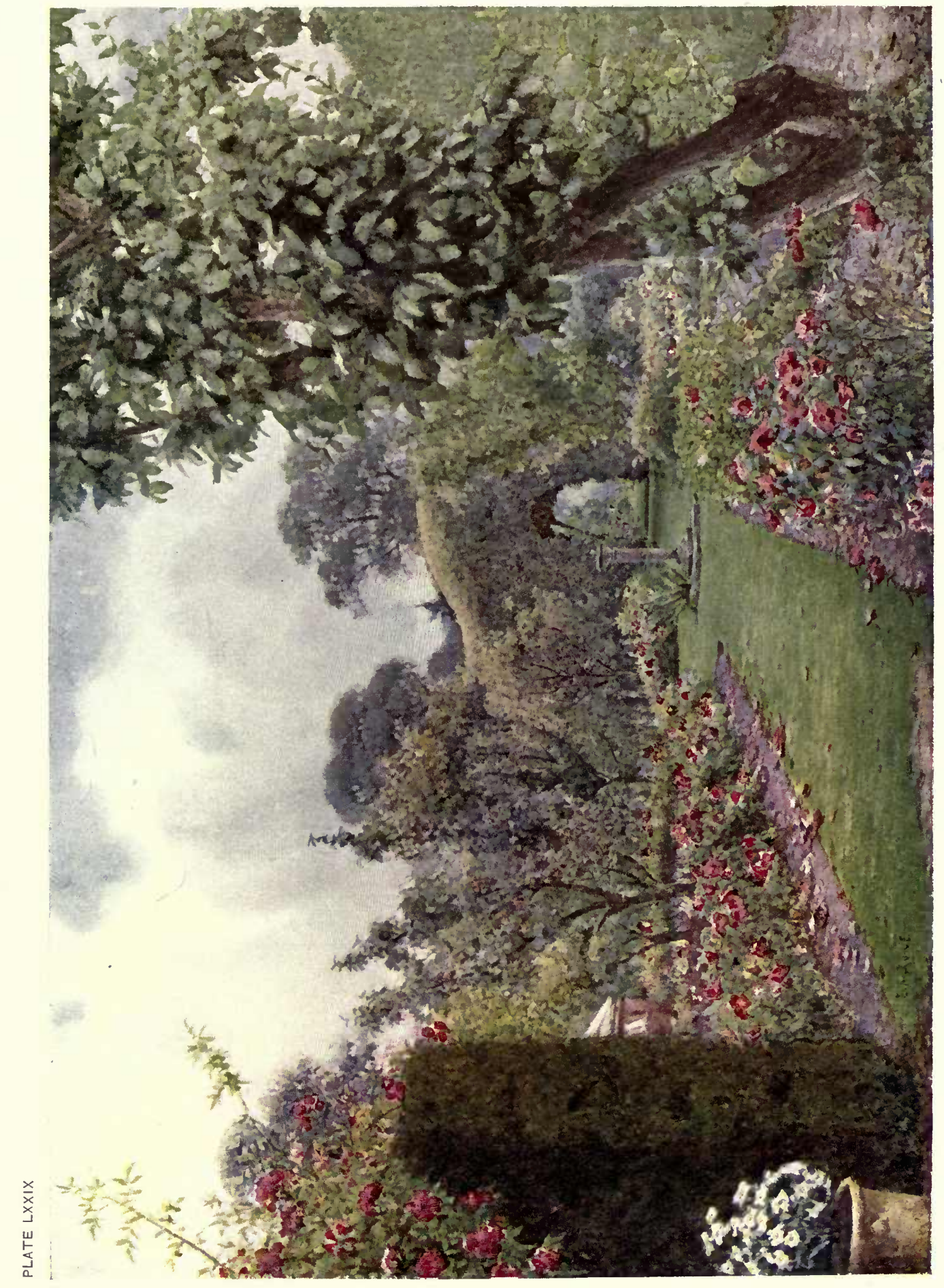





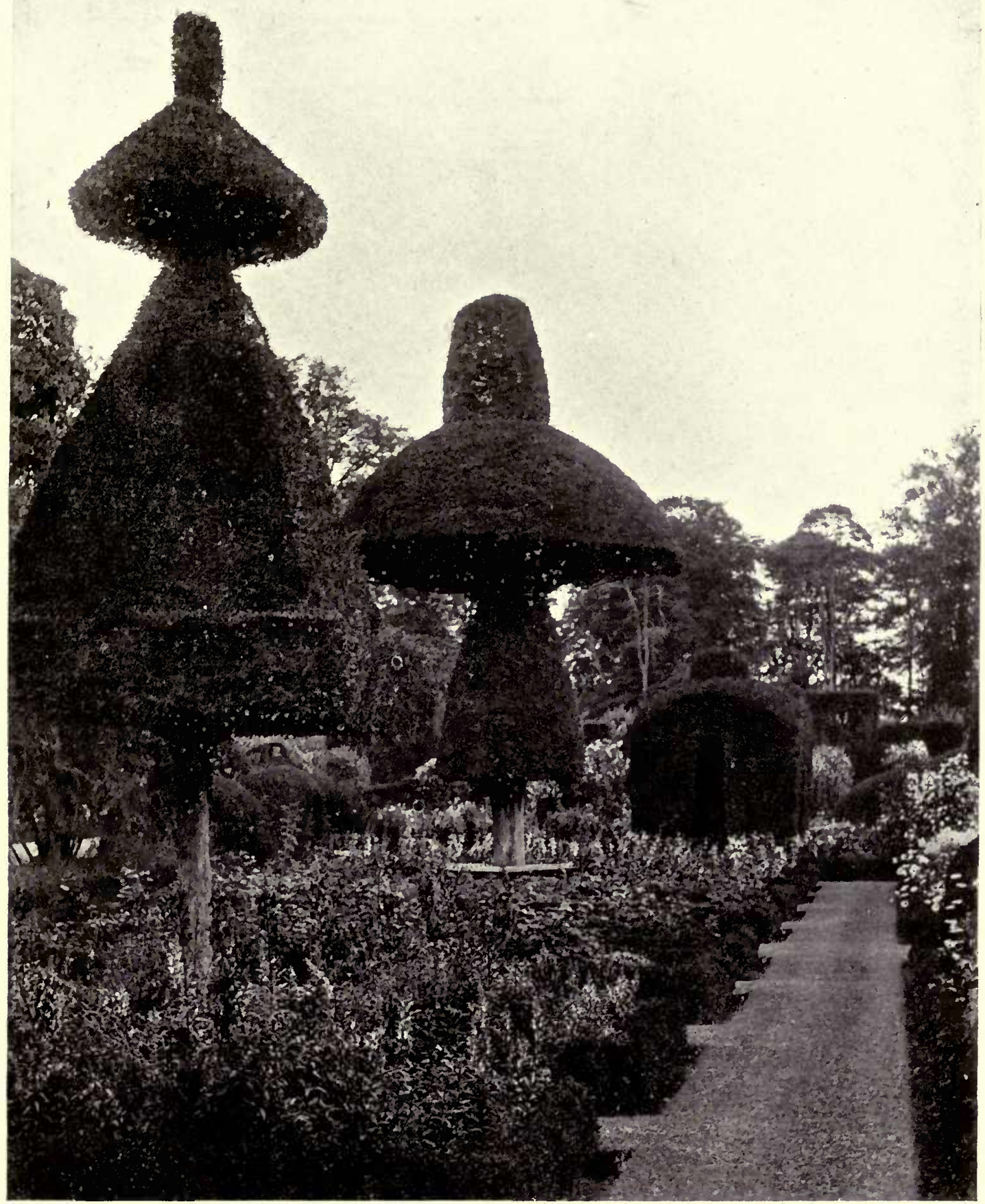




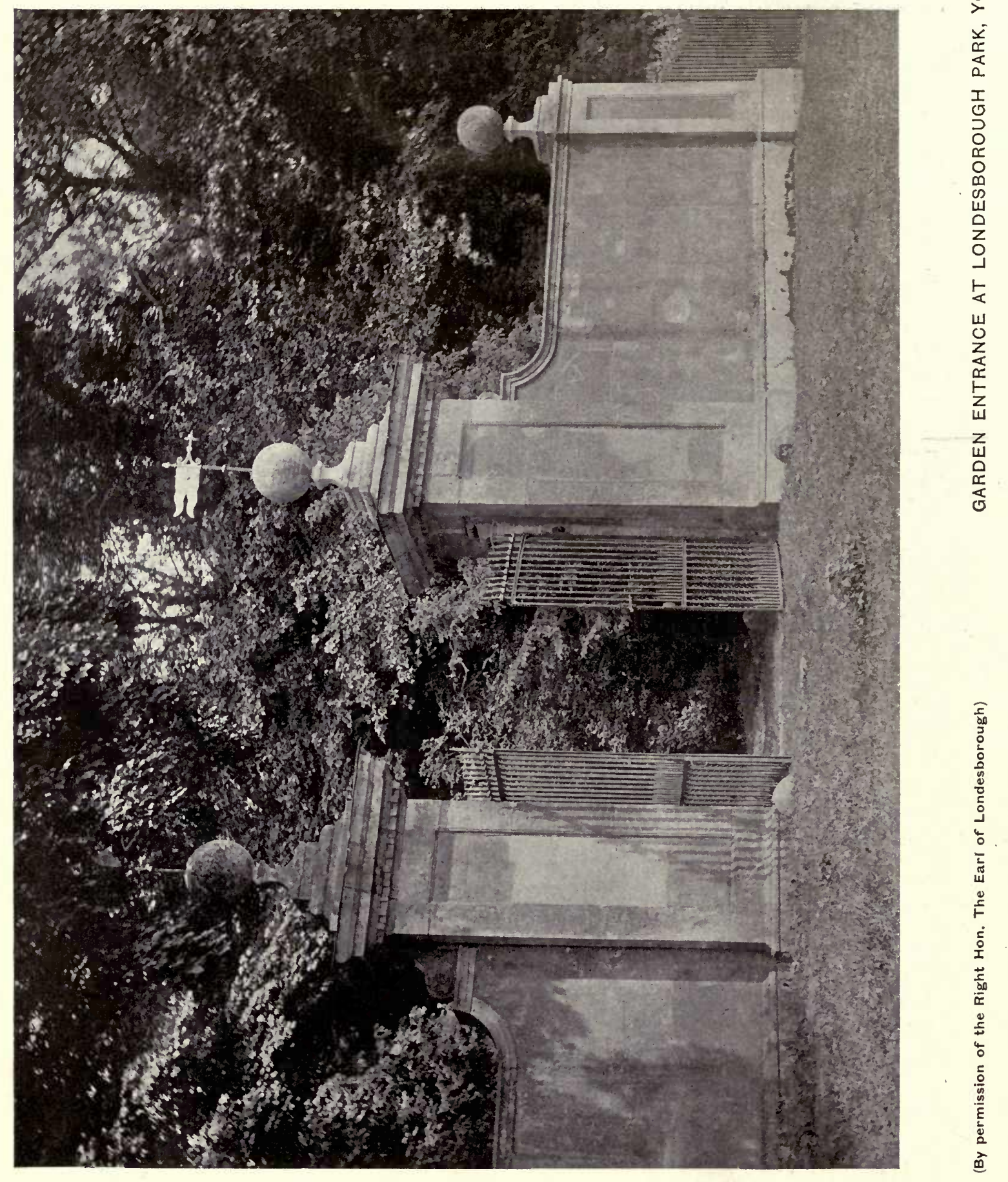




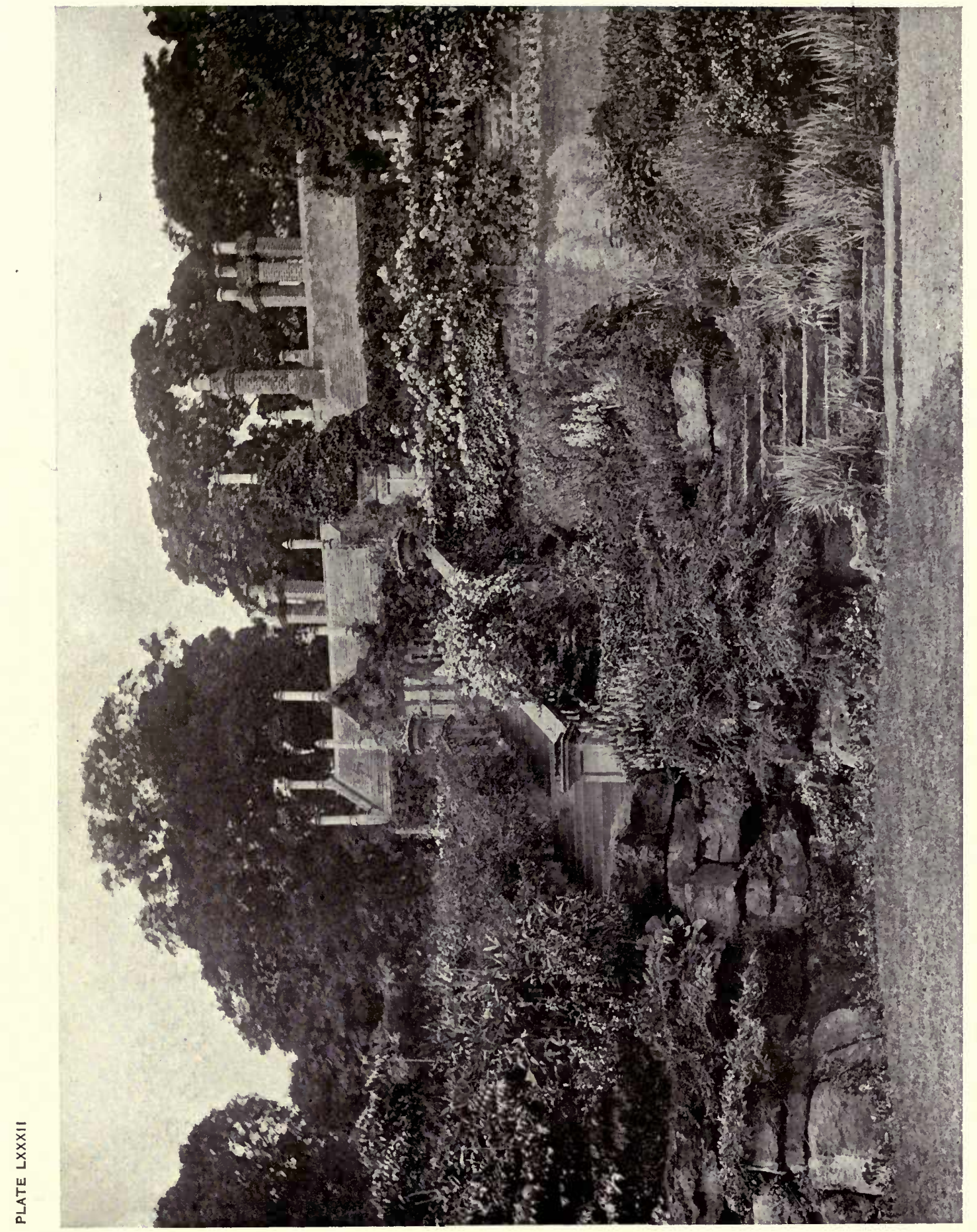

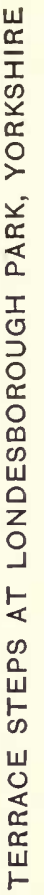

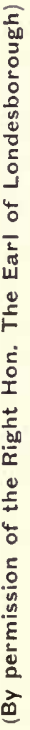




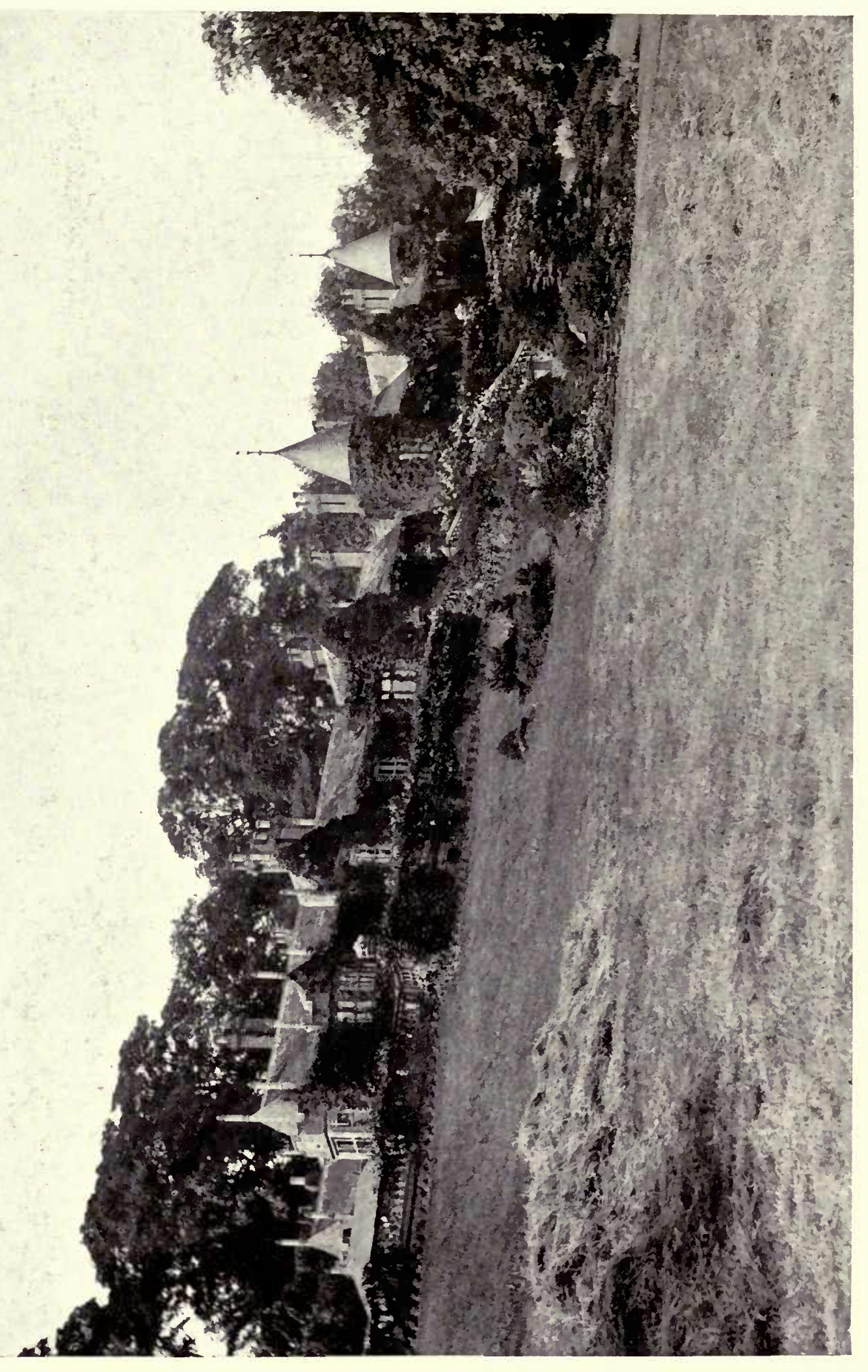

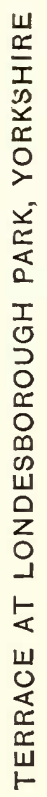




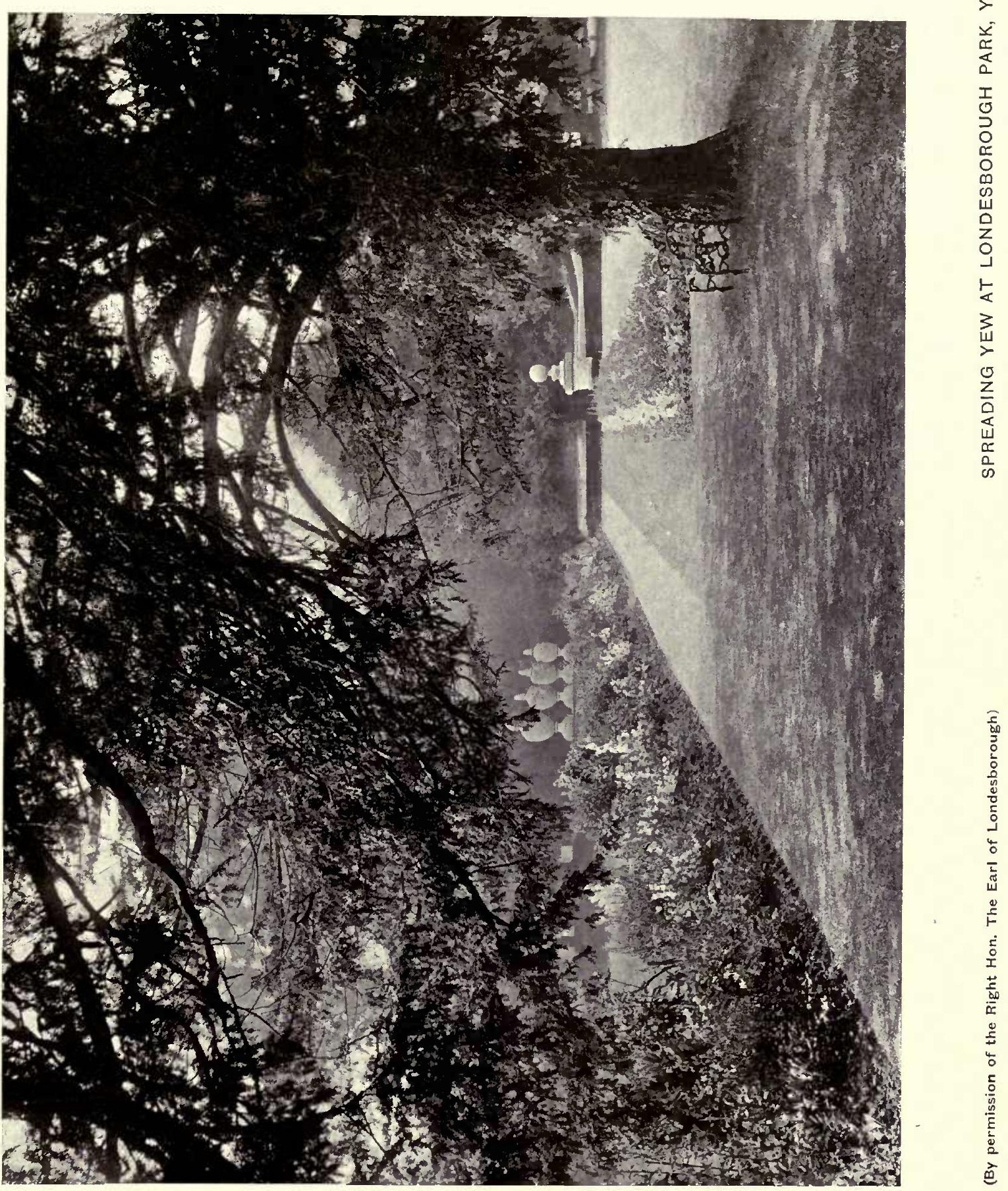




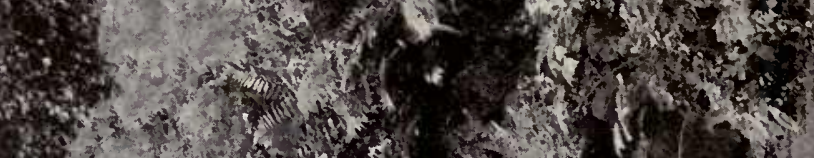

$$
\text { (3) }
$$

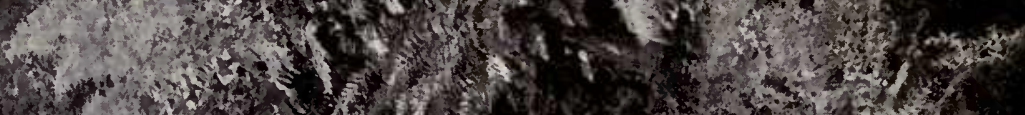

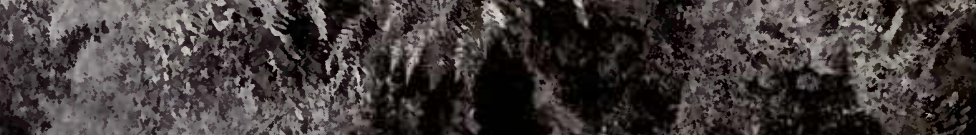

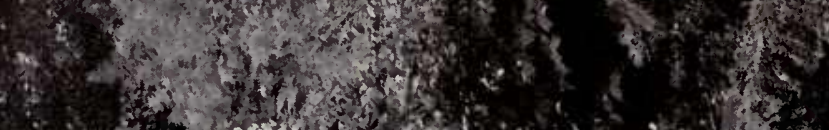

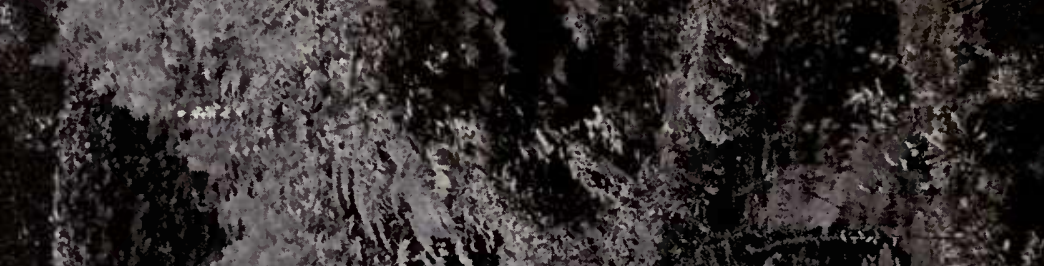

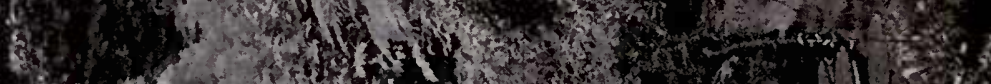
Q.

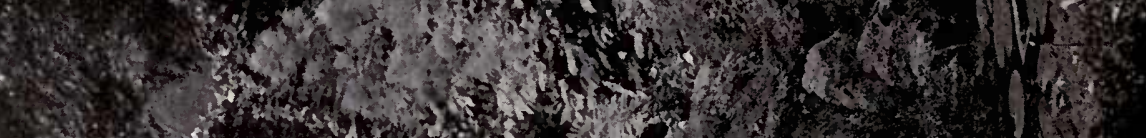

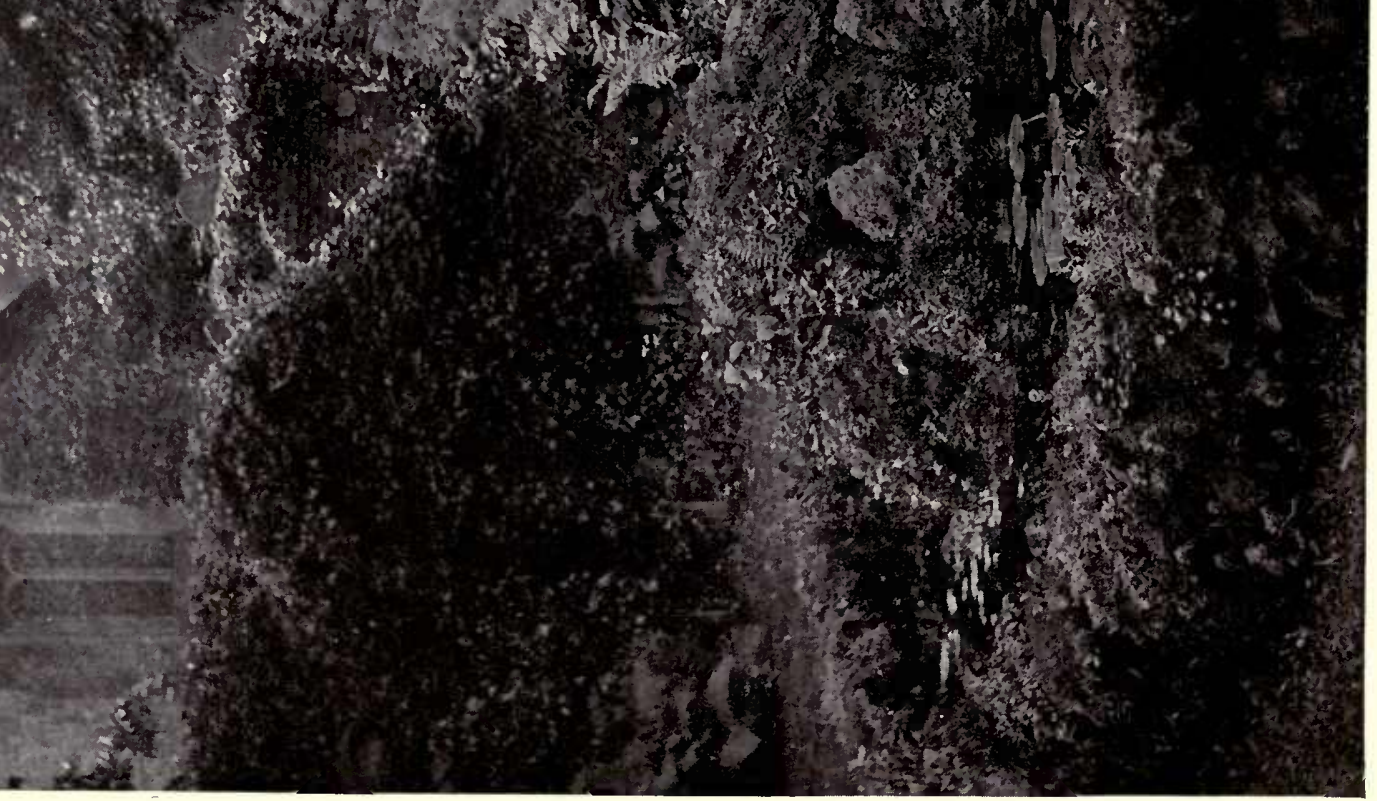




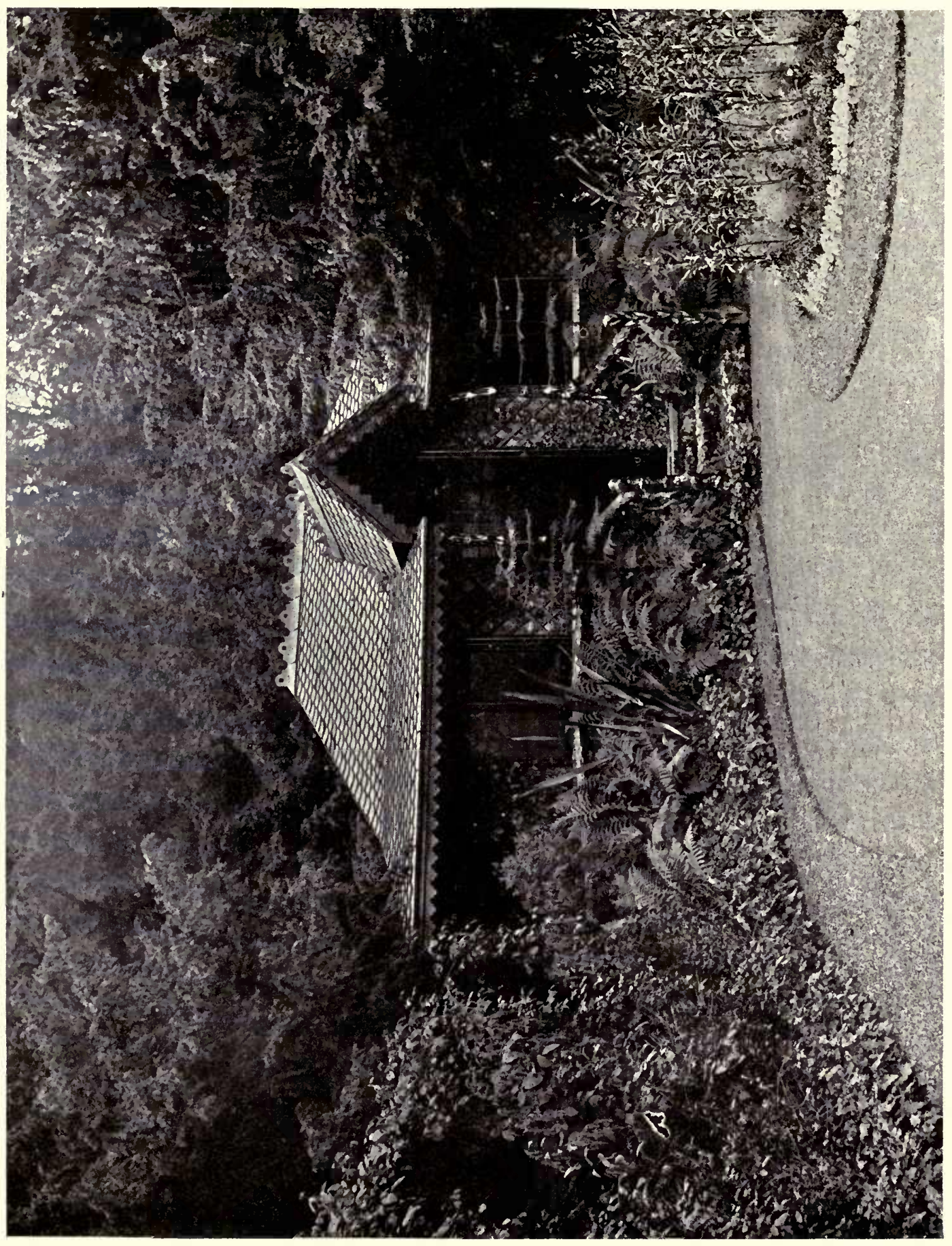




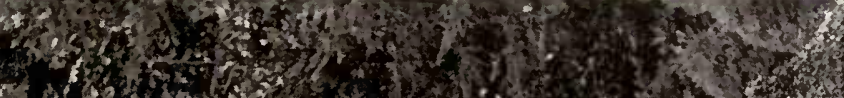

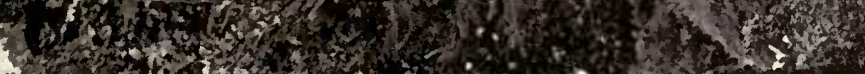

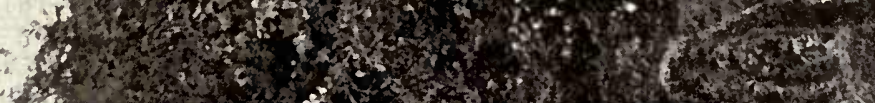
isto $+3$ Hent $-x^{2}$ $4+3 x^{2}+5$

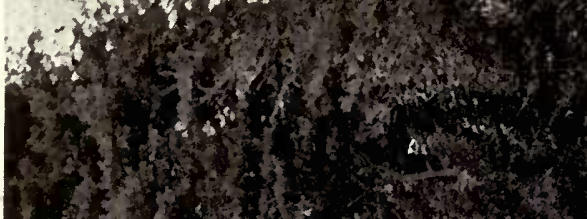

6.t.
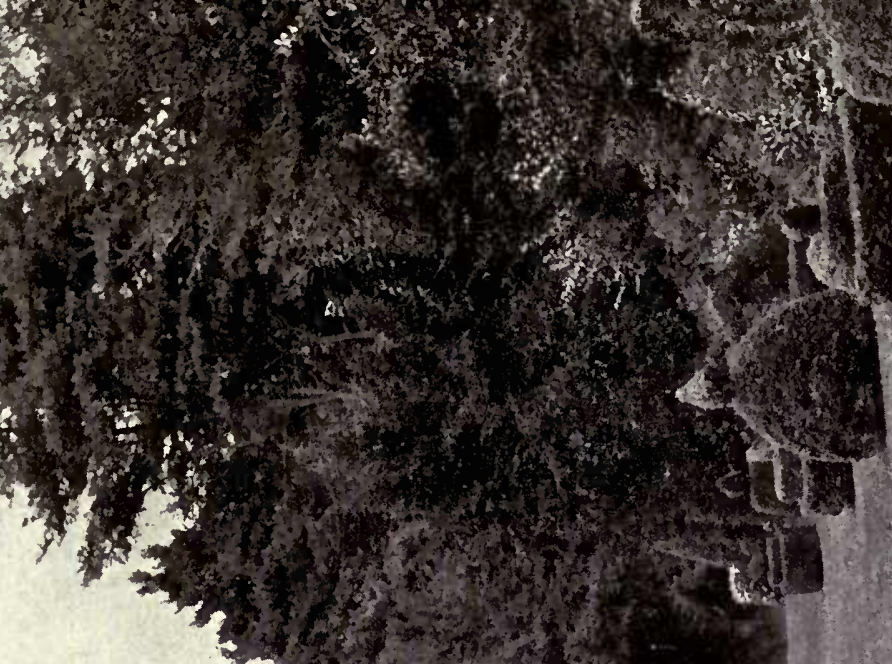

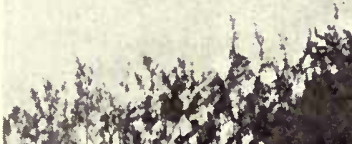

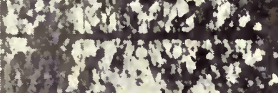

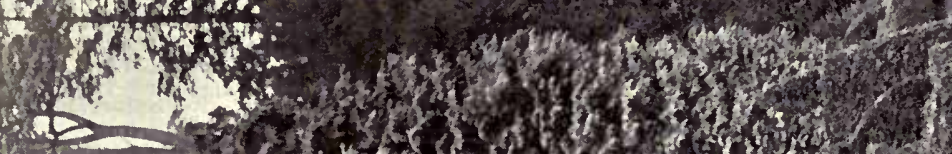

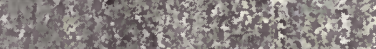

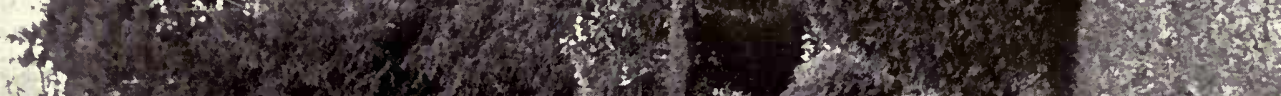

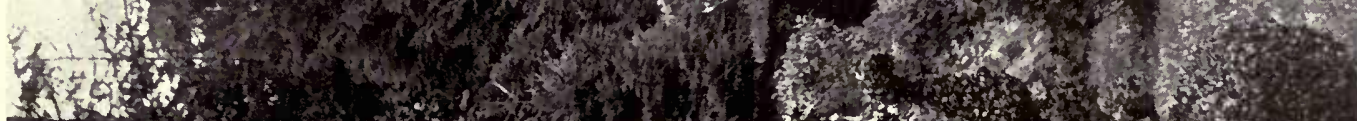

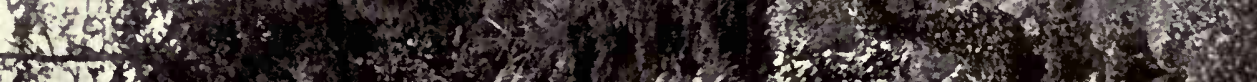
ext? 


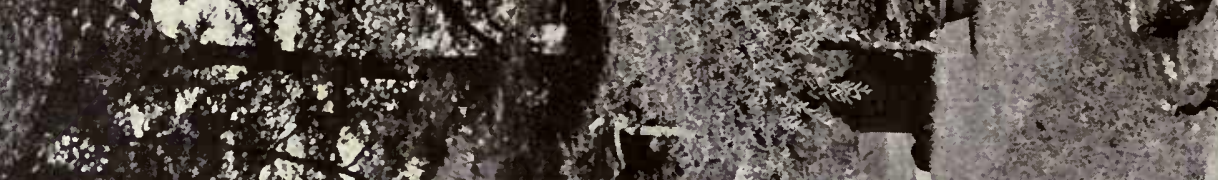

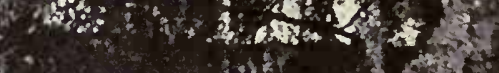

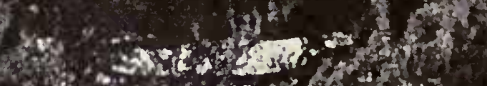

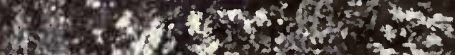

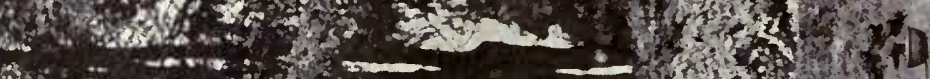

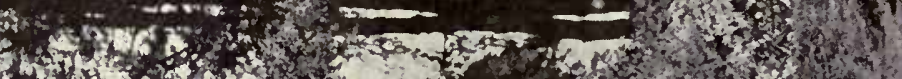

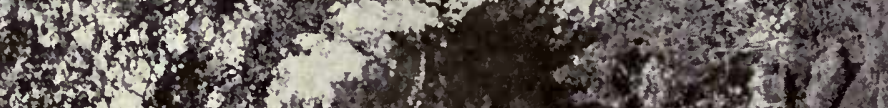

$67 x^{2}+x^{2}$

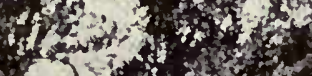

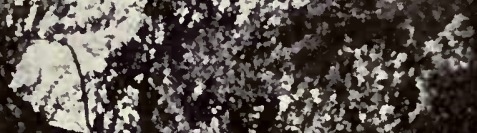

-

(1)

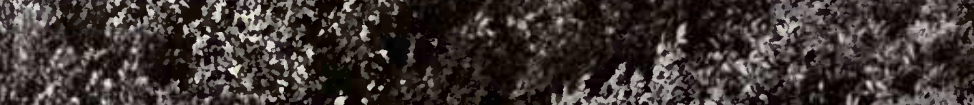

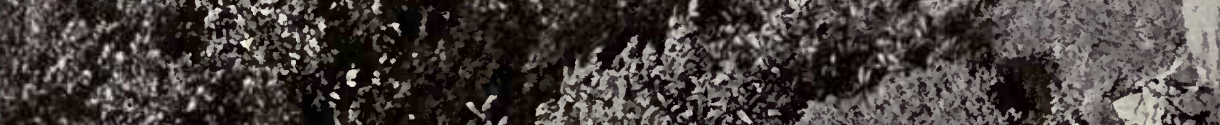

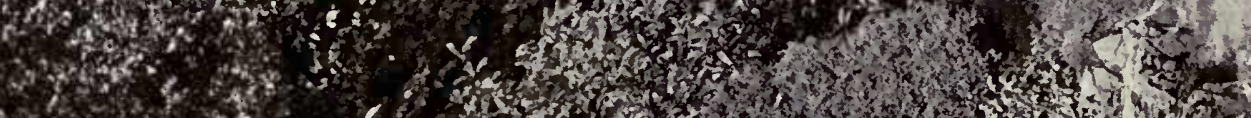

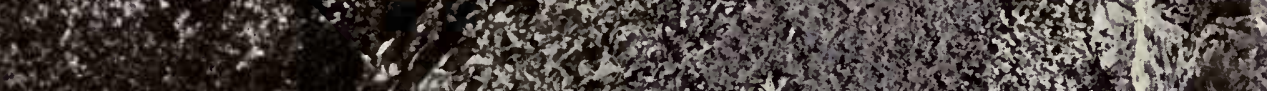
for.

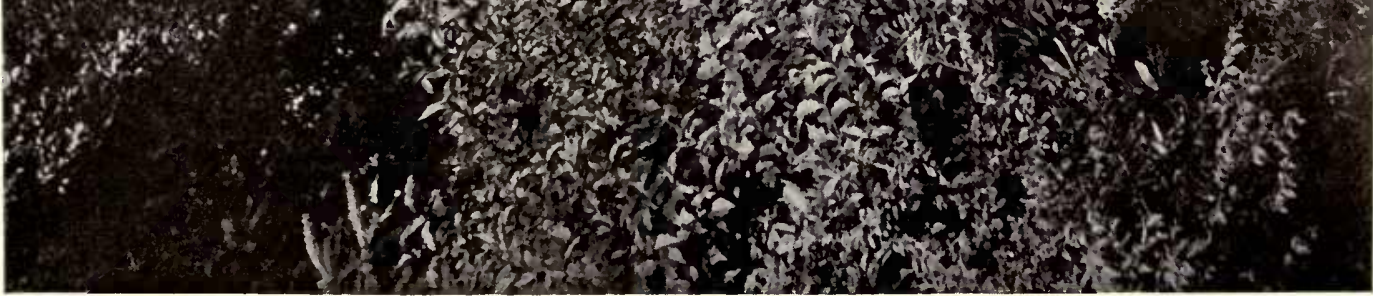




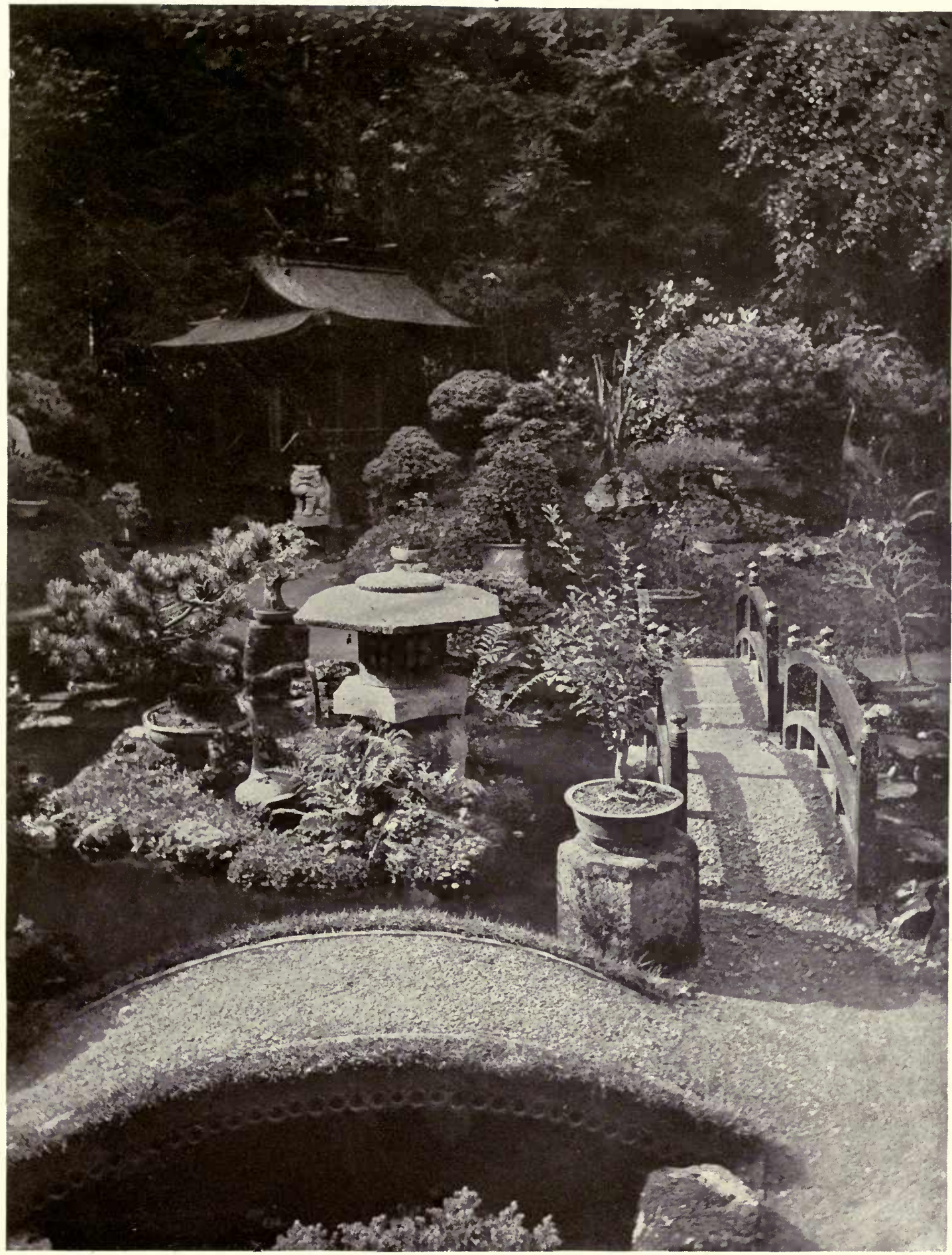




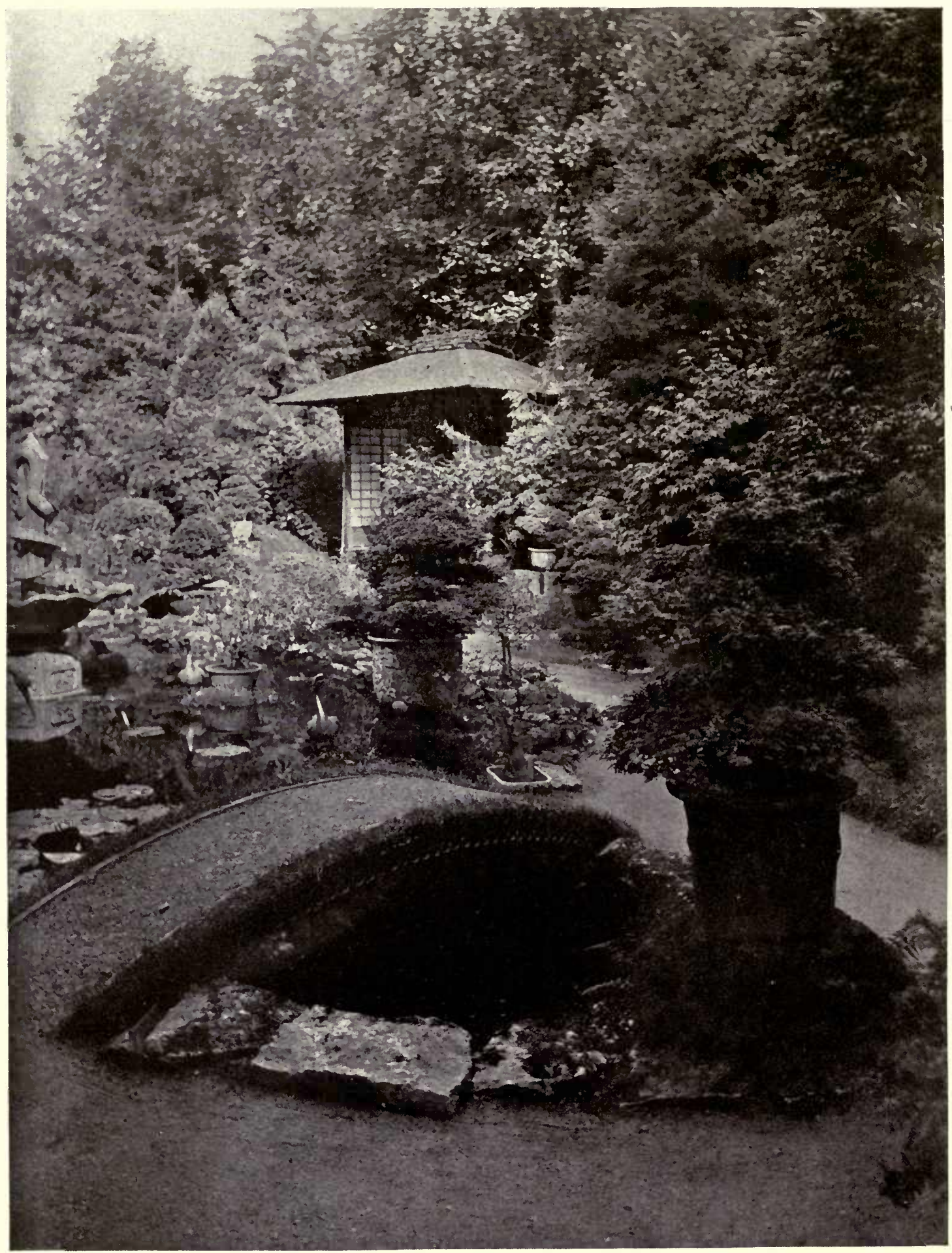




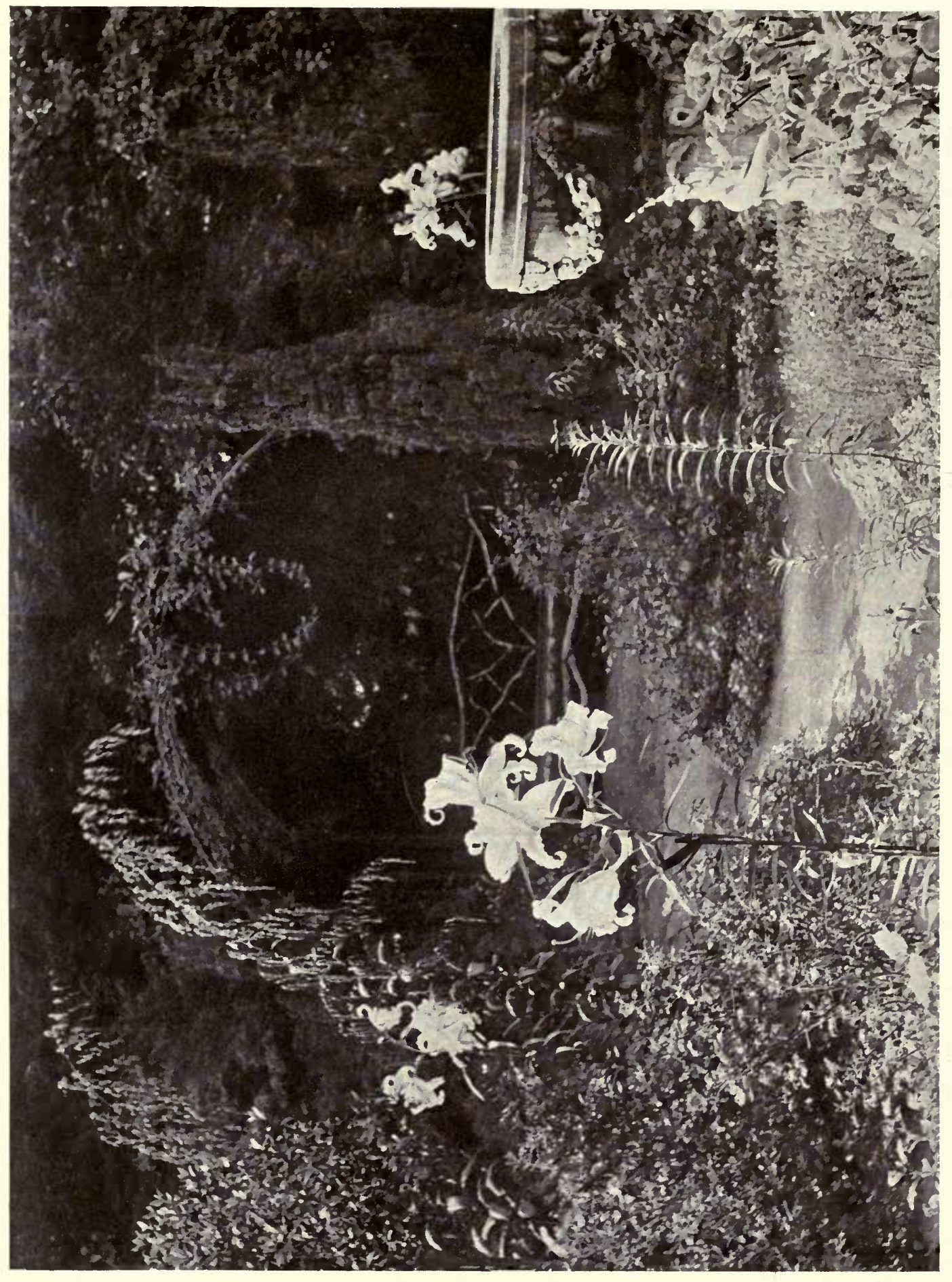

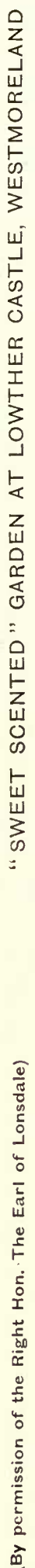




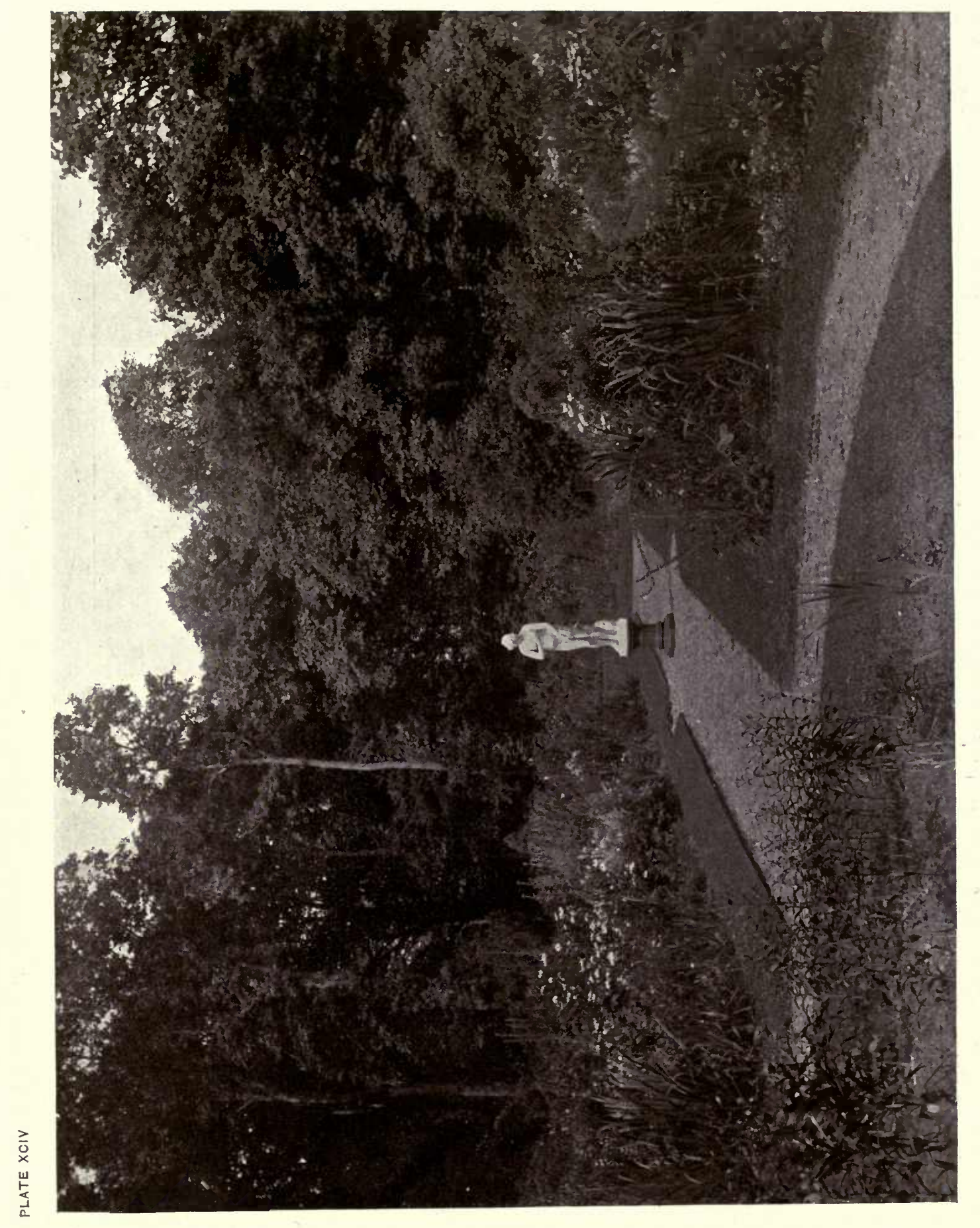

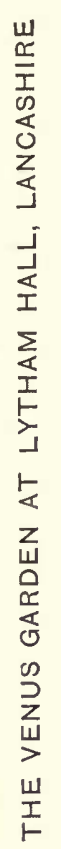




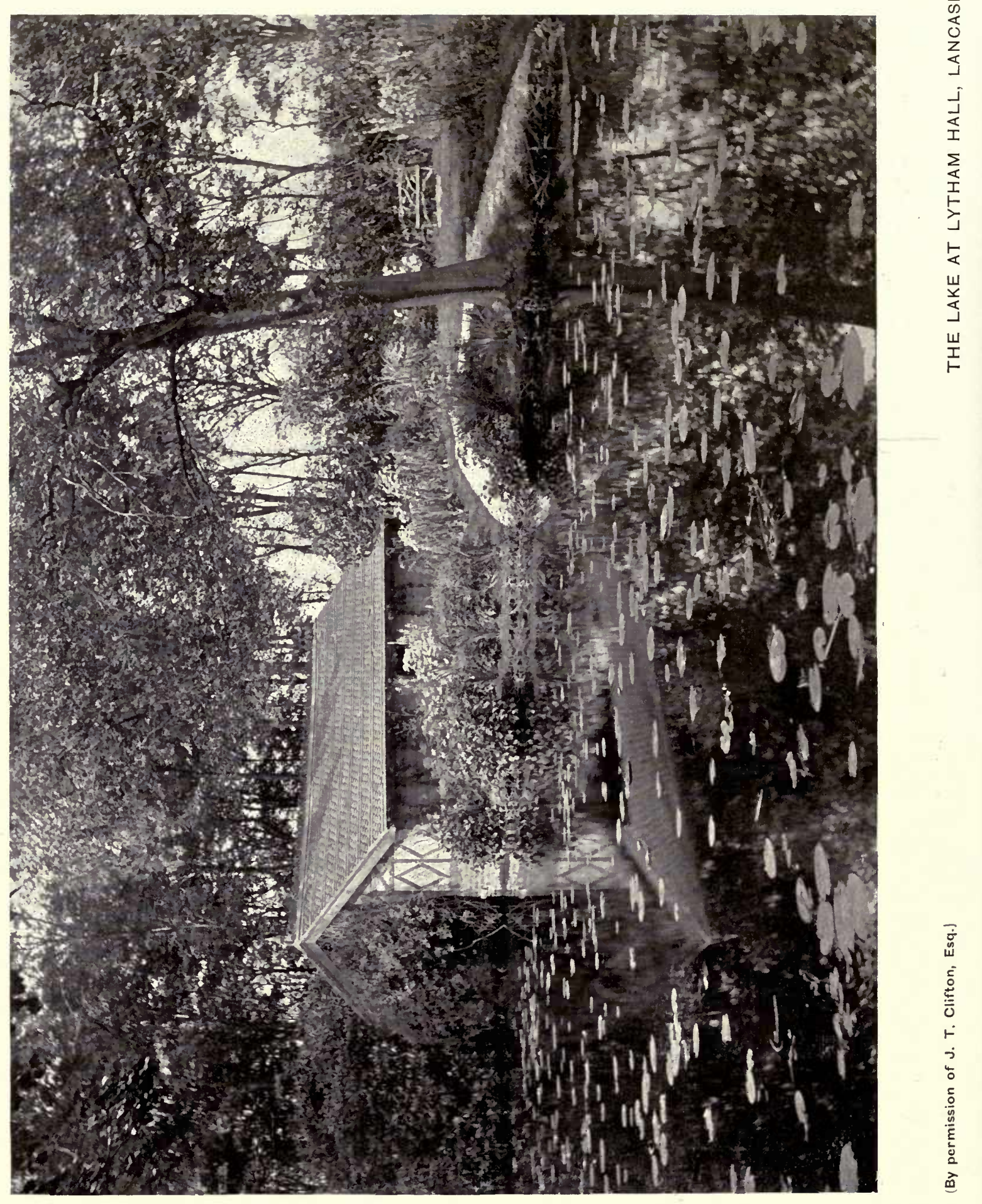



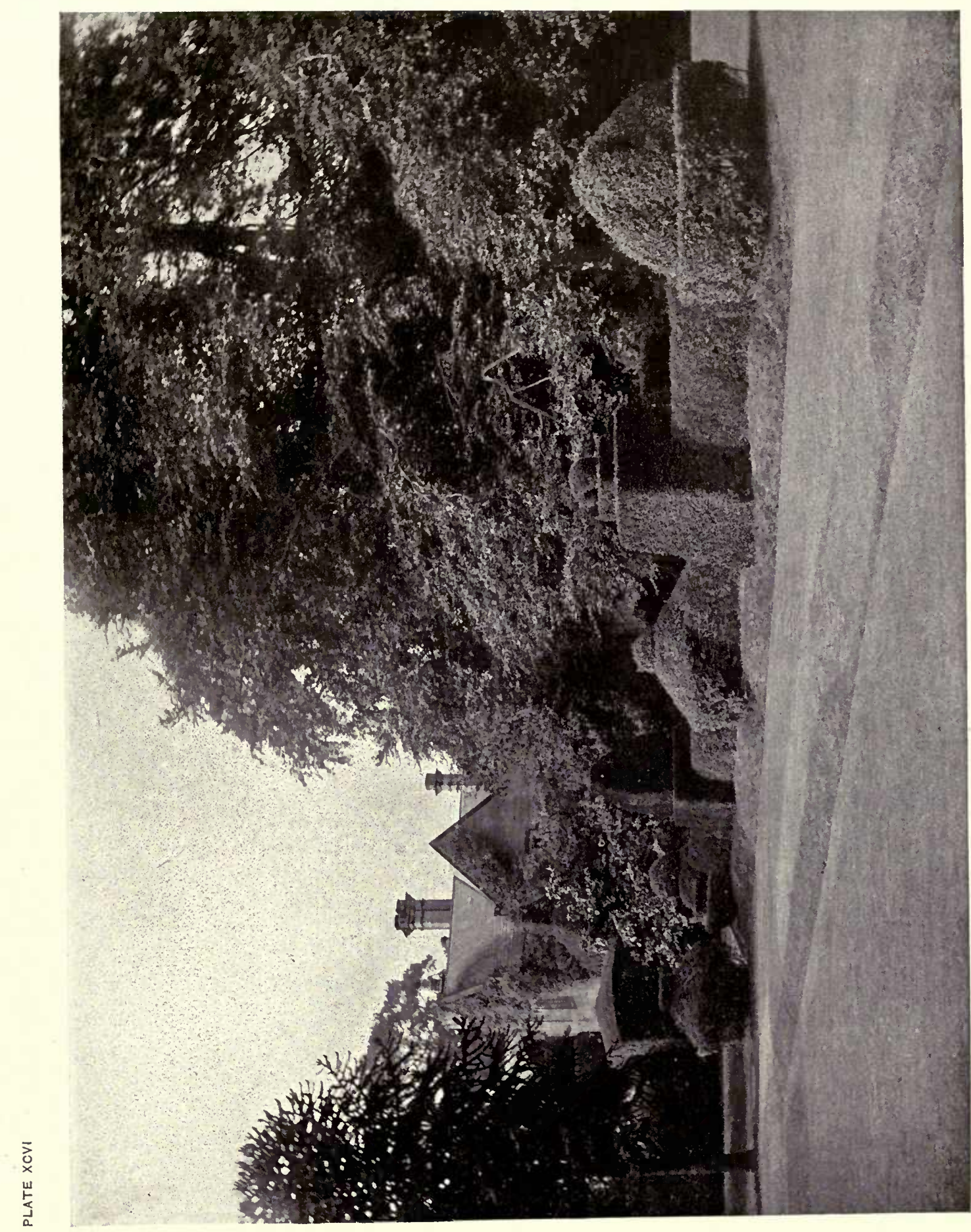

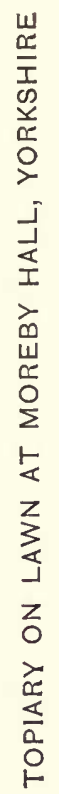

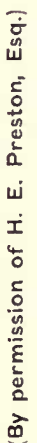




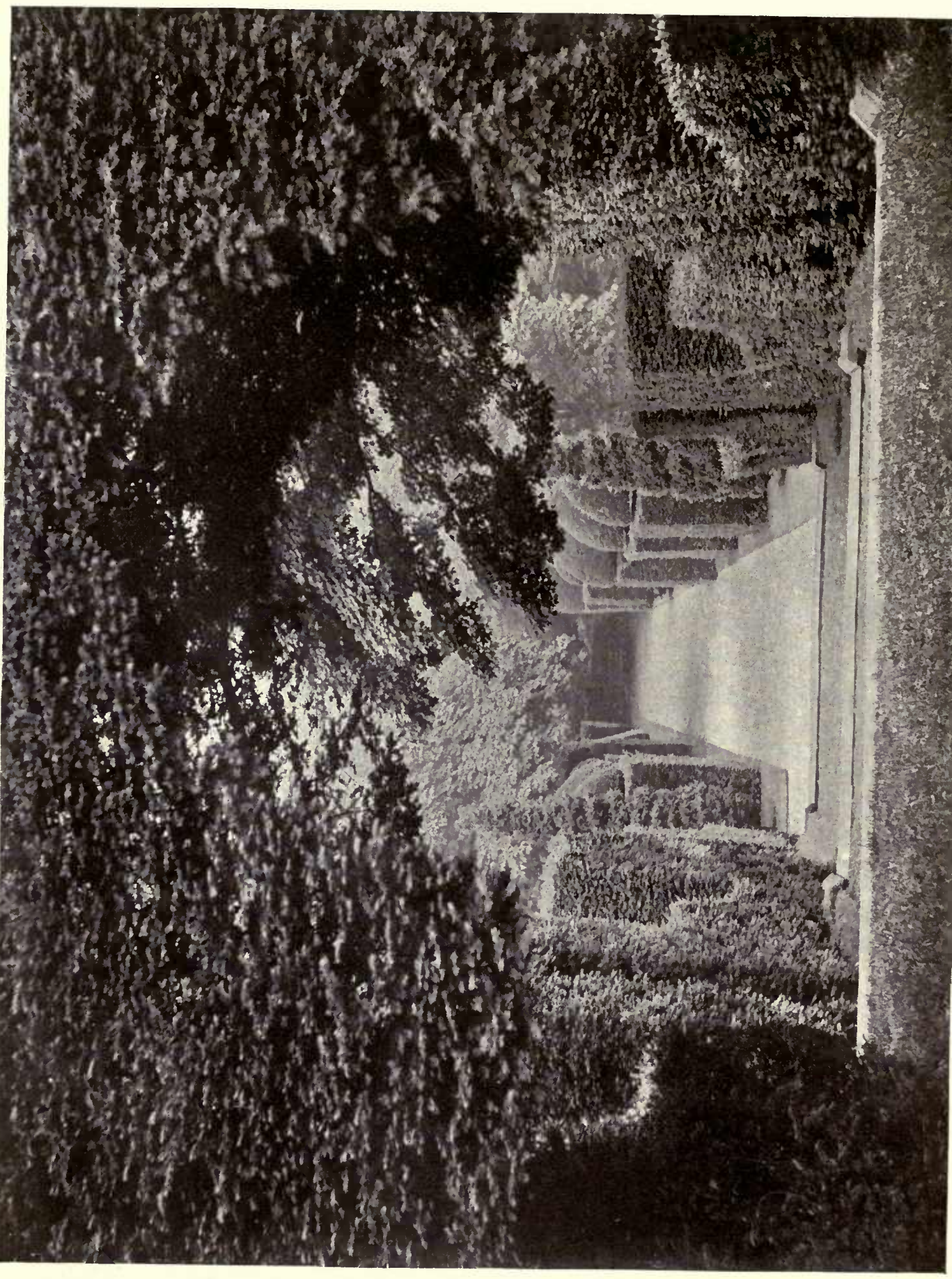

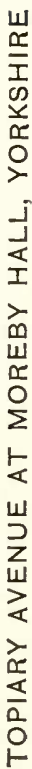




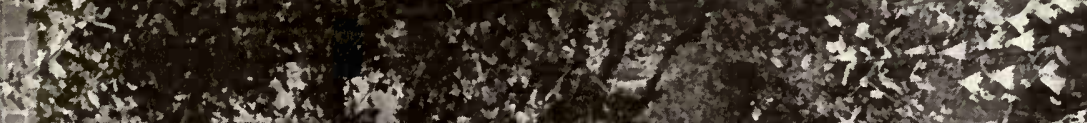

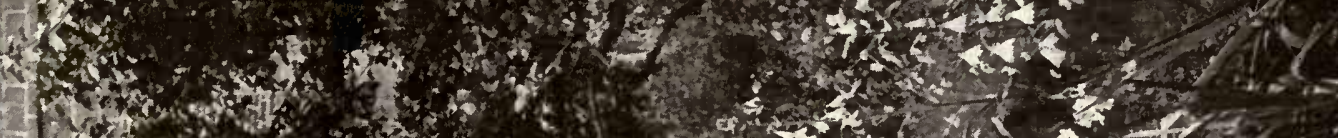

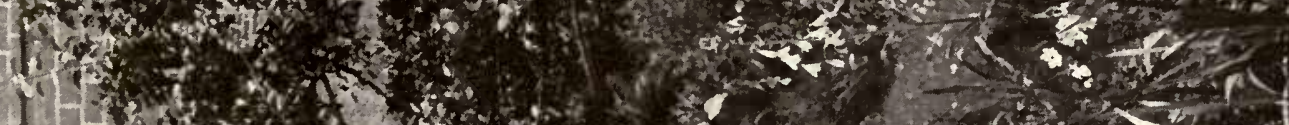

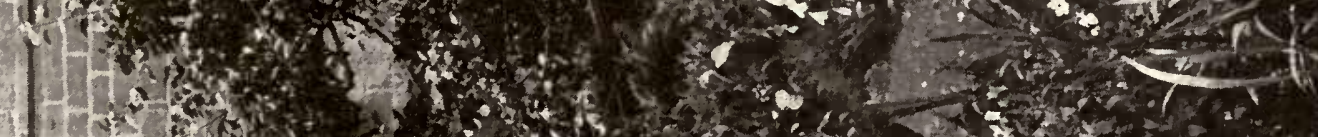
-119.

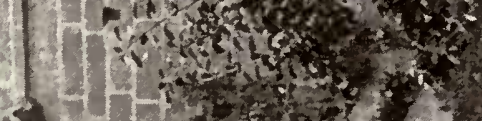

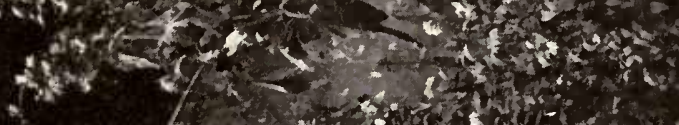

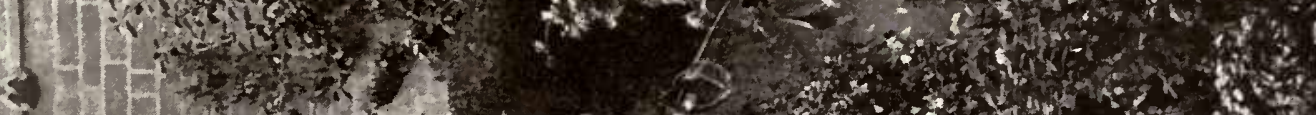

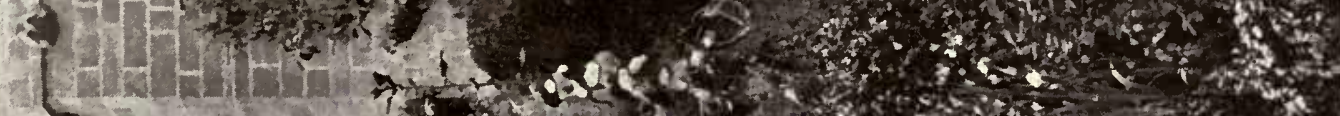
1
1

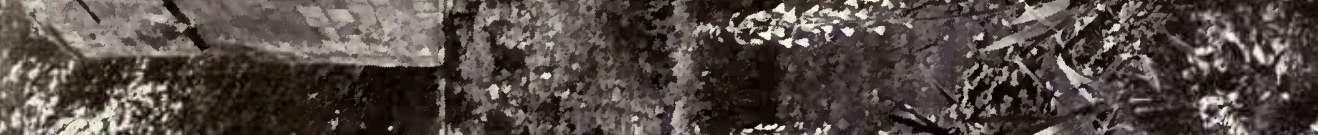

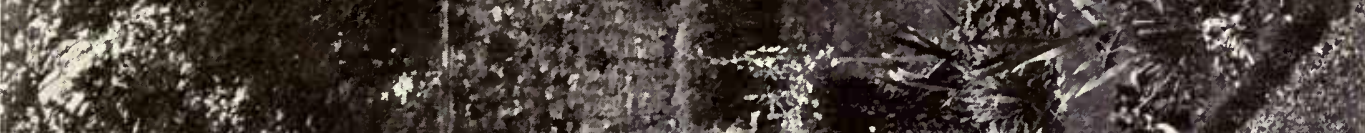

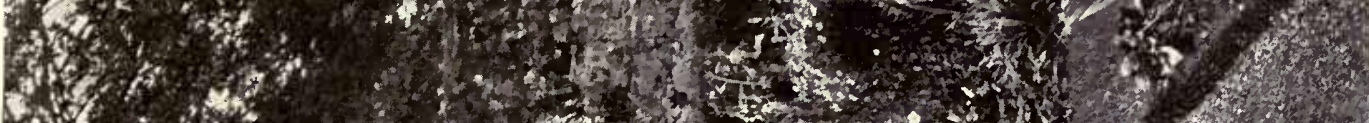

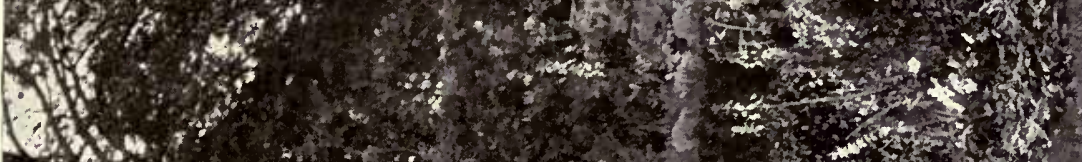

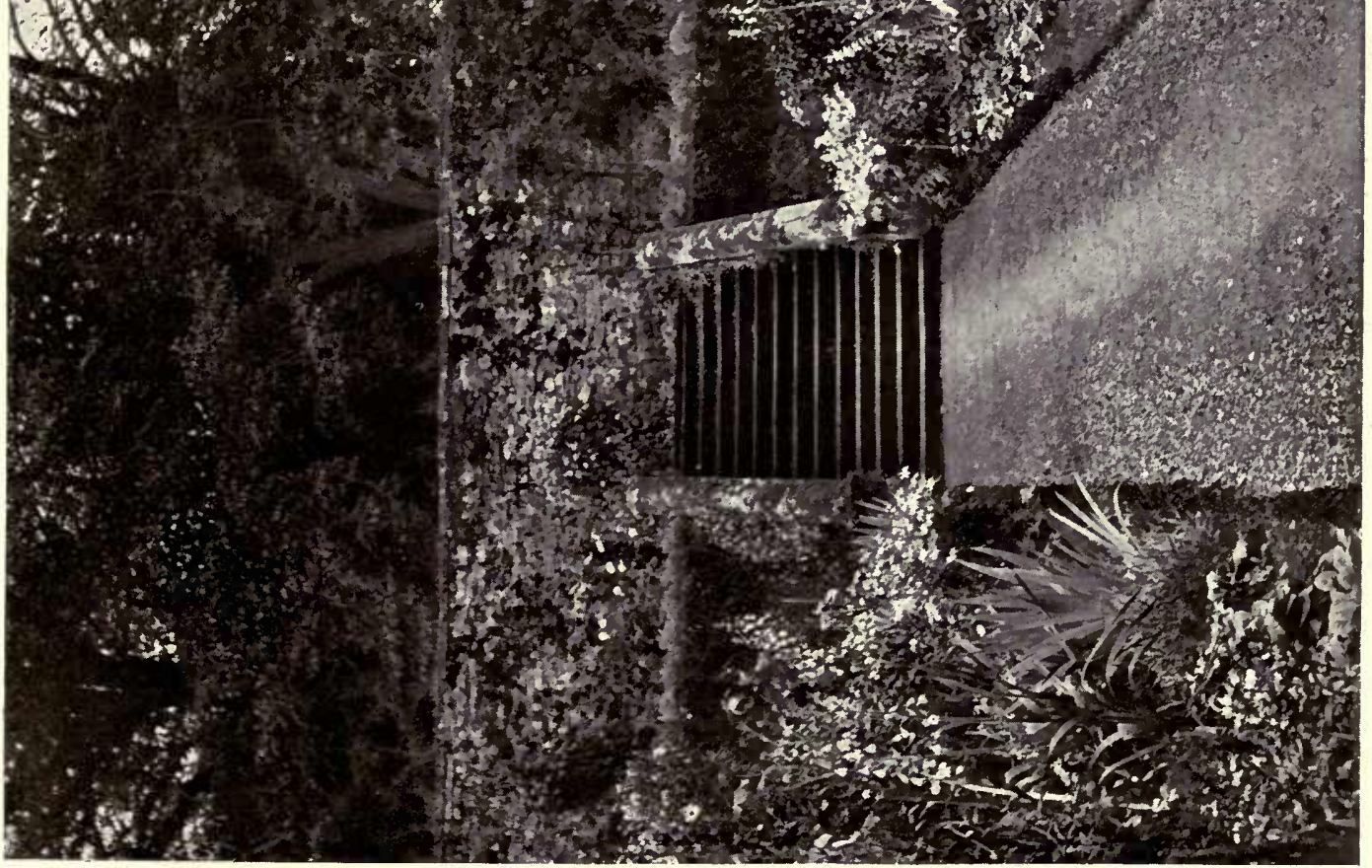




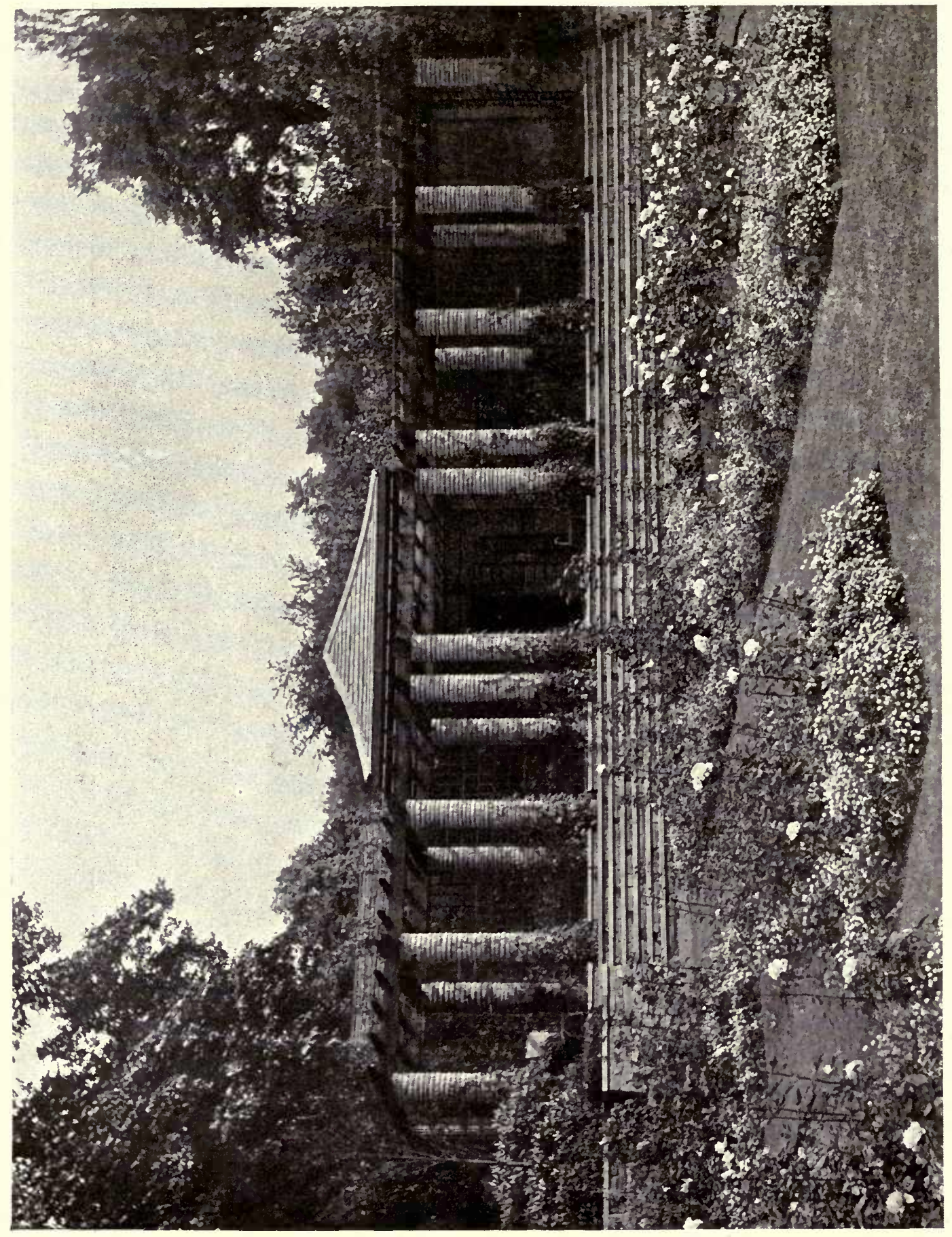

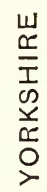

U 


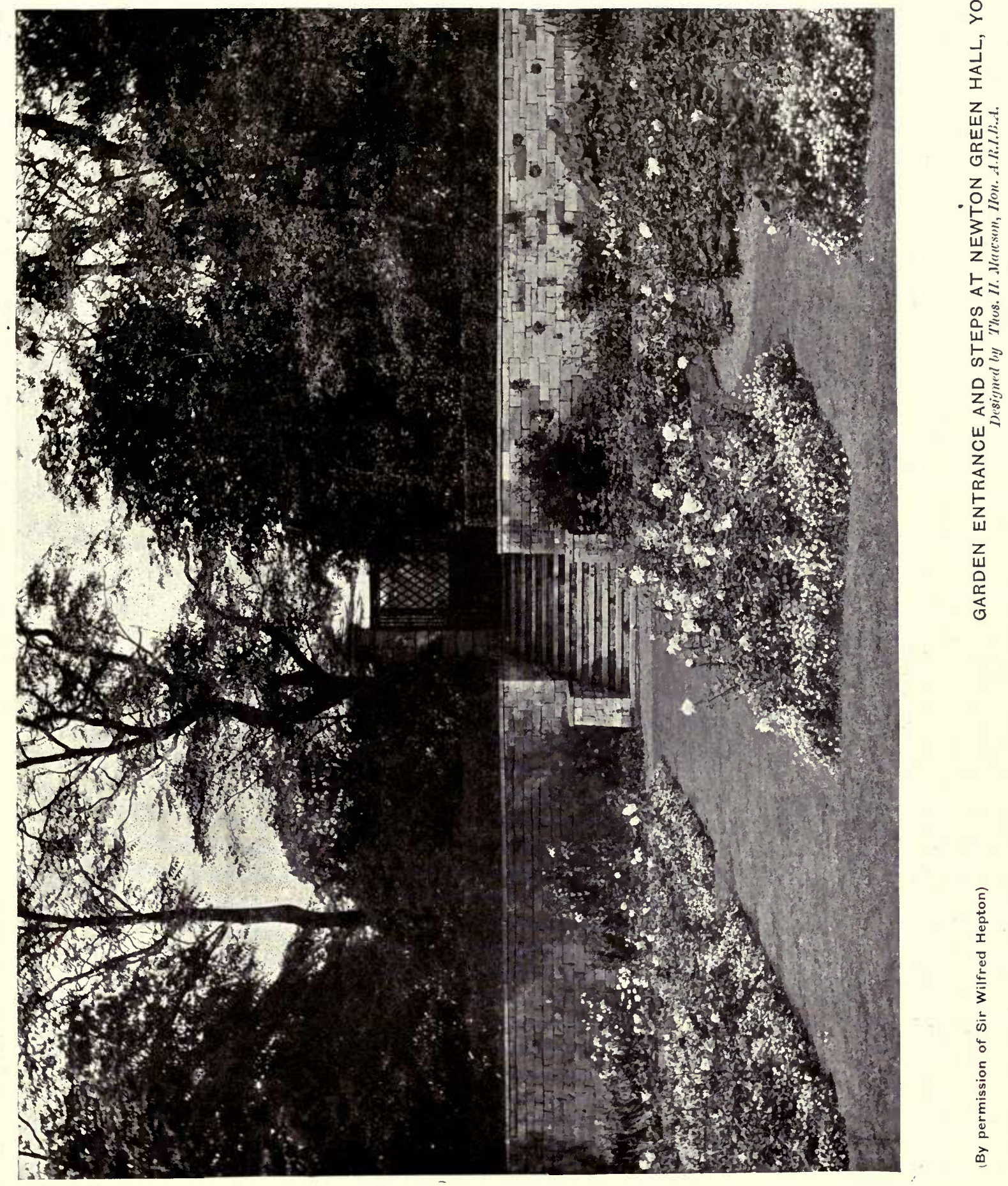




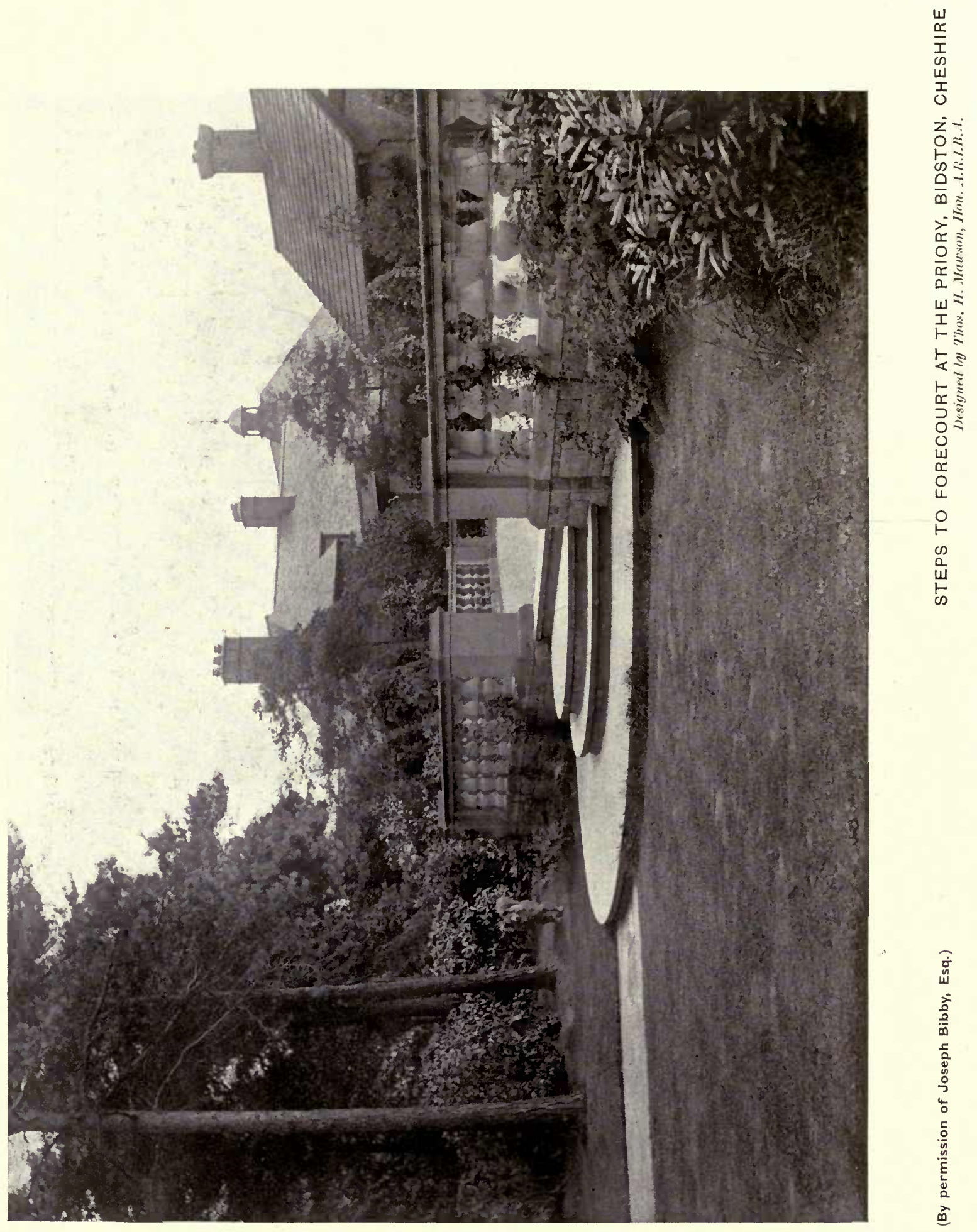



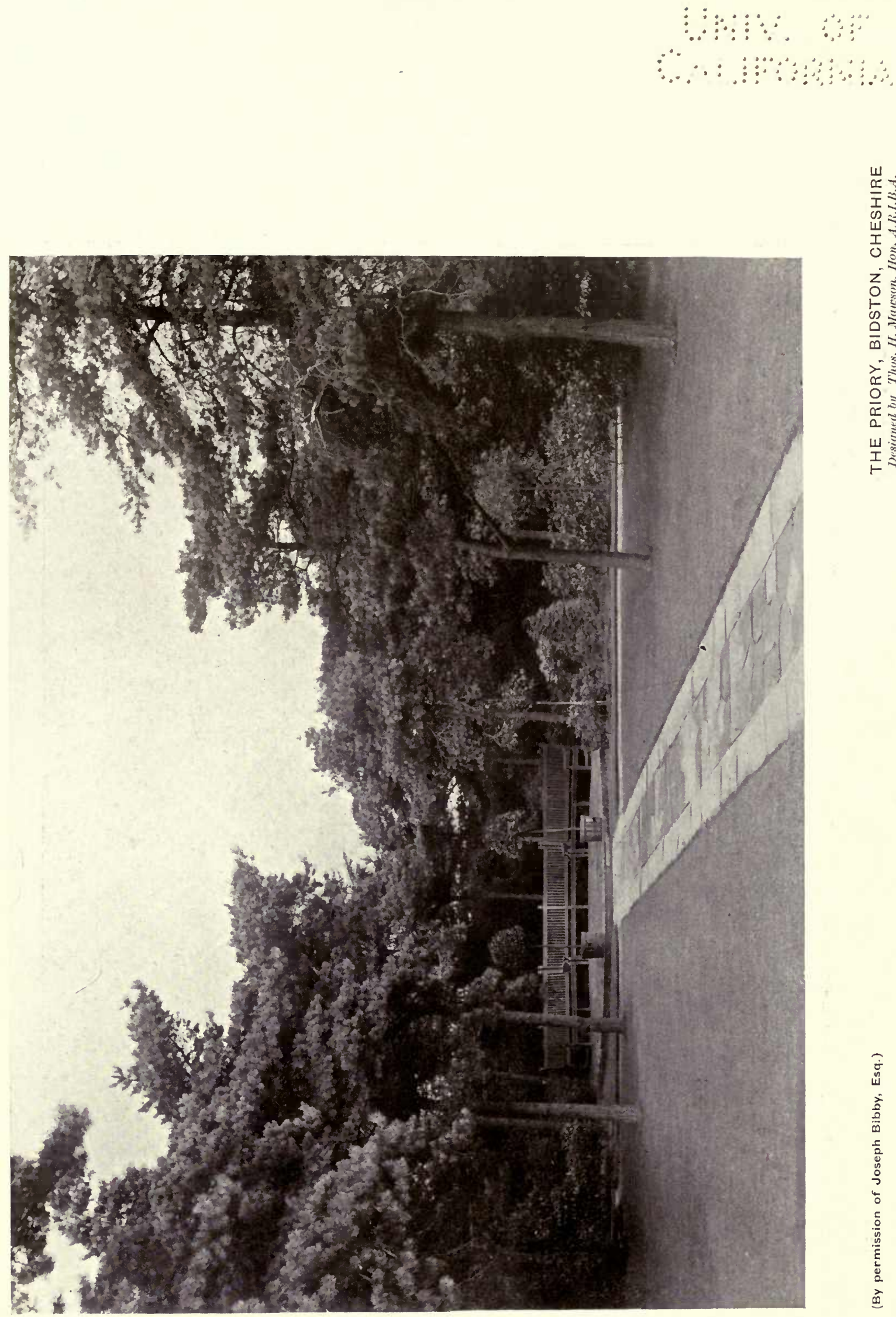

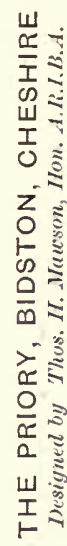




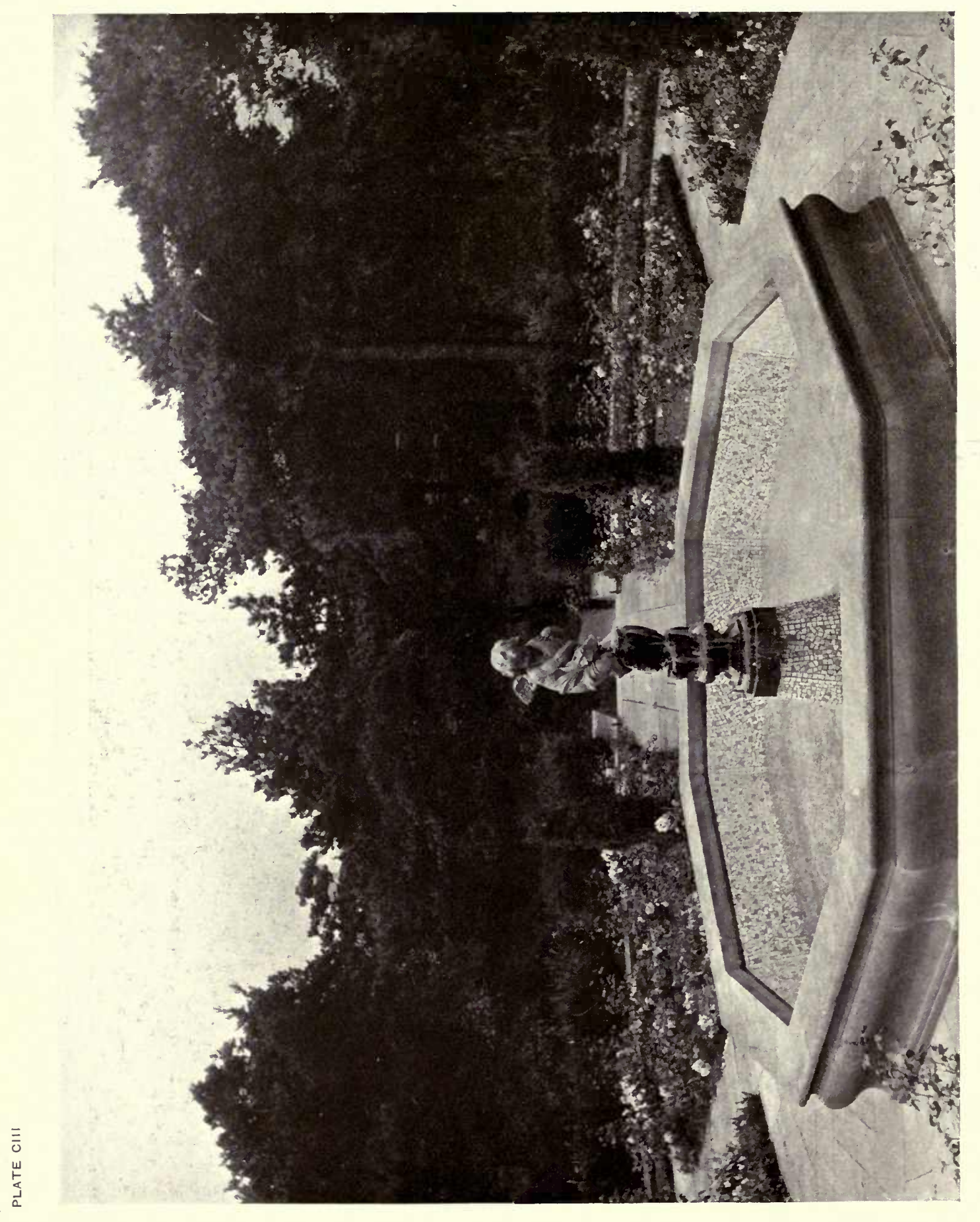

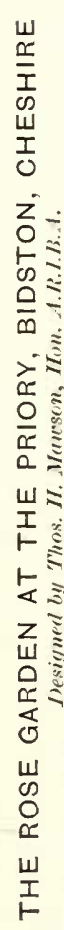




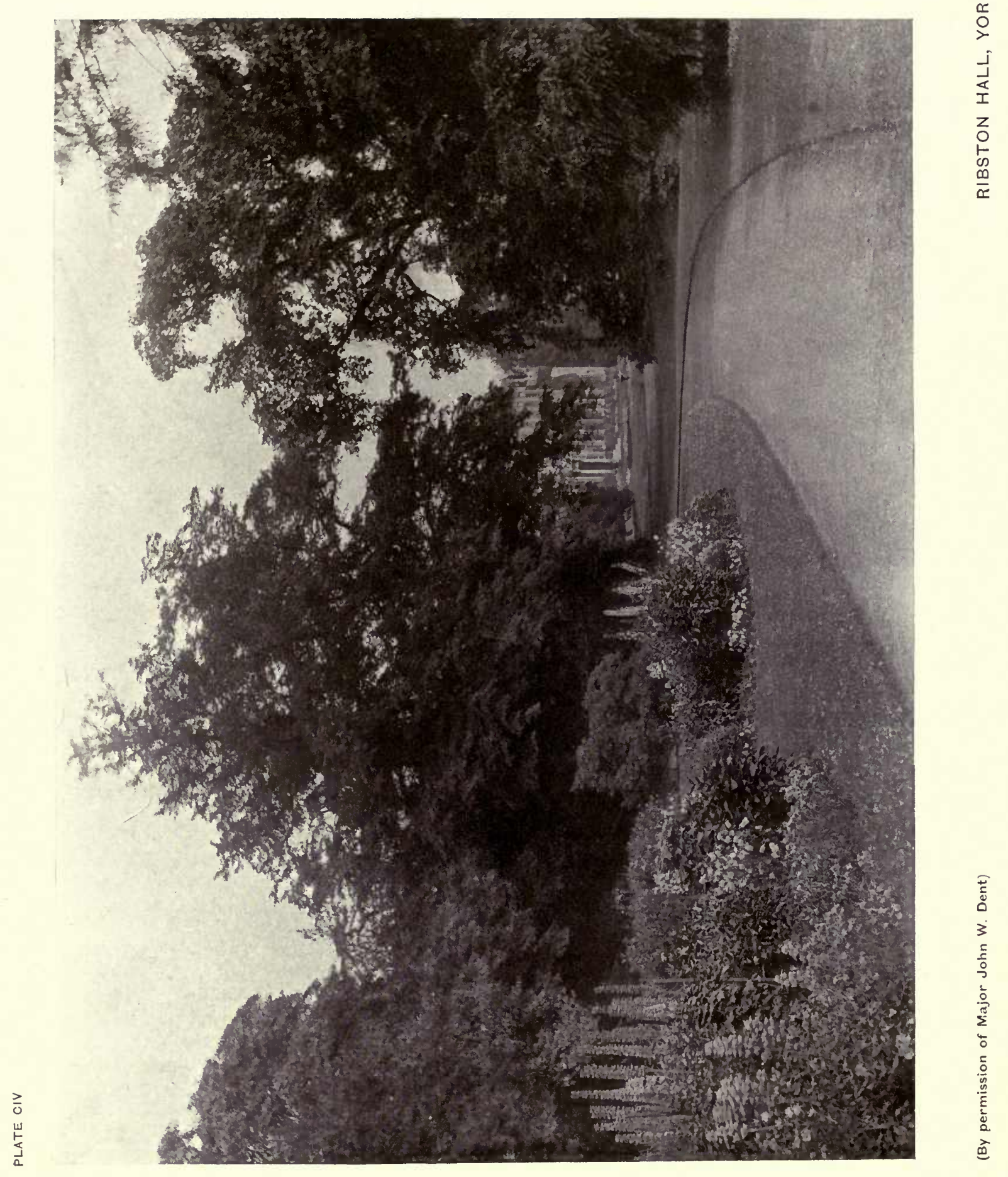




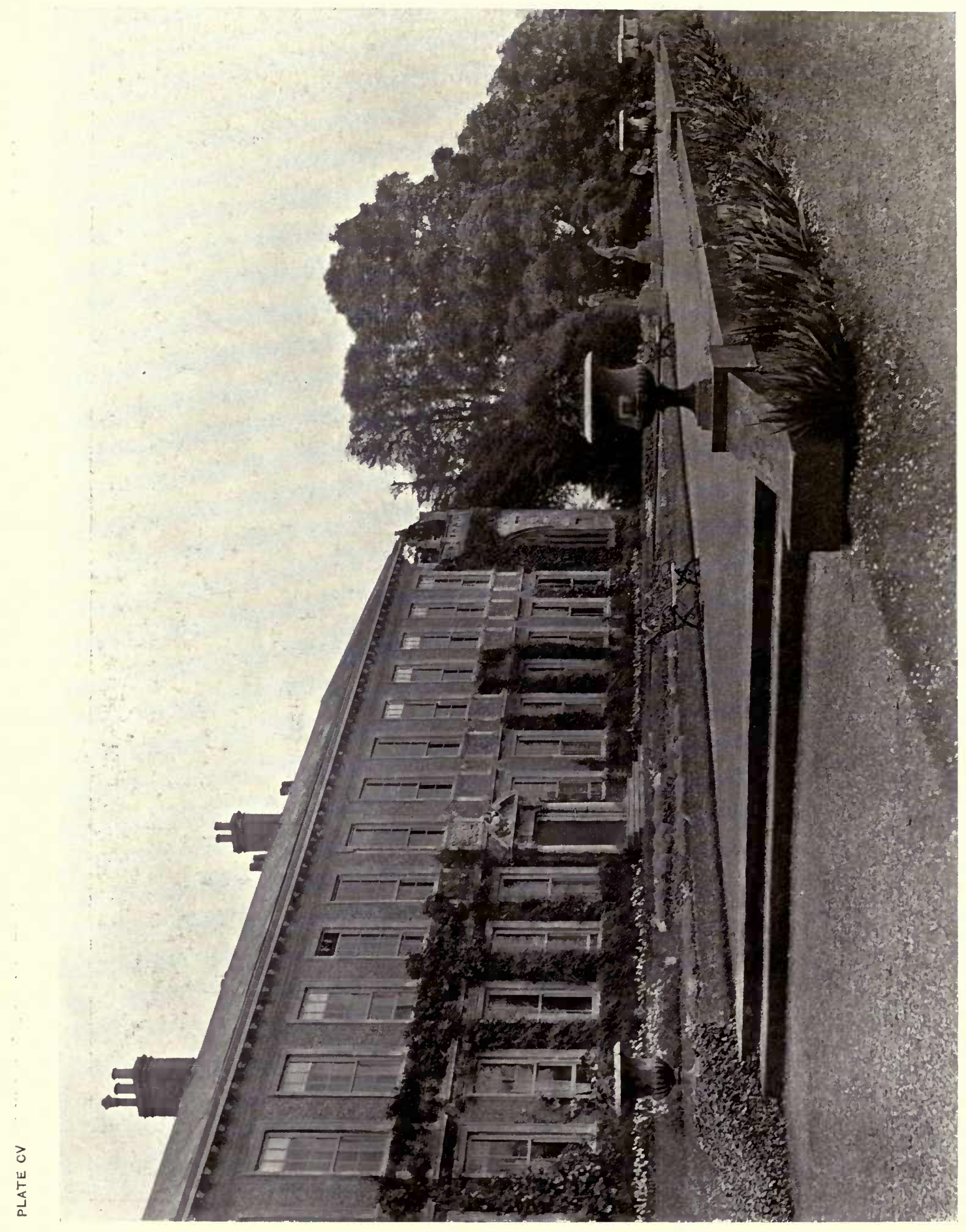

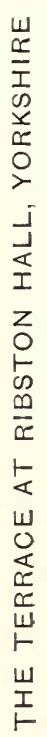




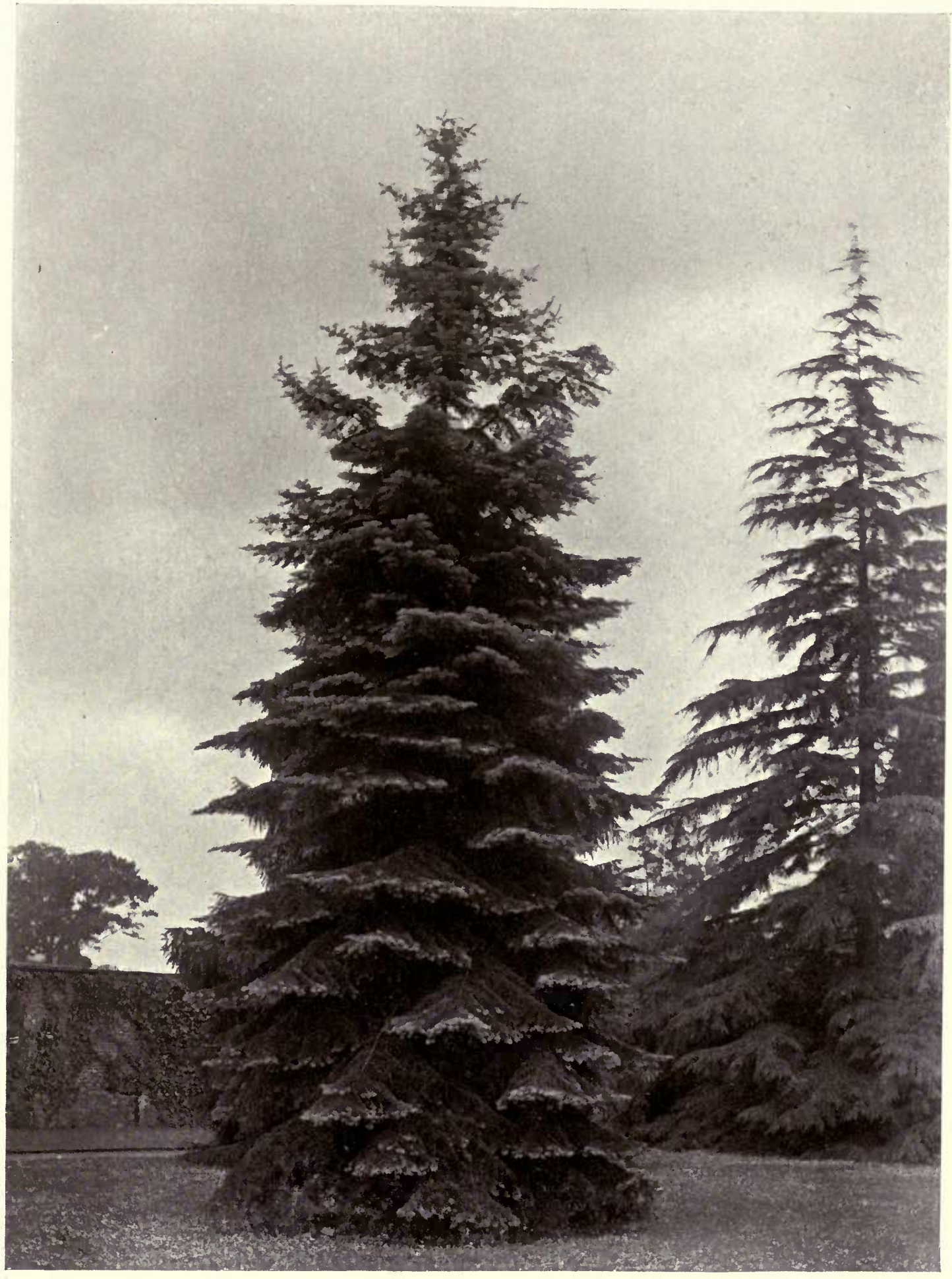




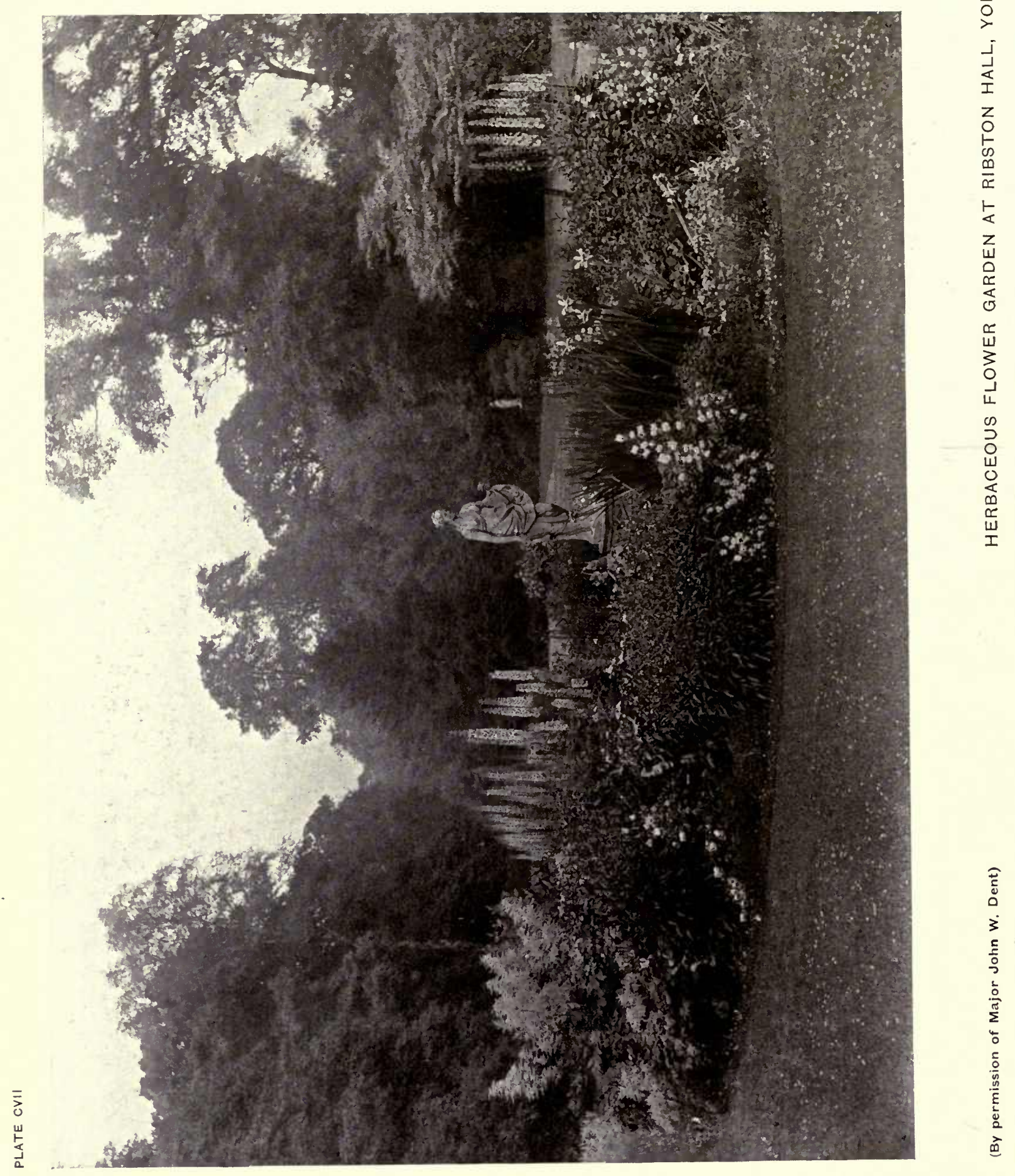




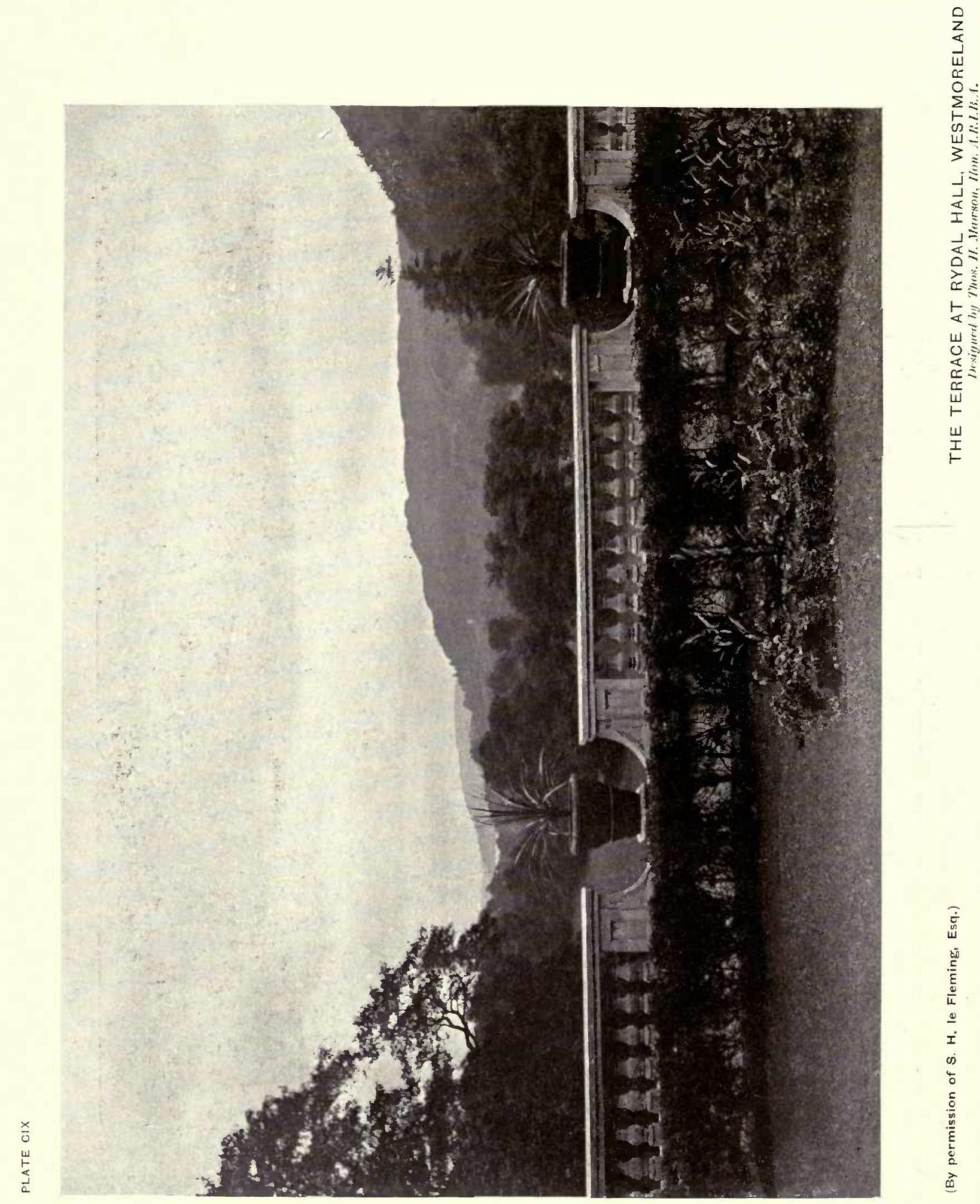




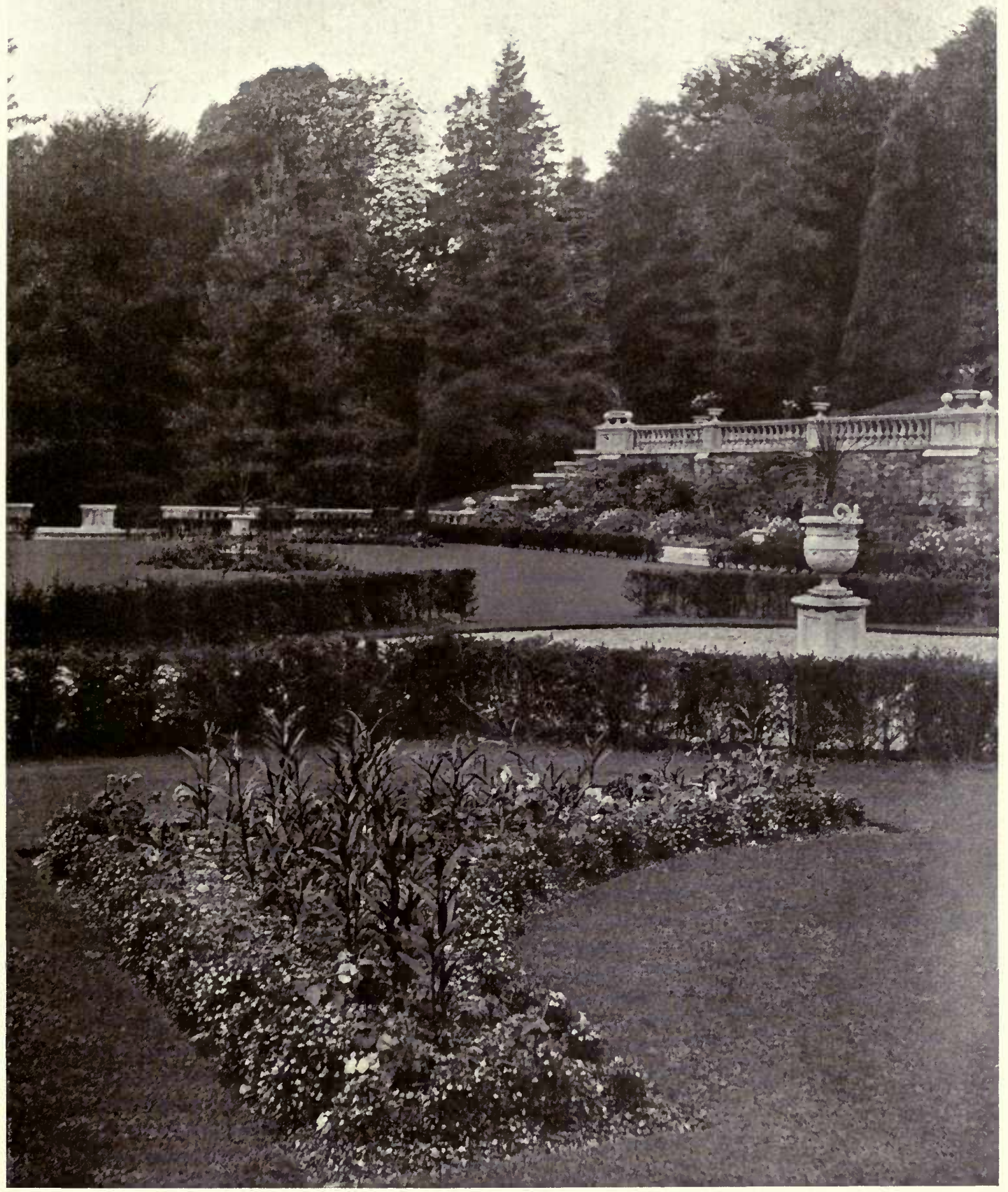




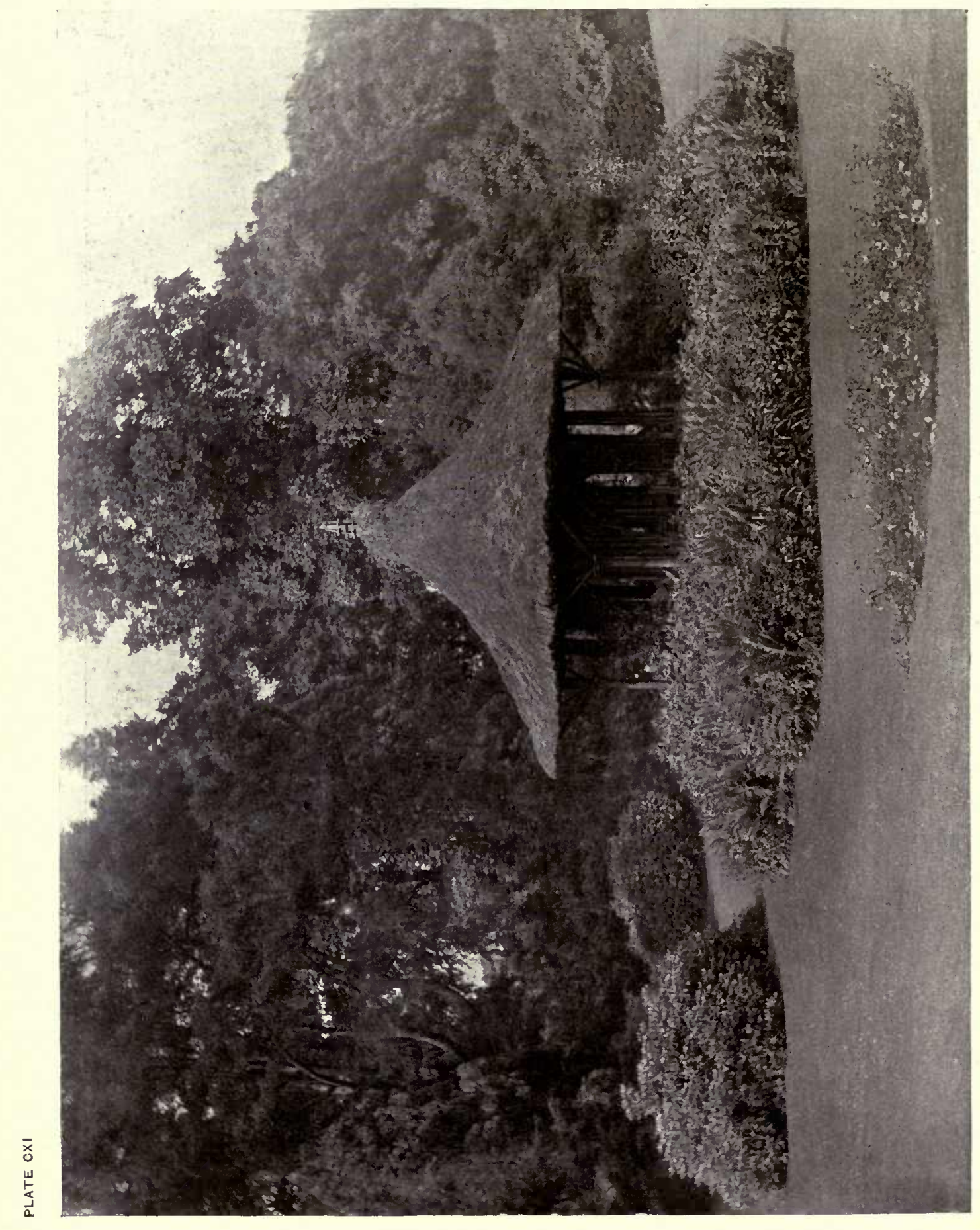

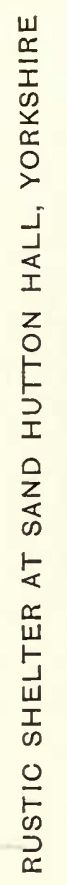

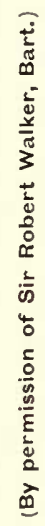




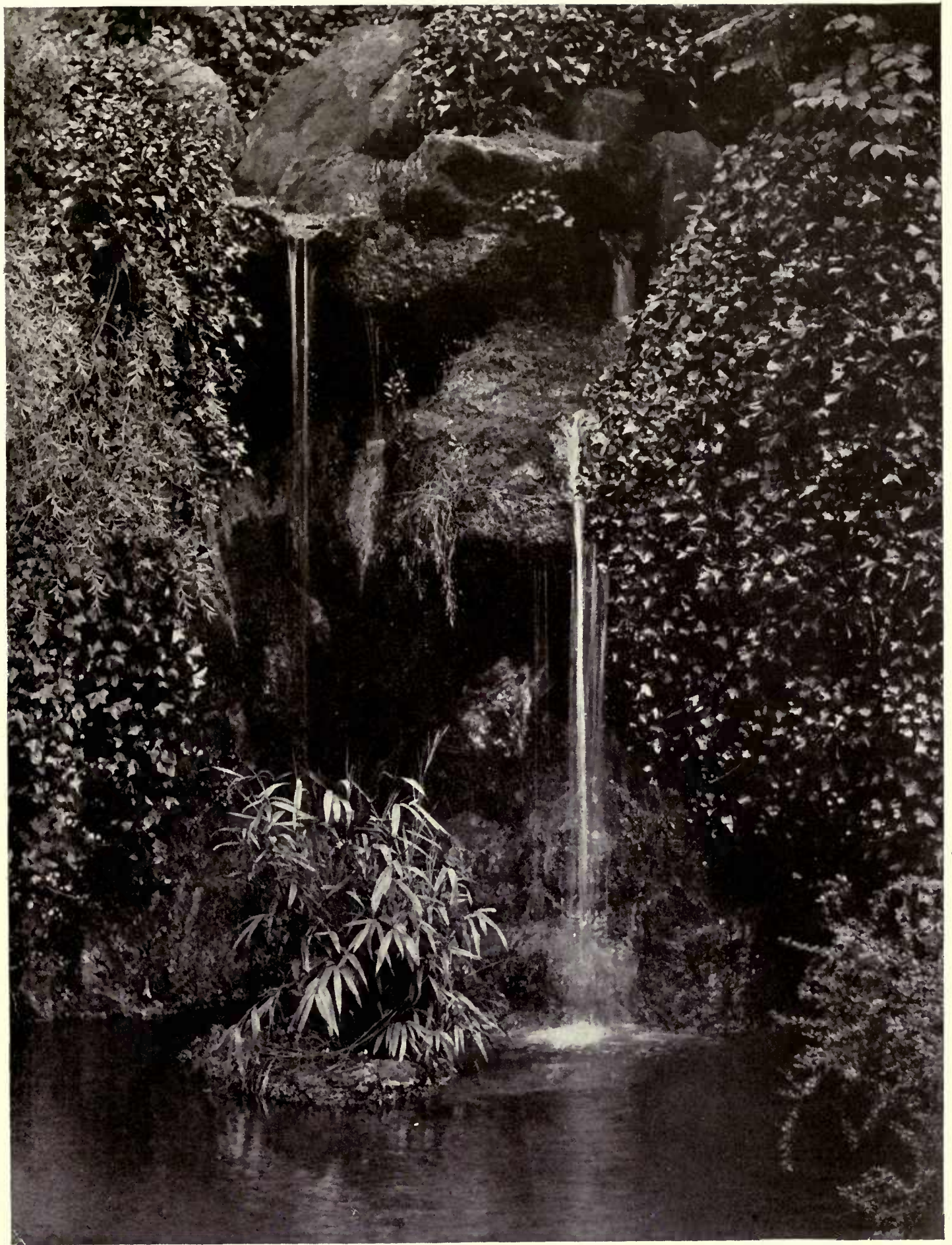




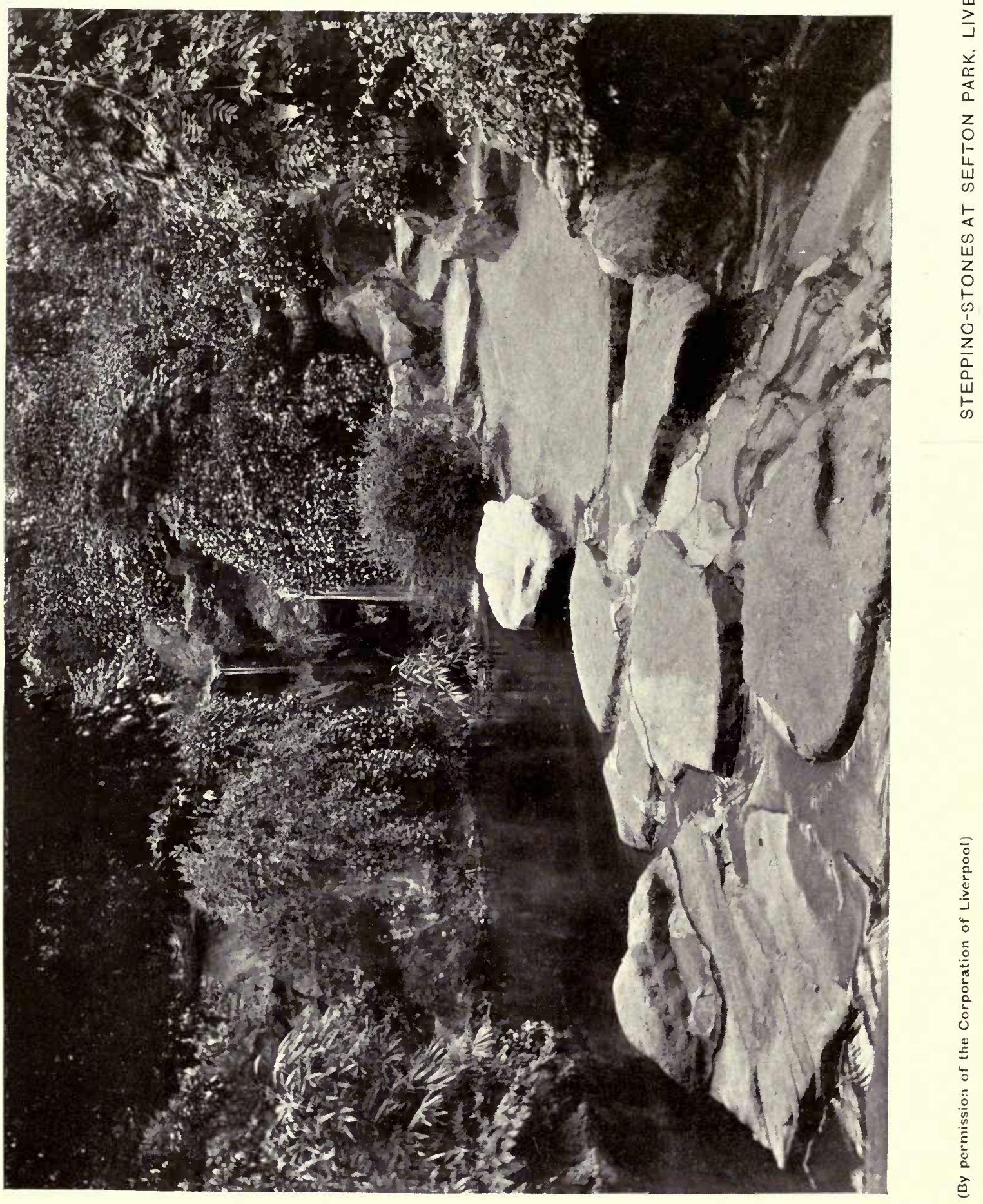




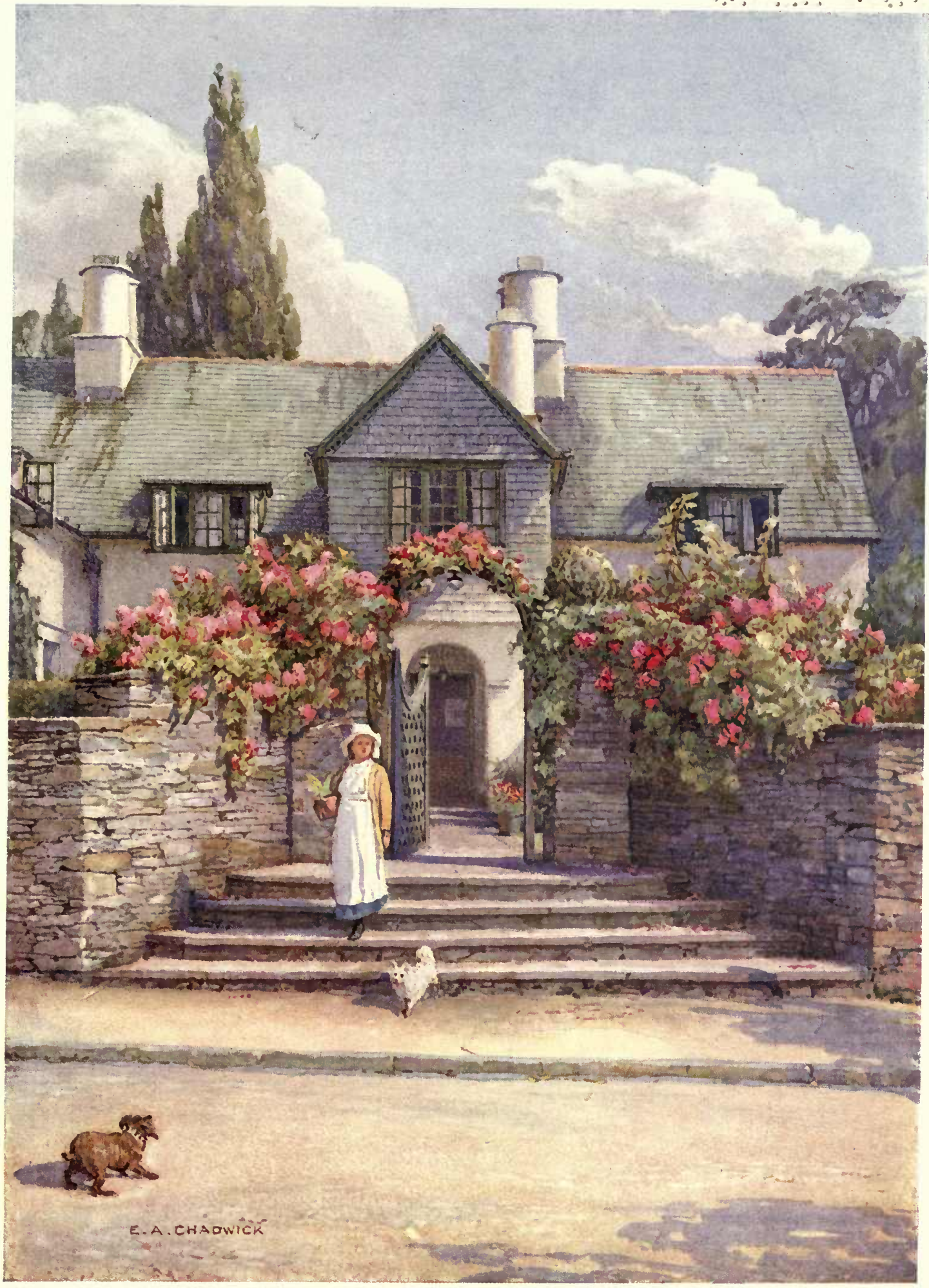


$\because 4 \quad \because 4$ 
$\because$\begin{tabular}{l}
$\cdots$ \\
\hdashline \\
\hdashline
\end{tabular}

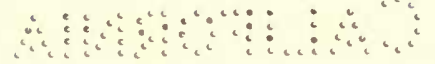

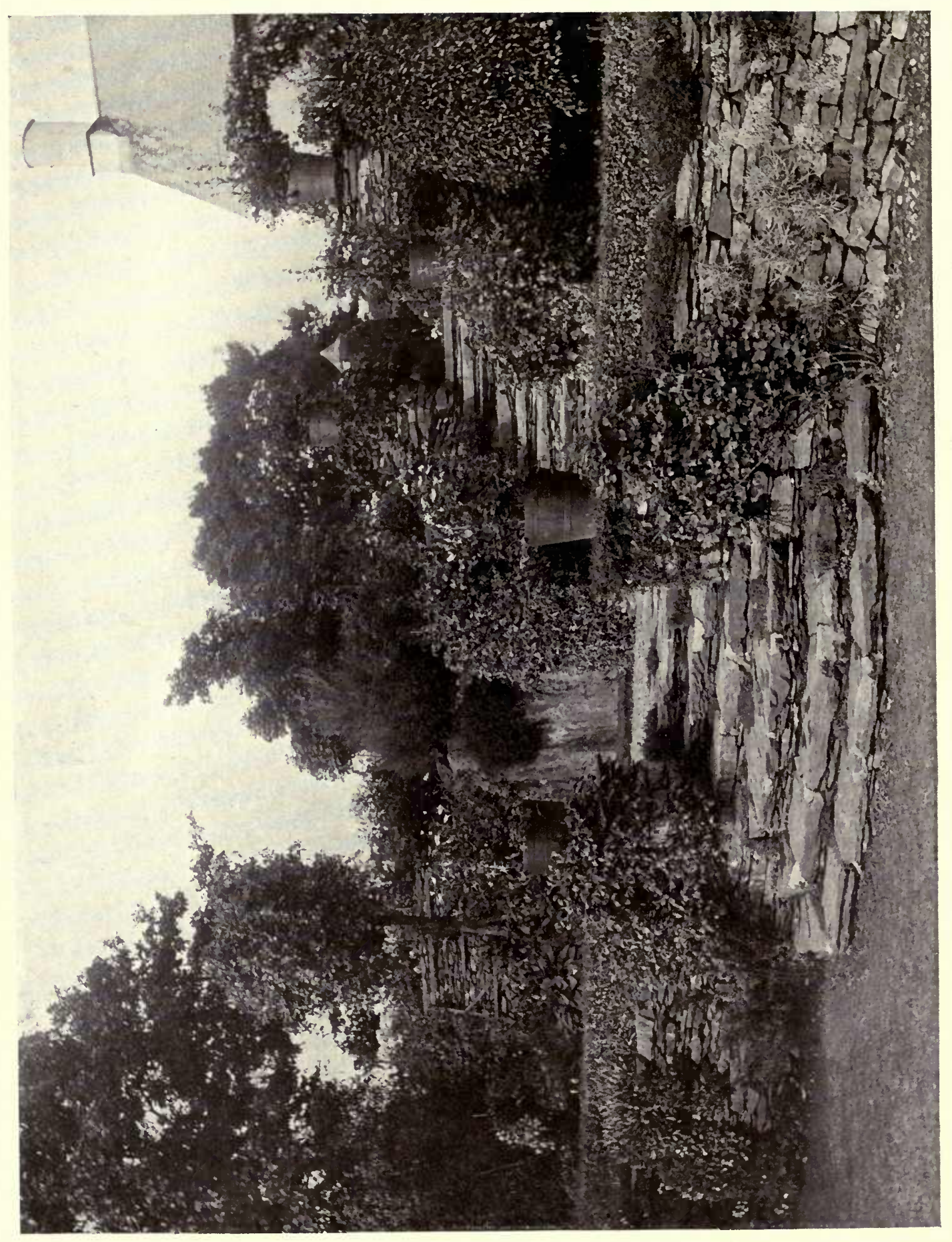

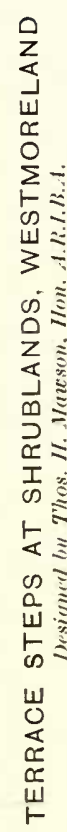




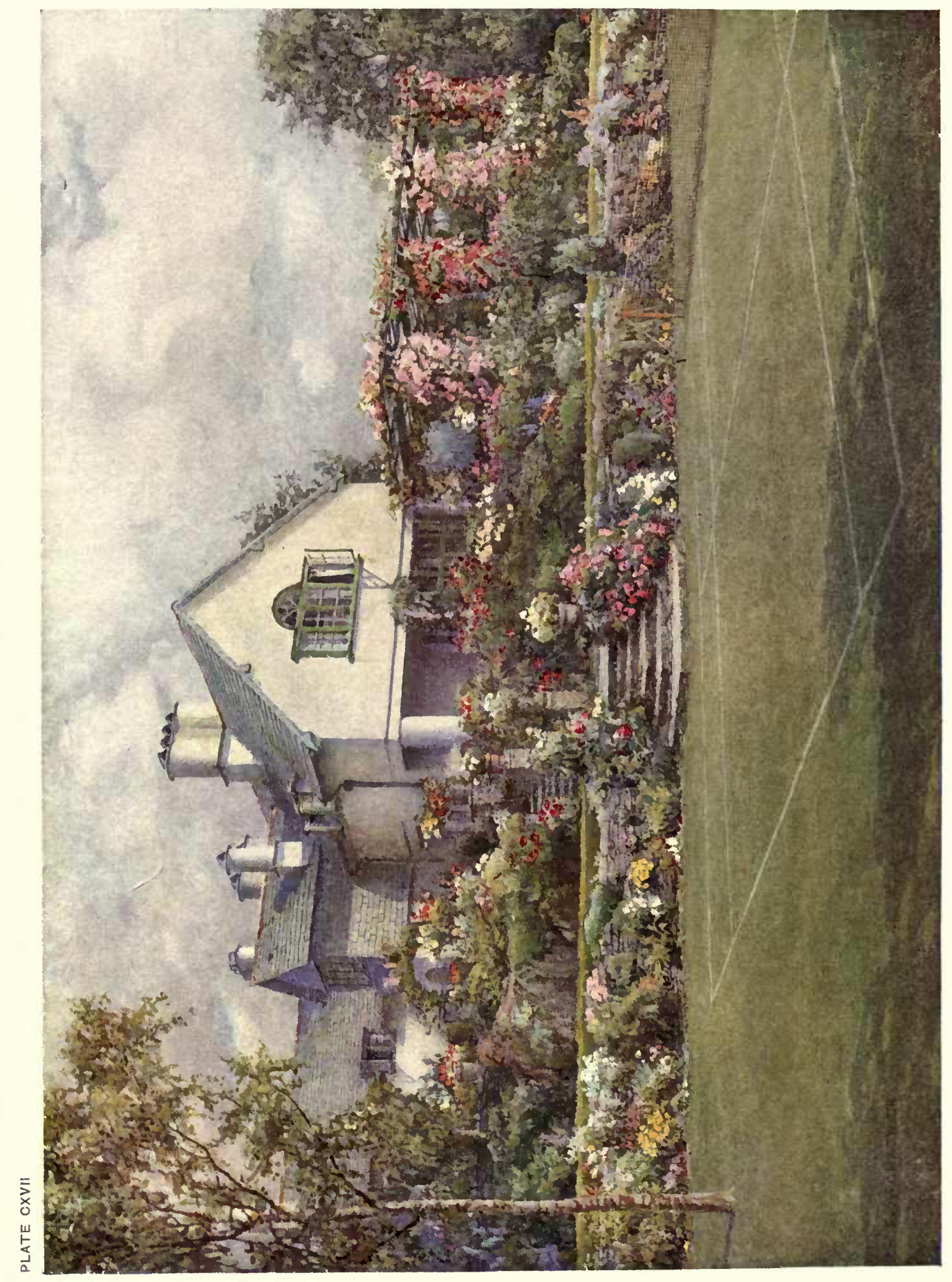




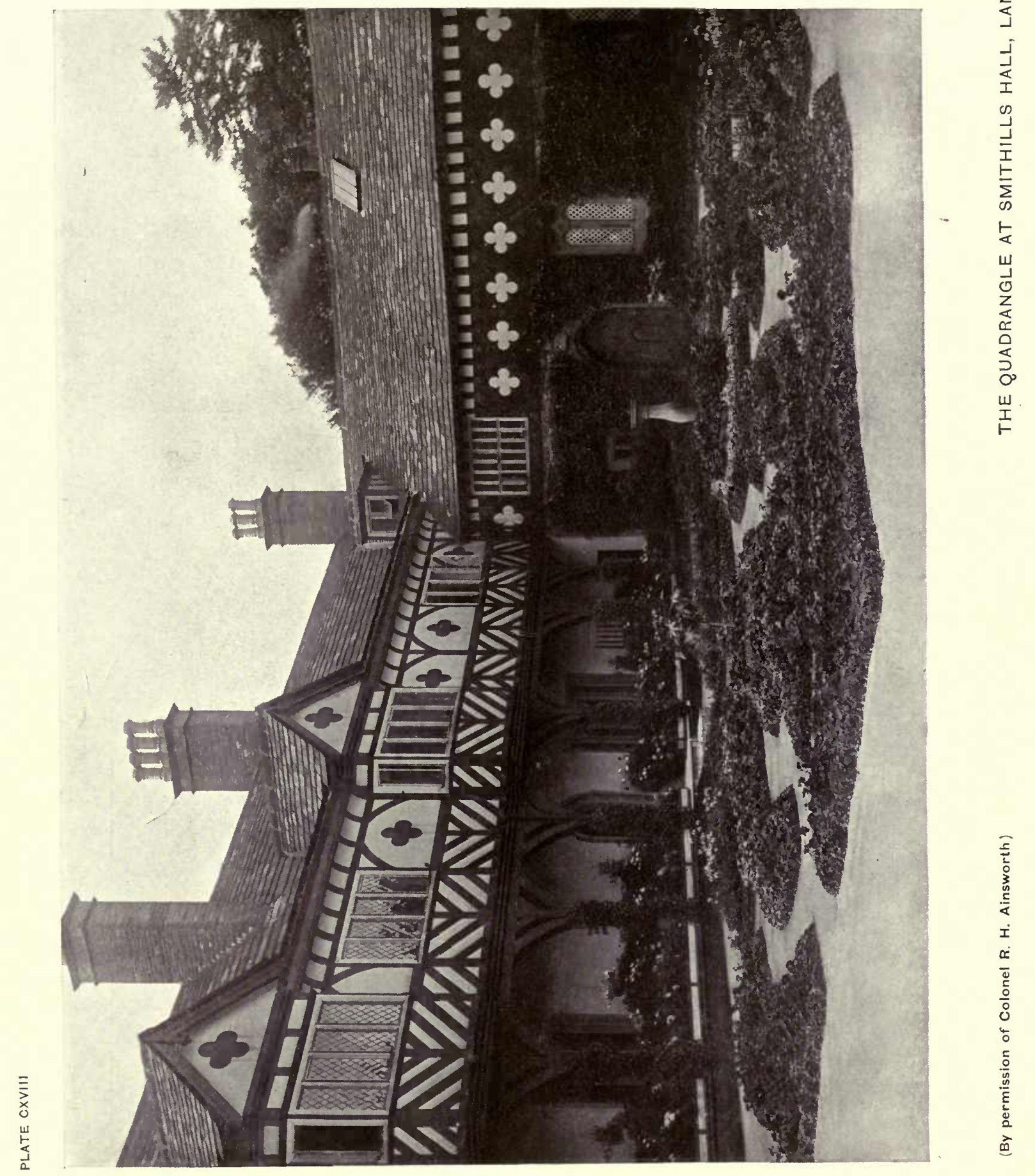


$\because$\begin{tabular}{cc}
$\cdots$ \\
\hdashline \\
\hdashline
\end{tabular}

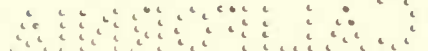

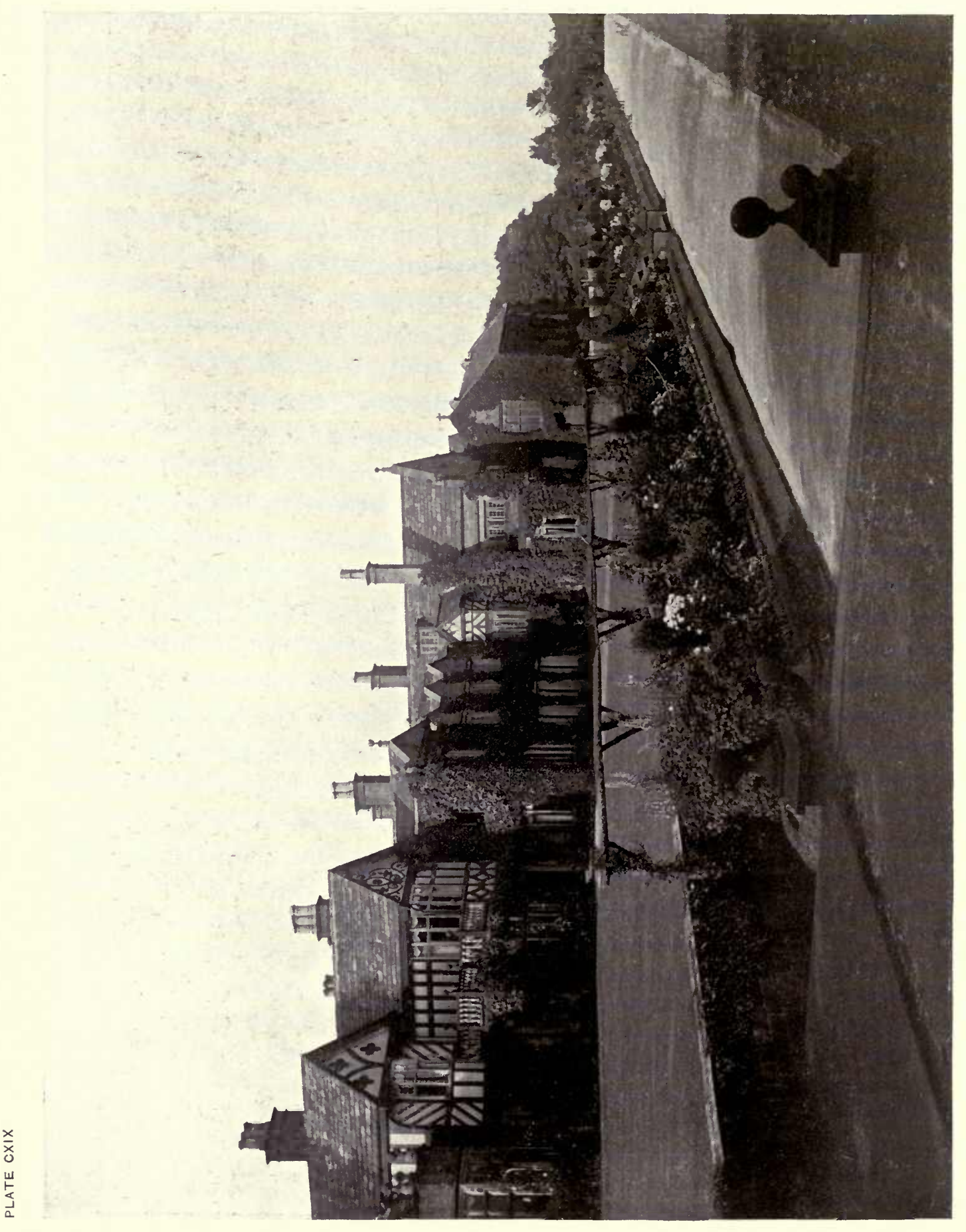

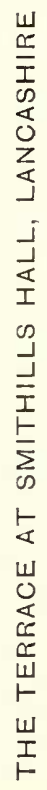

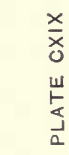




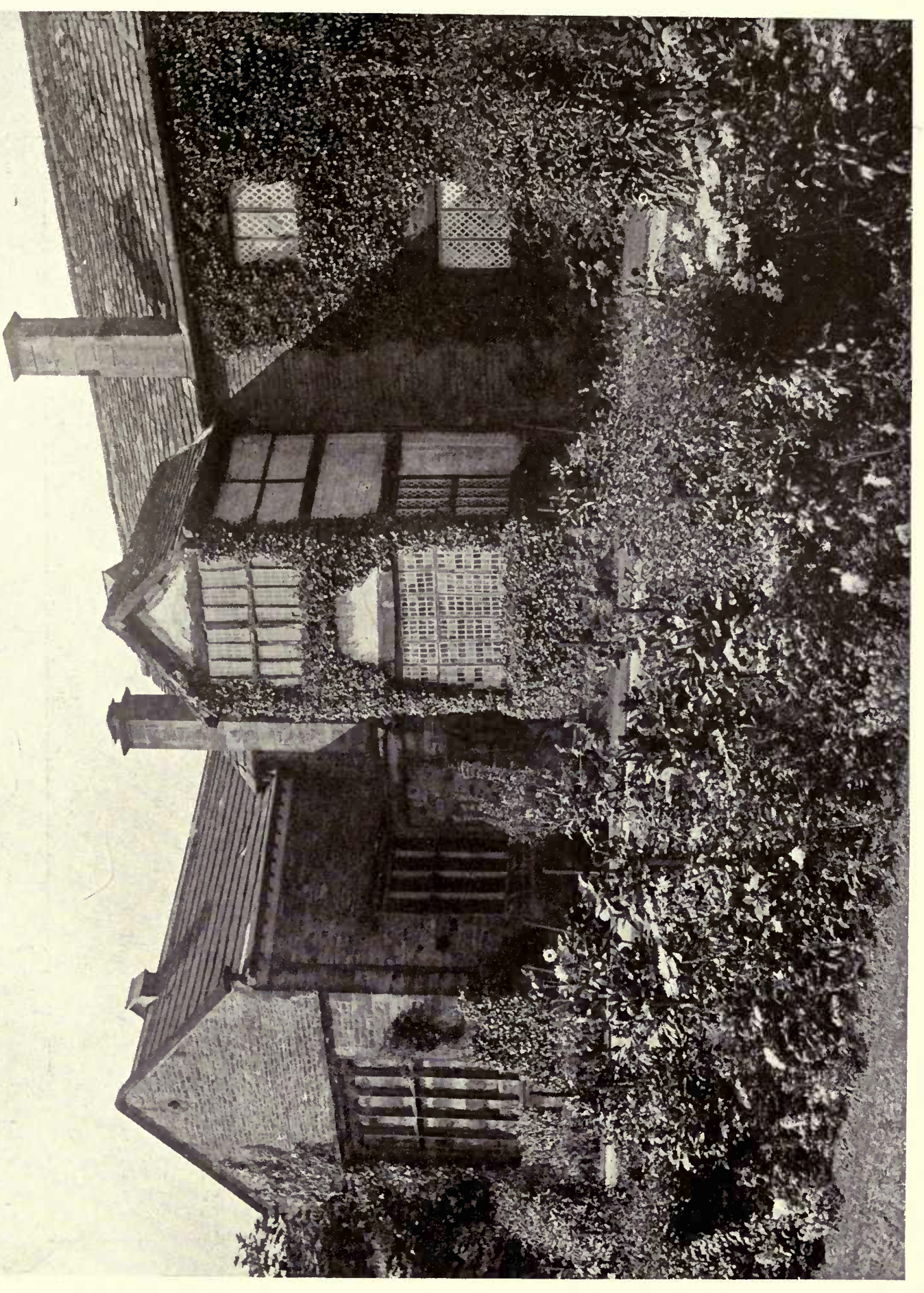

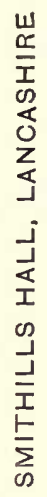




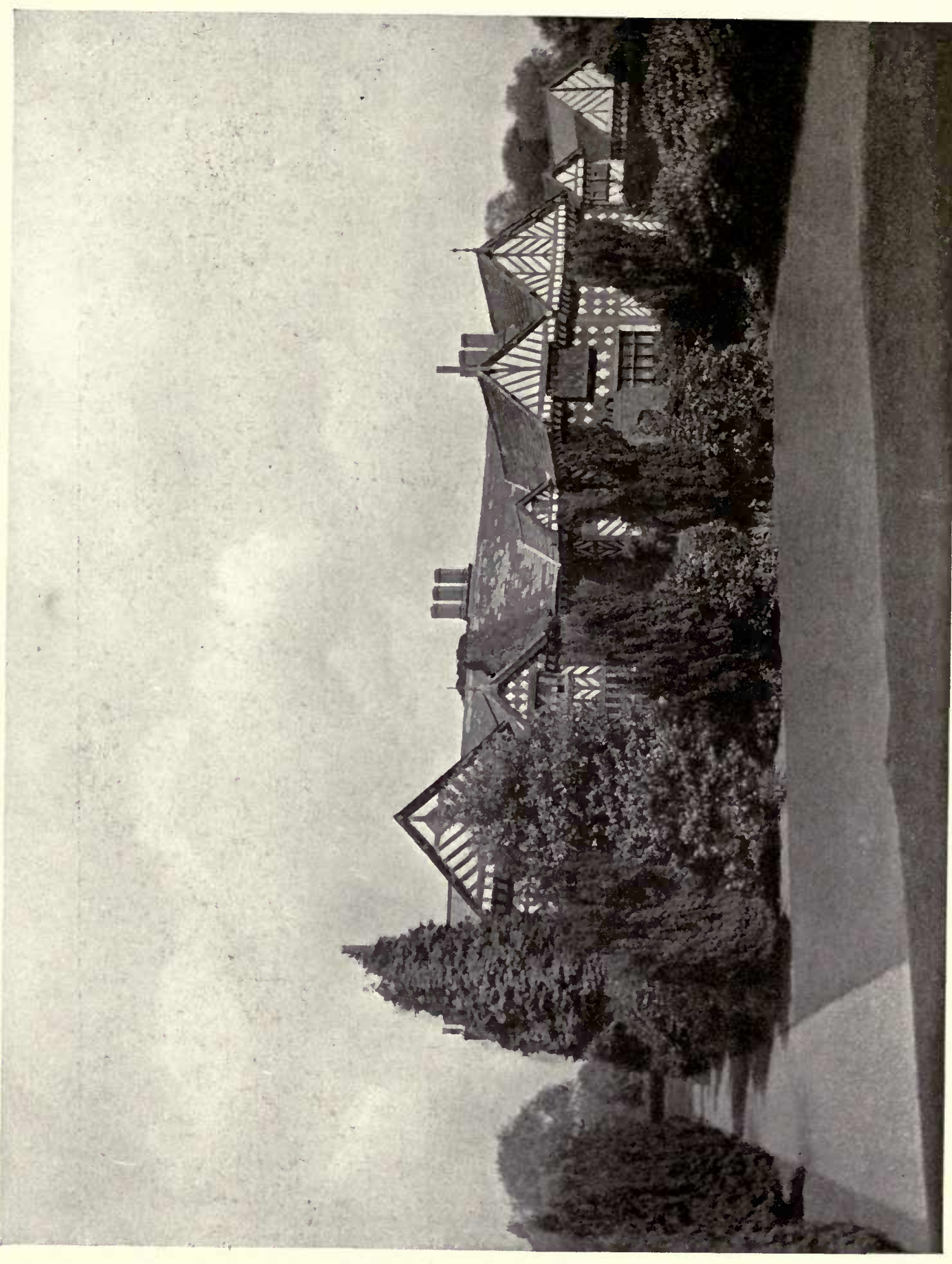

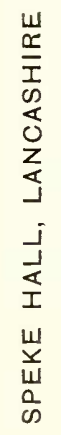

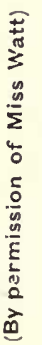



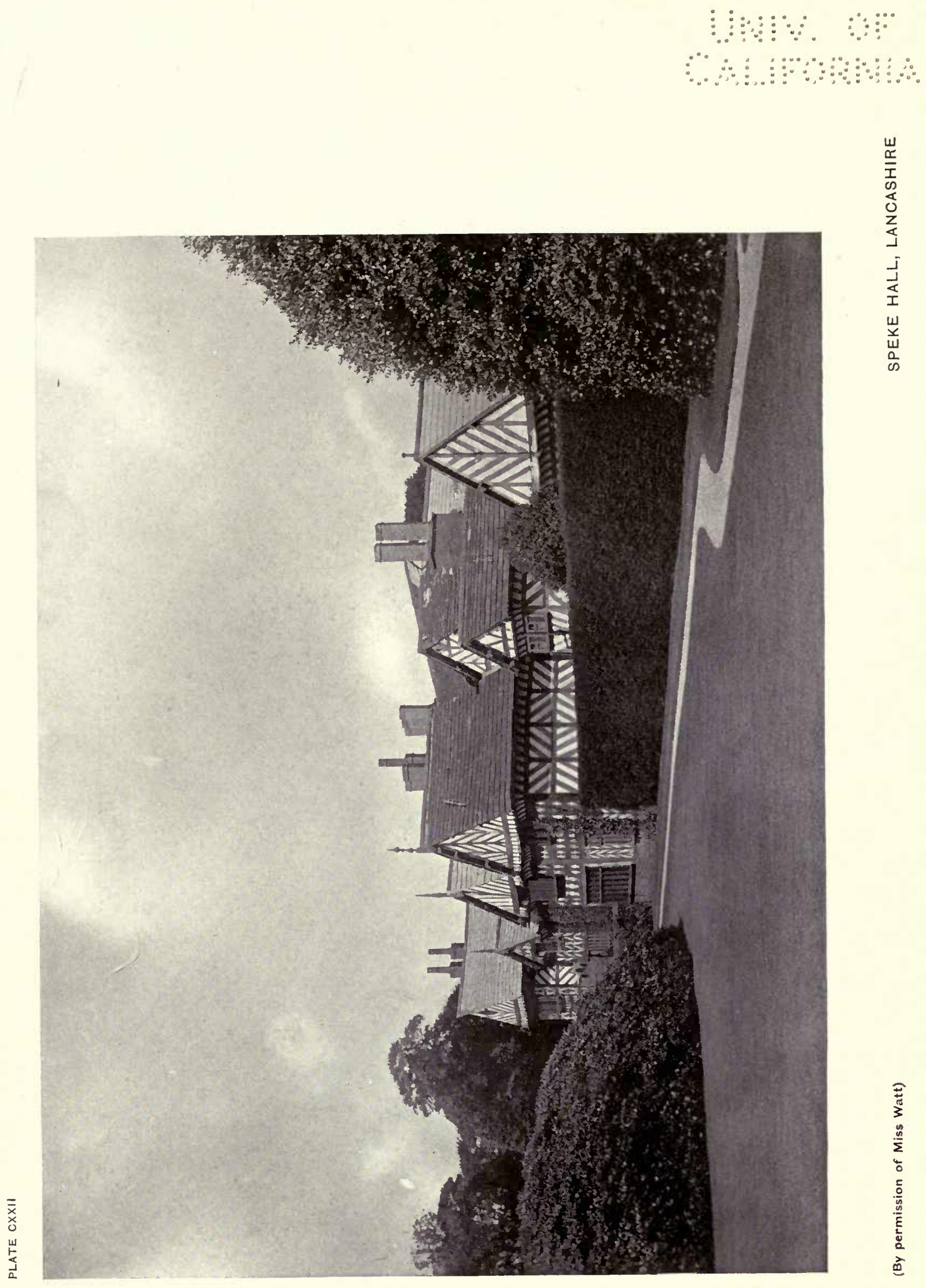

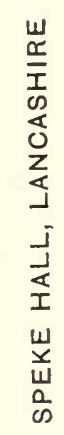




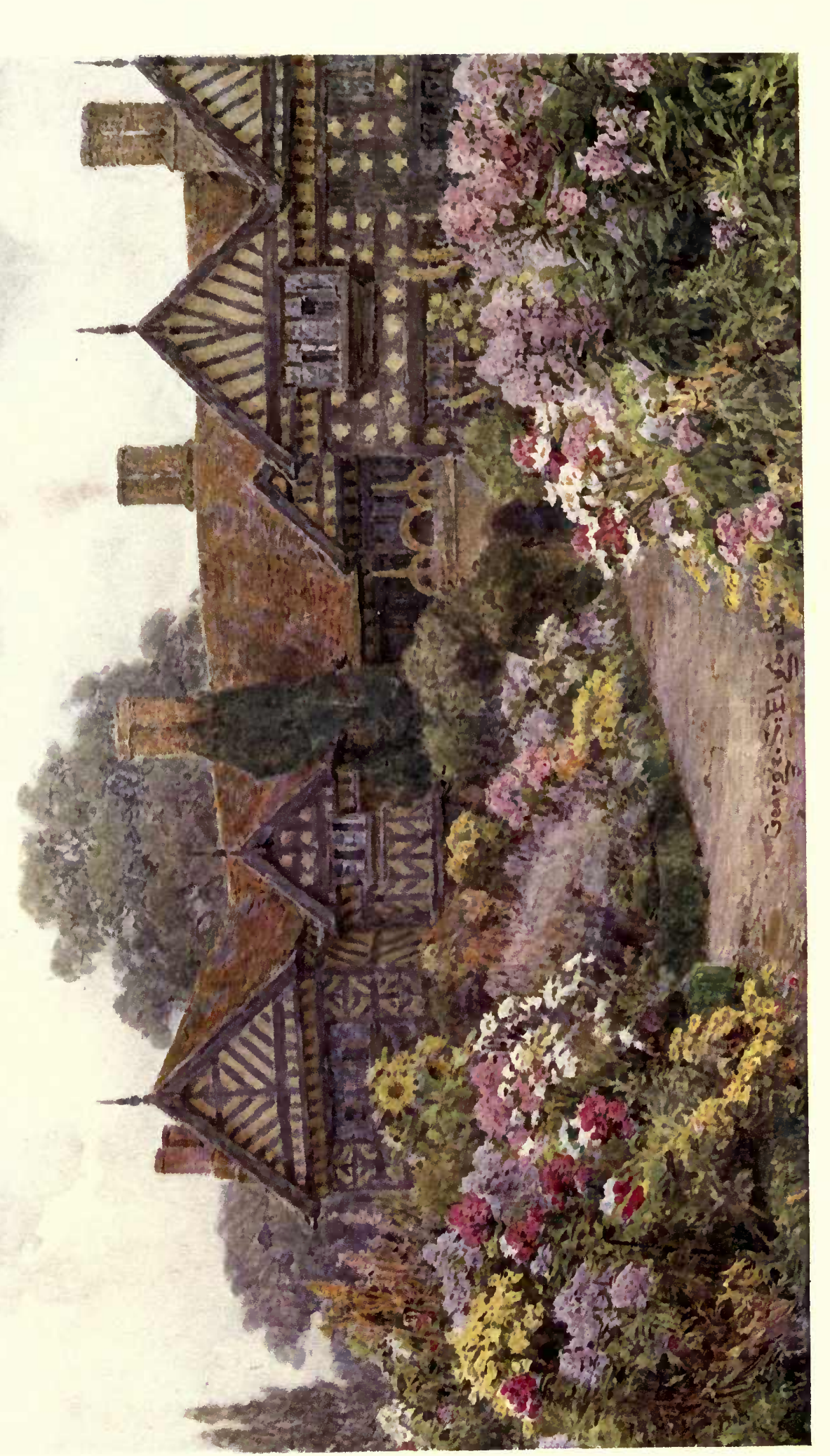

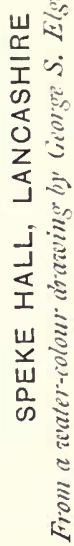


(3) 


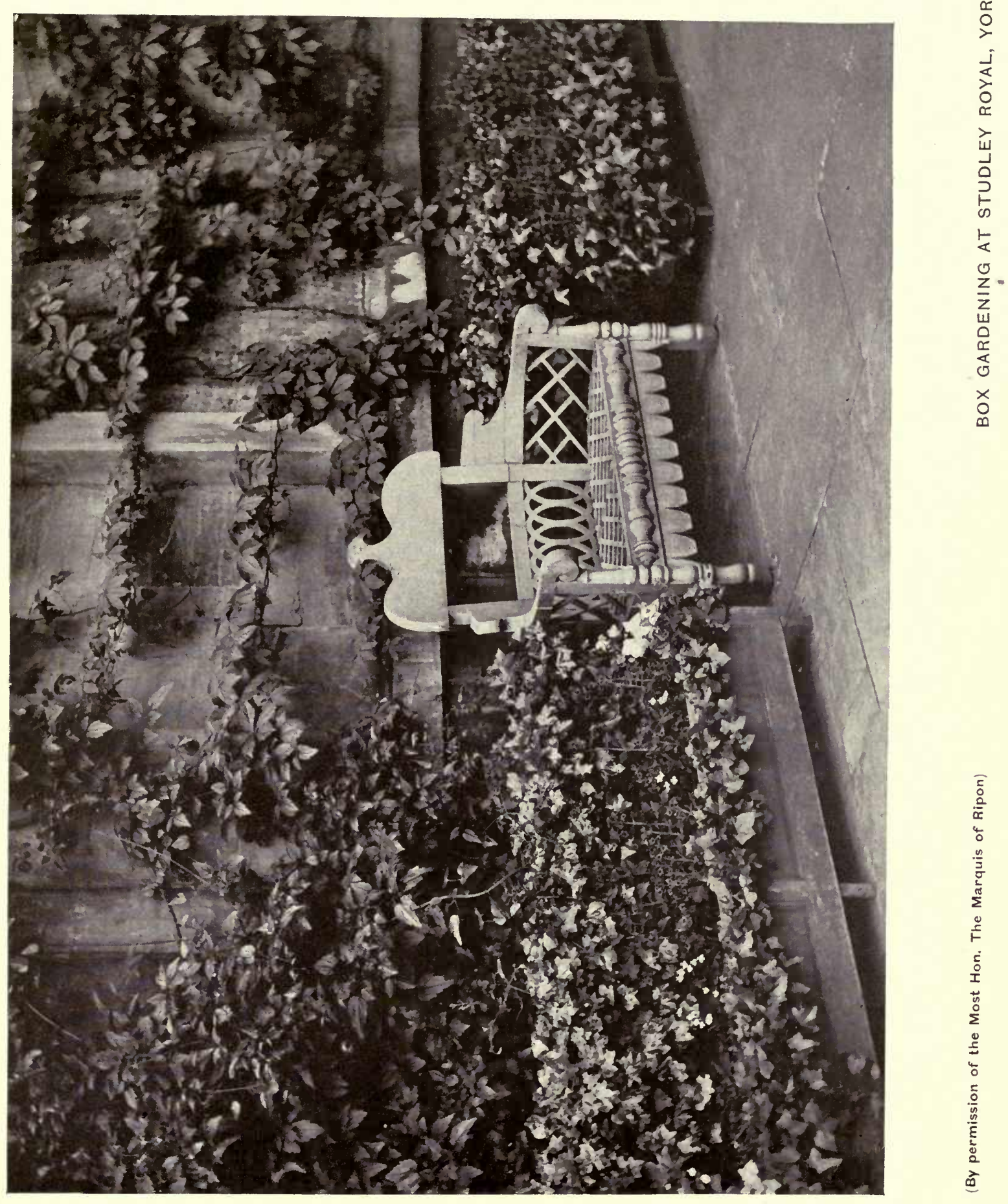




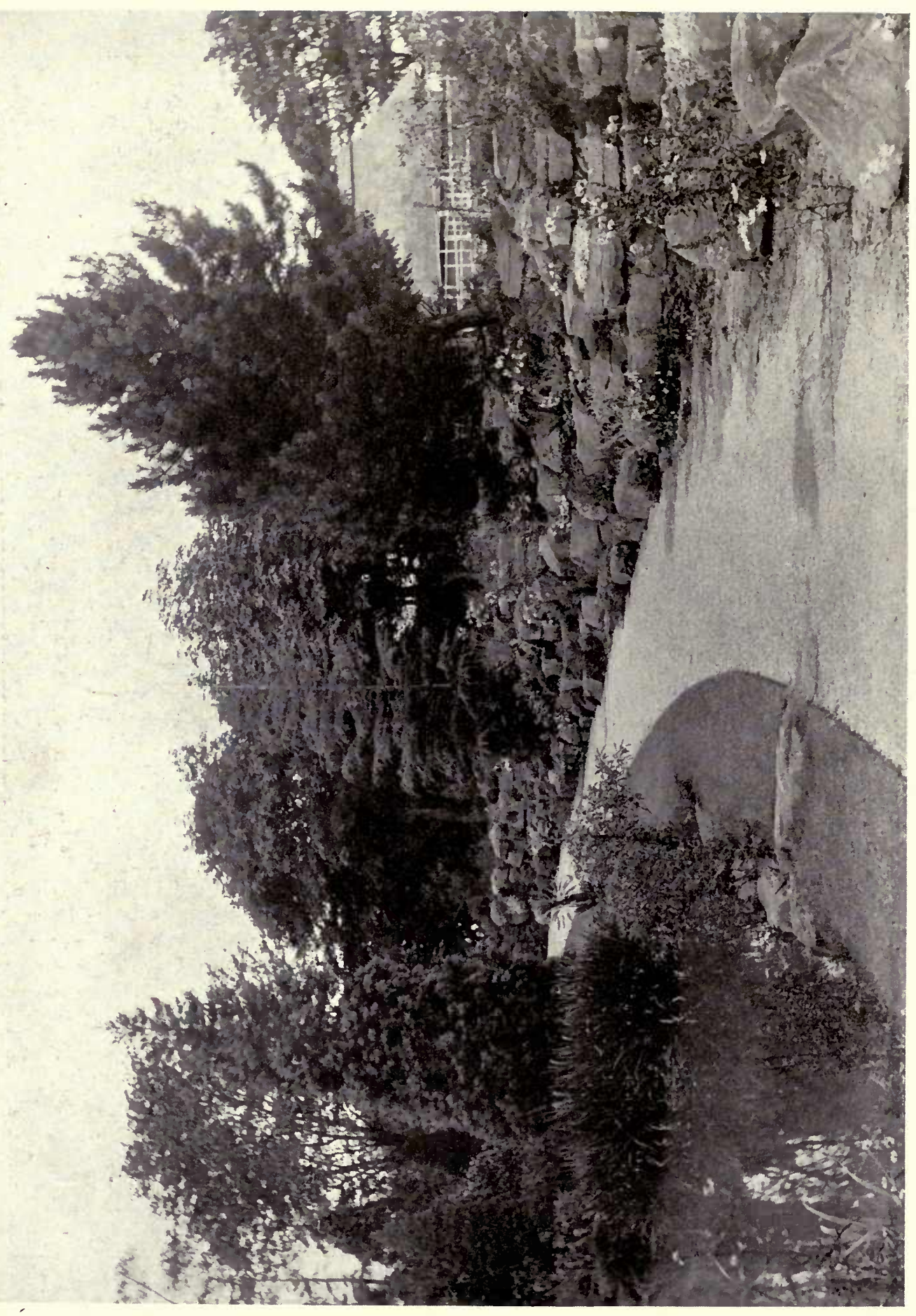

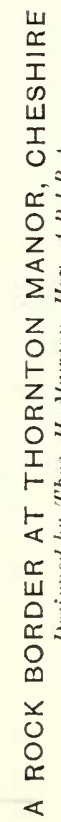

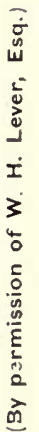




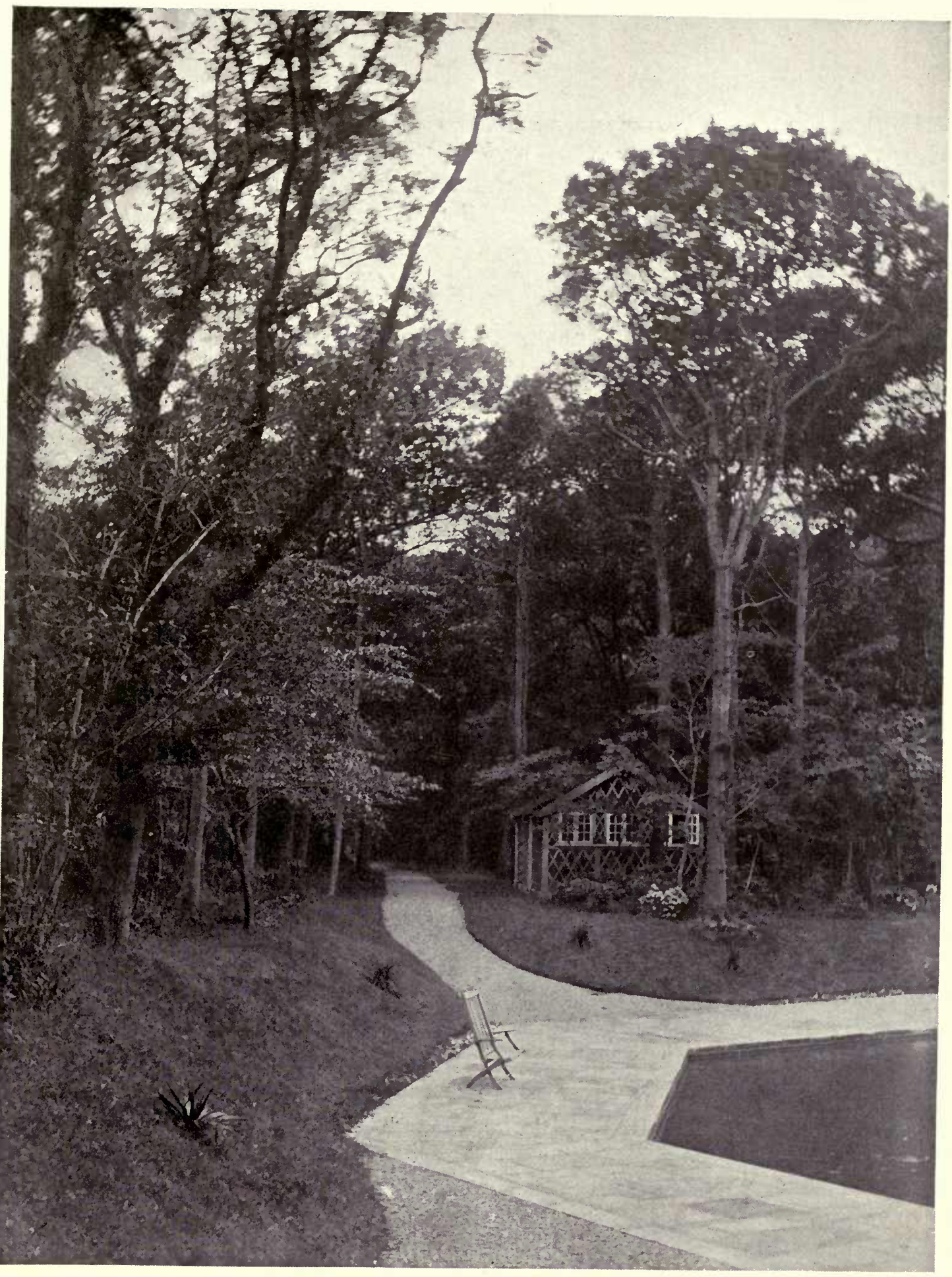




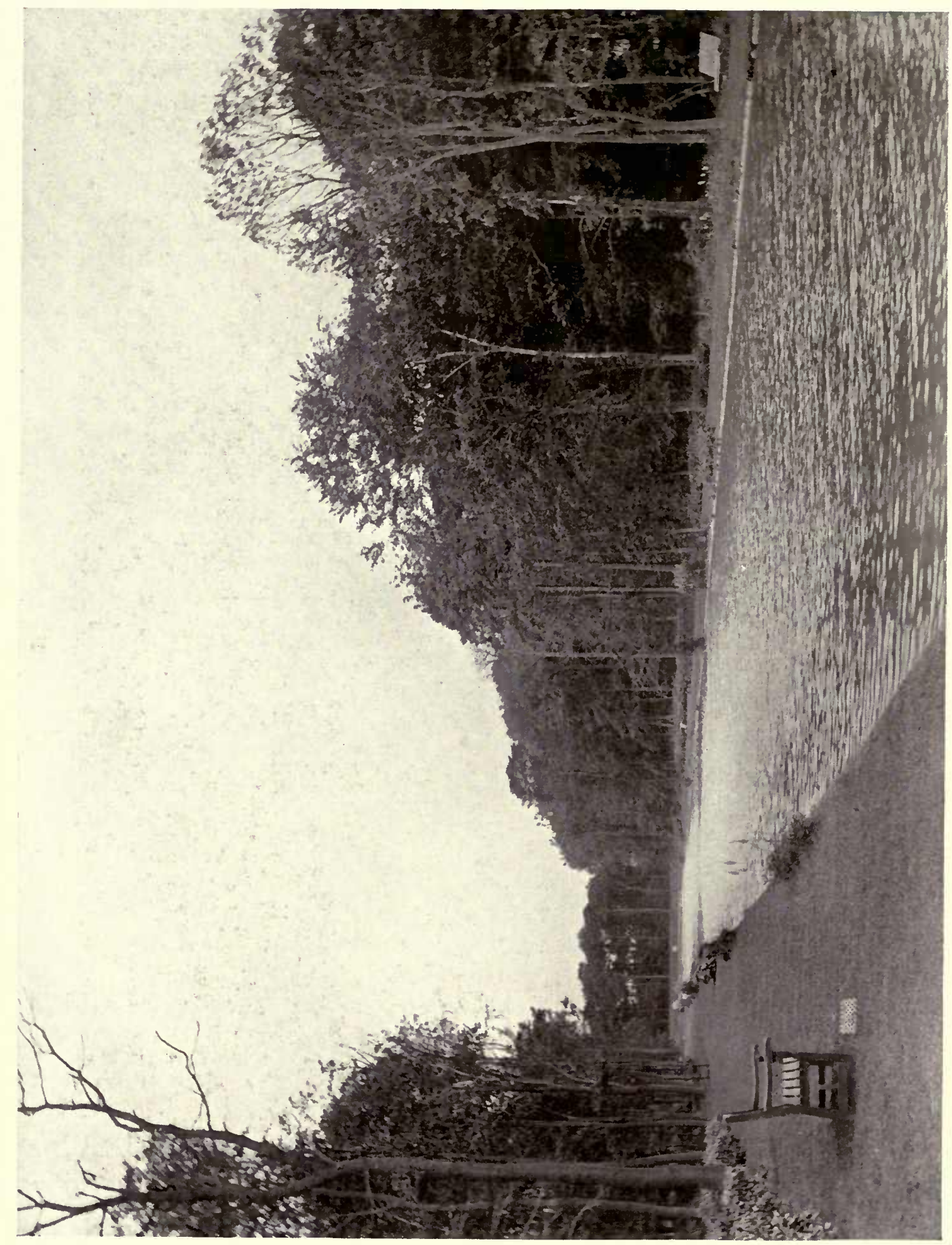

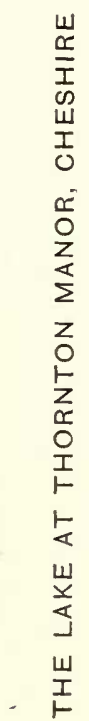





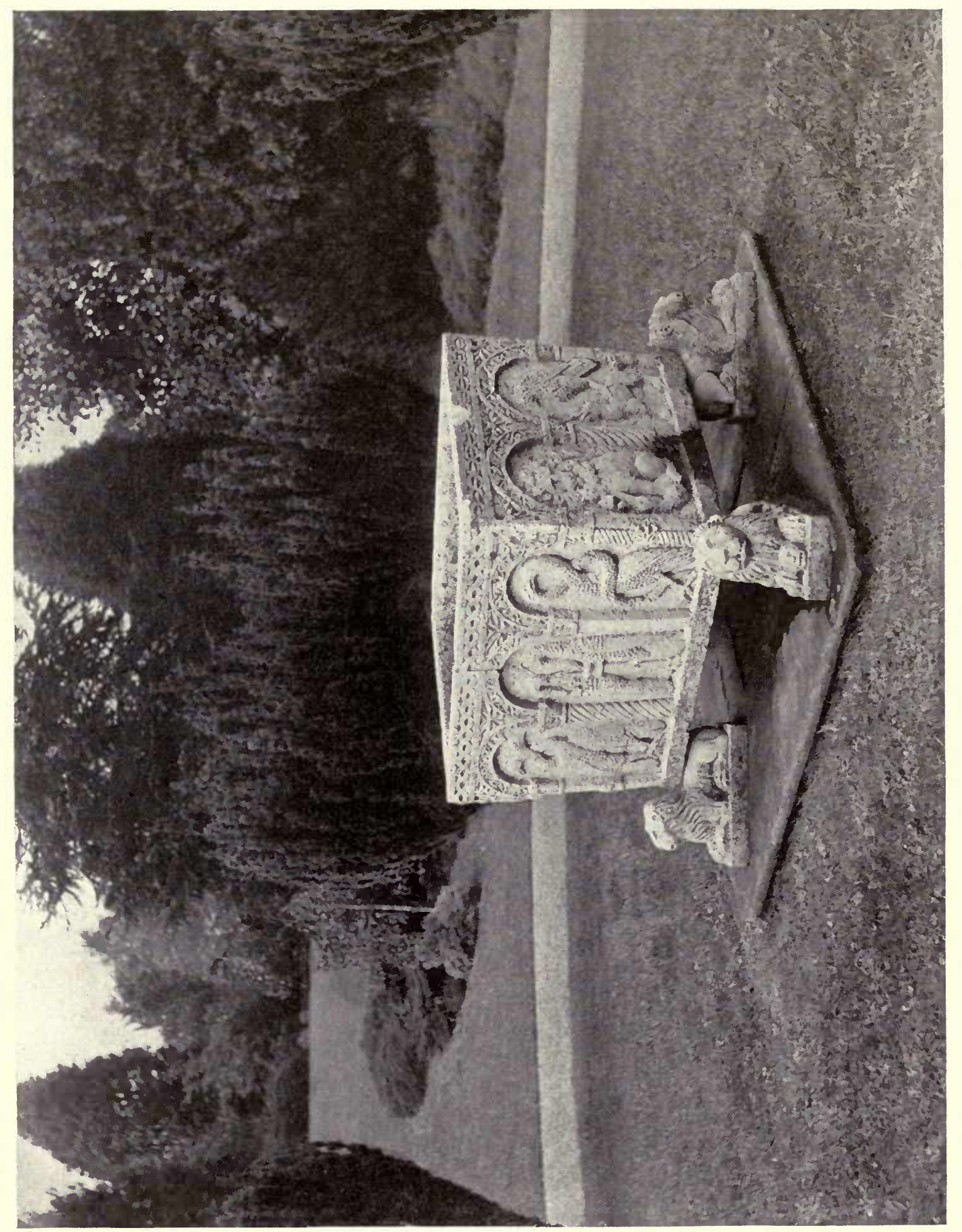

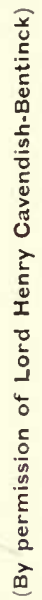




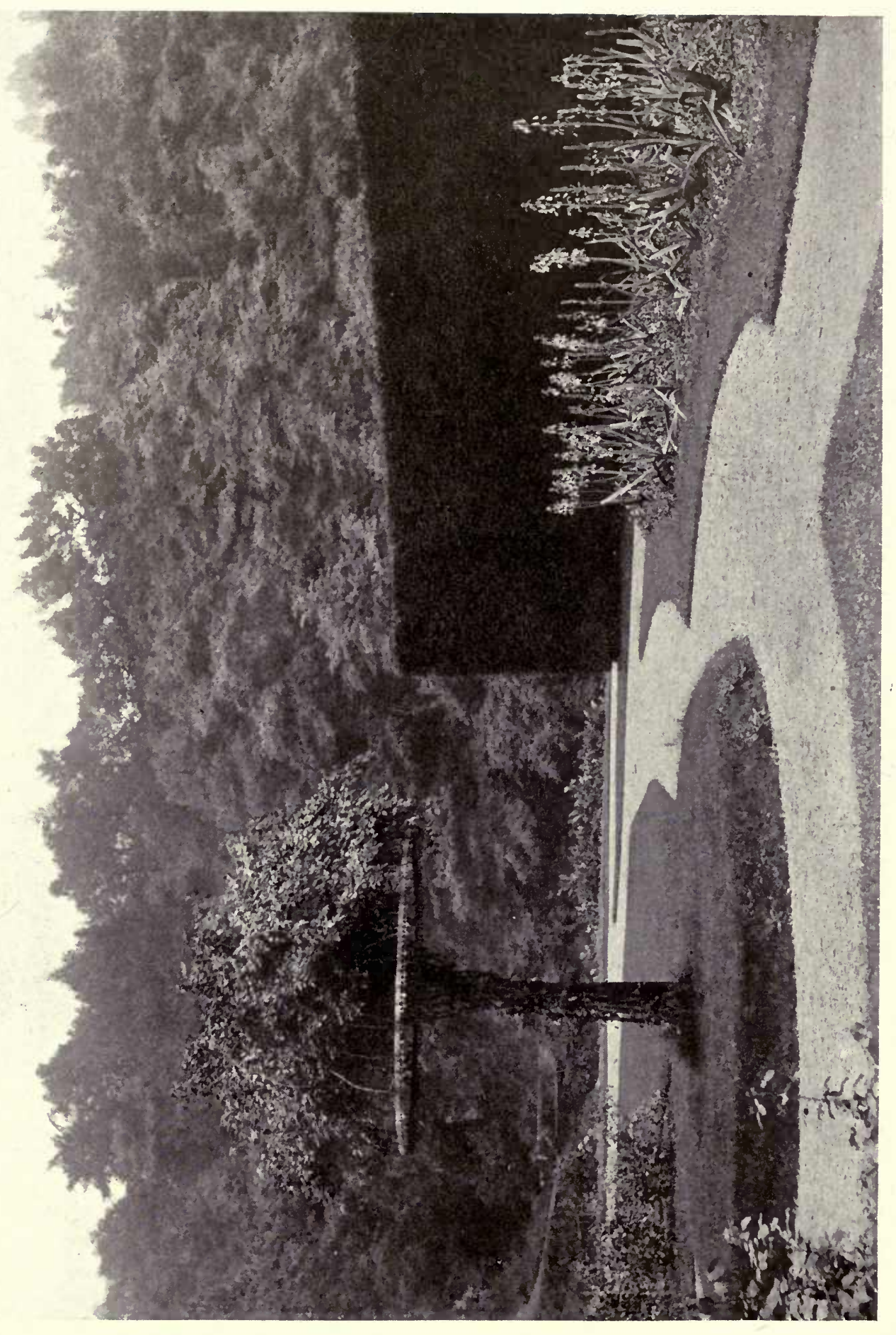

它

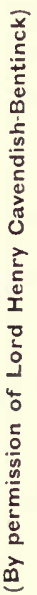




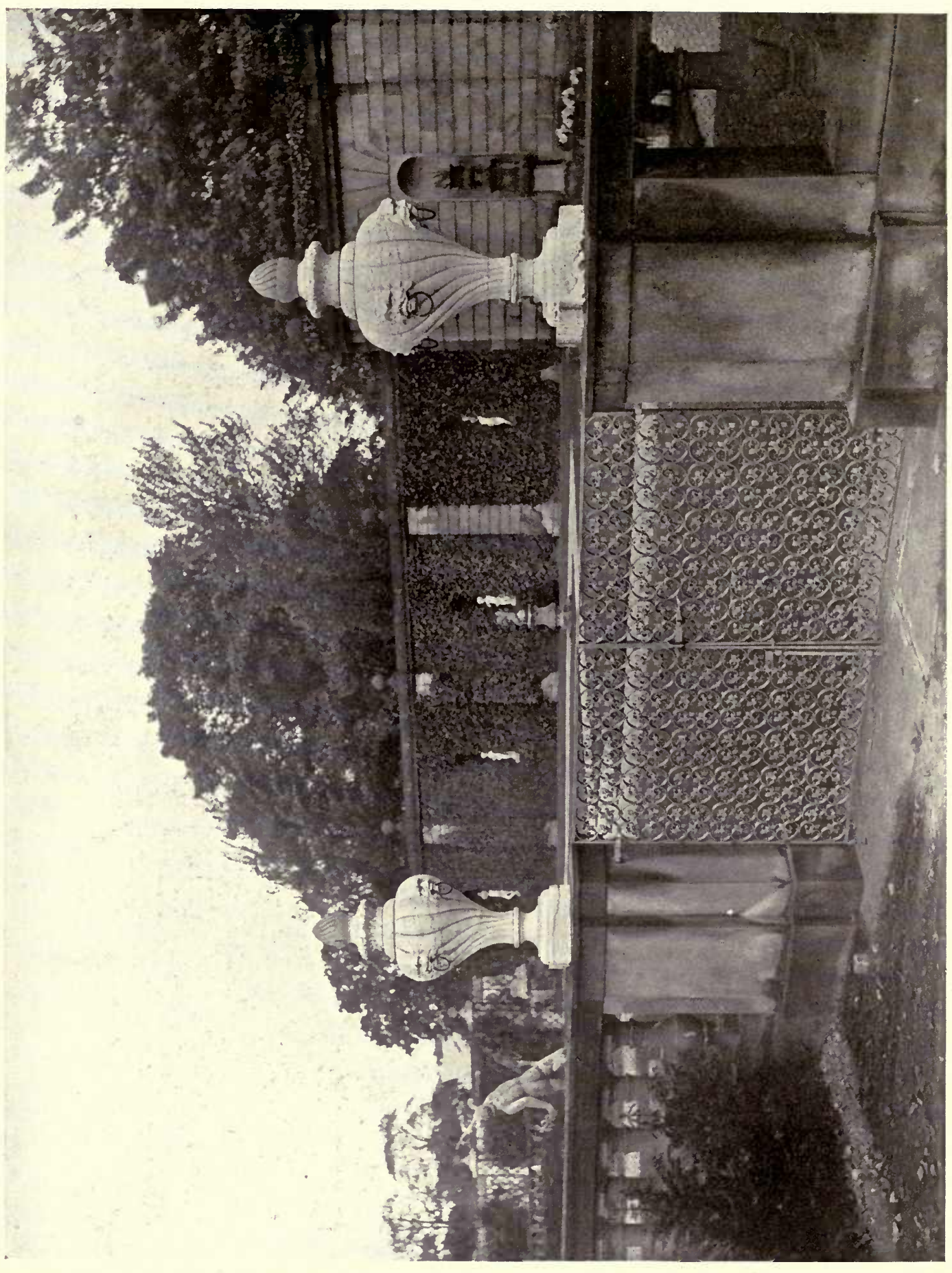

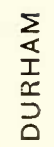

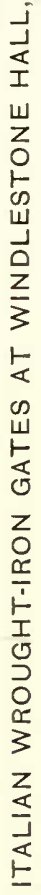

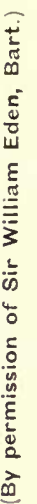




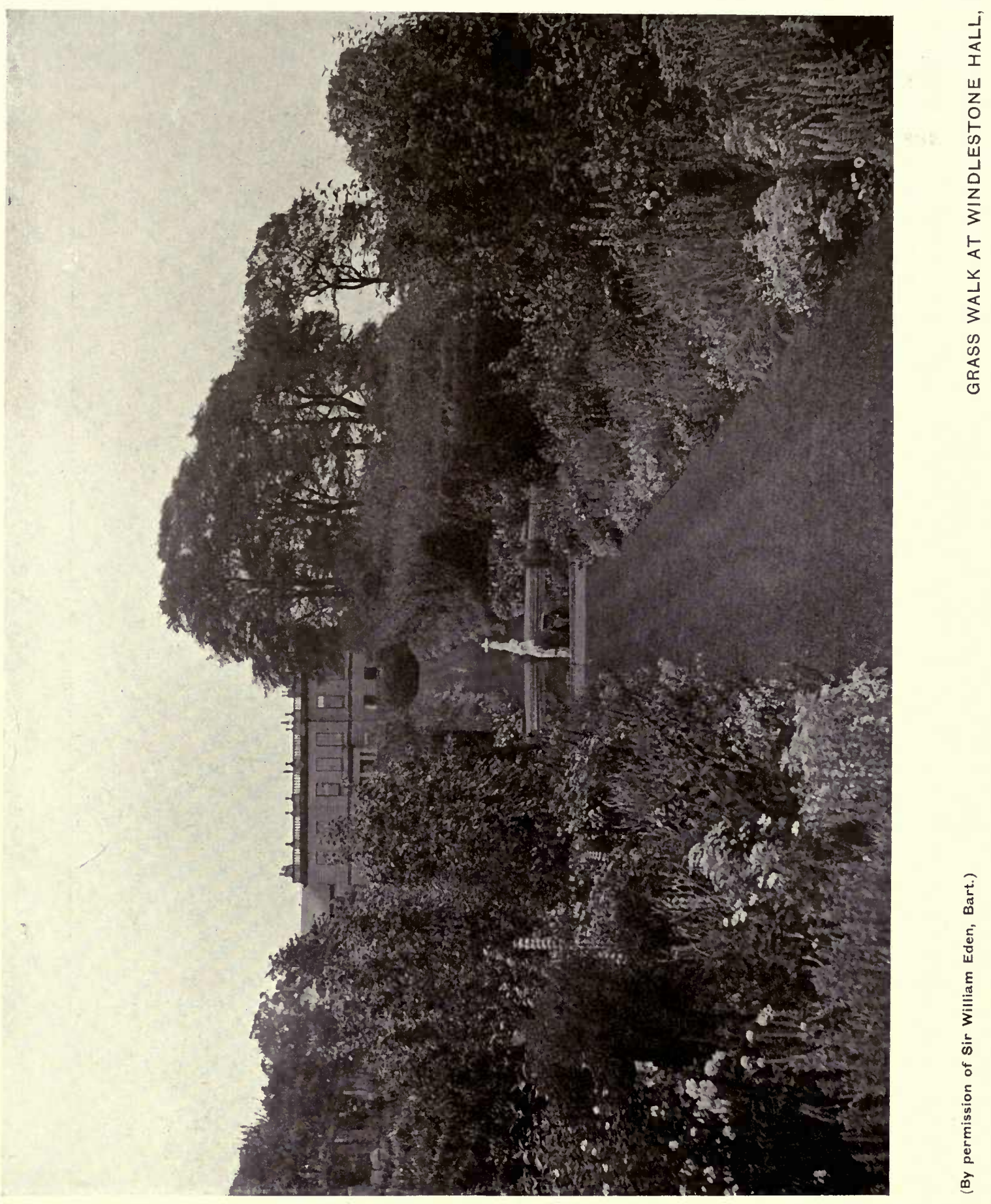

5
$\frac{1}{1}$
$\frac{1}{3}$
0 
$\because \vdots \vdots \quad \because \because \vdots \vdots \vdots \vdots \vdots \vdots$

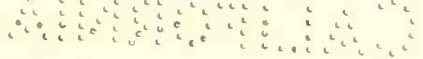

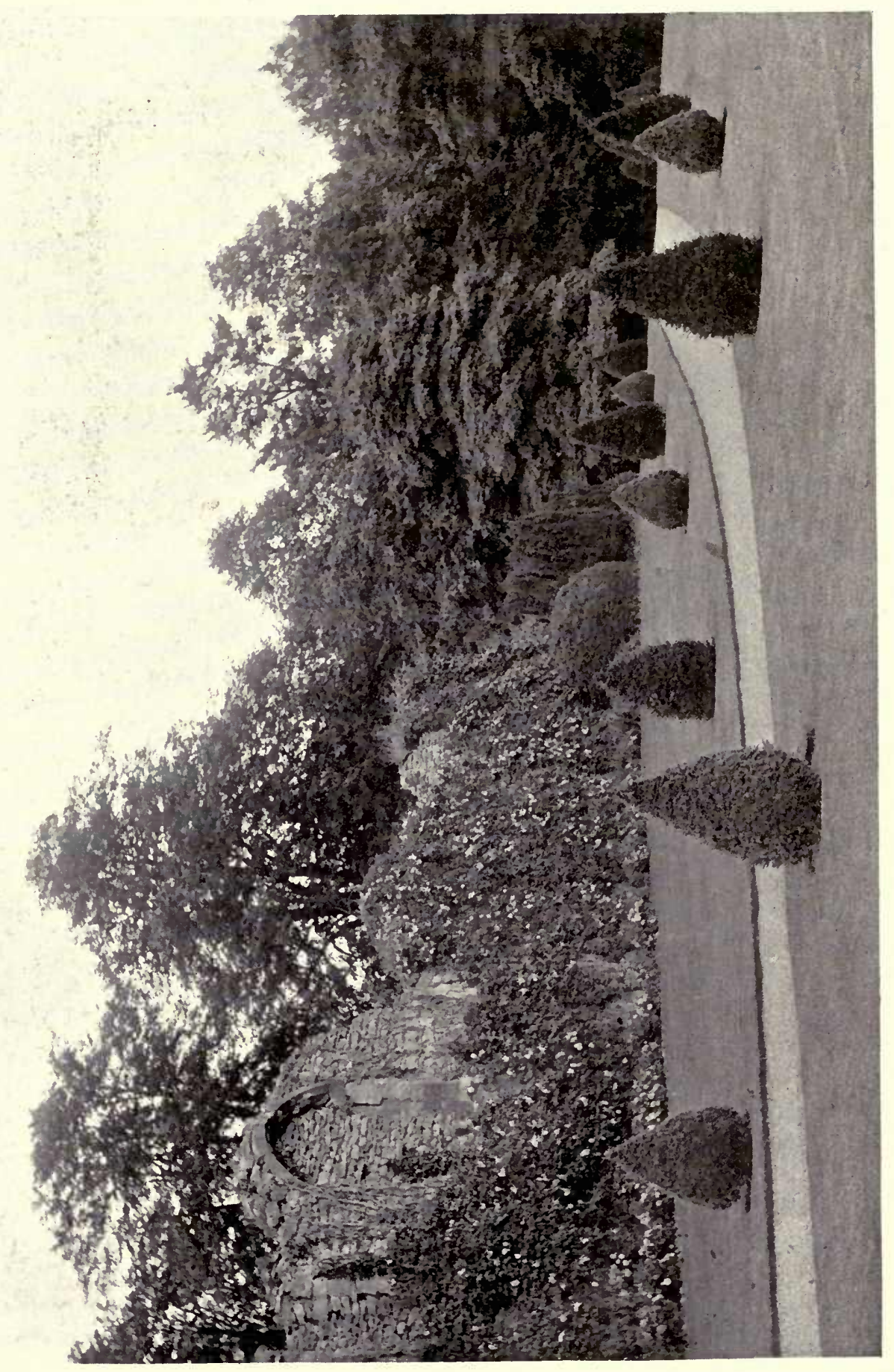




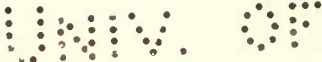

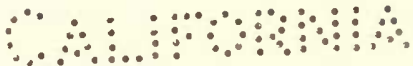

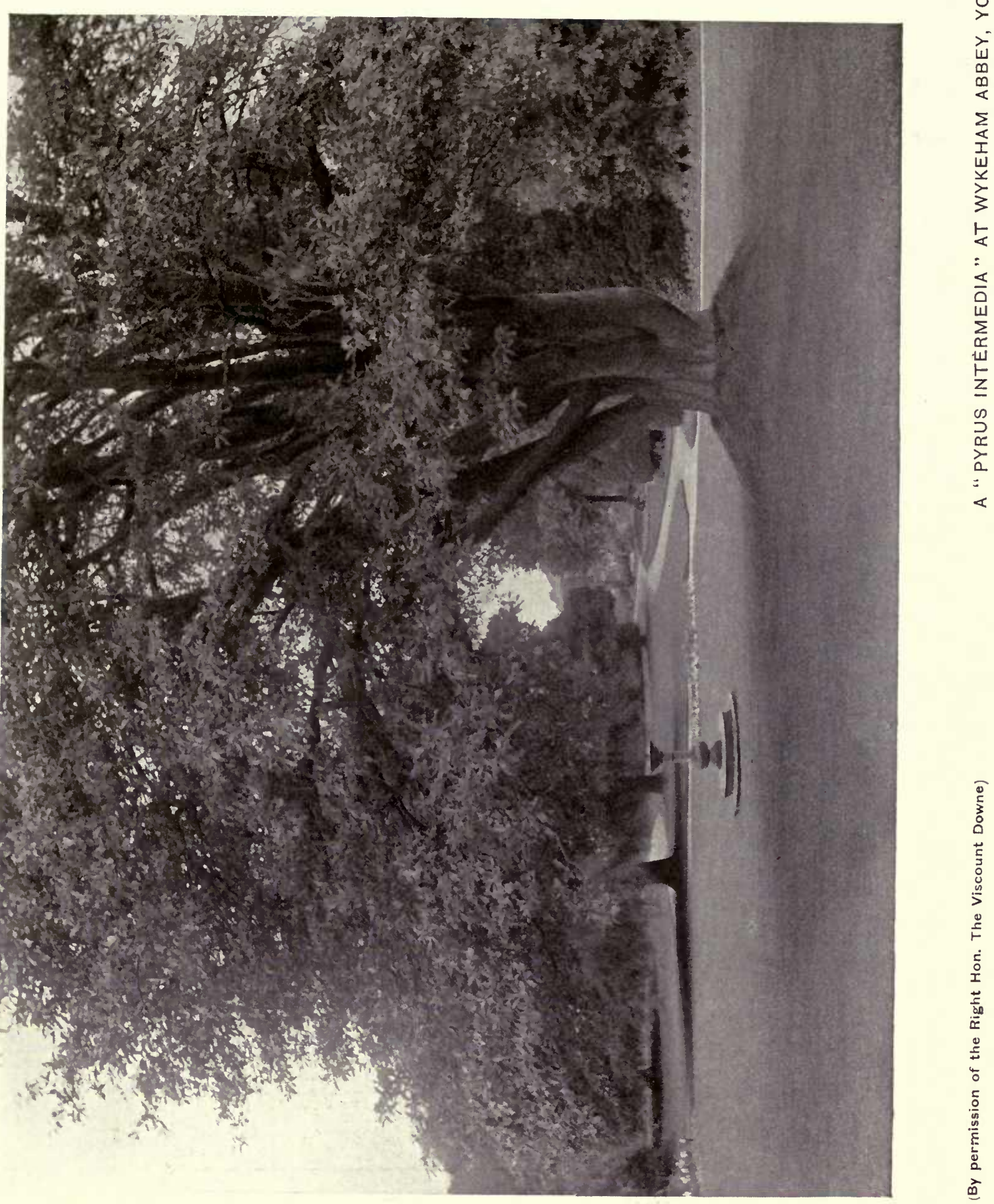




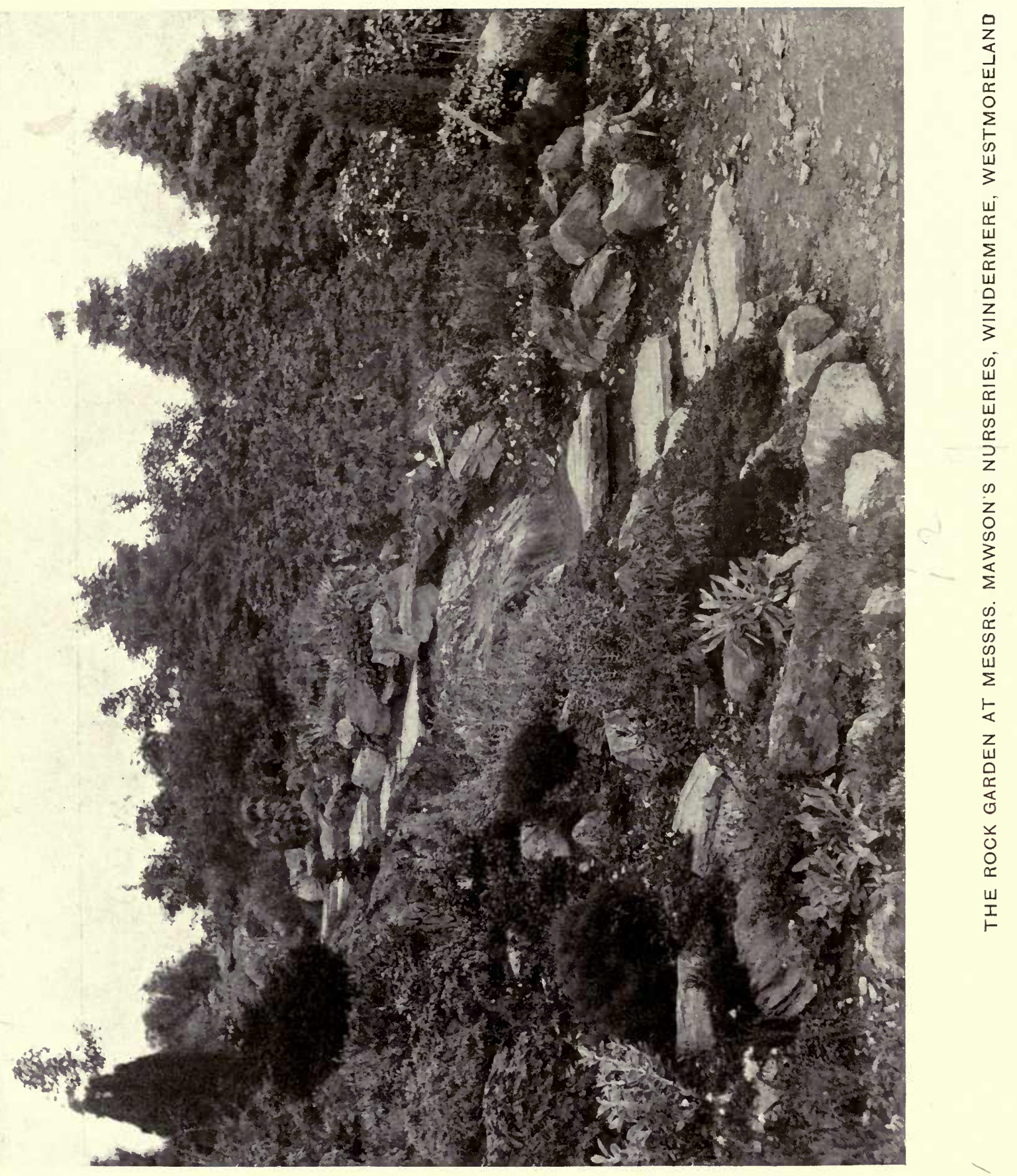





\section{DAY USE}

RETURN TO DESK FROM WHICH BORROWED

\section{LOAN DEPT.}

This book is due on the last date stamped below, or on the date to which renewed.

Renewed books are subject to immediate recall.

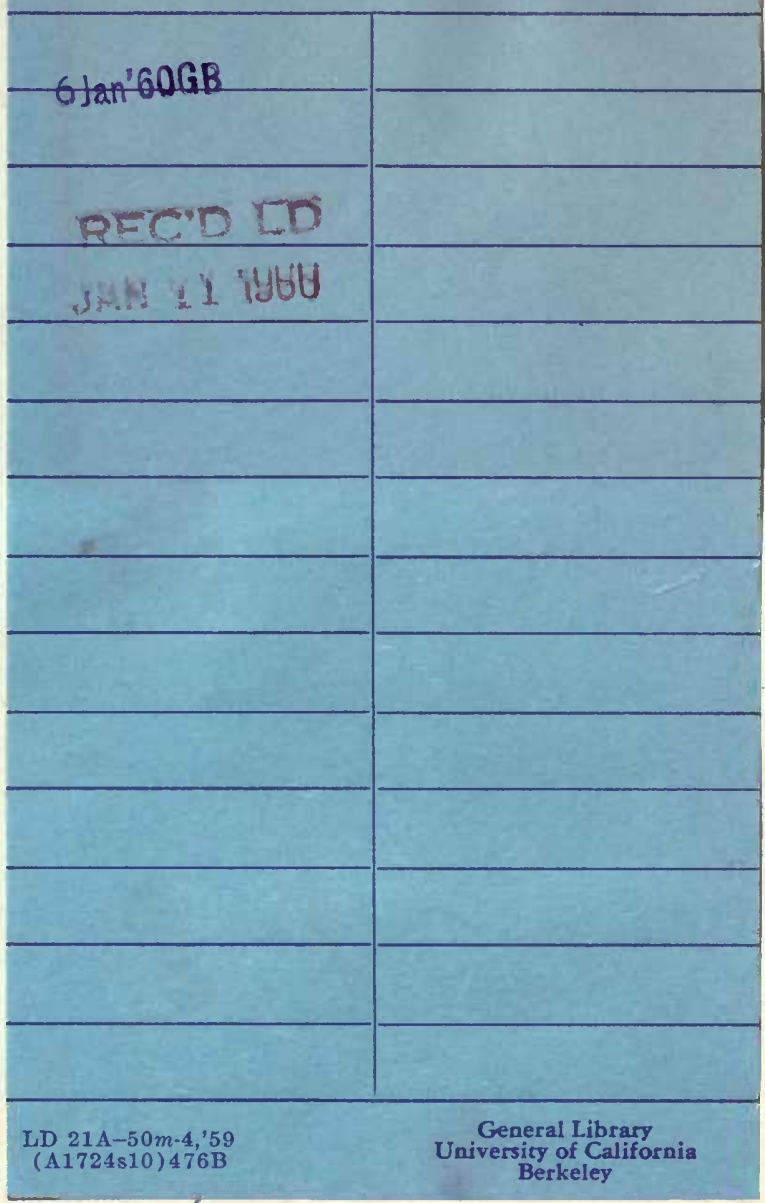




\section{YE 00933}

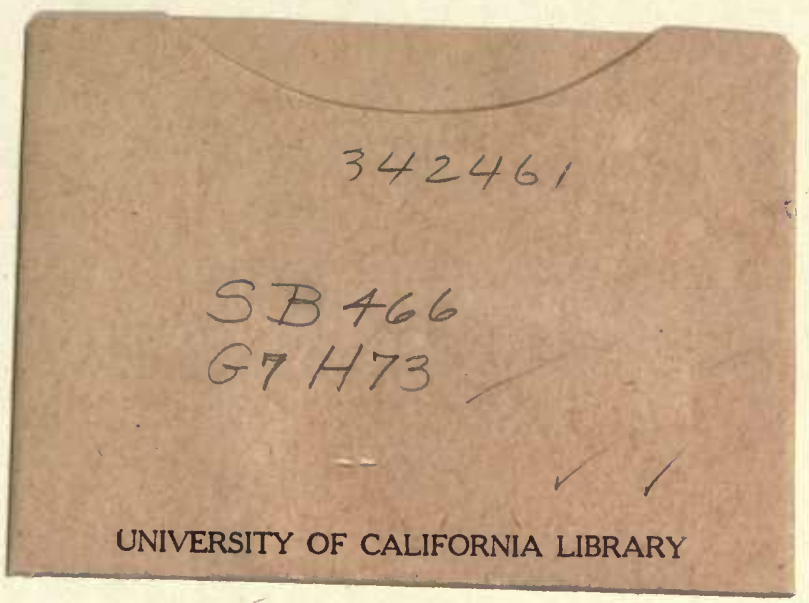


